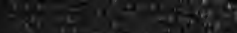



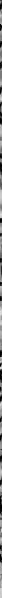

LIBRARY OF THE UNIVERSITY OF CALIFOAMIA
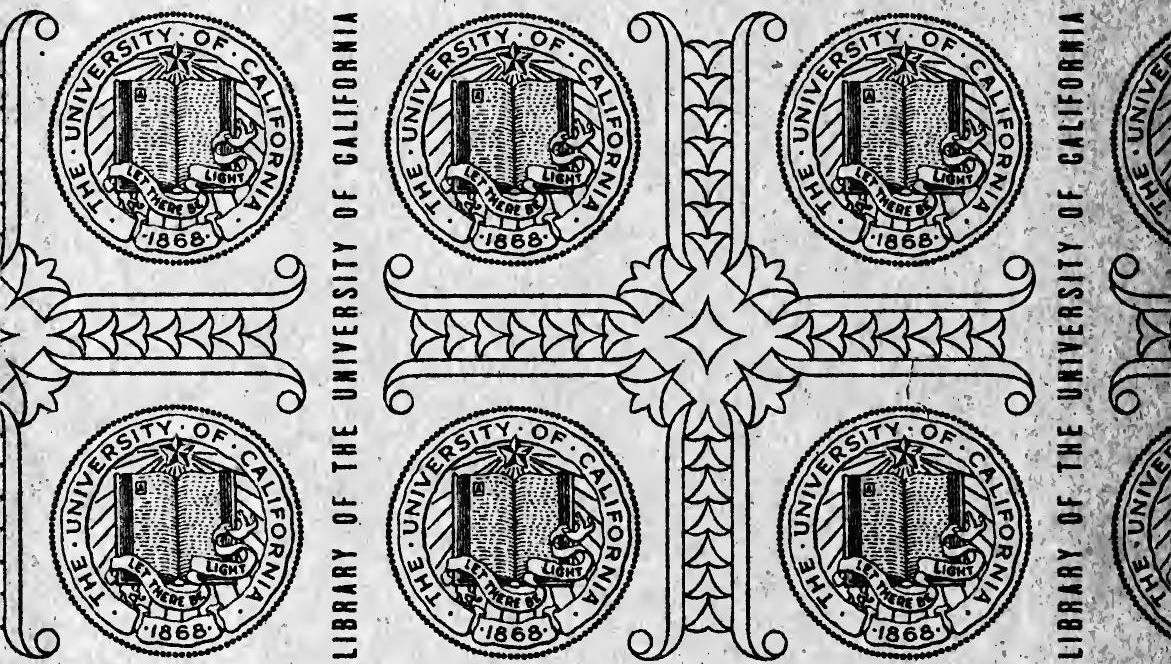

RSITY OF GALIFORIIA

LIBRARY OF THE UNIVERSITY OF CALIFOBMIA
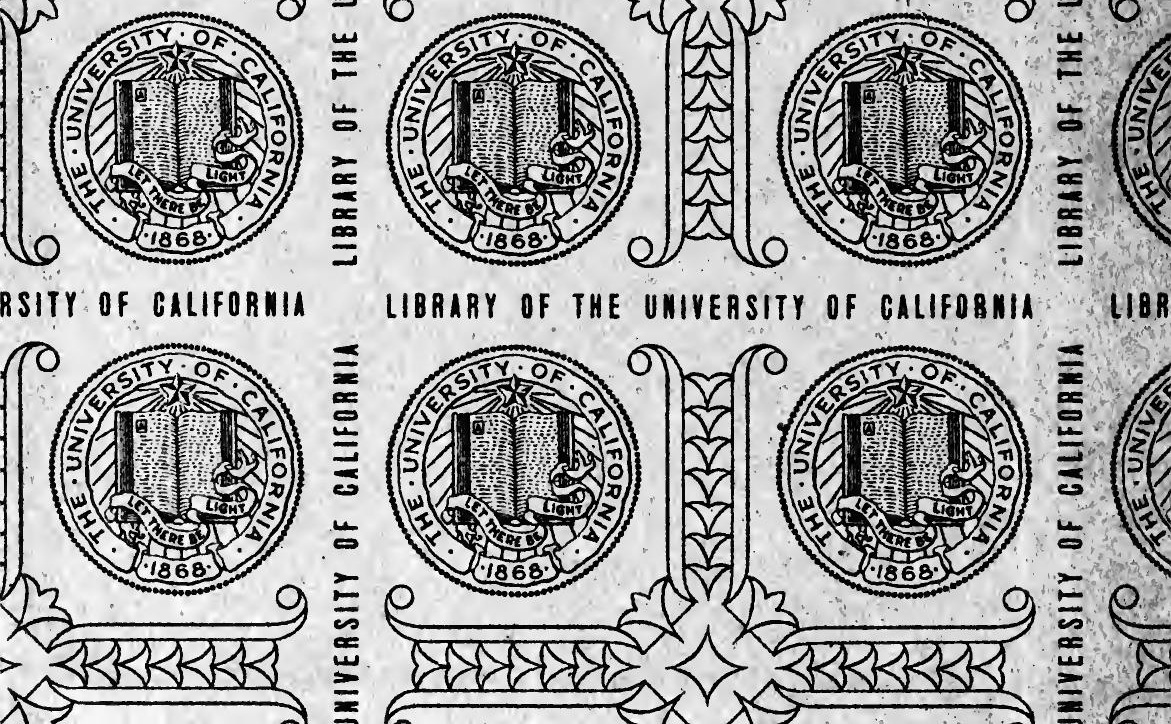


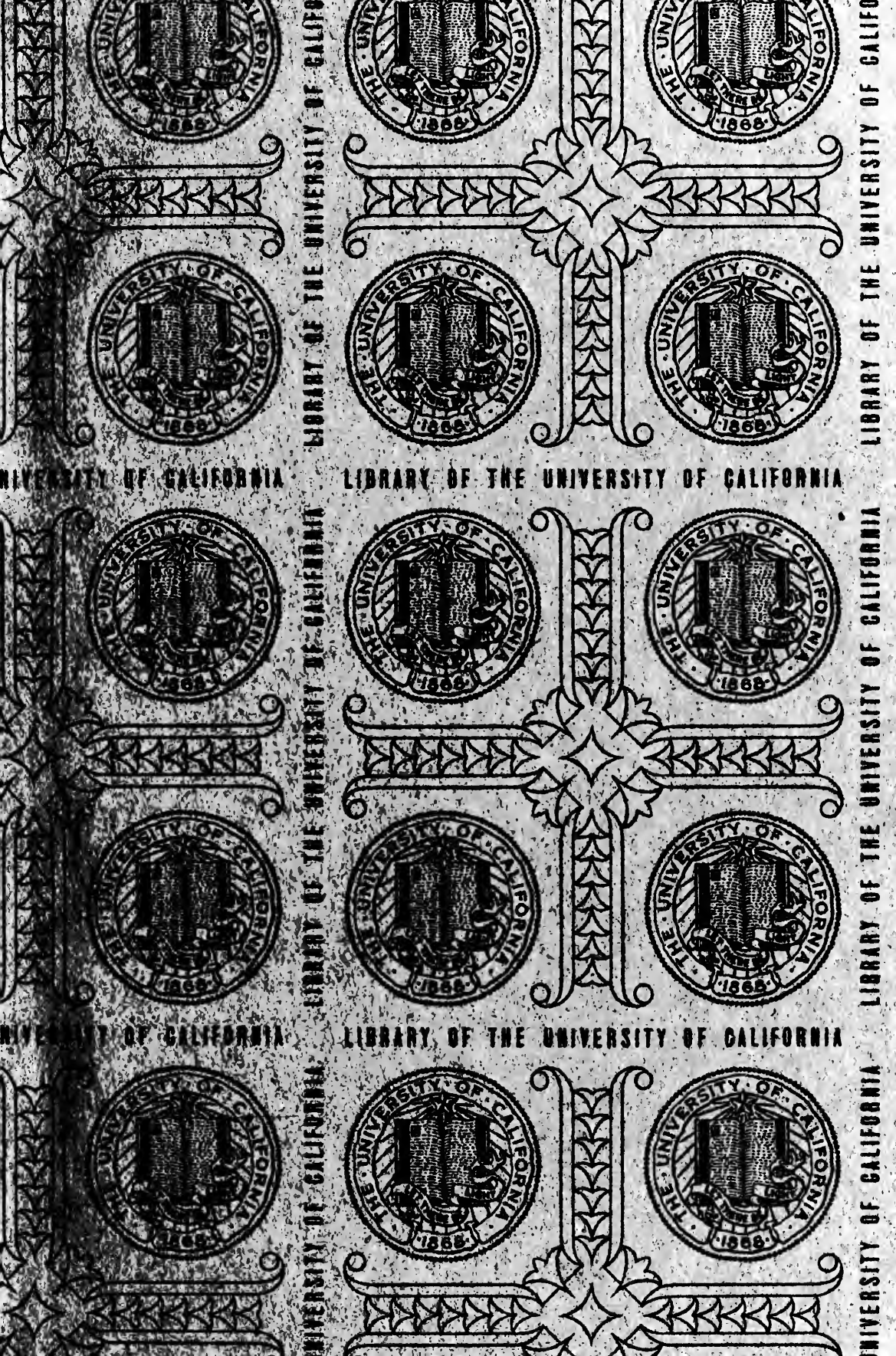




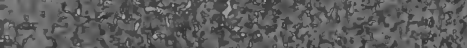

(3)

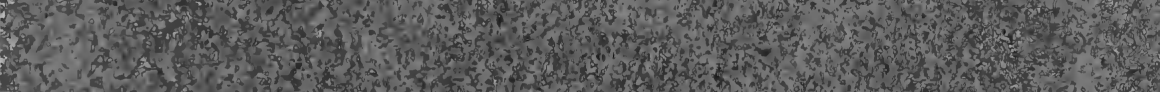

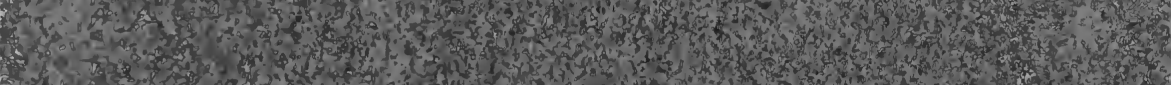

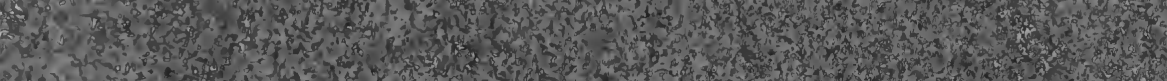
30 (1)

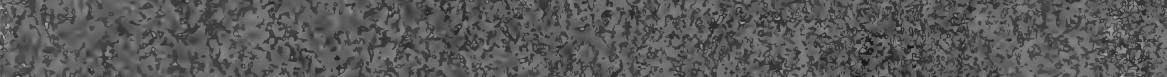

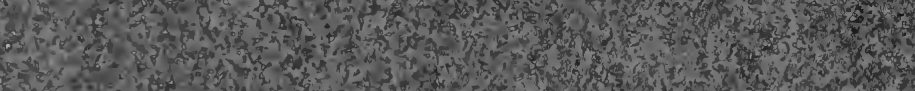

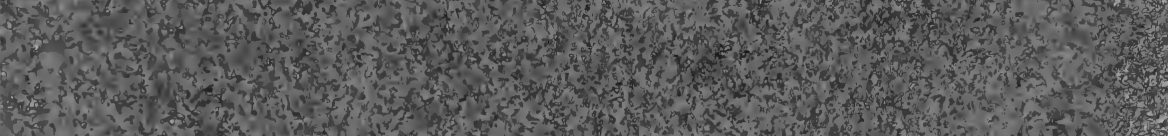
ato

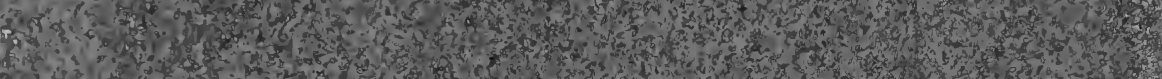

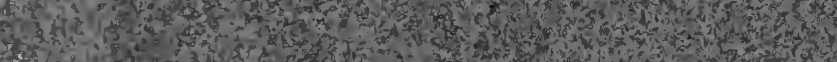

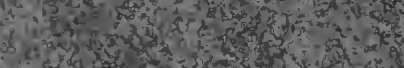

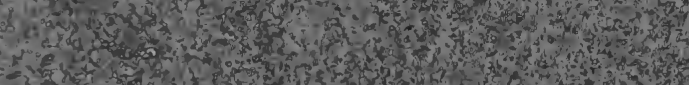

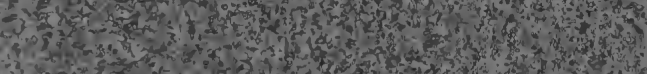

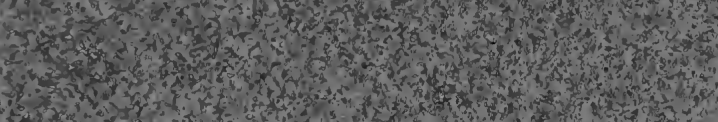

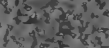

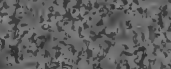

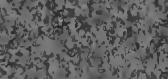

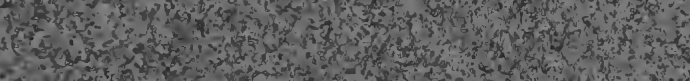

int

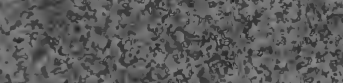

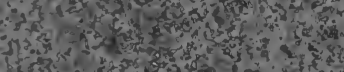

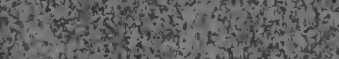

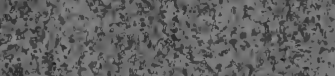

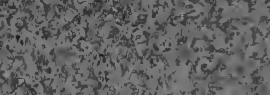

S.

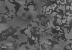

ती 4 ?

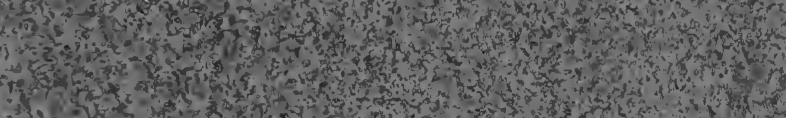

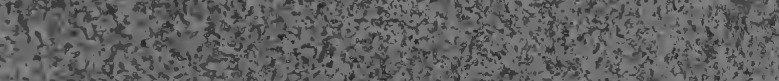

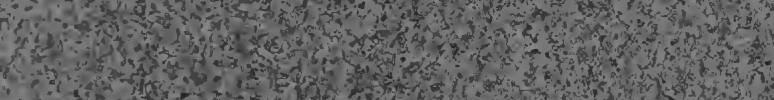

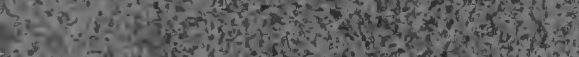

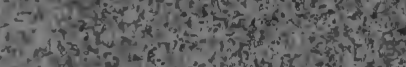

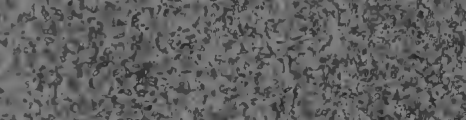

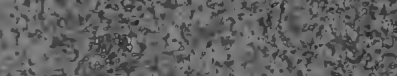

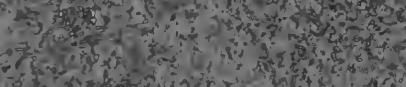

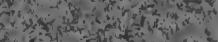

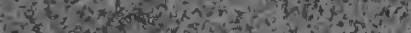

of

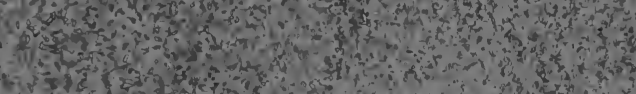

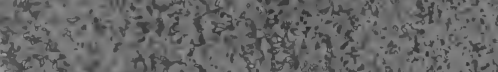

into

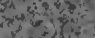

$x^{2}$

$c^{2} e^{2}$

hy

and

f $p+x+2$

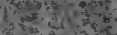

$x^{2}=x^{2}, x^{2}$

$x^{2} \mathrm{c} x$

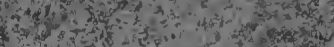

2,2

Cus a t 
Digitized by the Internet Archive in 2007 with funding from

Microsoft Corporation 


\title{
THE \\ Social Evolution \\ OF RELIGION
}

\author{
By
}

GEORGE WILLIS COOKE

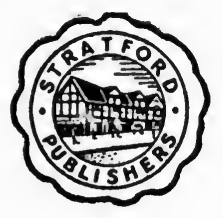

B OSTON

The Stratford Company, Publishers

1920 


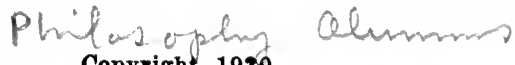

Copyright 1920

The STRATFORD CO., Publishers

Boston, Mass.

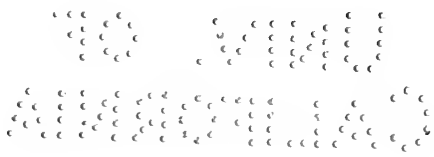

The Alpine Press, Boston, Mass., U. S. A. 


\section{$\mathbb{Z}$ 伊idcation of}

\section{The Social Evolution of Religion}

To the memory of LuCY NaSH Cooke, 18481919, who walked by my side for fortyseven years, - whose religion was love, whose life was fidelity, and whose ethical motive was devotion to the good of others. 
1

7 


\section{PREFACE}

$\mathrm{N}$ this volume have been stated the final results of fifty years 1 devoted to the study of religion in its varied manifestations. Accepting for many years the generally accredited interpretations of Christianity, I have gradually diverged from them as the result of a growing interest in anthropology, ethnology, psychology, and comparative religion.

These chapters were originally read to a small group of persons meeting in a private parlor in Boston, under the auspices of the local branch of The Free Religious Association of America. Not all which was written was read at any of these meetings, but often many pages were omitted in order that the lecture might be followed by questions and discussions.

The lectures have been carefully corrected, many pages excised, many more pages added, and the whole rewritten and thoroughly revised.

My friend, John Haynes Holmes, minister of the Community Church in the city of New York, has read the whole of the manuscript, given me the benefit of his suggestions and corrections, and written the foreword, which states briefly and pertinently that at which I have aimed in my book.

G. W. C. 


\section{Contents}

Preface

Foreward

Introduction

I. The Social Transmission of Human Experience . 1

II. The Creative Genius of Social Man . $\quad$ - 52

III. Communal and Tribal Religion . . . 109

IV. Feudal Religion . . . . . . . 148

V. National Religion . . • • • . . 189

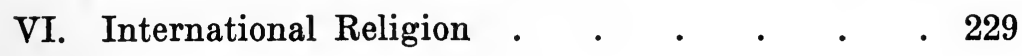

VII. Universal Religion . • • • • • . 291

VIII. Religion as Cosmic and Human Motive . . $337 \times$

Appendix to Chapter I . . . . . . . 405

Index 
$\approx$

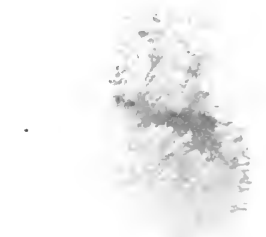




\section{FOREWORD}

THE changes which took place during the nineteenth cen1 tury in man's understanding of the world, and of himself as a denizen of this world, were undoubtedly the most remarkable in the annals of human history. They were nothing short of revolutionary in every department of knowledge. Old ideas went, and new ideas came, with a rapidity which was bewildering. Scientific and philosophic dogmas, long accepted as fundamental, were suddenly seen to be little better than myths; and speculations, at first regarded as phantasmal as they were degrading, were demonstrated to be true with a terrible finality. What was begun centuries before, in the so-called "Revival of Learning", was now carried through to heights of vision and depths of inquiry, which would have amazed the original innovators of that great period. Observation, investigation and experimentation - ceaseless accumulation of data, and daring hypothetical generalization upon the basis of this data-insistence upon facts and humble surrender to the leading of facts - in one word, the emancipated intellect, equipped with the modern scientific methods of inquiry, suddenly "made all things new." The world as it was, straightway took the place of the world as men had imagined, or wanted, it to be. With the result that, in the space of a single generation, so to speak, the whole volume of human knowledge was written anew, with indefinite extensions and marvelous transformations of material!

In no one department of inquiry, perhaps, was this change more remarkable - certainly, in none more startling - than in that of religion. A score of separate influences worked more 


\section{FOREWORD}

or less unconsciously together to shake down, as Samson the temple of the Philistines, the venerated structure of what was almost universally accepted as divine revelation. The higher criticism of the Bible, the new investigations of church history and the life of Jesus, the study of comparative religion, the disclosures of archeological research, the facts of anthropology, sociology, psychology, all combined to shatter every accepted doctrine of the origin, development and significance of religion, and to present anew the whole problem of this strange phenomenon in the life of man. One has only to name a few of the classic books of this period - Wellhausen's "History of Israel", Strauss's "Life of Jesus", Frazer's "Golden Bough", Tylor's "Primitive Culture", Sir Henry Maine's "Ancient Law" and "Early History of Institutions", Spencer's "Principles of Psychology" and "Principles of Sociology", Max Müller's "Sacred Books of the East"', Fiske's "Cosmic Philosophy"-to see something of the range of the influences which were at work, and the fundamental character of the results which they were achieving. Religion, as man had known it for nineteen hundred years, was now become a myth. The fact, as contrasted with the myth, was now being disclosed - slowly, imperfectly, with infinite labor and patience, much as a buried temple or tomb is disclosed by the excavator's spade - but with the certainty that in due season the revelation would be complete.

It is only in this, our time, that the permanent significance of these years of research in the field of religion is becoming apparent. Data gathered in a dozen different laboratories, have long been familiar. Only recently has it become possible to synthesize and generalize, and thus to present, with some degree of wholeness, the new picture of religion as a reality of human experience. What this picture is, may be variously described. But it is probable that we come nearest to the truth, and most 


\section{FOREWORD}

vividly set forth the nature of the change from old conceptions to new, when we say that we see religion to-day as a human product, rather than as a divine revelation. Religion, evolved from below, instead of imparted from above, is the transformation which modern investigation has worked.

In former days, it was believed that Christianity was a direct, perfect and final inspiration from God. In the old dispensation, Moses had received from the hands of Jehovah the two tables of the law. In the new dispensation, Jesus, the only begotten Son of the Father, had descended straight out of heaven, to bring salvation unto men. From this standpoint, Christianity was the one true religion. It stood, like Sinai in the desert, a single mountain, on which man could climb to, and at last meet with, God.

The discovery and sympathetic study of other great religions - Confucianism, Buddhism, Zoroastrianism, Mohammedanism - changed all this. It was seen that these other religions had claims to divine origin identical with those of Christianity. It was recognized that the theology and ethics of these religions were not altogether dissimilar to those associated with the prophets of Israel and the apostles of Christ. It was as though the single mountain peak were become a range of summits, each one of which touched heaven, and shone with the radiance of divine splendor.

Then came the discovery that behind these great religions were long periods of psychological and social development. The prophets were not isolated figures, but children of their time and race. The sacred literatures were not words from heaven, out myth, folk-lore, legend, redolent of the soil of earth and of the heart of man. These mountains, after all, did not meet the sky. Climb their slopes - and it was the substance of the level plains from which they rose, that met your feet. Stand 


\section{FOREWORD}

upon their summits - and you touched beneath, the granite frame-work of the planet, while above, and far beyond, the heavens still escaped you. The significant thing about these peaks, after all, was that they were rooted in earth, and thus a part of the native structure of the globe. On them, you breathed a clearer air; from them, you saw a wider horizon. But the revelation was from below upward, and not from above downward. The origins of religion, in other words, were human, not divine.

There are various lines of approach to this great truth various departments of knowledge which contribute data in demonstration of the thesis. Archeology is one. The study of sacred literatures, with their common background of mythology, is another. Psychology presents a fertile field of inquiry, as see Starbuck's "Psychology of Religion", and Professor James's great work on "Varieties of Religious Experience." All these, however, must yield precedence to sociology. The hidden tomb, the parchment manuscript, the confession of the individual soul, are all important. But not until we study the race, look upon man as a member of a group, follow step by step the evolution of society, do we come to the heart of the problem. Then, as if by magic, religion takes its place as a product of social experience, a form of social organization, an. expression of social need. Sociology, as Herbert Spencer long ago discovered, holds the key to the age-old mystery of God.

It is this social approach to the problem which characterizes this book by George Willis Cooke. Here are presented the human origins of religion in terms of the social history of the race. Two factors combine to make this a work not only of intense interest to the student, but of first-rate importance to the average reader. 


\section{FOREWORD}

On the one hand, we have in this volume an exhaustive and accurate presentation of the entire field of modern study of religion. The sociological aspect of the problem holds first place throughout, as of preëminent importance; but other aspects are not neglected. What the mind of man has accomplished in this field in the last one hundred years, is surveyed and summarized. We have here a rich accumulation of first-hand material, a testing of the worth of this material as evidence by the best standards of modern scholarship, and a judicious and unbiased presentation of the conclusions to which this evidence leads us. The book is the fruit of a life-time of patient and exhaustive inquiry. It accomplishes to no small degree in the sociological field, what James accomplished so superbly in the psychological field in his "Varieties of Religious Experience." Furthermore, it serves to correct the dangerous one-sidedness of that unique masterpiece.

Secondly, this book is important for its study of what the discovery of the human origins of religion is going to mean to religion in the future. Here the author turns from a study of the facts of yesterday to a study of the prospects of tomorrow. That the result is revolutionary, is stating the truth mildly. The thought of God, the function of worship and prayer, the hope of immortality, the place of the church in social life - all these are cast, as it were, into the melting pot. And out of it, is seen to come a religion.as different from that of the older time as the new world which is destined to emerge out of the Great War, is different from the world before the war. Chapter VIII is perhaps the most important, as it is certainly the most interesting, in the book. Mr. Cooke is prophet quite as much as scholar, and it is not too much to surmise that, for this final chapter of forecast, the rest of the book was written. 


\section{FOREWORD}

It has been my happy privilege to read this work in manuscript, and discuss it with its author. I have been instructed and inspired by this experience. It is a pleasure to take advantage of the opportunity granted me by Mr. Cooke, to commend the book to that wide circle of readers which it is sure to find.

JoHN Haynes Holmes.

New York City. 


\section{INTRODUCTION}

THE universality of religion is a generally accepted fact. The statement has been often made that certain bands or tribes were without any religious practice or belief; but it has been shown that this conclusion is a mistaken one. An acquaintance with the language of a people, and an intimate knowledge of its customs and institutions, is essential to a true understanding of its religious life and practices. When such knowledge has been secured, it has been discovered that the religionless people has not only a religion, but it may be much given to the exercise of religious rites and ceremonies.

Religion takes the widest possible range of expression, and in its earlier manifestations is not to be judged by the intellectual demands of the higher civilizations. The religion of primitive peoples is almost invariably expressed in rituals and cults, that is, in something done, and not in something believed. It may be truthfully said that such peoples have no beliefs as such, no purely intellectual or philosophical interpretation of life and its experiences. They dance or sing or act their religion; and they give it expression in festivals, ceremonials, and rituals.

The religion of the primitive or undeveloped peoples is emotional and not intellectual, poetical and not scientific. Wherever we find such a people and its religion, whether in the present or in a more or less remote past, we may discover, if we give close attention to the facts presented before us, that the attitude manifested is one of feeling and not one of reason. Such peoples do not deal with principles but with persons, not with ideas but with activities. 


\section{INTRODUCTION}

Since organic life and humanity have had a definite beginning, it must be supposed that religion also began at some remote period in the history of mankind. We do not know under what conditions or at what stage in human evolution it took its rise. Perhaps we may be justified in assuming that religion originated with man, and that it has been in existence ever since man became truly man. Indications of awe, reverence, and other emotional attitudes toward the environing world, have been attributed to animals; and it is therefore probable religion began with the beginnings of human experience. This means that religion had a most lowly origin and that it was at first an attitude rather than a reality, an emotion finding communal expression.

It must be recognized that all the evidence is in favor of the conclusion that the earliest manifestations of religion were those of a group, and not those of individuals. The child does not know himself as an individual for the first two or three years of his life; and, in fact, he does not attain full consciousness of self, with capacity to assert his right to a separate intellectual existence, until he reaches the age of puberty. In the same way, primitive man may be an individual from the first, but the attaining of personality comes only at a comparatively late period, as one of the results of the evolution of civilization. The primitive man and woman are members of a group, and they live its life without recognition of an existence other than it can give them. Its life is their life, its emotions their emotions, its religion their religion. They have not the mental capaeity for separating themselves in any manner from its rituals and its myths, its customs and its tabus; and they have no wish to do so. In fact, they are quite incapable of seeing the group life and the group religion in perspective or 


\section{INTRODUCTION}

of giving them an objective interpretation. In large degree the group life is coterminous with the individual life, and the individual emotion is emphatically that of the group. The evidence makes it quite certain that the individual of the primitive group recognizes himself only in his communal relations, and in these relations he realizes the whole of his being.

Because man begins his life as a member of a group, and, under the environing conditions of the earliest periods of his existence, could have survived in no other manner, we have a reason why from the first he was religious, that is, conceived of the environing world emotionally. That world, be it understood, was not the universe known to us; but simply and merely the group to which he belonged, and its immediate environing world. In that, and by means of that, all life, and all nature, were known to him. The circle of the world was the circle of the group. All outside the group, whether of the world that gave food and shelter, and contact with plants and animals, or inside of the world experienced in the relations of sex and childhood, and rituals which expressed the emotional content of the group life, was interpreted in terms of the group life and its demands as a group. In this communal existence the primitive man found the whole of his experience and the manner of his interpretation of every phase of the world around him.

In the fact that religion began as an expression of the group life, and as an emotional manifestation of its experiences, we may find reason for asserting that fundamentally all religions are the same, and answer to the same demands of man's nature. Although it is true that the more developed religions began at a period remote from the conditions under which all the primitive religions had their origin, yet none of them but were influenced by those traditions or survivals which came from the earliest period. All religion is essentially communal or social, 


\section{INTRODUCTION}

the expression of what belongs primarily to the community and not to the individual. The emotional nature of religion gives unity to all its varied manifestations. Human nature, in its primary qualities, is the same wherever found, in whatever religion or period; and therefore this expression of it that we call religion answers everywhere to the same needs, to the same sense of wonder and awe, to the same demand for the interpretation of life and death. No beliefs or practices of the most advanced religions but have their correlates in the more primitive practices and rituals of the communal or group religions. Religion, wherever manifest, answers to the same human demands; and it reaches the responding satisfaction by quite similar methods and to the same primary ends.

Any genuine study of religion, in its universal manifestations, demands sympathy and mental responsiveness to what is best in its several expressions, whether crude or advanced. This may require some degree of aloofness from all that is dogmatic and authoritative in any one religion. $\mathrm{He}$ who regards Buddhism or Christianity or Islam as final, as the one only religion which is true and revealed or as having any absolute value for those wha accept it, is not in a position to appreciate other manifestations of religion at their true social significance. It is for this reason that an attitude of unconcern about the dogmatic values of any religion, as relates to individual destiny, appears to be essential to a wise and just appreciation of the several phases through which religion has passed from the period of the earliest man to its latest manifestations in our own day. No demand is made upon the individual that he shall discard all religion, or that he shall turn aside from that into which he was inducted in childhood; but that he shall become undogmatic, appreciative of all that is human, and willing to consider sympathetically whatever ritual or creed has meaning for the 


\section{INTRODUCTION}

life of another community than his own. Whatever gives meaning and purpose and joy to the life of any individual may be regarded with respect, and should be studied, if studied at all, with sympathy and appreciation.

The contention here set forth is, that all religions are true to those who accept them as true, and to the extent to which they give meaning to the life of the group or the individual. Even the very crudest religions, those of the peoples the least developed, show forth qualities that serve a noble human purpose. Even such religions make men and women better and wiser in their relations to life and to one another. All religions have their heroes and their saints, and the good may be found wherever man exists. If any one religion developed the best life in all its followers, we need not hesitate to accept it as preferable to all others; but when we find the highest type of conduct in the most primitive groups and under the crude conditions of life they present and all the way up through every religion to the most developed in other respects, we may conclude that no ritual or creed is final. We need but look about us to see that Christianity has no monopoly of virtue in its followers, and that it cannot make better men and women than are to be found .developed by Buddhism and Mohammedanism. A noble life must be regarded as the true test for any and every religion; and noble lives are to be found throughout the world, in all communities and under all religions. If we accept this test, we must say that all religions are true as to the results they produce. It must also be said that all are false or imperfect, in so far as they fail to make sure of the good life for all who accept them. Even the most highly developed religions fail to realize their ideals, their standards of conduct, in the lives of all who receive their rituals and their creeds. 


\section{INTRODUCTION}

In recognizing these defects in the more advanced religions, we must not forget that all of them are shot through and through with survivals from the past, even from a very remote period in human history. Religion is a development, has had a very prolonged evolution, shows everywhere the results of its continuous advancement or degeneracy; and that what hinders its higher development, or may be properly regarded as its defects is in no small measure the result of this process of growth through the ages.

The religion of to-day shows on every hand the results which come from the attempt to put new wine into old bottles or to attach fresh rituals and beliefs to the old terms and traditions. An illustration of this may be found in the continued use of the word "salvation" for what in no sense connects itself with the origins of that term or whatever it connoted in earlier ages of the history of religion. Even H. G. Wells uses this word with meanings which have not the slightest connection with its earlier uses. We do not now believe that men are to be saved from the dungeons of a tyrannous king or the place of torment of a vengeful God. We do not believe that any impending dark and gloomy fate hangs over us from which we are to escape by means of magic or the recitation of rituals or the belief in cruel and awful creeds; and yet we continue to use a word which in all its connotations, historically speaking, means something of this kind as impending over us. Therefore it is desirable that we should discard a word having these implications. No modernization of it can cause the obliteration of the historic background of the word.

The same is true of many other religious words and phrases, that we have given them meanings which deny their historical origin and connections. Such a word is "sacrifice," which no longer means the killing of animals or men as offer- 


\section{INTRODUCTION}

ings to a God capable of demanding such a price paid to appease his wrath toward men, as not having in some minute detail gbeyed his arbitrary commands. We may recognize that our sacrifices of to-day are those of the suppression of selfishness, the giving freely of our substance to relieve the needs of our fellows; but not thus can we escape the tragical and awful history which has brought us this word and its historic significations through the ages. As we study that history we may rightly rebel against the use of a term with such a fateful and dark background of vengeance and cruelty and disregard of human welfare.

When we study thoroughly such instances in the evolution of religion we may query whether it is capable of correcting its own defects, and of eliminating by its own initiative the limitations and the vices of its past. It is doubtful if it ever does this without the aid of those collective forces which we describe when we use the word civilization. Religion is undoubtedly the most conservative social force known to the life of mankind, and it is always extremely reluctant to break with its own history.

Such being the tendency of religion, we may rightly accept an attitude of caution in regard to its dogmatisms. We may hesitate in regard to every dogma which is declared to be of undoubted veracity. The very claim of revelation, constantly made in the name of religion, is fundamentally of a dogmatic nature, intended to impose silence on all who would think freely and constructively. Religion is a growth, now in process of development as in the past; and, if it is to be regarded in any sense or degree as a revelation, it must be assumed to be a progressive, a constantly unfolding revelation, a continuous process of advance from lower to higher forms of expression. He who would study religion in an untrammelled spirit, 


\section{INTRODUCTION}

without fear and without prejudice, must do so without the slightest thought that the conclusions he reaches can determine his own future destiny. It cannot be assumed that any belief decides what is to be the nature of the life which will be that of the individual when he passes from his present state of existence. Belief in regard to subtle theological and metaphysical problems is not vital, does not forecast the issues of life, and can be in no sense fateful with regard to the determinations of the future. He who hesitates to think with absolute freedom on this account cannot have any opinions in regard to religion which will be of fundamental importance.

What this means is, that religion must be studied in the scientific spirit, and with the latest and most approved scientific methods. First of all we are to seek for the facts, what religion has been and is; and as if we had before us a plant or a star for investigation. That is, any concern as to what it may mean for us personally must be absolutely barred out. When we investigate a plant or a star what we are concerned with is its origin, its nature, the process of its development or its relations to other plants and stars. This, too, should be our attitude in the study of religions. In a word, we must apply to them the scientific method and purpose, that of knowing their origin, the processes of their growth, and what they meant to those who accepted them. This method in the study of religions has developed the newest science, that of Comparative Religion, or the study of all the religions of the.world in relation to each other, with a view to determining their common factors, that in which they differ, and the stages through which each has grown from its early beginnings to its latest manifestations of itself.

Such a study may not promote piety or worship or a dogmatic belief of any kind; but it does show us what purpose 


\section{INTRODUCTION}

religion has answered to in the evolution of mankind. We shall come upon much that is crude, vulgar, immoral or unmoral, wanting in all mental inspiration; but also upon much that is illuminating as to the nature of man, the manner in which culture and civilization have been produced. We will also find many a suggestion as to the future of religion, and the manner in which it can be purified of its crude survivals, and made a vital force in the future evolution of mankind.

It is the purpose of the following pages to set forth the human origin of religion, and especially those phases of it which reflect and interpret the needs and the aspirations of mankind. Whether religion comes to man through instinct, intuition, philosophical insight, revelation or some form of supernatural intervention, it must be ultimately brought within the compass of the human understanding and fitted to the needs of hoping and sorrowing men and women. It must be reduced to practice, fitted to daily utilities, and made to conform to individual and social demands. The more truly it is socialized, that is, brought to act as a motive cementing together groups of smaller or greater size, the more truly is it worthy of general acceptance. In a word, religion finds its real sanctions in its social values, in its eapacity for binding men together in unifying relations.

Religion cannot be understood apart from man and his needs. Since man has created all religions, and still retains in full measure that creative capacity, religion must be studied in the light of man's unfolding culture and civilization. The old thinker who said that man is the measure of all things said better than he knew, and far better than the succeeding ages have recognized. When it was said that man was not made in order that he might keep a day of rest, but the day of rest came into existence for the profit of man, its purport might be 


\section{INTRODUCTION}

extended to signify that religion has its real meanings in the values it confers upon humanity. Man does not exist for the sake of being religious, but religion has come into existence because it confers a human benefit. That benefit alone gives it meaning and value. Religion has not been imposed upon man from some extraneous source or thrust down upon him from above. He is the meaning of it, the worth of it, and the source of its inspirations and its higher values. Above all religions and all gods is humanity, the creator and the sustainer of them all. 


\section{CHAPTER I \\ The Social Transmission of Human Experiences}

DLIGION is of social origin, and, in its beginnings, is an 1 emotional expression of the relations of a group to its environing world. Fundamentally and essentially, it is a manifestation of the collective life of a band of men and women living together in social relations, in order that they may best meet the demands for food, the perpetuation of their own existence as a collectivity through the birth of children, the protection of the group from enemies of whatever kind, and that they may satisfy the claims of the collective life emotionally, ethically, and esthetically.

In the study of the history of religion it is of the first importance to recognize that it is socially, and not biologically, transmitted from generation to generation. We do not inherit religion from our ancestors by the process of physical or congenital heredity; but by the methods of training, education, culture, and social influence. We do inherit a greater or lesser predisposition in favor of religious experiences, so that we are more or less attracted to them when they come to us in the process of social transmission. We may have a religious diathesis, to use a medical term, or, in popular phraseology, we may have a religious constitution. Some persons appear not to be born with such a constitution, and are to a degree indifferent to the emotional and the social appeal of religion. Probably no 


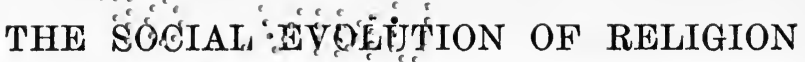

one can be wholly" indlifferento to the questions suggested by the phenomena of birth and death, by pain and disease, and by our relations to the universe of which we form a part.

Undoubtedly, however, there is a wide range in the ability to appreciate the appeals of religion; and if some are seemingly indifferent to these appeals, others are supersensitive to them. Granted this natural or inherited attitude towards religious experiences, the fact remains that the kind of religion accepted depends almost wholly on the process of social transmission, that is, on the religious environment of the individual, and on the training which he receives in this respect.

Religion is not peculiar because of the fact that it is socially transmitted. In this regard it shares with language, culture, civilization, and all that makes up the intellectual content of the mind, for all of these are socially, not congenitally, inherited. We do not biologically inherit anything more than a congenital capacity for industries, arts, sciences, literatures or spiritual experiences. It is doubtful if we inherit anything more than a predisposition to the kind of social conduct which we name morality.

In order to comprehend fully the fact that religion is socially and not congenitally transmitted, it is important to recognize that we do not inherit a language, but only the capac. ity for speech. We acquire language by a slow process of learning, and by imitation of those with whom we are socially connected during the period of childhood. Many persons never acquire the ability to speak correctly and intelligently the language of their parents and of their social group, partly because they do not inherit more than a limited capacity in this direction, but more especially because their social environment in childhood does not afford them a standard which they ean follow to a full measure of language attainment. Other per- 


\section{THE SOCIAL EVOLUTION OF RELIGION}

sons may inherit a great capacity for the acquisition of languages; but even for them some effort, some patient endeavor, is necessary to the securing of a new language equipment. This is to be recognized, that all languages are acquired, and none are born with us.

It may seem the merest truism, that we acquire a language, and are not born with it; and yet this fact is not always fully recognized as to its social bearings. It means not merely that language is the result of social transmission; but that religion, culture, morality and science are of the same nature, not born with us, but must be acquired. The mind in infancy has been described sometimes as a blank sheet of paper, with its watermarks, and with its capacity for receiving whatever we may wish to write upon it. In the instance of the human mind, however, the writing is produced socially, by the environing conditions of our childhood and youth.

Many years ago Stanley Hall made a sociological and psychological study of the children first entering the public schools of the city of Boston. The most patent fact resulting from that study was, that the amount of knowledge children of six years of age had acquired depended wholly upon their social environment during the preceding years. Those who had been born with a good heredity naturally had acquired more than those born with dull minds or defective brains. Nevertheless, the social environment had determined what Hall called "the contents of the minds" of these children. If the parents were educated the children had profited by that fact, but if they were ignorant, and without intellectual interests, the children had suffered from that limitation of the parents. If the children had been confined throughout their lives to the city streets, that fact appeared as to what they knew. In case they had never been into the country the sights and sounds there to be 


\section{THE SOCIAL EVOLUTION OF RELIGION}

met with formed no part of the contents of their minds. If the parents had traveled or if they had spent the summers in the country the breadth of the mental equipment of the children's minds was correspondingly enlarged. In a word, children entering upon the studies of the public schools have had their minds developed in harmony with their social environment up to that period.

Had Hall studied the religious contents of the children's minds who came under his enquiries, the same conclusions, essentially, would have been reached. He would have found that some of these children were endowed with more of religious sensitiveness than others, but that none of them had an innate or intuitive capacity to determine what they knew or appreciated in regard to religion. All that had been determined by their social surroundings, by the influence of their parents, and by imitation of them, by contact with other persons in the nursery or on the street, by their experiences in Sunday-school or church, and by the whole range of their social contacts, in so far as these had been of a religious nature.

\section{I}

In order that we may fully grasp the reasons why the contents of the mind are socially determined, it is necessary to study the ultimate consequences of the congenital and social transmission of the products of human experience. These two processes are essentially different, though they have been often regarded as of the same nature, and as giving the same results. Congenital transmission is a biological process, and is largely of a physical nature. Social transmission is a sociological and psychological process, and may be described as that which underlies all education, culture, and civilization. 


\section{THE SOCIAL EVOLUTION OF RELIGION}

At the basis of this divergence of the two processes of congenital and social inheritance or transmission is the law that acquired characters are not inherited. That is, the child receives in the process of physical, congenital, germinal, organic or biological heredity (all these words having essentially the same meaning), what is passed on to him from his ancestors, through his parents. This includes his physical organism and its strength or weakness, its predisposition to disease of one kind or another, or its capacity for long life and permanent good health. Whether the individual is small or large, short or tall, blonde or brunette, has one color of eyes or another, and other physical qualities and capacities, will be determined by physical inheritance. In the same way temperament is inherited, as well as what we call "disposition," a nervous diathesis or a rugged constitution.

Mental qualities and capacities are inherited by the same process. Congenital heredity gives an alert or a dull mind, one predisposed to an orderly, sane and moral life, or one that is predisposed to vice and crime. The students of heredity and eugenics have made much of this tendency to the congenital transmission of good or bad qualities. They insist that heredity of this kind determines the individual life, that a good parentage or ancestry is fundamental to a good or a noble and wise life, that no training or education can overcome the limitations and drawbacks of a bad heredity, and that what we are to care for most is that the coming generation shall be well-born.

We cannot question the fact that mental predisposition and capacity are determined by physical heredity. A long line of capable ancestry gives large assurance that the coming generation will be highly endowed. Genius runs in families, and the great men and women of the world have often been closely linked to each other by ancestral ties. The capacities of the 


\section{THE SOCIAL EVOLUTION OF RELIGION}

individual, and his predisposition to one form or another of mental activity, that is, as to whether he shall be manual laborer, artisan, artist, philosopher, scientist or saint is result, in large measure, of his ancestry.

The eugenists have collected a large number of instances of the inheritance of genius and talent, and of those who have been cursed with a heredity of mental and physical defect. In this country reference is often made to the family of the Jukes, the descendants of a defective woman living in New York during the eighteenth century. In the line of her descendants were a large number of mental defectives, criminals, prostitutes, and other persons who were a burden upon society. This family has been compared with the Edwards family, and its long line of descendants of the highest intellectual, social and moral endowment. Recently there has been studied a New Jersey family in which there appeared the same marked hereditary divergences. A young man at the time of the revolution became the father of an illegitimate child by a defective girl; and a long line of vicious, criminal and defective persons has resulted, only a small proportion of the descendants of this girl having been able to escape the results of the bad heredity. This young man later married a virtuous, educated and refined woman, by whom he became the ancestor of a long line of the leading men and women of his state, including many who have held the highest positions, and with only a small number of her descendants showing vicious or defective tendencies.

Such evidence seems to make it overwhelmingly true, as Francis Galton wrote, that nature is far more important than nurture in determining capacity and character. The eugenists have therefore proposed and urged, with all possible emphasis, that the utmost attention should be given to the mating of 


\section{THE SOCIAL EVOLUTION OF RELIGION}

capable persons, with a view to the producing a generation of sound and efficient men and women. They have gone even so far as to propose the elimination of those not capable of producing a sound offspring, either by the process of death or that of desexualization.

We may now turn to the process of social heredity or the transmission of the results of culture. We have already emphasized the importance of this form of inheritance in saying that language, culture, civilization, religion and morality are transmitted from generation to generation by a social process, and not by means of congenital heredity. An illustration may suggest the relations of the two, as well as the radical divergence in the nature of the two processes. Organic or congenital heredity produces the house in which we live, and all that makes it a fit place for human habitation. Its exposure, its geographical and human environment, its arrangement of rooms, its "modern improvements," its artistic decorations, assure its attractiveness, and make it a delightful place of abode. Here we have the body, with its mental capabilities, as endowed with brain and nervous organism. The house, in its interior furnishings, and in its human inhabitants, of whatever nature and capacities, may be compared to the endowments provided by social heredity. It is difficult to separate the house from its inhabitants, and what they bring into it that expresses their natures and their capabilities. Whether it shall express an artistic, musical, intellectual or social preference in the family will be determined by the equipments with which they provide it, and how they live as its occupants. It is evident that the same house may at different times have as its occupiers families of widely divergent tastes and preferences. But the house itself may represent biological heredity; 


\section{THE SOCIAL EVOLUTION OF RELIGION}

its occupants and their tastes the conditions afforded by social heredity.

It was suggested many years ago by Weismann, in an essay on the musical sense in animals and man, that the increased expression of musical ability in modern times did not imply that musical talent had been developed in equal proportion. It is not probable that such talent has increased for a long period, but that there has been a gradual evolution of the means of musical expression. The science and the art of music have been slowly perfected; and it is this development of the art through many generations which has enabled musicians to make of it a greater artistic power than it could have been in ages before it had reached the perfection it has attained in modern times. What we find, therefore, is not an increase in musical genius by means of hereditary transmission; but a perfection of the art with the aid of better instruments and a more fully equipped science of musical expression. Until the scale had been perfected, until there had been developed the laws of melody, harmony, orchestration, etc., it was impossible that any large degree of perfection could be reached even by men of the highest musical talent.

Weismann was evidently correct in insisting that the development of any mental faculty is not necessarily connected with an elevation of mental capacity in the individual. The capacity of the brain need not be changed or enlarged in order that there may be an increase in mental output. We can solve mathematical and mechanical problems far more successfully than was possible in the days of Aristotle, though the men who undertake these tasks are far less mentally competent than was he. Though there has been no increase in musical faculty since the time of the ancient Greeks, there has undoubtedly been a great development in the art and the science of music. Accord- 


\section{THE SOCIAL EVOLUTION OF RELIGION}

ingly, Weismann rightly suggests that there is to be recognized a complete distinction between music and musical talent, the one depending on the gradual advance in the art of music and the other on the hereditary equipment of the individual. For this reason Weismann concludes that the evolution of music does not depend upon any increase in the musical faculty or any alteration in the inherent physical nature of man, but solely upon the social power of transmitting the intellectual achievements of each generation to those which follow. This transmission of the results of human achievement from generation to generation by a social process will apply to religion as well as to music; and it will equally apply to language, art, science, morals, and all forms of developed human expression.

\section{II}

This capacity in man for the transmission of the results of social experience from generation to generation very distinctly separates him from the animals. It is true that some of the higher animals have this capacity in an embryonic form and extent; but in the absence of language, the animals have no adequate instrument for the transmission of the results of animal experience. All that the animals can accomplish in this direction is for each parent, and especially the mother, to train her young as best she can in those methods for securing food or warding off enemies, which she has found most successful. It may be that she has received these habits and customs from her parents, and now transmits them to her offspring. Lacking an adequate language, and therefore being unable to construct traditions, myths, elaborated customs and forms of social organization, the animals reach forward only a very little way in the direction of social heredity and social institutions. 


\section{THE SOCIAL EVOLUTION OF RELIGION}

The lower animals are guided wholly by instinct, every phase of their lives being determined by congenital heredity. In the higher species the brain and the nervous system have become more complicated, with the result that the young are born in a degree imperfect, and need some weeks or months or even years in which to reach the full adult stage. During this period of immaturity the young must be cared for by the parents, and especially by the mother. It is at this time that the young, being no longer under the complete domination of instinct, can be taught something of what the parents have learned, either by individual experience or as the result of animal tradition, that is, what they have been taught by their own parents in the period of youth.

In his Cosmic Philosophy, published in 1875, John Fiske was the first person to point out the great importance of the prolongation of infancy in man as a means of moral and social evolution. He showed that in the animals the instincts were fully organized at birth, while in man the organization of the instincts, primary and secondary, are continued through the early years of life. In this manner there arises the phenomena of infancy, in which period the nerve-connections and correlative associations necessary for self-maintenance become permanently established. The growing complexity of intelligence demands this prolonged period for its growth and maturing, with the result that infancy becomes a most important psychological factor in the evolution of man. Even to a larger degree it establishes man's sociological development, and the growth of human society. "The prolonged helplessness of the offspring must keep the parents together for longer periods in successive epochs; and when at last the association is so long kept up that the older children are growing mature while the younger ones still need protection, the family relations begin to become permanent.... 


\section{THE SOCIAL EVOLUTION OF RELIGION}

Enduring from birth until death, these relationships acquire a traditionary value which passes on from generation to generation, and thus there arise reciprocal necessities of behavior between parents and children, husbands and wives, brothers and sisters, in which reciprocal necessities of behavior we have discerned the requisite conditions for the genesis of those ego-altruistic impulses which, when further modified by the expansion of the sympathetic feelings, give birth to moral sentiments."

In several essays of a later date Fiske elaborated this conception in regard to the social functions of infancy, and the immaturity of the growing child and youth. Such immaturity gives opportunity for the social education of the individual, for the play of suggestion, and for the whole of the process of training and the passing on to him of some, at least, of the results of human experience accumulated through the ages. This process has been defined as social heredity, in contradistinction to congenital heredity. When it is desirable to emphasize the process of this transmission of the products of social heredity from generation to generation it is sometimes called tradition, which has been defined as "the handing down of knowledge, behavior, modes of life, etc., from generation to generation without physical heredity; applied also to that which is handed down."

We do not know precisely how it came about that man begins life in a condition of weakness, helplessness, and immaturity far greater than in the case of the most highly developed of the animals. We do know, however, that this immaturity of the child at birth has had the greatest consequences for the individual and for the race. At birth the child is utterly helpless, wholly dependent upon others, is not able to hear or see distinctly, can use none of its limbs to any purpose, knows nothing but that it is hungry and that it may be uncomfortable. A bundle of possibilities only, it must live, if it lives at all, dependent 


\section{THE SOCIAL EVOLUTION OF RELIGION}

for months and years upon the care of its mother, father, nurse, and the environing society of which it becomes a part.

The brain of this child is immature, in some considerable degree unorganized; and its nervous system is far from being fully developed. Without the aid of other persons it will grow up to become little more than an animal; and it is not too much to say that it is wholly dependent upon society as to what it may become during the years of its maturing, which may be twenty and may be thirty-five, before it attains to the fullness of its powers. During all this period the individual is profiting in many ways by the results of human experience through the ages, as passed on to it in the form of training, education, contact with individuals and society, and by all the processes by means of which the contents of the mind are being secured. It is not the intellect alone, however, that is trained and matured by human contacts; but the emotions and feelings are being organized, the conscience guided, and the whole of the personal existence brought into what it ultimately becomes. Nor are we to assume that it is alone by human contacts that the individual is attaining his maturity, for he may be largely influenced by nature and by association with animals.

The prolonged period of human immaturity after birth has the effect of making the nervous system, the brain, and the mind highly plastic and receptive. To such an extent is this the case that a French sociologist, Gabriel Tarde, has made imitation the basic principle of both psychology and sociology. The infant begins its education by imitating those about it, and in this manner learns how to use its limbs, acquires habits which determine its conduct, and slowly gains ability to make use of speech in expressing its wants. What Tarde claimed for imitation, however, though in no small degree resting upon a sound basis of fact, has not been more recently accepted as the founda- 


\section{THE SOCIAL EVOLUTION OF RELIGION}

tion of all individual and social life, as he taught in his numerous works. Without doubt, however, the capacity of learning by imitation, and especially of acquiring what society has to communicate in the form of training, education, and culture, is the process by which the immature child and youth come to the maturity of their powers.

Recent psychologists are more inclined to emphasize suggestion than to give such credit to imitation as was done by Tarde. The conception of suggestion, according to James Mark Baldwin, in his Mental Development in the Child and the Race, affords "an extraordinary point of vantage for estimating the development view of the origin of the social and personal sense. We have in it direct evidence of the growth of the social instinct by accretions from experiences of social conditions, and direct evidence, further, of the lines of progress which these experiences and variations have marked out."

Suggestion comes from many sources and takes many forms. The whole process of the contact of the child and youth, and even in no inconsiderable degree also the adult, with society is one giving him suggestions, hinting to him of the manner of his right thinking, his correct way of feeling and acting, the conduct which ought to be his, and the nature of his religious attitudes. Included in suggestion is imitation, direct teaching, and all manner of emotional responses. In its most emphatic expression suggestion takes the form of a hypnotic imposition of the will of society, or of some powerful individual, who speaks for the social body; and the youth finds himself compelled to obey. What thus results is not the mere imitation of one person by another, but the overpowering mastery of the individual by a social force he cannot resist.

Keeping in mind the fact that the lower animals have their lives completely determined by congenital heredity in the form 


\section{THE SOCIAL EVOLUTION OF RELIGION}

of instinct; and keeping in mind the other fact that instinct has only a comparatively limited control over the human individual, and that he has open to him the accumulated results of human experience as these have been elaborated through the ages, we see not only the wide limit there is between congenital heredity and social heredity, but also the vaster degree of divergence there is between the animal and the man. It is to be borne in mind that man is an animal, that he is of animal origin, that he continues to inherit congenitally much that belongs to the animal nature; but in many respects he has left far behind his animal instincts and desires. He has somehow, in the course of the ages, acquired that marvellous instrument for the development of social heredity, language. With its aid he has also organized social and political institutions, developed arts and sciences, and attained to morality and religion.

In order to make certain that we clearly comprehend the difference in nature between congenital and social heredity, we may turn again to compare them with each other. There resulted from Darwin's publication of his Origin of Species and Descent of Man, and the studies to which these works gave rise, the placing of a great emphasis upon the conditions and laws of biology, which led to the elaboration of the principles of heredity and eugenics. For some years all phases of human life were interpreted from this broad conception of the nature and significance of biology; and heredity became the fundamental law not only of animal existence, but also of sociological interpretation. The primary idea set forth from this point of view was that heredity determines the life of the individual, and through him of society itself. The conclusion being accepted, as it was accepted by Darwin and many others, that natural selection is a universal law, and that the results produced by its operation are transmitted by means of con- 


\section{THE SOCIAL EVOLUTION OF RELIGION}

genital heredity, it was assumed that all progress results from the passing on to the child of the results of the parents' experiences, and their acquisitions of every kind.

In large degree we owe it to Weismann, as already indicated, that this biological conception of human nature and progress has been modified. His conclusion that the results of individual experience and learning are not inherited congenitally, or, as it has been termed, that acquired characters are not inherited, has been gradually developed by a succession of investigators, into its modification by the law of social heredity or the social transmission of the results of human experience. This means, in simple statement, that what the teacher obtains of facility in the acquisition of knowledge or the blacksmith of muscular development in the pursuit of his craft are not passed on congenitally to their children. The teacher may train his children to the acquisition of what he knows, and the blacksmith may train his children to the mastery of his craft; but neither gives them anything congenitally in the way of larger brain development or greater muscular power. Weismann showed us that the only manner in which individual acquisitions can be transmitted to offspring is by means of a change in the germ-plasm, that is, through the modification of the germ from which the individual begins his life. Such modification of the germinal factors takes place only rarely or through some process that acts continuously for a considerable period, and appertains to a large number of individuals through many generations. Something of this kind has been made certain as the result of the studies in biology and heredity begun by de Vries and Mendel.

Whatever modifications may have been made in the theories of Weismann, it is now quite certain that individual acquisitions are not fully transmitted to offspring, and that 


\section{THE SOCIAL EVOLUTION OF RELIGION}

human progress is not exclusively the result of the passing on to children of the gains made by the parents by means of the congenital process of heredity. Very slowly this conclusion has been reached during the last half-century; and the emphasis now placed upon social heredity has given an essentially new conception of human nature and the processes which have given us what we call civilization.

A remarkable instance of the dawnings of the new conceptions of the nature of the social process may be seen in the experiences of Thomas H. Huxley. In his Romanes lecture at Oxford, in 1893, on Evolution and Ethics, Huxley showed himself much puzzled as to the results of congenital heredity and natural selection as antagonizing the ethical efforts and demands of man. The cosmic process means struggle and strife, while the moral nature of man, and the demands of human society, call for good-will, love and justice. Plants and animals have advanced as the result of the struggle for existence and the survival of the fittest; but social progress for man demands a checking of this cosmic process, and the substitution of another, what may be called the ethical process. In place of the ruthless self-assertion of the cosmic process, the ethical process in man demands self-restraint, regard for the welfare of others, and attention to the needs of society. "The history of civilization," Huxley proceeds to say, "details the steps by which men have succeeded in building up an artificial world within the cosmos." This world, as he indicated, is that of culture and civilization, and he might have added, that of morality and religion.

It seems probable that Huxley was much puzzled over the disparity between what he called the cosmic process and what he might have called the human process; and it is certain that many of his friends and admirers thought that he had forsaken 


\section{THE SOCIAL EVOLUTION OF RELIGION}

the conclusions of Darwinism and of evolution, and had retreated to the old conservative conceptions of philosophy, if not of theology. However, if Huxley had lived to our own day he would have found this puzzle in large degree solved by the laws of social heredity, and the recognition of the processes by which the whole of the results of culture and civilization are transmitted from age to age. Huxley saw that there was here a great problem to be solved, to which biology and heredity had not given the clue. That clue, it is now evident, is to be found in the law of social heredity, and the transmission of acquired characters by the processes of imitation, training, education, and social contact. This process is not one merely of the passing on the results of individual experiences by parents and teachers to the young, but that of a vast and complicated social process by which culture and civilization have been developed through the ages, and are socially transmitted from generation to generation. Here we have something as intimate and as insistent as the biological process of the transmission of the results of congenital heredity. It links together even more intimately the generations to each other, and it insures to the coming generations that they shall be fitly equipped with the best which humanity has acquired through all the ages of its struggles and endeavors.

\section{III}

When we consider the ultimate results of the two forms of heredity, we come upon a conclusion of much scientific and philosophical importance. In congenital heredity we find the basis of individuality, and in social heredity the foundations of personality. What these two words represent has never been very clearly defined; and they have been often, in philo- 


\section{THE SOCIAL EVOLUTION OF RELIGION}

sophical statements, as in popular usage, confounded with each other. It seems to be plain enough now that the individual connotes everything implied by congenital heredity. The individual organism, with its separate physical structure, its independent nervous system and brain, constitutes a distinct physiological entity, with its own separate demands and desires. From our present point of view it affords the matrix or vehicle for the hereditary transmission of the racial qualities to the next generation. Though that fact may seem to connect it, as it does, most intimately with the racial process, yet in order to do this, it appears to be necessary that the individual shall be in himself a complete entity of the physiological or biological type.

We may therefore define individuality, or that which constitutes the individual human being, as the product of congenital heredity. Within itself it contains everything transmitted from its ancestry to this kind of entity. The hereditary process demands the intimate linking together of the generations, and the dependence of the individual, not merely on his parents, but on a far-back ancestry, which ultimately includes the whole of the population of the earth. Not the less, however, is there something very positive in the individual organism, which concerns its nature as a distinct physiological entity. We conclude, therefore, that it is the process of congenital heredity which elaborates the individual, and equips him with all his biological qualities and capacities.

Not the less surely does the process of social heredity endow this individual with what we call personality. In order to accept this conclusion we may need to put aside many philosophical and theological presuppositions. It assumes that the person as such is the product of a great and universal social process, that extends in its workings from the time of the first 


\section{THE SOCIAL EVOLUTION OF RELIGION}

human beings to our own day. The word person originally means a mask, the assuming of a character on the stage, a character other than that of one's own being. The social process, the transmission traditionally of the results of acquired characters, is the masking of individuality by personality. What the individual may be, as the result of congenital heredity, is added to in the social process, and he assumes another and more elaborate character. When society has adopted this animal individuality into its confidences, and socialized him in the whole process of his education and his civilization, he comes forth no longer a physiological unit, but a member of society fit to live the mental and the moral life - the life of taste, culture, and refinement.

Individuality is that which separates the physiological entity from other individuals, and gives him an existence of his own. Personality is that which unites the individual to the racial life, socializes him, makes him what mankind desires him to become as the result of its influences; and fits him to become a part of the racial continuity. Personality is therefore a social product, the elaboration upon the individual of the activities of the social process, which ultimate in some measure in the creation of a being adapted to live the social and the moral life. What we are saying here is this: that the highest type of existence known to mankind on this, earth, that of personality, is distinctly, and it may be said solely, the product of the workings of what we know as society. We may claim, if we have a preference for that conclusion, that the person is the highest result of the process of social heredity. A broader and more scientific conclusion, however, is that culture and civilization most perfectly define what social heredity brings into existence. 


\section{THE SOCIAL EVOLUTION OF RELIGION}

It has been claimed that personality brings man into touch with the spiritual world, and gives him a like nature with that of God. Whether this be true or not, it does undoubtedly bring him into the most intimate relations with the racial life, and with all which is human in the past and in the present. As truly, it binds his life to the future, and makes him one in nature with the processes which are to determine the quality and worth of the coming generations throughout all the time man occupies the earth. Certainly, this is no beggarly manner of defining personality or any limiting of the range of its capacities and its possibilities.

Defining individuality and personality in this manner leads to the conclusion that they are permanent qualities in the life of man, whether as a separate physiological entity or as a product of the social process. In fact, this manner of conceiving of the nature of man and of humanity may add dignity and worth to both of them. It may increase the worth of the individual as a link in the hereditary process, and it may greatly enlarge our conception of the social man, the man who belongs to the vast social process which unfolds throughout the ages.

\section{IV}

What is the social process of which mention has been made more than once? What is the exact nature of social heredity, and how does it operate in the production of culture and civilization? To fully comprehend this process we must recognize the fact that man began his career with none of the animal equipments which enable the lower species to survive. Without weapons, without clothing and shelter, without claws and teeth fitted to serve as means of securing food, he was com- 


\section{THE SOCIAL EVOLUTION OF RELIGION}

pelled to provide substitutes for these. The first of these substitutes was found in social combination, in the use of the herd instinct as a means of both securing food and providing defense. It is true some of the higher animals had already shown the way by combining in flocks, herds, schools or packs; and, rather curiously and suggestively, it is these animals, almost without exception, which have afforded man the opportunity for their domestication.

The suggestion forces itself upon us, when we study man from this point of view, that the herd instinct has not only led to the invention of tools and weapons, to the organization of social institutions, but even to the elaboration of the mind itself. This may be a daring assumption; but when we study intimately the higher animals with reference to the hints they afford of mental processes, and when we in like manner study the lower races of men, the conclusion will suggest itself, not only that mental capacity grows with the socialization of a species; but that somehow mentality, what we call the mind, is involved in this acquisition of capacity for social combination.

Turning again to the child as hinting at what was the process at work in the nature of primitive man, we discover that for the first years he is merely an individual, and that his personality develops with the gaining of more and wider contacts with his fellows. It is quite certain that self-consciousness is awakened, if not created, through social contact with others. His mind broadens and deepens as his range of interests enlarges, that is, as he comes to know more of what mankind has been and done, as presented in home, school, church, society, the library, the world of science and of culture. As a rule, with many exceptions, his personality will unfold in proportion as he is permitted to come into contact with, and to master, the resources of the life of humanity as passed on from the 


\section{THE SOCIAL EVOLUTION OF RELIGION}

past to the present in the form of history, social and political organization, the sanctions of morality, and the elaborations of knowledge and wisdom. If, from any cause, he is barred from these contacts, by so much will his life be narrowed, and his ignorance and mental defect show the greater.

These are some hints that the mind may be a social product, that is, a product of the whole of the contacts of man, as the result of congenital heredity, with what the race has experienced as a continuous process, not merely in its individual or tribal life. This may be said, at least, that the contents of the mind of the child on entering the school, and of the individual throughout the whole of his life, come to him as the result of his membership in the race, and his profiting by what it has provided for his nurturing. Apart from his racial connections he is nothing, and can accomplish nothing that has any real significance. Without the racial contacts man is merely an animal, and may live only an animal existence. This is such a mere truism that it seems futile to repeat it; but it is a fact often disregarded, and one which many persons appear not to realize as of the most fundamental importance to the recognition of the nature of the individual and the race, and in what manner they are dependent on each other.

The individual claim to freedom must be recognized, that he has a right to his own thoughts, and that in large measure he determines his own conduct; but if he assumes, on the basis of his individuality, that he is independent of society, that he need not accept the results of the past, that he is free to elaborate a moral code of his own and to follow it, then he shows the depths of his ignorance, and the futility of whatever thinking he may have done.

The great and eternal law of life, so far as man is concerned, is that of co-operation, social combination, mutual aid, 


\section{THE SOCIAL EVOLUTION OF RELIGION}

and fidelity to the higher racial needs. The law of competition is not the law of natural selection, and it has never been operative as a basic principle in the production of man and his social institutions. In the very nature of competition is assurance that back of it, and far greater than itself, is the law of combination, the method of the social process. Man has survived and developed through the ages because he has learned to recognize his dependence on the social process and the law of mutual aid. If he has struggled to any permanent purpose, it has been with the intent of perfecting the processes by which the social group has been enlarged, and with the aid of which the mutualities of life have extended to wider and wider circles of his kind.

Recognizing the fundamental importance of the laws of heredity, that obedience to them must in the future become one of the cardinal principles of an ethical life having the sanctions of religion, it may be doubted if nature is more important than nurture, as claimed by Francis Galton. In his interpretation of heredity Galton was essentially an aristocrat, and he failed to recognize the full value of opportunity, education, culture, and civilization. The kind of fact Galton presented in the interpretation of his theories of heredity was drawn from that class of persons in society who have enjoyed all opportunities, and have not been denied the great advantages of education and social prestige. He never definitely dealt with the problem as to what would have been the career of a son of a great parentage, if that son had been shut out from the training schools, the universities, the best society, the opportunities which family position gave him. Had such a man been placed in the position of a manual laborer, with all his hereditary capacities upon him, what would have been the outcome of his life? On the other hand, we have in all democratic countries 


\section{THE SOCIAL EVOLUTION OF RELIGION}

many instances of men with what appeared to be the most unpromising heredity rising to the highest positions. The number of such men and women assures us that opportunity counts for much, and that it cannot be ignored in any true estimate of the forces making for the development of the individual of talent and genius.

The foregoing interpretation of the nature of social heredity, culture, and civilization makes it certain that no theory of congenital heredity which ignores these social forces can be accepted as having a genuinely scientific basis. It is for this reason that the eugenists are to be mistrusted in regard to much of their teachings. They have not taken into consideration all the facts. To a large extent they are enthusiasts or sectarians. They look at one class of facts and ignore all else.

The contents of the mind are of as much importance as the congenital structure of the mind itself. If the mind is left untrained, the best heredity serves the individual to poor purpose. In fact, no separation can be made between heredity and culture, as concerns the full measure of individual attainment. The defective mind cannot be fully trained, and the defective training cannot make a genius on the basis of the best heredity. The claim that supermen can be produced to order by the processes of eugenics may be taken with much skepticism. The social theory on which such a claim is based is not only aristocratic and autocratic, but it lacks in the scientific basis which would give it validity. It may be doubted, too, if the elevation of a few great minds is what the world is most in need to acquire. We have had historic observation of such men, and have seen little good of these super-geniuses. We know that the world owes much to its Alexanders, its Caesars, and its Napoleons; but we also know that its debt to them is 


\section{THE SOCIAL EVOLUTION OF RELIGION}

of evil as well as of good. We are not anxious for more of their kind. We do not crave for a larger number of Bismarcks and Diazes however valuable they may have been in their time and place. It is the elevation of the great population, the democratization of the people, the universal spread of the means of genuine education, the placing of opportunities before every man and woman, which is most of all to be desired, not the eugenic production of supermen.

The eugenic theory as often presented, and the theory of the superman, parts of one whole, is but a surviving phase of the old aristocratic conception of humanity, that men are not able to care for themselves; but that they have need of some supernatural or highly endowed person to watch over their lives and to give meaning to their existence. Were such persons always fatherly, unselfish, true protectors of the people, real leaders in ways of wisdom and peace, it might be desirable to have many of them; but the whole history of mankind proves that they have used their superior advantages, in a great majority of instances, not as friends of the people, but as their masters and as autocratic lords. Such supermen are more likely to be a hindrance than a help to mankind. It is not to be forgotten, too, that the large majority of men and women are of sound body and sane mind, that they know their own needs, that they are able to control their own affairs, and that they do not need any kind of superman to guide them in any other spirit than that which is afforded by science and a democratic national life.

As has been already recognized, congenital and social heredity are intimately linked to each other. While they are of quite a different nature, yet in their action they cannot be separated. In the same way, eugenics and culture are never far from each other in their action in behalf of the individual 


\section{THE SOCIAL EVOLUTION OF RELIGION}

or the nation. The assertion that nature is of far greater importance than nurture cannot be accepted, for the reason that they act together when worthy results are produced. All attempts to make heredity, in the form of eugenics, the dominating force in social development must prove abortive.

What we are in need of is not great men, but great ideas and great institutions. When we have the institutions the men will match up to them. We can no longer assume that great institutions are the reflections of great men, but quite the contrary, that great men are made by a social life which gives them great opportunities. Here again, however, we must recognize the fact that the men and the institutions fit into each other, that neither ean exist without the other. If men make institutions, it is not the less true that institutions produce men who match with them. They are but the two sides of the same shield.

\section{V}

The study of religion in all its phases, from that of the most primitive peoples to that of the most highly civilized, makes it quite certain that in all its earlier stages it is most intimately bound up with the social life. It is, in fact, impossible to distinguish it from the social grouping, as it unfolds to meat the needs of the primitive bands, clans or tribes. This intimacy of association is so great that Durkheim, in his work on Les Formes élémentaires de la vie religieuse, translated as The Elementary Forms of the Religious Life, is of the opinion that religion is at the basis of all social, political, scientific and philosophical development. It comes first in the developing life of primitive peoples, and all else expands from it, or results from it by processes of differentiation. Whether this be 


\section{THE SOCIAL EVOLUTION OF RELIGION}

true to the full extent that Durkheim suggests or not, it is undoubtedly the fact that social growth and religious development are at first not distinguishable from each other.

This unity of society and religion has led most of the writers on subjects connected with the new science of Comparative Religion to assert in a quite positive manner, that religion in all its earlier stages is distinctly of a social nature. Such is the character of this tendency to the socialization of religion, that in the band, clan or tribe the individual has no opportunity for self-assertion. There are then no heretics and no skeptics. The life of the clan is a religious life, and religion has no existence whatever apart from the clan life. This is one reason why in all early societies the progress of religion is very slow; and it is of such a nature that degeneracy may appear, as well as progress. The man of superior mental powers may be able to suggest new rituals or modifications of old ones, provided he does this in harmony with that which is the established custom and ritual of his group. He can introduce no great innovations, for the simple reason that the clan is not ready to receive them. Far more likely is it, that he does not make any but the slightest suggestions as to such modifications; but, if others of the more vigorous minds associate with him in this process, the changes he proposes may be brought into active operation.

Why religion has always been extremely conservative, and especially so in all the early ages, it is very desirable that we should understand in the study of the evolution of this phase of human progress. It has been conservative as the result of its social nature and its methods of development, because it has never been distinctly an individual process; but one that was fundamentally and intimately associated with, and expressive of, the demands of man's social nature. 


\section{THE SOCIAL EVOLUTION OF RELIGION}

Some familiar historic illustrations of the manner in which religion has expressed itself, as intimately associated with the social developments of peoples, may help us to comprehend more fully this phase of its evolution. No people of the ancient world was more progressive and mentally alert than the Greeks, and yet their religion was not that of individuals, but that of the city and that of its institutions. It is true that such men as Socrates, Plato, and Aristotle were in large degree independent thinkers, and suggested modifications of the established religion of great importance, and that they have had a large influence on the subsequent ages.

Any intimate study, however, of the rites, festivals, and "mysteries" of the religion of the Greek people, shows the large degree to which these were customary, traditional, and ritualistic. Athens had its skeptics, but few other Greek cities showed this development of individuality in any considerable degree. Dances, songs, festivals, marches in processions, dramatic expressions of religious rituals - these showed the true type of the Greek religion. The great Mystery of Eleusis, the celebration of the advent and adventures of the Mother and the Maid, expressed the truly social character of the religion of Athens, that most highly civilized and intellectual of all the Greek communities.

Some interpreters of religion, in its historical developments, are ready to admit that the early religions are essentially of a social nature, but they insist that the later manifestations of its qualities show it to be of an individual nature, and not dependent on the influences of society. In large measure this seems to be the position of William James in his Varieties of Religious Experience. The instances he gives in that unusually interesting work are largely of individual experiences. He selects the mystics, those of a highly sensitive development 


\section{THE SOCIAL EVOLUTION OF RELIGION}

as concerns religious manifestations, as illustrative of the manner in which religion has expressed itself, and of the processes by means of which it has grown from age to age. It is a remarkable fact, however, that William James, in selecting such individuals as typical of religion and its growth-processes, has hit upon, almost invariably those types of religious expression which are abnormal or pathological. The result was that, for the most part, he ignored those phases of religion which lead to assemblies of those like-minded, and that he overlooks the church and every kind of religious congregation. In only one of his lectures did he deal with the social or normal phases of religious manifestation, that of the great mass of mankind in all ages.

It can be truly said that William James has given us the most interesting and suggestive book as yet published dealing with the nature and processes of religious expression. At the same time it is one of the most misleading of all modern books on religion, for the simple reason that he deals almost wholly with the special, the peculiar, the distinctly individual phases of religion. In his second lecture he defines religion as "the feelings, acts, and experiences of individual men in their solitude, so far as they apprehend themselves to stand in relation to whatever they may consider the divine." He regards theologies, philosophies, and ecclesiastical organizations as merely secondary growths from these individual experiences, in which alone does religion have its origin. In regard to the relations of personal and institutional forms of religion James has this to say: "Worship and sacrifice, procedures for working on the dispositions of the deity, theology and ceremony and ecclesiastical organization, are the essentials of religion in the institutional branch. Were we to limit our view to it, we should have to define religion as an external art, the art of win- 


\section{THE SOCIAL EVOLUTION OF RELIGION}

ning the favor of the gods. In the more personal branch of religion it is on the contrary the inner dispositions of man himself which forms the center of interest, his conscience, his deserts, his helplessness, his incompleteness. And although the favor of the god, as forfeited or gained, is still an essential feature of the story, and theology plays a vital part therein, yet the acts to which this sort of religion prompts are personal not ritual acts, the individual transacts the business by himself alone, and the ecclesiastical organization, with its priests and sacraments and other go-betweens, sinks to an altogether secondary place. The relation goes direct from heart to heart, from soul to soul, between man and his maker."

James proceeds to inform his hearers that he proposes in his lectures to ignore the institutional branch of religion altogether, to say nothing of ecclesiastical organization, and to consider systematic theology as little as possible. That is, he proposes to confine himself to individual religion pure and simple. Which means, that he ignores entirely the historical phases of religion, that he feels no concern as to its evolution, and that he does not connect it with culture and civilization.

It cannot be doubted that amongst the more advanced peoples, with whom James mostly deals, the abnormal and pathological types of religious devotees have had a very great influence in modifying religious rituals and beliefs, and of turning religion in new directions. The changes thus brought about, however, have been too often in directions full of excess, wild enthusiasms, and irrational beliefs. It is not from the abnormal and pathological individuals, who see visions, and enter into worlds not known to the ordinary man and woman, that we are to gain the rational, sane, and vigorously moral development the future demands. 


\section{THE SOCIAL EVOLUTION OF RELIGION}

It is characteristic of the later and higher religious developments, such as are found in the greater religions, - Buddhism, Christianity, and Mohammedanism, - that they have had individual founders. Even these religions, however, have not been able to escape the phases of growth which have come from the pathological. The influence of Paul on the theological development of Christianity has probably been greater than that of any other man, and yet much time has been spent in discussing the nature of his pathological defect, and the extent of its influence upon his religious attitude and beliefs. Mohammed was also in no small degree the victim of some form of abnormal mental development, which undoubtedly had a large influence in shaping the character of the religion which originated with him. It may be doubted if any man is quite wholly sane who is willing to desert wife and child and social responsibilities for the life of an ascetic, as in the instance of the Buddha.

A more truly scientific conception of the relations of religion to the pathological than is that of William James may be found in the works of Sigmund Freud, the originator and interpreter of what he calls psychoanalysis. As a student of hypnosis and its kindred phases of dealing with abnormal mental conditions, and as a working physician, he developed a new method for treating all phases of neurotic disturbance. In the course of his investigations into these abnormal mental conditions he also has contributed largely to the psychology of the normal life of the individual and of races. In his book on The Interpretation of Dreams, that on Hysteria and other Psychoneuroses, that on The Psychology of Everyday Life, and especially in that on Totem and Taboo he has presented a new and scientific psychology. While these works do not deal directly with religion in any of its forms, they throw a flood 


\section{THE SOCIAL EVOLUTION OF RELIGION}

of light on the methods of its evolution, especially with reference to all which is pathological and mystical in its nature. Freud differs widely from James, in that he regards the abnormal phases of religious growth as not only individual in their origin and nature, but as leading away from what is healthy and normal. He also recognizes the mass or group phases of religious evolution, and that among all primitive peoples it is the group, and not the individual, who really gives direction to the growth which is made.

In the concluding pages of his Totem and Taboo Freud says that he bases everything upon the assumption of a psyche of the mass in which psychic processes occur as in the psychic life of the individual. On the succeeding page he says that without the assumption of a mass psyche, or a continuity in the emotional life of mankind which permits us to disregard the interruptions of the psychic acts through the transgression of individuals, social psychology could not exist at all. If psychic processes of one generation did not continue in the next, if each had to acquire its attitude towards life afresh, there would be no progress in this field and almost no development.

In the same work, treating of the ambivalence or twofold division of the emotions, and at the very end of that essay, Freud again recognizes the intimate relations of individual neuroses to the conditions of the racial life, that is, the life of mankind in the mass. On this subject he says: "In one way the neuroses show a striking and far-reaching correspondence with the great social productions of art, religion and philosophy, while again they seem like distortions of them. We may say that hysteria is a caricature of an artistic creation, a compulsory neurosis a caricature of a religion, and a paranoic delusion a caricature of a philosophic system. In 


\section{THE SOCIAL EVOLUTION OF RELIGION}

the last analysis this deviation goes back to the fact that the neuroses are social formations; they seek to accomplish by private means what arose in society through collective labor."

It will be seen that this is the very opposite of the method followed by James, and that it asserts for the normal life of man, as well as for religion, conditions which arise out of the social experiences of the group. All forms of the abnormal, all phases of neurotic disease, come from what is asocial, and from an excessive emphasis on the demands of the individual. A normal life is a social life, and no religion that is radically individualistic can be in any true sense normal or sound. In any true meaning of the word, religion is always a phase of mass thought and action.

\section{VI}

Coming to the ordinary, normal and sane developments of religion, we need have little difficulty in understanding the manner in which they operate in order to make a nation of Christians or of Buddhists. It cannot be supposed that all persons in the United States become at least nominally Christians, all in China Buddhists, or all in Persia Mohammedans, simply and solely of their own individual choice and preference. Recognizing the fact that fashion, conventionality, and the pressure of social demand, have a great influence in determining what we believe, it is not to be supposed that the great majority of a vast population accept without thought the religious practices and beliefs of the social world around them.

As we have already seen, we speak English, and the people of China speak Chinese, for the reason that Engliah presents itself to the child born in this country, and Chinese to the child born in China. The child born in this country of American 


\section{THE SOCIAL EVOLUTION OF RELIGION}

parents, who speak English and that only, would, if carried to China in infancy, and heard Chinese only, acquire Chinese as readily as it now does English. The child is born with a greater or lesser degree of speech-capacity, but its heredity does not give it even the slightest preference for one language over another. There is nothing in the nature of the Chinese people which makes their language congenitally preferable for them as a people; and there is nothing in the American nature which makes English to be acquired more readily by an American child than Chinese. The process of language acquisition is wholly social, and the speech accepted by any child is due solely to its culture-environment. It is impossible that the infant should make a choice of the language it shall acquire, and it readily accepts what is given it by those who surround it in the most plastic and receptive period of its life. At a later period it may acquire other languages because of some definite preference; but this cannot be true for the infant.

What is true of language is also true of religion. We do not choose our religion when we are young, but we find it all about us in the life of the community which gives us our earliest social environment. If that environment is Roman Catholic we accept that form of religion as naturally as the infant seeks its mother's breast. We have no choice as to the religion we acquire; and society and the religion see to it that we do not have a choice. That may come later when we find that there are other religions in the world, and when our educational processes fit us to appreciate some other than the one of our social environment in childhood. The child, by the very nature of its mentality, its imitativeness and its receptive capacities, accepts whatever is presented to it daily and hourly. 


\section{THE SOCIAL EVOLUTION OF RELIGION}

It can do no other, and therefore it takes what the social environment offers it for its acceptance.

How else could the child live, and grow, and come to man's and woman's estate? In the modern world, in due time, the child learns to think for itself, to form its own judgments, and to select its own religion. It is true, however, that the majority of men and women, even in the most highly advanced of modern nations, retain throughout life the religion in which they were trained in childhood and youth. It has been shown by several students of the psychology of religion that the greatest number of conversions take place in youth. It is then the majority of persons acquire their religion, and unite with the religious organization with which they have been associated from childhood. Perhaps the number of religious adventurers, who connect themselves with some other religious body than that into which it may be said they were born, or who withdraw from all religious associations, increases in these modern days; but even with these persons it is almost always some modifying study or social contact which ultimately leads to a change of religious connections.

New religions come into the world from time to time, all of which have in some form or another grown out of preceding religions, as Christianity grew out of Judaism and Buddhism out of Brahmanism. However great the founder of a new religion, he must bring it into harmony, in some degree, with his environing world or it will not live. All the higher religions show this necessity, and indicate that no person can disregard the social processes ever at work in human society. It is a simple fact of history, that all religious prophets and founders at first are rejected of men, that they are not welcomed save by the few. Mohammed found his first converts in his own family, but for several years he had no other fol- 


\section{THE SOCIAL EVOLUTION OF RELIGION}

lowers. In the history of Islam no event is of such significance as the hejira, his flight from Mecca to Medina, because his tribesmen would not accept his teachings and did not believe in his visions.

Every new religion, every fresh development of religion, must pass out of the personal stage, and become socialized, before it can meet with a success that is enduring and effective. Again and again this has been shown to be true in the history of religion. Every existing religion offers testimony to its truth. A few instances of the process by which this takes place may be cited. Mithraism, which originated in Persia, was the greatest of the rivals of Christianity during the earliest years of its development. More than any other religion of the age it threatened for a period to become the faith of the Mediterranean world in the place of Christianity. It was largely accepted by the men of the Roman armies in every province where they were to be found; and it had a ritual and a series of ceremonials which were in many respects more impressive than any Christianity could offer. Why did Mithraism disappear and Christianity succeed? Two suggestions may be made in answer to this query. Christianity, in its early stages, was very distinctly a religion of the working-class, of the great mass of the people within the Roman Empire. On the other hand, Mithraism was especially acceptable to men of virile character. Christianity, also, made a much larger appeal upon women, who accepted it with eagerness, and helped largely to win for it enduring success. On the other hand, women were not admitted to the Mithraic church.

An Egyptian ruler of the fifteenth century B. C., by name Khu-en-Aten, (afterwards Ikhnaton) who as a sovereign was known as Amenophis IV, undertook to introduce a new type of religion into that venerable land. He had become an embryo 


\section{THE SOCIAL EVOLUTION OF RELIGION}

monotheist, and sought to induce his people to recognize that there is only one great universal ruler in the universe. $\mathrm{He}$ named the solar disk Aten-Ra, and regarded it as a symbol of deity, the highest expression of the divine reality. He elaborated this worship, blotted out from the monuments the evidences of the old polytheistic worships and the names of the old gods. While Khu-en-Aten was alive he carried all before him, and his religion was universally accepted.

J. H. Breasted, in his Religion and Thought in Ancient Egypt says that Aton, this new god, in his fatherly solicitude for all creatures, lifts "the movement of Ikhnaton far above all that had before been attained in the religion of Egypt or of the whole East before this time." Referring to the statements of this new faith, and its embodiment in hymns and sayings, Breasted remarks; "all this discloses a discernment of the presence of God in nature, and an appreciation of the revelation of God in the visible world such as we find a thousand years later in the Hebrew psalms, and in our own poets of nature since Wordsworth." One of the assertions of faith in God is in these words: "Whether he is in the sky or on earth, all eyes behold him without ceasing; he fills every land with his rays, and makes all men to live; with beholding who may my eyes be satisfied daily, while he dawns in the house of Aton and fills it with his self by his beams beauteous in love, and lays them upon me in satisfying life for ever and ever."

Soon after Ikhnaton had passed to the world of his fathers, his faith, and his worship of the new god, were rejected throughout his empire, and the old faith and the old worship were brought back in every part of the kingdom. We of today judge that this was a very remarkable instance of a striving after a monotheistic faith, and that the religion of Khu-enAten was distinctly better than that which it superseded. $\mathrm{He}$ 


\section{THE SOCIAL EVOLUTION OF RELIGION}

had failed, however, to convince the Egyptian people and especially the priesthood of Amon of this superiority. That is, he had failed to socialize his religion, had not brought it home to the convictions of the people. The result was that soon after he was dead all that he established was ruthlessly swept away, and even his own name was removed from the monuments he had erected in honor of the new god. This is one of the most remarkable of the historical instances of a great religious reform failing because it failed to convince the mass of the people. The old faith came back in all its power, and it is only in recent years that we have come to know of this abortive attempt to create a new religion in that far-off age.

These historic instances illustrate the law that a religion must be socialized in order to endure and become successful. It must become the method of social expression of a clan, tribe, city or state or it will not win its way to any large place in the life of mankind. The method of socialization is that which has been already suggested, namely, the giving it prestige by its acceptance in childhood and youth. This cannot be at first the method of its diffusion, and therefore it wins its way slowly and through much tribulation. Its earliest followers must accept contumely, scorn, hate, and even persecution. They must also accept the fact that few minds are at any time prepared to change their religion wholly, and to make the sacrifices necessary to the success of the new religion they adopt. Because most of those who accept the new religion bring with them the remnants of their early training, and because any such religion meets with the conditions, and the antagonism, on every hand, of the established religions, which have been in existence through many centuries, and may have come out of an antique past, it follows that it will not for more than a generation or two remain true to its founder. 


\section{THE SOCIAL EVOLUTION OF RELIGION}

All religious history shows us that new religions, and modifications of old religions, in a short time depart from the teachings of their founders. It is repeatedly asserted that Christianity has never followed truly the teachings of Christ, but has been modified in a great number of directions. Therefore, we read of the "corruptions of Christianity;" in a word, it is pointed out that the Christianity of our age, as of preceding ages, is not that of its founder. It may be heard, even, that the religion of Christ has never been put into practice. Such a statement, in so far as it is true at all, is equally true of Buddhism and of Mohammedanism. The Buddhists tell us of the greater and of the lesser vehicles of their sacred writings; and we know from many sources that the faith of eastern lands is not the faith found in the earliest Buddhist traditions. Buddha found no place in his religion for a personal god; but he has been himself elevated to that position, and in the Buddhism of China and Japan, as well as other countries where it is accepted, gods many have been developed by this godless religion. In the same way, and for the same reason, a religion that spoke of Nibbana (Nirvana), a future life of absorption into universal being, has developed creeds teaching a positive personal immortality.

The fact of the first importance to be recognized, in connection with the nature and the history of religion, is that it is distinctly and inevitably social in its origin and in its development. It may be accepted by the individual, and there may be personal expressions of its essential qualities; but in itself and in its fundamental nature religion is social, one of the greatest manisfestations of the social nature of man. It has its origin, therefore, in the social needs of human communities, and it voices their demand for the unity and sovereignty of the group life. Whatever other sources religion 


\section{THE SOCIAL EVOLUTION OF RELIGION}

may have, whether of intuition, inspiration from some supernatural source, or revelation from a divine being, it remains, and is essentially a product or manisfestation of the social demands of human naturè. We have no right to dogmatize in regard to the extra-social sources of religion, its supernatural origin and character, that is, as to the claimed sources in intuition or revelation; but, from whatever such source religion may come, if it comes from any, it must become socialized before it can have any permanent and enduring effect on the life of tribes and nations.

Accepting for the moment, at least, all that has been claimed in regard to the divine nature and mission of Christ as a Saviour of the world, there is overwhelming historical evidence that his religion met with no large and permanent success until it had secured for itself a fellowship in the life of the generations immediately following his time. Crucified, reviled, rejected as a heretic and busybody, his religion won only after a struggle of three or four centuries, and then gained political power only by means of questionable value to its integrity as a reforming force in the Roman Empire.

This is perhaps only saying in another way, that in religion, as elsewhere, it is requisite that there shall be secured a body of earnest followers in order that an institution or an ideal shall win to an enduring permanence. Something more than this, however, was essential to the perpetuation of Christianity and the failure of Mithraism. The new religion, first of all, must fit into the old religious ideals to a degree which insures that it will be accepted widely. Then it is necessary that it shall appeal to youth, to woman, and to the great democratic mass of the people. In this regard, it is of great interest that the early followers of Jesus were all young men, in the most susceptible period of their manhood. The elders, the 


\section{THE SOCIAL EVOLUTION OF RELIGION}

Sanhedrin, the scribes, did not follow him; but youth, men of the crafts, and the women who had known him, constituted the earliest fellowship gathering about the new religion. So it has ever been in the history of religion. All of which means, that religion wins because of its social appeal, its power to create a comradeship of devoted and faithful disciples, around which may gather a fellowship or a church-community.

Here we have, then, the first fact to recognize in the interpretation of the history of religion, that it is the vital life of a community, the energizing force in a human fellowship. However a religion may come into existence, however supreme and divine its origin, it cannot win the devotion of a clan, a city, or a state, until it becomes the cementing social attraction within that community, binding together all its members and all its interests. The real significance of any religion is to be found in this ability to ereate social bonds, to establish an ideal fellowship, to furnish the cement that will hold together all antagonistic and recreant forces tending to its disintegration and destruction. Through however many generations and ages it may live, it will be enduring in proportion to its ability to charm youth, and to create a fellowship that will endure all tests and all distractions.

The purport of these statements is, that religion is dependent on culture and civilization; and that the growth of these is promoted by great universal processes inherent in the relations of man to the universe in which he has had his origin and his evolution. Religion is not something apart from these causes of man's progress through the ages, but an innermost phase of his evolution. As it were, it is the inmost core of civilization, the ultimate in progress. So regarding it, it may be wise to set down here some hint, as to the causes of human progress. To do so may justify the conception that religion 


\section{THE SOCIAL EVOLUTION OF RELIGION}

is as wide in its manifestations as the whole range of life and all its expansions through the ages.

\section{VII}

Precedent to any study of the causes of human progress we must recognize (a) that men are the same in nature in all ages and under all forms of society (the brain has not enlarged for many thousands of years, and apparently the powers of the individual mind have not increased); (b) that progress does not consist in a radical change in the structure of the mind or in the fundamental character of social transmission; (c) that progress results from a change in the environment of man, either material or social, in the creating of new social arts, industries, institutions, and methods of culture, and in the increase of facilities for their transmission. Recognizing these primary conditions some of the causes of social and religious progress may be suggested in the following statements :-

1. Childhood, and its inventive capacities, especially in the direction of the invention of new words, and in slight degree the ideas which they represent, is one of these causes. Children are not as yet brought under the spell of tradition and social custom, and therefore they are free to exercise their inventive skill in devising new plays, customs, words, and habits or thought. These become fixed in the social group which acts together, and may be passed on to the larger life of the clan and tribe or to the later human groupings.

2. In adolescence the youth no longer conforms always to the demands of tradition and custom, which he may discard in a somewhat revolutionary spirit. It is well known that in this period many persons revolt in one degree or another from 


\section{THE SOCIAL EVOLUTION OF RELIGION}

what has been implicitly accepted in childhood, and break out ways of their own. The group of initiates who enter the tribe at the same time may bring to the tribal life fresh ways and ideas at this period; and the individual may persuade his associates to adopt what has newly come to him as result of revolutionary tendencies.

3. Women also contribute their share to making progress possible, though it is not always adequately recognized. The earliest division of labor, that between women and men, undoubtedly had considerable social consequences. Women in early society invented the primary arts and agriculture, and they gave a distinct impulse to the evolution of religion and morals. Their influence as mothers in the development of the family, in the creation of social sympathy, in the growth of moral convictions, and in the evolution of humane purposes seems to have been very considerable.

4. Of very great importance was the invention of tools and weapons. The discovery of the bow and arrow, the hoe, skin-dressing, spinning and weaving, pottery, the use of metals and the methods of transportation represented by the boat, the cart and the taming of the horse and other animals, was of great effect. These inventions did not change the nature of the individual man, and probably only slowly his methods of thought and his beliefs; but they had their effect in bringing about the greater amalgamation of peoples, with the consequences which followed from that social cause. They gave man a new environment, and one that he has slowly learned to shape in accord with his intellectual and social needs.

5. Not less important, probably, was this change in man's environment, both physical and spiritual. The fact that all the early civilizations grew up in river valleys or in localities open to the sea on all sides, indicates what influence was thus 


\section{THE SOCIAL EVOLUTION OF RELIGION}

exerted. A change in social environment results from the invention of new tools, institutions, and processes of thought, thus enlarging the scope of human activities.

6. In the early phases of tribal life land and all kinds of property, except individual tools, weapons and clothing, belonged to the community. All economists emphasize the large results which followed on the evolution of individual property, by which the individual was enabled to accumulate for his own advantage and that of his family, the results of his labors. The less promising phase of this evolution was that it gave the power of aggrandizement into the hands of chiefs and kings, and that it aided greatly in dividing communities into classes and castes, on the basis of property and the power it gave, and not on the basis of individual merit.

7. Migration must be regarded as a considerable cause in the liberation of the social mind from the customary and traditional, enabling it to see the world in a new spirit.

8. Tribal contacts had a similar effect in giving an enlargement to the range of conceptions entertained, enabling individuals to realize that their own traditions do not mark the limits of experience, custom, and thought. It results in the borrowing of customs, myths, rituals, and inventions, and in the coalescence of cultures.

9. To the same effect is the passing of products of skill over wide areas, and in some degree the circulation of customs, myths, and rituals over extended regions.

10. War distributes more or less widely these products of culture, and brings tribes and peoples into closer contact. In itself it always makes for destruction, but in its throwing of peoples together, and in thus enabling them to learn of the customs and arts of other peoples, its influence is sometimes very great, especially in the early ages of civilization. 


\section{THE SOCIAL EVOLUTION OF RELIGION}

11. In the same way slavery, as one of the results of war and conquest, serves as a means of widening contacts of peoples, thus leading indirectly to progress. The captive carries his language, his religion, his crafts, his customs to those by whom he is enslaved, and in that manner traditions and cultures are passed on to those who may in time profit by them.

12. Probably it is the capture of women which has the largest influence in this direction, for they are likely to change in a degree the ideas and beliefs of the men to whom they are assigned as wives. Especially, if many women from the same tribe are captured, they may have a considerable influence on the traditions of the tribe into which they are introduced.

13. Economic causes are not to be ignored, since these operate to widen the industrial activities of a people. The advance in methods of transportation, trading of tribe with tribe or exchange of products, commerce, and all methods of systematic manufacture, are capable of greatly enlarging the tribal life. They advance the interests of property, facilitate a better food supply, give better habitations and clothing, and serve to bring peoples into closer contact. What thus facilitates the material interests of a people, also adds to the range of social customs, traditions, and religious adaptations.

14. Many of these processes of larger adaptation and social flexibility may be described as the results of social invention. They are not of the nature of individual discoveries or inventions, but come about as the result of the relations of the tribe to its environment, and may be best described, perhaps, as products of accident. Of this nature, it may be, were the discovery that seeds may be placed in the soil and produce a supply of vegetables, thus leading to the invention of agriculture and horticulture. Of the same nature was the domesti- 


\section{THE SOCIAL EVOLUTION OF RELIGION}

cation of animals and the making of them serviceable to man. These enlargements of the tribal life, and its industrial and social opportunities, were not of the nature of deliberate inventions on the part of individuals, but products of the contacts of the tribe with its environment.

15. This acceptance of the process of social invention does not mean that the other process of individual invention and discovery is to be ignored. However, this does not appear to any but the most feeble extent in early society. In clan society the power of tradition and social custom are too great to permit of any but the most limited expression of individual genius. Without doubt it cannot be assumed that in the tribe all individuals were equal in mental capacity or in originality of mind. At a later stage, however, when the bonds of custom and tradition had in some degree been broken, there came an opportunity for the man or woman of genius to have a hearing and to get his fresh ideas recognized. A result of this liberation of the individual mind was a much more rapid advance in progress, the origin of new institutions, and the beginnings of science, philosophy and religious ideas.

16. Then came the ages of the great founders in culture, institutions, and religions. These men were not wholly original in any instance. They built on the foundations already laid. To no small extent their work or what resulted from their activities, was of a syncretist nature. In a word, their originality often consisted in bringing together older cultures from perhaps widely extending regions, and giving in this way new impulses and creative resources to the communities which they influenced. This does not mean that personal genius is to be ignored, for it is a great factor in all phases of the world's progress. 


\section{THE SOCIAL EVOLUTION OF RELIGION}

17. The bringing to birth of new cultures and institutions, however they may originate, facilitates mental activity and broadens the outlook of men upon the world. This is seen in the sometimes great rapidity with which a people advances in all directions when it comes in contact with a new form of civilization, as in the instance of the Japanese as the result of the opening of their ports to the world. In their mental capacities it is not to be supposed that any essential change has taken place; but cultural contacts have awakened fresh motives, incentives and energies.

18. This process may be described as one of mental release from the thralldom of custom and tradition, leading to the rapid formation of new habits of mind and fresh conceptions of the world and human interests. The same kind of liberation is taking place at the present time in India, but more slowly, and on the part of individuals or groups, rather than on the part of the whole population. It cannot be said, however, that all the Japanese people were made free by $\mathrm{Eu}$ ropean contacts, but it was rather the samurai than the people as a whole. This process of liberation has been described as mental or psychological, a change in the attitude of the mind, rather than any progress in industrial, economic, or commercial interests. Breaking the bonds of custom and tradition, it frees the mind for rapid enlargement of social and intellectual processes.

19. This process of liberation has been greatly facilitated by the methods of science. We cannot say that man has ever been wholly free from the exercise of that spirit, for even in the age of magic it was present in a desire to know and to control the processes of nature. It is true, however, that the methods of science were of late appearance, and that it was only within the limits of the greater civilizations that it found 


\section{THE SOCIAL EVOLUTION OF RELIGION}

opportunity to manifest itself. At an early time the study of the heavens began, then mathematics had a considerable development, and the spirit of free inquiry into the laws of the natural world had a striking expression in Greece. With modern times science has come more and more to supersede all other interpretations of the universe in all its phases.

20. Also in the modern world the contact of ideas-the wide range of culture processes-has had the effect of awakening thought, arousing the individual mind, and stimulating the untrammelled acceptance of whatever truths may come to hand.

21. These tendencies also result in the growth of toleration and the spirit of free inquiry. At the same time there is aroused a desire to test all traditions and past ideas, to investigate all old theories of the universe, and to be satisfied with nothing that cannot be reasonably proven to have a sound basis in fundamental truth.

22. The growth of the critical spirit is also of great importance, since it leads to an attitude of suspicion of what is antique and has merely a basis in tradition. The traditional attitude is that of the implicit acceptance of what is handed down from the past, with all its credulities, and its belief in miracles and the supernatural. On the other hand, the critical spirit questions these, and will not accept them until they answer to the sound results of the scientific method of inquiry by investigation and hypotheses.

23. Freedom of inquiry, right to think in an untrammelled manner, and to express fearlessly what is thought, is one of the most important of the later phases of progress.

24. A belief in progress, a confidence that man is capable of going forward and is making advance, marks the modern in contrast with the ancient world. Ancient thought was 


\section{THE SOCIAL EVOLUTION OF RELIGION}

largely dominated by the idea that in the past man had been better, nobler, and happier than in the present, and that he had fallen from conditions of perfection in a golden age. Modern thought, on the contrary, is characterized by the conviction that man is making a more or less steady advance, that progress can be determined and controlled by mankind, and that the true destiny of the race is to be worked out in the future.

25. One of the most highly important of all causes making for progress has been the profiting by the great traditions of the race in the form of education and culture. In the past education has been limited to the few; now it is gradually spreading to all persons of every class and condition. A great step forward will be taken when it is possible for every child and youth to secure a thorough training, thus profiting fully by what the race has experienced, discovered and invented; and is able to know and profit by history, art, science, and all the causes in the past that have led to human progress.

26. The increasing size of social and political combinations has undoubtedly had a large influence in securing that mental expansion we designate as progress. The food-group consisted of a score or two of persons, the tribe brought together a few hundreds or thousands, while the state gathered to itself hundreds of thousands or millions. Mere numbers do not necessarily facilitate political progress, but growth in size means a greater variety of contacts, an increase in diversity of occupations, a broader range of traditions, an enlarging mental outlook, and a great increase in facilities for co-operation on the part of individuals and groups.

27. The increase in the size of a community has meant that there has been secured a more efficient measure of combination. A large range of contacts, a more effective extension of the division of labor, added facilities for exchange and for 


\section{THE SOCIAL EVOLUTION OF RELIGION}

commerce, a deepening and enlarging spirit of loyalty and patriotism, and a broader perspective view of life in all its phases, have been secured by the growth in size of the political group.

28. The ethical life has grown with the growth in political combination. The early groups were clannish, intolerant and exclusive. As the tribe has expanded into the great state ethical principles and the practice of morality have become less traditional, more rational, and better fitted to secure a more social and juster life. In their turn, the acceptance of broadening principles of justice and humanity have facilitated the inner growth of states in the direction of greater stability and a right regard to the welfare of all their members.

29. The destruction of the spirit of autocracy, the divine rights of rulers, the theory that some individuals and classes are born to rule others, the breaking of the bonds of slavery, feudal control and the power of wealth, the crushing of despotism in all its forms have largely promoted the growth of freedom and democracy. The rights of man, the demand for individual liberty, may be often sentimental in their expression, and with too little conception of what they mean; but there can be no question that they afford incentives to mental advance, ethical probity and political synthesis.

30. Great and stimulating ideas in all the higher reaches of civilization have had a large and growing power of expansion. In the modern world democracy was an idea incapable of practical application, though the attempt was many times made, until it found its opportunity in the last years of the eighteenth century on a narrow coastline on the western side of the Atlantic. In Europe many an effort was made to imitate this new form of state, but they were always ruthlessly suppressed. After more than a century this struggling idea ap- 


\section{THE SOCIAL EVOLUTION OF RELIGION}

pears to have conquered the world, and now democracies arise on every hand. No longer are autocracy and armed force capable of suppressing these demands of the people to rule themselves. The growth of the democratic demand, and the attempts to make the rights of the people more secure and ampler, indicate the vast evolutionary power there is in such an idea. The rights of women, the pleas for industrial democracy, the desire for truly universal facilities for education, though not welcomed by conservatives and reactionaries, have in them an expanding power which insures their final success. 


\section{CHAPTER II}

\section{The Creative Genius of Social Man}

7 HE new science of Comparative Religion seeks to investi1 gate, in a spirit of free inquiry, all the religions of the world, from the lowest to the highest. What it aims at is an ample knowledge of the various phases of religious development, desiring only to know the truth in regard to them. Not only does it assume that religion is universal, and that all religions are fundamentally the same in motive, and in their primary answer to human needs; but it regards religion, wherever manifest, as an expression of the creative power of social man. Whatever else religion may be, it is human, and it is an outgrowth of human desires and aspirations.

Religion everywhere is influenced by the environing conditions of human life. The social and political forms of organization have an influence in shaping its external manifestations. Whether men are hunters, herdsmen, farmers, or devoted to commerce or war, has a perceptible effect in giving direction to the religious demands of a people. The ceremonials and the rituals of hunters are not the same as those of a people who have advanced to the cultivation of the soil. Tribes who live in mountain regions always vary somewhat in their religion from those who live on the seashore, even though they accept the same historic faith.

The evidence does not justify the conclusion that religion has its origin in the conditions of the physical environment or that it grows wholly out of awe, fear or any similar attitude 


\section{THE SOCIAL EVOLUTION OF RELIGION}

with reference to the phenomena of nature. We may find abundant evidence that religion is influenced by industrial and economic conditions, but it cannot be assumed that these are the causing agents bringing it into existence. The great religions have not arisen accidentally, under any and every condition, in any and every region; but only after long preparation for them, and under the conditions of a comparatively high civilization. This means that religions of the higher type have not been solely due to individual genius or that they have had their origin alone in personal initiative.

The religion of a people is to be measured by the degree of its social advancement. The same religion varies greatly according to the political and industrial activities of those who accept it. Some of the tribes in east Central Africa have become Christians, and are devoted to the faith that has come to them with the aid of missionaries. It cannot be claimed that their Christianity is in every particular the same as that of the most advanced peoples of Europe or America. Some of the western Eskimos have also been converted to Christianity, but their new religion is not a duplication of that of the African tribes or that of Great Britain. All the more certain is it that those peoples which have retained their aboriginal religions vary in regard to them with the varying conditions of their habitat, the manner of their securing a food supply, and the stage they have reached in their culture development.

What men believe in regard to God and the future life will vary in large degree with reference to the forms of their social institutions. In the kinship clan and tribe the gods are friendly, for the most part, and are regarded as of the same nature as those who worship them. Where there is an autoeratic chief the god will be accepted as of the same nature as their ruler. Especially is this true where a people has developed 


\section{THE SOCIAL EVOLUTION OF RELIGION}

a political form of institutions admitting of kingly rule and power. As is the king so is the god, an autocrat if he wields autocratic power, a kindly sovereign if he rules with leniency and regard to the welfare of his subjects. When the king rules despotically it is more certain that the god is defined as a great autocrat whose will is absolute.

Such comparisons may not be pressed too far, but it is probable that they are not without their suggestiveness with regard to the ideas men have of the gods they worship. We see this process of theological modification going on about us at the present time, and it shows how intimately the ideas entertained in any age reflect the human institutions out of which they develop. The theologians of the eighteenth century insisted upon the sovereignty and the supremacy of God. At the present day we hear on every hand of the immanence of God. What is this but a result of the changes which have taken place in the political institutions of America! We have passed from under the rule of an autocratic king, from social and political institutions that were aristocratic and despotic to those which are democratic, and based on conceptions of personal freedom. Has not our religion made a like change, the political revolution leading to that in religion?

\section{I}

No attempt can be made here to follow out these suggestions in all their details or with the presentation of the great number of illustrations which might be brought forward in order to sustain them. What we are to recognize is, that in all the earlier ages of the world religion is intimately bound up with every other phase of a people's life, whether it be a hunting band, a kinship tribe, a city-state or a great feudal nation. In 


\section{THE SOCIAL EVOLUTION OF RELIGION}

the periods of the primitive peoples, which we are now more especially studying, the various phases of human development are not separated from each other as they have become in modern times. Now we hear of art for art's sake, and in the same manner of many other phases of our lives. No one in this country thinks of identifying politics and religion. In the primitive ages this differentiation had not yet been made, and there was no distinct division between politics, art and religion. It is not in any degree to exaggerate to say that religion in primitive society permeates the whole of life. No phase of human expression has been distinctly withdrawn from the sway of religion, and religion appears on all occasions, in all the events of life.

In his book on The Delphic Oracle: Its Early History, Influence and Fall, T. Dempsey says of the relations of Greek religion and politics: "The history of ancient Greece shows a remarkable closeness of relations between politics and religion - a closeness that is somewhat surprising to the modern world, which so often see separation, or even overt hostility, between church and state. To the mind of the Greek such hostility of the state towards religion would be a piece of insolent pride and folly, which was sure to call down the nemesis of heaven. For the success alike of the state and the individual the good-will of the gods was essential: no institution could flourish, no project be successful, for which there was not the divine sanction."

This is but another way of saying that the early religions are social, and have their origin and sanctions in the life of the community, whatever its distinctive form. In such a community there was no personal freedom, no opportunity for the individual to think independently. The clan was supreme, and its will was alone effective in guiding the lives of men and women. Singular as it may seem, from our point of view, 


\section{THE SOCIAL EVOLUTION OF RELIGION}

there was in such a community nothing that may be called individual development, no personality expressing itself in independent methods of culture. What the clan did the individual followed without doubt or hesitation. The manner of conduct prescribed by the clan was that unhesitatingly accepted by all its members. The religion of the clan was the religion of every one of its members; and within its fellowship there was no dissent, no heretics, no skeptics.

We find this sovereignty of the group or clan or community, whichever we may prefer to call it, developed to such an extent that in it we may find what may be regarded as a group-mind or a collective soul. The ability had not yet been developed for independent thinking or, it may be said, that the group so far obsesses the individual that he follows unquestioningly its dictation. Thinking is done by the mass, as it were, and is not individualistic in its nature. Many evidences are to be found favoring this conclusion, since all forms of human expression within the group take on one form, are shaped to one end, have one emotional type. What one thinks or believes all think and believe, and what the mass holds to masters every person within the group. While it is true that the germs of individual thinking are latent in any such group, there may come in time manifestations of personal opinion and revolt against established or group thinking; but these have as yet in no distinctive form asserted themselves.

If we are not disposed to accept the idea of a group mind or a collective soul we may call that which these phrases attempt to express by the term collective mentality. A statement of this conception of mind may be found in Daniel G. Brinton's The Basis of Social Relations, where, in his study of the ethnic mind as seen in the individual and the group, he says: "The closer we study the individual, the more do his alleged individ- 


\section{THE SOCIAL EVOLUTION OF RELIGION}

ualities cease, as such, and disappear in the general laws by virtue of which society exists; the less baggage does he prove to have which is really his own; the more do all his thoughts, traits, and features turn out to be those of others; so that, at last he melts into the mass, and there is nothing left which he has a right to claim as his personal property. His pretended personal mind is the reflex of the group-minds around him, as his body is in every fibre and cell the repetition of his species and race."

If such a statement can be made of the society of to-day, with all its assertion of personal freedom and democracy, all the more emphatically might it have been made of the primitive group, whatever the particular form it may take. Turning to that chapter of Emile Durkheim's The Elementary Forms of the Religious Life, (Les Formes eléméntaires de la vie religieuse,) wherein he treats of the idea of the soul, we find him saying that "the individual soul is only a portion of the collective soul of the group; it is the anonymous force at the basis of the cult; but incarmated in an individual whose personality it espouses." Again, in the chapter on the elements of sacrifice, he declares that "the individual gets from society the best part of himself, all that gives him a distinct character and a special place among other beings, his intellectual and moral culture. If we should withdraw from men their language, sciences, arts and moral beliefs, they would drop to the rank of animals. So the characteristic attributes of human nature come from society."

The theory that there is a collective mind has been accepted by too many of the ablest psychologists to make it possible to reject it without a careful inquiry into the reasons for its acceptance. The objection that there is no organism through which the social mind can express itself does not carry convic- 


\section{THE SOCIAL EVOLUTION OF RELIGION}

tion to those who recognize to the full the nature of the primitive group, and the extent to which all its members think to one purpose and in an identical manner. When we give consideration to the nature of personality as defined in the first chapter, it no longer appears impossible that the same mental processes may operate in a social group, with the result of bringing about what is a complete unity of thought and action. It may be questioned if the very nature of the individual mind, the manner in which it acquires its ideas, does not compel us to accept the unity of the social group as regards the processes of intellection, as well as the processes of emotional expression.

What we are to seek for, then, are the evidences that in the primitive group there is such a degree of common or collective emotion, and action, and thought, that inevitably there is the most harmonious unity of purpose, justifying the theory of a collective mind or common social center of activity. It is certain that we do not find in such a group any distinctly individual aims or desires, any demand for individual action or thought. The group acts as if it were one person, though its members retain their individuality to the fullest extent, as defined in the first chapter. Without doubt the individual organism has its separate existence and functions, that it lives wholly within itself as a distinct organic entity, derived from its ancestors by the process of congenital heredity. Equally without doubt, it would appear, is the fact that the mind acts collectively, in the sense that its contents, what makes up its personality and its knowledge, its motives and its ideas, are the result of there being transmitted to it, in the whole of the process of training and education, such results of human experience as have been acquired by the group throughout its whole past. 


\section{THE SOCIAL EVOLUTION OF RELIGION}

\section{II}

Turning now to the evidence which justifies the conclusion that the primitive group is in the largest degree a collectivity with a life and mentality of its own, we are impressed, as a result of any extended study of such groups, with the fact of their creative power. This is one of the strongest evidences in favor of the conclusion that there is a collective mind. The primitive group not only has life of its own, but it acts and thinks and creates in a manner distinctive from that of other groups. In this respect it has many of the characteristics of an individual, who elaborates his own opinions and beliefs from the materials which are given him in the process of his education, meaning by that word all which he acquires from society in any of its manifestations.

The group creates, not only through its individuals, but as a collectivity, as the result of its communal activities, emotions, thoughts and powers of imagination. Ribot, in his work on the Creative Imagination, says that the era of the primitive man is for the imagination its golden age, and that it reaches its full bloom in the creation of myths. He says that before man attains to civilization he is a purely imaginative being, and that the imagination is able to exercise its powers to the largest possible extent because it does not encounter traditions and restraining ideas or beliefs. The ground it occupies is not already preempted by those who have gone before, and the mind is therefore free to work unhindered and unrestrained. Too much emphasis must not be placed on this conclusion, for the absence of tradition, and established convictions of any kind, result of previous human experience, forbids the training and discipline of the mind, and allows of its running wild, and rioting through regions hitherto unexplored. In fact, no human group shows the absence of tradition. 


\section{THE SOCIAL EVOLUTION OF RELIGION}

The mind of the primitive man as we know him to-day is not free, but bound in fetters of custom and ritual and social routine. He accepts what his social group offers him with the utmost confidence, and does not seek to modify it or only in the slightest degree. Probably it can be said, however, that though he is thus bound as an individual, he is freer in his group life, in the sense that the collective imagination is at work in the borrowing, or in the creation of, new myths or larger interpretations of the world about him, and the realities of his own inward life. Backward and stagnant as some such peoples appear to be, as, for instance the aborigines of Australia, there is no evidence that they have not acquired the power of creation.

The creative mentality of man, working collectively, begins in directions that can be regarded as quite similar to the early mental activities of children. When the child, using his imagination unrestrained by previous teachings of adults, attempts to explain what he sees and hears about him, he gives to every event a personal character. That is, what he observes he describes as the result of the actions of individuals, not as the result of material or cosmic processes. When it rains, he says that it is some one in the sky emptying his watering-pot. When it thunders, he describes it as God beating on the floor of heaven. In the same manner the primitive, being a child in mentality, and having no parent or teacher to modernize his conceptions, reaches essentially the same conclusions as the child of to-day before he had been taught; and he personalizes all phenomena, or attributes them to the action of an individual of the same nature as he is himself. This personification of phenomena leads to the creation of myths. A myth describes the adventures of a superhuman being, who is the agent producing what the primitive finds in himself or in the world of nature. As 


\section{THE SOCIAL EVOLUTION OF RELIGION}

concerns the primitive man, at least, all phenomena ascribed to the action of gigantic persons are of the nature of myths.

\section{III}

Physiological demands call for rhythmical or measured expression. The nature of such expression, and of its interpretation has been much discussed by scientists; but need not cause us to pause for their consideration. It suffices our purpose to recognize the fact that the earliest of the arts to which early man gave his attention was that of the dance, and in connection with religion to a large extent. Even in our own time and country the Shakers dance to the Glory of God, and we may recall that the Hebrews worshipped their God in the same manner.

The dance secures unity of expression in the social group, responds to the demand for rhythmical action, and insures a pleasant excitement to the nervous system. When carried to the height of its activity, it results in a species of mental intoxieation, and may lead to a high degree of excitement, to feelings of ecstacy, and to a kind of inspiration. The heightening of mental action may be accepted by the primitive man as the result of the presence of some spiritual being in the movement of the dance, especially when it is the manifestation of the group emotion, as is very nearly always the case. This spiritual exaltation immediately results in the acceptance of the dance as a means of securing to the members of the group the excitement and the emotions which are distinctly religious in their nature.

We have already indicated that no one manifestation of the religious nature of the primitive man stands by itself. Because his religion is a group religion, and all his life is under religious sanctions for that reason, when he dances, he also sings 


\section{THE SOCIAL EVOLUTION OF RELIGION}

or he makes use of some kind of rhythmical noise which has the effect of giving unity or harmony to the group activity in the dance. The women of some of the tribes of Australia beat on their opossum-skin rugs with their hands, and in that manner secure for the dancers the necessary rhythm of movement. In Africa the drum is used for the same purpose; and in different parts of the world a considerable variety of erude instruments are brought into use.

In some instances a soloist furnishes the time-beat by means of song; or it may be that a group of singers serve the same purpose. At a somewhat higher stage in musical development a soloist and a chorus alternate in furnishing the music for the dances, especially if some degree of dramatic skill has been developed in connection with them. Even before this step has been taken there is a considerable advance beyond the time-beat as securing harmony to the movements of the dancers; and the dances become in a degree dramatic. A number of men, it may be, when they are dancing, will act out the scenes of a hunt, some of them representing the animals hunted, and others the hunters. Those who have witnessed these dances ascribe to them great realism, and a remarkable degree of dramatic power. Then again, a fight between individuals or a group of warriors will take the place of the hunting scene. It may be, in some instances, that love between the sexes will be the theme, though this is usually in the form of a contest between two men for the possession of a woman.

These dances, as thus described, may seem to be of a purely secular nature, and to have no real connection with religion. Very nearly all of them, however, are enacted in connection with some religious festival, at the initiation of youth, or as having, in themselves, the purpose to excite religious emotions. At this period it is impossible to separate religion from any 


\section{THE SOCIAL EVOLUTION OF RELIGION}

form of the daily life, the distinction has not yet been made between what is natural and what is divine, and no line is drawn between the sacred and the secular. All is sacred or has an underlying relation to the purposes which may be defined as religious.

At a somewhat later stage, and especially after the arts of grinding grains in preparation for food or after the cultivation of the soil has been introduced, song appears as giving rhythm and social unity to the labors of the toilers. In this manner many a task is lightened, and many a dull routine made less irksome, by means of social harmony secured by song. This is especially true of women, whose tasks are nearly always those of cultivation and the preparation of grains for food. Here, again, song seems to be purely secular, as it may be; but it is more than probable that it has an underlying religious reference. The earth in which the grain grows, the soil which is turned over in its cultivation, even the grain itself, whether it be wheat, barley or maize, is of a divine nature; and the act of its cultivation is a religious one almost invariably. Even the vessel the woman constructs for the purposes of her cooking, and not the less the materials out of which she constructs it, are divine or have the nature of spiritual entities. Religion, therefore, is never absent from the toils of the primitive man or woman.

The songs and the dramatic representations connected with the dances, or which eventually superseded them, were invariably improvised for the occasion. This means that they were not of individual composition, but were collective in their origin. They related, it may be, to the events of the day, to the hunt and its adventures, to the grinding of the grain or to its cultivation; and as the dance went on the singers described these, sometimes the leader represented a phase of the scenes 


\section{THE SOCIAL EVOLUTION OF RELIGION}

enacted, which is repeated by all present or the chorus gives a response to the words of the leader. Whatever the manner in which the scenes enacted were presented, the interpretation of them, as well as the accompanying songs, were the work of a collective improvisation.

It may be said, in answer to this statement, that the songs came from a leader or that they were the work of some one of the members of the group. To a degree this was true; but, nevertheless, it was no individual, but a collective, motive which found utterance, and which held the group as in the grip of one common emotion and purpose. In his book on The Beginnings of Poetry, Francis B. Gummere gives numerous illustrations of the communal nature of all primitive art, and makes it certain, that evidence from many lands can prove what he calls the collective origin of song and music and poetry. These arts, as he observes, are closely linked to each other in their communal origination, and for the reason that the social group of early man has but one common mind. This is his statement: "The circle, the close clasp, the rhythmic consent of steps and voices; here are the social foundations and the communal beginnings of art. Then comes the improvised song, springing, however, from these communal and choral conditions, and still referring absolutely to present interests of the horde as a whole. All poetry is communal, holding fast to the rhythm of consent as to the one sure fact." This last reference is, of course, to the nature of primitive poetry.

\section{IV}

Another phase of the communal life connected with religion is to be found in the initiations of the young into the life of the tribe or other social group. Such ceremonies are to be 


\section{THE SOCIAL EVOLUTION OF RELIGION}

found in almost every part of the world amongst primitive and barbarous peoples. They are of a serious and impressive nature, emphatically calculated to give the young a profound regard for the tribal customs and traditions. As a rule, these initiations were quite different for the boy and the girl. The girl, at the age of puberty, was prepared for marriage and motherhood, often by means of seclusion, fasting, tasks to be accomplished, and duties to be acquired for the whole conduct of her life. For her, as was most often the case, these ceremonies were solitary, and calculated to impress her with the responsibilities she was to assume as the mother of the new generation.

For the boys the initiation was prolonged, severe, and crucial. It often included mutilations, rigid fasting, the heroic endurance of pain, and subjection to the will of the older men, who conducted these ceremonies. In many tribes there was a most impressive enactment of the death of the youth, and finally his resurrection to a new life as an initiated member of the tribe, with full rights in its fellowship. What the boy had been taught was now put aside, and the inner secrets of the tribal life were made known to him. He had been taught, it may be, that the turndun or bull-roarer was the voice of a god; but now he was shown its real nature, and how its distracting music was actually produced. He had been taught that the gods or demons, who roved through the village on certain occasions were actually denizens of another world, who had come forth to punish the boys, and to warn the women. Now he had the secret revealed to him that these supernatural beings were men in disguise, perhaps his own father or brother or neighbor.

The effect of these initiations was to teach the boy most impressively, and in a manner he could never forget, the customs and the traditions of his tribe. If some secrets were revealed that might seem likely to turn him from the teachings 


\section{THE SOCIAL EVOLUTION OF RELIGION}

now given him, the effect was quite otherwise, for he became as never before a tribal member, with an absolute faith in all its commands, and in its requirements of whatever kind. We might say that he became the slave of the traditions and customs of his people; but it is also possible to say that he was now for the first time born into the life of his social group, and came really to live its life, to feel its emotions, and to think its thoughts.

The ceremonies connected with the initiation of boys into the communal life were usually of a very crude nature; but they were elaborate, and they were calculated to make the deepest possible impression on the mind of susceptible youth. They undoubtedly served as a cement to bind together with unbreakable bonds the members of the group. Being enacted at an age when the mind is open to every kind of mental obsession, and when it is most capable of receiving an indelible impression, that will remain unchanged throughout life, the initiation served its purpose to the fullest degree.

The initiated members of a social group became a band of brothers, closely and intimately bound to each other, and made as it were kinsmen by ties more effective than those of birth. All the members of the social group, it is true, were of the same blood, as a rule, and bound to each other by ties of consanguinity; but the initiation ceremonies gave a more enduring bond of affection and fellowship to all the initiates.

When the group had progressed socially to that stage when others than the consanguinous ties were those found throughout its membership, because of the coming into it of those not of the same blood, there developed what are known as secret societies. These may exist alongside the tribal group or they may supersede it, when that form of organization has in a degree lost its power to hold together its members. In all parts of the world 


\section{THE SOCIAL EVOLUTION OF RELIGION}

such societies may be found amongst primitive peoples. The members are initiated by impressive and solemn rites, and by the most binding oaths. In some regions these societies serve to preserve order and to enforce custom or law. In others they degenerate into the means of terrorizing those not connected with them or of the extortion of wealth from those who will not yield it up in any other manner.

In many regions, and especially in southern and eastern Asia, are to be found communal houses, the homes of these secret societies. In these the men and boys may live, and in them the communal business is transacted or the festivals held. The women are sometimes excluded, and sometimes they are admitted; but these houses are more especially the meeting-places of the men of the communal fellowship. What is especially to be recognized in regard to them is, that they are of a communal nature, and that they serve the purposes of the collective life of a group.

Perhaps as growing out of the initiations, or, it may be, in some instances, developing from the secret societies, may be found what are usually called mysteries. These appear widely in the higher stages of savagery and in the barbarian age. They are distinctly of a religious nature, with the purpose of initiating those who accept them into a fellowship that is spiritual, that is, into a condition of preparation that is calculated to insure communion with the gods or entrance into the immortal life. The most widely known of these mysteries was that of the Eleusinia, which took place at Eleusis, twelve miles from Athens. We know little of these initiations, for the reason that no one dared reveal their secrets. At first confined to the tribe with whom they originated, they were extended to the citizens of Athens, and, finally, to all Greeks, both men and women. Based on a reverence for nature, and the recognition of the earth as a 


\section{THE SOCIAL EVOLUTION OF RELIGION}

great creative mother, as well as on the divinity of the cereals on which the Greeks mainly subsisted, these nature-deities, with the nature-symbolisms connected with them, came to have an important influence on Greek religion. When the Olympian gods had lost their power, and their persuasive capacity to hold to the faith the more cultivated Greeks, these mysteries drew all hearts and minds. They gave initiation into the spiritual world, and they made the worshipper certain of a continuous life after death.

The mysteries, however, were by no means confined to Greece or to the more highly civilized peoples of the ancient world. They were to be found in Egypt, in Syria, and widely elsewhere, even among the tribes of Africa and India. Wherever they appeared, they had a social and political significance, as well as one that was profoundly religious.

Primitive religion does not consist in beliefs, but in acts, that is, in rituals, ceremonies and festivals. What it teaches is not in the nature of a creed, but largely relates to conduct, to the enforcing of customs, and to the impressing upon the young of what is to be done. To a large degree the conduct inculcated is that supposed to be demanded by the gods, by the ancestral spirits or by the divine heroes of the tribe. The rituals present this form of conduct in the shape of dramatic presentations of the acts of these divine ones; and the worshipper is supposed to imitate the customs thus brought before him.

These rituals are regarded as having a magical effect, in that they bring the worshipper into intimate contact and sympathy with those worshipped and giving control over them. Many of the rituals act as restoratives of health, others are performed for the express purpose of bringing an abundance of animals to the hunters of the tribe, or a rapid growth of the seeds which have been placed in the earth. The increase of the 
food-supply is one of the most desired of all things which appeal to the primitive man, and to this end, above all else, he invokes the higher powers. The early religions are abundantly occupied with this interest in an adequate food-supply, and this demand gives a considerable measure of interest in plants and animals, which hold a large place in all of them, with few exceptions.

The next most urgent interest of the primitive man is sex, the control of the relations of men and women, and the securing to the tribe a provision for its continuity through the birth of children. After the conditions controlling the food-supply have been mastered, sex stands out very largely as an interest of the primitive and the barbarian man. In many a tribe the process of creation is one of generation, Father-Heaven and MotherEarth holding a very large place in many a religion of the early times.

The causes of disease, the nature of death and what follows after it, the processes of birth and growth, the kind of conduct which will preserve the life of the tribe, the interests of the hunt and of war - these are always present to the primitive man as determining his relations to the world of the spirits and the gods. His religion seeks to control all these interests, not in any manner known to a scientific age, but by the aid of magic, by sacrifices, by ritual representations of what is desired, and by communal appeals to the powers controlling the life of the group.

This brief outline of the nature of early religion will indicate that it is in no sense individual but social. Rarely, perhaps never, does the primitive man seek for what he desires of the higher powers by any personal appeal or act. If he does so, some interpreters of early human life, for instance, J. G. Frazer in The Golden Bough, are of the opinion that it is to be called magic and not religion. Frazer says that magic is individual, 


\section{THE SOCIAL EVOLUTION OF RELIGION}

but that religion is social. Other students are of the opinion that no such distinction is to be made, that in the earliest periods there is no true differentiation between magic and religion, though this undoubtedly comes at a later time. Religion is communal in the very nature of it, for the reason that it seeks the interest, not of an individual as distinct from other individuals, but that which will equally benefit all the members of the group. Food for one means food for all, and the appeal to the creative powers is in behalf of the clan or tribe in its communal capacity. All the land which forms the habitat of the tribe belongs to the group in its tribal capacities, though individuals may use portions of it in behalf of their families. The law is that all such land reverts to the tribe as soon as it is not used for the purposes which promote the interests of the family. In Australia, and in many another part of the world, primitive men share and share alike with the food-supply, perhaps a definite portion of each animal killed going to one or another member of the food-group.

\section{V}

It may not be necessary to labor this fact, that the early man lives communally, and that his religion is distinctly social in its nature. We may therefore pass on to the consideration of another phase of the group life, that which shows primitive man to have been endowed with a creative capacity of a social nature. We have been to such an extent imbued with the conviction that all thinking is individual, that it seems to be nearly impossible for us to recognize the conditions of social thinking and creation. The tales, legends, and myths of tribal communities give no evidence of individual origin. Whence they came, who originated them, never appears. No author's name attaches 


\section{THE SOCIAL EVOLUTION OF RELIGION}

to them. In their very nature and structure they are of the communal type, voicing the desires and interests of the group, whether it be a hunting-band, a food-group, a communal village or a tribal fellowship of kinsmen. The tales may be of recent origin or they may have on them the marks of a hoary antiquity. They may relate to hunting or fishing, to battles with other tribes, to adventures of those who have gone down into the world of the dead, to ascension into heaven and intercourse with divine beings, to the coming of heroes who teach the people new methods of life, to the origin of plants and the acquiring of a knowledge of their cultivation or to the manner in which some animal or ancestral being gave the tribe its rituals or its festivals.

It may be at once noted that all such tales or myths relate to the communal interests. If the new custom or ritual is revealed for the first time to an individual, its purport is always tribal in its nature, to the ends of the benefit of the group to which it is communicated. Since dreams are always individual in their nature, what is thus acquired comes through some one person; but the use made of them is to benefit the tribe by some new access of power in behalf of all its members. A new secret society, a ritual or festival, comes into existence in this manner; but the command of the dream-spirit is that the clan or the tribe shall be benefited by what is thus communicated.

Almost universally in primitive, tribal and feudal society appear those who recite the tales or rehearse the poems or sing the songs belonging to the life of the past. To the really primitive group the tales are legends of adventure, of contact with spirits, and are of communal origin. These tales or legends relate to the causes of what the primitive man wishes to understand. Many of them are childish, grotesque or fantastic from our point of view. All of them are animistic or anthropo- 


\section{THE SOCIAL EVOLUTION OF RELIGION}

morphic, that is, are based on the conception that all events and acts are those of personalities-animals, men, or spirits. The primitive man has no conception of material or general causes, and he sees in everything beings like himself. The wind blows as the act of Boreas. The earth quakes because a god is inside it turning over or trying to get out of his prison The sun is a divine being moving around the earth diurnally, and disappearing at night because he goes down through the land of the dead.

The legends and myths of the primitive man, therefore, are adventures of beings in some way like himself. They are tales of giants, of men in animal form, of men who have gone into the world of the dead, of spirits who act through the powers of earth, or of divine beings who control the courses of nature and of human activity. Wheat grows, and gives an abundant harvest, because it is a divine being or has a spirit of vegetation living or manifesting itself in each spear as it grows or, it may be, in the species as a whole. The tree, the moon, the stars, the earth itself, are, in their physical natures, merely the outward manifestations of a being of a divine nature embodied in them. The oak, the mistletoe, bear, and bison have qualities which are more than vegetable or animal in their nature; but are at once, in each and every instance, personalities or of a god-like nature. Sometimes each individual has this quality of divinity, but in other instances there is a power that is personal to a species - a power that is superior or divine.

The tales, therefore, are often of beings who are supernatural, possessed of magical or divine powers, and who may be regarded as creators. In some instances, it is true, the tales are purely secular, relating to events in the lives of men and women; but more often they have a tinge of what is beyond the natural acts of human beings. It is not surprising, there- 


\section{THE SOCIAL EVOLUTION OF RELIGION}

fore, that a people who find the spiritual everywhere, who are daily, if not hourly, in contact with beings who are more than human, should delight to hear of the adventures of these beings. They may be of animals, but these are only men in disguise, and may be at any time transformed into their real nature. It may be the doings of the powers of nature-mountains, storms, stars, sun-rise, the moon-whose acts the tales recite; but these are all beings who act as men act. In a word, nothing appears in the world of the primitive man which is not possessed of personality, which is not a projection of the desires, the emotions, and the acts of human beings.

In studying the tales and the myths we come upon two facts of importance. They may be communicated from one tribe to another, and they may spread over a wide territory, with the result that tribes living remotely from each other may have the same tales. In other instances the process of intercommunication cannot be accepted as the explanation of why it is that two peoples have essentially the same tales, myths, rituals or explanations of phenomena. When the tribes are on distant islands or on continents too remote from each other to permit of such communication from one to the other, the similarity must be ascribed to a like psychological nature in primitive men responding to similar conditions in their environment.

We must recognize the fact, also, that all peoples have the creative gift, though they vary greatly in this respect. The tales and myths of some tribes are meager and poor, while others possess an astonishing creative power, taking a wide range of expression. The mythology of the Chinese is crude, materialistic, and unimaginative, while that of the Hindus is abundant, highly spiritualized, and transcendant in form and nature. The Chinese myths relate largely to ancestors, those of the Hindus to the adventures of gods of the loftiest type. 


\section{THE SOCIAL EVOLUTION OF RELIGION}

\section{VI}

A few illustrations from the myths of primitive peoplesthe word primitive being used throughout in preference to savage, and applies to those who are undeveloped in industries, arts, and culture-may aid us in comprehending what the tales are like. The Caddoan tribes of the southeastern plains region of the United States had a myth relating how Mother-Corn came to them, and taught them how to cultivate that cereal. She came as a woman, passing from tribe to tribe giving each the seed of the maize, and instructing the women in its planting. and tending. She also showed them how to prepare it for food, how to make offerings to the stars and to the heavenly bodies, as well as to the supernatural beings of the earth. When she had given all these instructions, she told the women she was about to depart, that she would reappear to them as the moon, and that in that form she would be the guardian of the women. The monthly changes in the phases of the moon would be as those of the life of women, and that when they looked upon the moon they would know that she was with them and watching over their interests. In this manner the Caddoans came to know how to cultivate corn, that it was but another phase of the life of the moon, as well as that of women. Corn to them was a great divine Mother, a goddess beneficent, and watchful of the peoples' interests. This personification of maize is similar to what is to be found widely over the world, wherever any kind of cereal is grown, at first by women, and then by men. More highly elaborated myths of this type are to be found in Egypt and in Greece.

The Natchez, who lived on the lower Mississippi, in Louisiana, had a tale of a culture-hero, who came to them to teach them how to govern their tribes wisely and well. He came from the Sun with his wife, seemingly being regarded as a 


\section{THE SOCIAL EVOLUTION OF RELIGION}

being of the nature of the sun itself, who was the supreme god of all the peoples living in the gulf-region. This being said to the Natchez that he had looked down upon them from his abode in the sun, and had been moved to come to them to teach them how to conduct their life as a people. He taught them to kill no one except in self-defense, not to touch any woman except one's own, not to take from another that which belongs to him, not to lie or get drunk, not to be avaricious of wealth, but to give freely for the welfare of others, and to share food with those who are without it.

These were the rules the Sun-man gave for the guidance of individuals, and, if they were observed, the people would be able to live orderly and contented lives.

The people were so far pleased with this teaching that they chose this divine being as their chief, which position he held for a long time. He made the condition that the people should remove to another country; and the Natchez traditions said that they had come from the westward to the land they occupied when the whites first came to know them. The culture-hero divided the people into castes or orders; he made rules in regard to the intermarriage of these orders; and he ordered the building of a temple and the establishment of definite rites of worship of the supreme powers. When this being who had come from the sun came to die, he was succeeded by his descendants as the sovereigns of the Natchez, and, after him, they were called Suns, and were assumed to partake of the nature, in some degree, of that great luminary, ruling for the enlightenment of the people.

One of the most interesting of all the myths of the aborigines of North America is the creation story of the Zuni of New Mexico, as told in outline by Frank Hamilton Cushing, in the thirteenth Report of the Bureau of American Ethnology. In 


\section{THE SOCIAL EVOLUTION OF RELIGION}

the beginning, according to this myth, there existed the All-covering Father-Sky and Four-fold Containing Mother-Earth, and these two lay together on the great world waters. By generation these great ones produced all things which are, though the Earth, before she gave birth to men, and all things men ean desire, repulsed the Sky from her, and he went up aloft. The Earth gave birth as a woman gives birth, and from her womb came forth men, and all the other creatures who live with them. This myth of Earth and Sky is to be found widely throughout the world, as is that other myth of the Earth as a mother producing in her womb all the creatures of whatever kind who live on her bosom. This myth of the Zuni is worthy of comparison with any that has been produced by Hindus, Egyptians, or Greeks, and has some close resemblances to those of which one may read in the pages of Hesiod's Theogony.

Many of the myths recite how one or another man or woman, perhaps whose mate has gone down below in death, enters the world of the non-living to find how the inhabitants there order their lives, to find what is the happiness there enjoyed, or, more probably, to bring back to earth a beloved one. One of the greatest of these tales is that of the descent of Ishtar, the great goddess of Babylonia, into the land of No-return. Her search was for Tammuz, who had been cruelly slain by a boar in the mountains of Lebanon. When she came to the first. gate of entrance to that world of the dead, she addressed its guardian, who went to the queen of that land, Allatu, that permission might be obtained for the search for her beloved. When permission had been secured, the porter at the first gate, took off the crown from her head. When she inquired, "Why, 0 porter, hast thou taken off the great crown of my head?" $\mathrm{He}$ replied, "Enter, my lady, for such is the custom of Allatu." At the second gate there were removed the ornaments of her 


\section{THE SOCIAL EVOLUTION OF RELIGION}

ears, and in succession the chains about her neck, the ornaments of her breast, the girdle of her waist, the bracelets of her hands, the anklets of her feet, the garment covering her body, until, without ornament or clothing, she appeared in the presence of Allatu, the goddess of the underworld. Allatu did not welcome the adventure of Ishtar or grant her request; but she ordered Namtar, her messenger, to return Ishtar to the upper-world, and to restore to her as she passed out of the land of No-return the ornaments and the clothing of which she had been deprived as she entered. Accordingly Namtar sprinkled Ishtar with the water of life and brought her forth.

He led her out through the first gate and restored to her the garment covering the shame of her body.

He led her out through the second gate and restored to her the bracelets of her hands and the anklets of her feet.

He led her out through the third gate and restored to her the studded girdle of her waist.

He led her out through the fourth gate and restored to her the ornaments of her breast.

He led her out through the fifth gate and restored to her the chains about her neck.

He led her out through the sixth gate and restored to her the ornaments of her ears.

He led her out through the seventh gate and restored to her the great crown of her head.

In studying such myths as these it becomes evident that those of the more advanced peoples are essentially the same as those of many of the savage and barbarian races, and that their only superiority is in the literary treatment which they have received in their later developments. Heredotus informs us that the Greek gods were invented by Hesiod and Homer, but we now know this statement not to have had any foundation in 


\section{THE SOCIAL EVOLUTION OF RELIGION}

truth. The myth of Demeter, as told in the Homeric Hymns, shows us that this goddess of the ripened corn (wheat and barley) was essentially the same being as the Corn-Mother of the Caddoans, though it had been greatly elaborated in the Eleusinian Mysteries and by the poets. We can conceive it to have been possible, if the Caddoan peoples had been left undisturbed for a thousand years, that they might have developed mysteries similar to those of Eleusis, and hymns similar to those attributed to Homer. It is not probable, but possible, that such a result may have been in time worked out.

The Mountain and the Night Chants of the Navaho of New Mexico, a crude and uncultured people, of Athapascan or Dené origin, having come from some far northern region centuries ago, may show us what is possible to a people of this type. These chants or ceremonies are for the healing of the sick, and had their origin in the demand for some effective method in dealing with disease. These ceremonies are held in winter, and consist of songs, a variety of ceremonies, paintings made in painted sand to represent the gods and their acts, and prayers to the divinities for health to the people and to some individual who is able to meet the expense of these prolonged ceremonials. In his book on North American Mythology, the tenth volume in the Mythology of All Races, Hartley Burr Alexander says of the Night Chant that it has a nine day period. He gives this account of the ritual: "On the first day holy articles and the sacred lodge are prepared; on the second, the sweat-house and the first sand-painting are made, and the song of the approach of the gods is sung: prayers and a second sweat-house are features of the third day, while the fourth is devoted to preparations for the vigil which occupies the fourth night, at which the sacred masks of the gods are sprinkled with pollen and water and a communal supper is followed by a banquet; the 


\section{THE SOCIAL EVOLUTION OF RELIGION}

principal feature of each of the next four days is the preparation of an elaborate sand-painting of the gods, each picture symbolizing a mythic revelation, and the touching of the affected parts of the body of the sick with the colored sands from the analagous parts of the divine image; the ninth day is devoted to preparations for the great ceremony which marks the ninth night, at which the masque of the gods is presented. It is from this masque of the ninth night that the Night Chant gets its name, and this is the night, too, of that prayer to the dark bird (of thunder) who is the chief of pollen which is perhaps the most poetic description of the genius of thunder-cloud and rain in Indian literature, and which runs thus, abridged from (Washington) Matthew's translation-

\section{In Tsegihi,}

In the house made of dawn,

In the house made of evening twilight,

In the house made of dark cloud,

In the house made of rain and mist, of pollen, of grasshoppers,

Where the dark mist curtains the doorway,

The path to which is on the rainbow,

Where the zigzag lightning stands high on top,

Where the he-rain stands high on top,

Oh, male divinity!

With your moccasins of dark cloud, come to us,

With your leggings and shirt and head-dress of dark cloud, come to us, With your mind enveloped in dark cloud, come to us,

With the dark thunder above you, come to us soaring,

With the shapen cloud at your feet, come to us soaring,

With the far darkness made of the dark cloud over your head, come to us soaring,

With the far darkness of the rain and mist over your head, come to us soaring.

With the zigzag lightning flung out on high over your head, With the rainbow hanging high over your head, come to us soaring. With the far darkness made of the dark cloud on the ends of your wings, 


\section{THE SOCIAL EVOLUTION OF RELIGION}

With the far darkness made of the rain and the mist on the ends of your wings, come to us soaring,

With the zigzag lightning, with the rainbow hanging high on the ends of your wings, come to us soaring.

With the near darkness made of the dark cloud of the rain and the mist, come to us,

With the darkness on the earth, come to us.

With these I wish the foam floating on the flowing water over the roots of the great corn.

I have made your sacrifice,

I have made a smoke for you,

My feet restore for me.

My limbs restore, my body restore, my mind restore, my voice restore for me.

Today, take out your spell for me,

Today, take away your spell for me,

Away from me you have taken it,

Far away from me it is taken,

Far off you have done it.

Happily I recover,

Happily I become cool,

My eyes regain their power, my head cools, my limbs regain their strength, I hear again.

Happily for me the spell is taken off,

Happily I walk; impervious to pain, I walk; light within, I walk; joyous, I walk.

Abundant dark clouds I desire,

An abundance of vegetation I desire,

An abundance of pollen, abundant dew, I desire.

Happily my fair white corn, to the ends of the earth, come with you, Happily my fair yellow corn, fair blue corn, fair corn of all kinds, plants of all kinds, jewels of all kinds, to the ends of the earth, come with you.

With these before you, happily may they come with you,

With these behind, below, above, around you, happily may they come with you,

Thus you accomplish your tasks.

Happily the old men will regard you,

Happily the old women will regard you,

The young men and the young women will regard you,

The children will regard you,

The chiefs will regard you, 


\section{THE SOCIAL EVOLUTION OF RELIGION}

Happily, as they scatter in different directions, they will regard you, Happily, as they approach their homes, they will regard you.

May their roads home be on the trail of peace,

Happily may they all return. .

In beauty I walk,

With beauty before me, I walk,

With beauty behind me, I walk,

With beauty above and about me, I walk.

It is finished in beauty,

It is finished in beauty."

Here we have a prolonged series of ceremonials, which constitute together a prayer to the higher powers for health, prosperity, and peace. Had they been developed in Babylonia, Egypt or Greece they would have been minutely studied and interpreted. In fact, this chant is worthy of comparison with many of the Homeric Hymns. It is not more repetitious, and it has fully as much poetic beauty. Although it is cruder, less perfected, this may be wholly owing to its not having passed through the hands of a poet of cultivated tastes.

The chants of the Navaho, taken in connection with their mythology, the story of the adventures of the Great Goddess, and their lesser divinities, may be brought into juxtoposition with the Egyptian myth of Osiris and Isis, and not wholly suffer in the comparison. At any rate, it is by studying the myths of these more primitive peoples that we come to a comprehension of those of the more advanced nations of antiquity.

The myth of Osiris and Isis is one of the most important of all those which come to us from the ancient world, and appears to have originated in the pre-historic age. Evidently it was developed out of very early conditions, when the valley of the Nile was being reduced to a state of cultivation. It probably underwent in the course of ages many a transformation, and grew with the growth of Egyptian civilization. The story is that Osiris was a king of Egypt, that he married his sister 
Isis, according to Egyptian custom, that he was slain by his brother Set, who scattered the parts of his body far and wide. Isis gathered together the fragments, and, with the aid of the gods, Osiris was restored to life, became the father of Horus, who avenged his father's death in the destruction of his uncle. Osiris became the god of the under-world, and the type of resurrection from the dead to immortality. Isis was perhaps a goddess of fertility in plants, animals, and women. Her devotion to Horus led to her elevation to the position of the great Mother-Goddess. Out of the relation of the two grew the myth of the mother and the child, the forerunner of that of the Madonna and the Christ-child. The worship of Isis spread widely in the Roman world, and for a time she was revered more zealously than any other divinity.

\section{VII}

These glimpses at various phases in the growth of myths may hint at their communal or group-nature. They did not originate in the genius of individual poets, as Herodotus assumed to be true with regard to the myths embodied in the Iliad and the Odyssey. Some suggestions as to their growth may be found in the history of the Rig-Veda. The thousand or more hymns of the Hindu collection, the oldest work in the literature of India, were originated at an early period of the presence of the Aryans in the peninsula of Hindustan. They were composed perhaps a thousand years before writing was invented, were carried in the memories of the bards from whom they came, and then were transmitted from one generation to another of the priestly class by whom they were especially conserved. It cannot be supposed that while these hymns were being retained by the members of some twenty-five generations of bards and priests 


\section{THE SOCIAL EVOLUTION OF RELIGION}

without being put into writing, that they underwent no change. We know that the tales recited by primitive peoples are constantly undergoing a process of growth, that every clever reciter of them modifies them in one degree or another. In this manner they are being brought into conformity with any changes in the tribal life, either through culture-growth, or as the result of contact with other tribes.

The same processes undoubtedly went on in India, and the Vedic hymns show many evidences of this process of elaboration in the mythology they present. In this way we may account for the varied phases of that mythology, its ascribed supreme power to several different gods, its advance from a crude polytheism to a highly refined pantheism in the most remarkable of the hymns, and even to an earlier type of monotheism, or what has sometimes been called henotheism.

In a later age somewhat the same processes brought the Mahabharata, the great epic poem of India, into existence. This most extended of all the epic poems of the world has been described by Julius Eggeling as "consisting of a heterogeneous mass of legendary and didactic matter, worked into and round a central heroic narrative." Although the name of Vyasa is attached to this great work, it is quite evident that it could not have been produced by one person, but that it was the growth of many years. Parts of it are distinctly traditional, and may have been the growth of many centuries. Other parts of it, as the particular portion known as the Bhagavat-gita, were proably the work of individual poets. In this work myth, legend, folk-lore, tradition of historical events, early poetic productions, were being gathered together to form a remarkable whole. It has little unity, and is a rambling miscellany of poetry, some of it of great beauty, but much of it crude and of the essential nature of prose. 


\section{THE SOCIAL EVOLUTION OF RELIGION}

The evidence seems to indicate that the Mahabharata is somewhat of the nature of an anthology, even though there runs through the work a central heroic narrative. According to Arthur A. Macdonell, in his work on Sanscrit Literature, this epic contains archaic verses and old prose stories, artificial speeches, legends about gods, kings, and sages, accounts of cosmogony and theogony; disquisitions on philosophy, law, religion, along with an extended epic account of a great battle. As Macdonell says, the poem contains an original kernel of historic truth, in a conflict between two neighboring tribes; and one of the chief characters in it also finds a place in the RigVeda. The earliest stage of the poem goes back, probably, to the tenth century B. C. Old battle-songs of the tribal conflict were handed down by word of mouth, and recited or sung in the popular assemblies or at the great public sacrifices. These may have been brought together into a short epic narrative about the fifth century B. C. In this part of the work are to be found the accounts of the old heroic spirit and the descriptions of tribal life. Here the chief god is Brahma, who is presented almost in a monotheistic spirit.

In this age before writing, in which the poem took its first form, it was recited by bards or rhapsodists, and by them was gradually expanded with the incorporation of new materials. Vishnu, especially as incarnated in Krishna, was developed as one of the great gods, and Civa was also given a place, though not one of as much importance. At a later stage the Brahmans incorporated in the work that kind of didactic information which was designed to impress the kings and the people with the importance of the priestly caste. A great number of episodes, many of them of considerable length, not only increased greatly the bulk of the poem, but were evidently added at various periods, and had no real connection with the original epic nar- 


\section{THE SOCIAL EVOLUTION OF RELIGION}

rative. It is not improbable that the poem was in the process of growth during several hundred years. The ascription of the authorship to Vyasa, which name means "Arranger," can mean nothing more than that some poet brought together the several parts of the great poem, and arranged them in the form which has been known almost since the beginning of our era.

It would appear, therefore, that the poem as we have it is a growth, that some of its parts, such as the Bhagavat-gita and the concluding Harivamca, were written by individual poets; but that large portions of the whole work may be attributed to a collective origin, that is, that they had a distinctly traditional or legendary source. This conclusion is confirmed by the fact that the poem was at an early time recited in the temples, and in some of them daily. Even down to the present such recitations are frequent, sometimes in temples and sometimes in families. The object is to give information to those not otherwise able to acquire a knowledge of the work. Such recitations, however, are not confined to this poem, but include other of the older works connected with tradition or with history. In this manner, or one similar, the Vedas were brought to a knowledge of the people. It would appear, therefore, that this practice was regarded not only as desirable, but as in harmony with the sacred or highly important character of such works. Such practice in the early time would give the amplest opportunity for the incorporation of fresh materials into the poem and into other works. In this manner they grew, fortuitously, as it were, and without any distinctly individual authorship. In time what was in this manner incorporated with the poem came to have a like value, and to be received as equally authentic in its nature. Probably the sacred books grew in the same manner; and the new materials, soon acquired a sacred nature compatible with the older portions. 


\section{THE SOCIAL EVOLUTION OF RELIGION}

The Jewish sacred writings afford an illustration of the manner in which early works were composed. In Genesis, Judges, Kings, and others of the early books, we find a large amount of folk-lore, legend, and other traditional material of various kinds. Some of it was primitive poetry, some of it attempts to account for the origin of the earth, man, languages and the varied features of human institutions and customs. A considerable body of this material is to be found in the Babylonian legends and cosmological narratives, but reinterpreted to suit the monotheistic ideas of the later Jewish beliefs. Then there are legendary narratives of the migration of the Jewish people to Palestine, their battles with the previous inhabitants of that land, and the establishment of the monarchy, the struggles with polytheism, the wars with the neighboring great nations, and the subjection of the Jews to these greater powers. There is no reason for doubting that much in these narratives, especially in the later periods, is essentially historical, as much so as any early history.

What is evident, however, is that these books are compilations, and that their contents are results of long-continued processes of growth. It is now fully recognized that the Penteteuch, and other works, were compiled out of two or more previously existing books or legendary narratives, some of the smaller portions of which were, perhaps, not previously committed to writing. For more than a century it has been definitely recognized that the Penteteuch embodies two quite distinct narratives, one of them naming God as Yahweh and the other as Elohim; and these works vary from each other in many another particular. The two were brought together at some period after monotheism had been accepted, and the attempt was made 


\section{THE SOCIAL EVOLUTION OF RELIGION}

to bring them into complete harmony with each other. A considerable amount of other material was also made use of by the compiler or compilers. At what period or by whom this compilation was made we do not fully know; but it must have been at a comparatively late era, and after Judaism had taken on a definite form. The monotheistic interpretation of the world and life had been then definitely accepted, and the old narratives were reconstructed to fit into this new conception of the nature of God and of the life of humanity.

In the second book of Kings there is an account of the finding of Deuteronomy in the temple in Jerusalem, and it was made the basis of a radical reformation of the old religion. It may be conjectured that at this period, and in connection with this reformatory movement, the reediting of the old narratives took place. Some interpreters of the Jewish sacred books, however, are of the opinion that there were later and more radical reconstructions, at least so far as concerns the interpretation given to the history and to the theology of the Jewish people. If the reform connected with the writing of Deuteronomy was priestly in its source, the prophetical works, so called, owed their origin to another class of men, known as the prophets, who were essentially reformers. They gave a later, and a much more advanced, interpretation to the historical narratives, and of the relations of the Jewish nation to its God.

What the higher critics of the sacred writings of the Jews suggest is, that the books brought together in these scriptures were the result of more than a thousand years of growth, that many, if not nearly all, of these works had no individual authorship, that the names attributed to them as their authors were only traditionally so; and that the idea of their sacred character was in itself the result of a long evolutionary process. 


\section{THE SOCIAL EVOLUTION OF RELIGION}

\section{VIII}

A controversy of more than a century in duration has developed around the Greek epics attributed to Homer. Was there a man of that name who wrote them or were they the growth of many centuries of poetical expression? The tendency recently seems to be toward the conclusion that the poet Homer is of legendary origin, that we have no definite information in regard to him, and that in reality he represents a profession or a succession of bards, rather than any distinct individuality. Gilbert Murray, in his lectures on The Rise of Greek Epic, says that "what the Greeks of the sixth and early centuries meant by 'Homer' was the whole body of heroic tradition as embodied in hexameter verse." He goes on to say of the body of epic verse which was described under the appellation Homer: "It must really have been something more primitive and less differentiated, of which the epic epos, the lists of ancestors, the local chronicles, the theological, magical, and philosophical writings, as well as the heroic poems, are so many specialized developments. It has long been clear to students of early Greece that the Iliad and Odyssey are not primitive poems. Not only their art and construction, but their whole outlook on the world and the gods is far removed from that of the most primitive Greeks known to us. Both poems, indeed, contain a great deal of extremely ancient matter; but both, as they stand, are the products of a long process of development."

Since no one has more clearly and definitely stated this view of the origin of these epics than has Gilbert Murray, there may be summarized here his conclusions, as stated in the above mentioned work, and in his book on Greek Literature. At the beginning of his sixth lecture he says that the Iliad is a traditional book, modified by succeeding generations, and gives us a mixture of earlier and later customs. While he admits that 


\section{THE SOCIAL EVOLUTION OF RELIGION}

there can be no demonstration of that kind of origin for the epic which he believes is the true one, yet he presents a considerable body of evidence in favor of the conclusions which he has reached. There is no positive proof that these poems grew through several centuries, and that they are the work of a long succession of epic poets or schools of such poets; but the cumulative evidence of all kinds gives very strong intimations that such a conclusion must be accepted. This view of their origin gains added emphasis from the fact that all other similar works of the early period appear to have had a like origin.

In the early Greek traditions everything heroic was attributed to Homer, with the result that several works not included in the Iliad and Odyssey are credited to him, for there was a Little Iliad, a Cypria, a Telegonia, and other poems or bodies of legendary narrative. Aeschylus credited to Homer the whole of the heroic saga, and Athenaeus says that the dramatist rejoiced in the epic cycle and made whole dramas out of it. Xenophanes in the sixth century credited to Homer and Hesiod the epic traditions, sagas and theogonies alike. Herodotus believed these poets made the Greek religion, gave the gods their titles, honors and crafts, and gave a description of each of them. Tradition attributed to Pisistratus the collection of the Homeric sagas, which were formerly sung in fragments. Such evidence as this may have little value, but it tends to corroborate the theory presented by Murray, that the poems grew out of the developing poetic life of the early Greeks.

To the same effect is the fact that late in the sixth or early seventh century the Homeric poems were recited in Athens publicly in a prescribed order. "They were recited not by one bard," says Murray, "but by relays of bards, in fixed order at the Panathenaea, the greatest of all the festivals of Athens, recurring once in four years and lasting several days. The 


\section{THE SOCIAL EVOLUTION OF RELIGION}

recitation formed one step in a movement on the part of Athens to establish herself as head and mother-city of all the Ionians. So much seems historically clear. It matters little that, in attributing the institution of this recitation to a definite founder, our authorities waver between three almost contemporary names, Solon, Pisistratus, Hipparchus. These festivals meant much more in ancient life than any corresponding ceremony at the present day. At the back of them there was a living religious effort; there was the ancient warmth of patriotic feeling towards a city which formed for each man his one earthly protector and his intimate home, and which, for a further claim upon emotion, was never for long quite out of mortal danger. The Panathenaea in especial formed the great occasion for the gathering of all Ionian cities under the wing of the great Metropolis, their champion and leader against the barbarian."

Pindar, and tradition down to his time, knew all the Trojan and Theban epic poems as those of Homer. In Ionia this body of epic poetry was in the possession of the 'Homeridai' or 'rhapsodoi;' organized, as there is evidence for thinking, into schools or guilds. Pindar tells us that these rhapsodes introduced their recitations with a hymn to one or another god, such as we find in the Homeric Hymns, which were probably produced in this manner. They recited, following this prologue, some selected old heroic legend in their own words, and with such interpretation of it as would most appeal to their hearers, whoever they might be. They had no prescribed text, no authenticated version, since writing had not as yet come into use. They followed their own devices, contracting or expanding the legends as they pleased or adding new materials, if such had come within their reach. Murray is of the opinion that the Homeric epics are full of traces of the work of the rhapsodes; "they are developments from the recited saga, and where they 


\section{THE SOCIAL EVOLUTION OF RELIGION}

fail in unity or consistency the recited saga is mostly to blame."

It must be recognized, also, that there is in these poems a a development of social customs, which may be traced through them, a considerable advance having been made from the earlier to the very latest parts of the epics. This growth pertains to marriage customs, to the interpretation of the nature and characteristics of the individual gods, and also to the whole manner of regarding the supernatural.

The Iliad may have begun, as did the Mahabharatta, as an episode concerning two contending warriors before Troy, that is, as an account of a great battle between tribes or civilizations. This battle narrative invited additions, incorporation of other incidents, description of the combatants, the causes of the struggle and a great number of other expansions, growing through many centuries. The language used especially grew up to meet the needs of these heroic narratives, and was highly poetical, artificial, distinctly conventionalized, though it acquired a sonorous and splendid character. This wonderful mode of speech, according to Murray, was for centuries kept alive to serve nothing but the needs of poetry. This also he says, and it is very pertinent to our present purpose: "The intensity of imagination which makes the Iliad alive is not the imagination of any one man. It means not that one man of genius created a wonder and passed away. It means that generation after generation of poets, trained in the same schools and a more or less continuous and similar life, steeped themselves to the lips in the spirit of this great poetry. They lived in the Epic saga and by it and for it. Great as it was, for many centuries they continued to build it up yet greater."

How this was done Murray very definitely states in the last paragraph of his seventh lecture, where he says: "The Greek traditions from the very outset were made into Lays to be re- 


\section{THE SOCIAL EVOLUTION OF RELIGION}

cited by bards for the delectation of the camp or the hall. If men were not interested, it was the fault of the bard and his poems. And in the very earliest times of Greece we meet with that characteristic and only half praiseworthy Greek institution, the public competitive recitation. The poems became, in the Greek phrase, epideiktika, things of display. The bards who knew the traditions came to recite at the great games and gatherings. Each recited his own poems-i. e. those that he 'possessed,' not necessarily those that he had composed-and tried to make them more attractive than other people's. He was bound, of course, not to violate history too grossly; not to be pheudas, or false-speaking, above all not to be ignorant. But he might, by the help of the Muses, tell his audience a great deal more about the heroes than by any human means he was likely to know. He could work up the known incidents till they became more and more moving, more edifying or more pleasing. An element was thus admitted which leavened the whole lump, an element which, in the hands of a less wonderfully gifted people, must, one would think, have led to bombast and vulgarity, but which was somehow stopped when it had done its maximum of good and was only just well started on its career of evil; I mean that strange mixed passion known to all artists, which consists, at its highest end, in the pure love of beautiful or noble creation, and, at its lower end, in conscious strain for the admiration of an audience."

We have but to assume that these epic products were gradually gathered up into the great poems as we possess them. The process may not have been precisely that of Lönnrot in the production of the Kalevala; but his method may suggest what process may have been followed at the earlier period. All other epics seem to have come into existence in much the same manner, there being no unequivocal proof in any instance that 


\section{THE SOCIAL EVOLUTION OF RELIGION}

they were owing to the work of individual poets, such as tradition provided for them. This appears to have been the case with the Shah Nameh, and with many another epic poem of the earlier centuries. It was markedly true of the Nibelungun-lied and the sagas of the Scandinavian countries. The legends which appear in the Nibelungun-lied began their growth in the primitive period of the Teutonic peoples, spread from one tribe and nation to another, gradually expanded in the number and variety of their incidents, were recited in halls and castles by a long succession of bards, and finally took the form in which we know them. Not one of these epics can be said to be exclusively the work of a single poet; and this is so far true that for most of them no personal name appears as the author. Even where this is the case these names are as legendary as the episodes in the poems themselves.

It must be recognized, of course, that the Nibelungun-lied has a basis in history, as in probably the case with all the epics of which we are now treating. Some of the episodes are historical, the customs may be of the same character; but the incidents are growths of the epic genius of the people, not of an individual poet of whom we can give definite and positive information. The process of development is essentially that described in the instance of the growth of the Iliad. The same general description will apply to the Norwegian and Icelandic sagas. If the Greeks had in any degree an epic genius superior to the more northern bards, which may be questioned, it does not appear in their possessing any different or superior method in the production of their poetic legends, now appearing as epic poems. The process as to methods of creation appears to have been essentially the same, and the results were not widely different. In all parts of northern and western Europe similar poems made their appearance, and in considerable numbers; but they 


\section{THE SOCIAL EVOLUTION OF RELIGION}

were produced, we must believe, in the same manner and for the same purposes. They were originally the work of generations of bards, wandering minstrels, reciters of poems in the house, the castle or in the public assembly. In the later tribal, and in the feudal ages, everywhere such productions were in great demand for this purpose. The demand produced what was required, and, wherever heroic poems were thus produced they served the same essential purpose of keeping alive legends and traditions in an age before writing was invented or had come into active use.

\section{IX}

Turning back again to Greece, we have to consider a poetical development more intimately and directly connected with the history of religion than was the case with most of the great epic poems. We may recognize that the gods of the Iliad were those of Olympus, and the religious traditions contained in it were those of the migrations, that is, the coming into Greece of those northern peoples who settled on the coast of Asia Minor, in the Peloponnesus, and in other parts of the islands and mainland. These peoples brought with them legends of an Olympian pantheon, though these grew and expanded greatly after they settled down in Greece. They were in the patriarchal stage of social development, were warlike and heroic in their customs and in their legends. The peoples they found in the country were more primitive, may have come originally from northern Africa, had their chief center of development in Crete, and were known as Pelasgians. Although that name now has no very definite meaning, and has been largely superseded by the use of the words Aegean and Minoan, which mainly refer to the phases of the recent archaeological discoveries, the use of that word is sometimes retained. This early people or peoples was 


\section{THE SOCIAL EVOLUTION OF RELIGION}

doubtless in the matriarchal period of development, traces of which remained here and there to quite late periods in Greek history and religion.

We do not know precisely in what manner the legends connected with this early phase of Greek life and religion were related to those of Babylonia, Syria, Asia Minor or Anatolia, Crete and Egypt. What appears to be true is, that these countries of the eastern Mediterranean basin had in many respects the same legends and the same religious rites. The Greeks are recognized as borrowing and assimilating those of the other neighboring lands, thereby considerably expanding their own pantheon and their religious ceremonies and festivals.

Although the Olympic gods and rituals are usually assumed to be those the most distinctly Greek, it must now be recognized that these came in with the migrations from the north. They were more distinctly feudal and aristocratic, as well as patriarchal, than those of the peoples they conquered or superseded in the Greek lands. The primitive religion, whether we call it Pelasgian or Aegean, was more distinctly agrarian and matriarchal than that of the invaders. That is, these peoples had begun the cultivation of the soil, and their religion circled about the need for the fertility of the land they cultivated. They worshipped Father Heaven and Mother Earth, and their gods were largely of the feminine type, august and loving mothers. Their rituals celebrated the coming of spring, when seeds could be placed in the ground, and when all green things sprang out of the earth. They conceived animistically this upspringing of life as a maiden, beautiful and most attractive, bearer of children, and yet remaining virgin. In many of the legends she had with her a son, who became in some way her husband also. This is myth, and is not to be assumed to reflect Pelasgian custom at any primitive period. Then the 


\section{THE SOCIAL EVOLUTION OF RELIGION}

autumn was personified as the mother of the younger goddess, and her worship and festivals were connected with the harvesting of the products of the gardens and fields, orchards and vineyards. Since these peoples buried their dead in the earth, and since the products of their cultivation sprang from the earth also, the two processes were intimately connected. The cult of the fields and the cult of the dead were related to each other, and the fertility of the fields depended on the presence of the divine mother in the world of growing things. In the myths of the Sun-goddess in Japan, Ishtar in Babylonia and Syria, and of Demeter in Greece, their descent into the lower world or their withdrawal from the upper world, caused the cessation of all fertility to fields, animals and men. The fertility of the earth and that of woman were also the same essentially, and what hindered the one lessened the other.

The gods and the rites of this more primitive religion do not to any extent appear in the Iliad and the Odyssey. The latter belonged to the Olympic cycle, and are fundamentally patriarchal and feudal. The other cycle is agricultural, matriarchal, and primitive. The rites are those connected with motherhood and agrarian life. Since much of the intimacy resulting from the burial of the dead in the earth and its cultivation for the producing of plants and fruits, suggest for them a common origin and influence, this agrarian religion was largely concerned with the dead and their interests. The rites were at once agricultural, to insure good crops, and, at the same time, to provide for the denizens of the underworld, which was below the soil, in the bosom of the earth. The Pelasgian religion found the world of the dead below, the Olympian above in the sky or in some far western region beyond the setting of the sun. The rites connected with the dead reflected these two conceptions of the abode of the ghosts. 


\section{THE SOCIAL EVOLUTION OF RELIGION}

The Pelasgian rites and festivals were the results of the combination of these two orders of experience and thought. They sought the fertility of the earth, and they also aimed at protecting the interests of those who had passed into the world of the dead. Out of this combination of interests came what is known as the "mysteries," rites having these two objects more or less in view in their performance. The myths resulting were those growing largely out of the animistic conception of nature, the personification of the perfected life of the year as a Divine Mother, and the uprising of nature in the springtime as a Divine Maid. The snatching of the Maid from the mother by the god of the underworld, as in the myth of Demeter and Kora or Persephone, is but a method of defining the relations of the world of man's daily interests to the natural round of the seasons. In some of the more eastern phases of this cult, as it is found in Syria, for instance, winter appears as a youth slain when the spring returns, and for the rescue of whom the mother or wife goes down into the underworld to secure his return. In the Greek myth, as found in the Theogony of Hesiod, Ge or Gaia is the earth, the broad-bosomed one. Many of the other goddesses also, in one or another degree, represent the earth, as is true of Demeter, Hera, Athena, Artemis and Aphrodite. The earth is often regarded as the Mother of the Gods, the AllMother, and as the primary source of the whole creation. These same goddesses, however, take on other characteristics, and may have another origin attributed to them. For instance, Demeter is sometimes represented as the ploughed field or as the furrow in that field. She is, therefore, intimately connected with the processes of the cultivation of the earth, sometimes being regarded as the cereals cultivated, and especially wheat and barley. Since the English give the general name of corn to these cereals, Demeter is sometimes known as the Corn-Mother. Per- 


\section{THE SOCIAL EVOLUTION OF RELIGION}

sephone is the young plant as Demeter is the ripened corn. Demeter, however, ranges through the whole world of cultivation, and she is often the personification of all vegetation and fruits, and is not less intimately connected with pastoral life and the domesticated animals. Kore or Persephone, although connected with the upspringing plant, and with the shoot bursting out of the earth, owing to her rape by Pluto or Hades, is also connected with the lower world, in which she spends a part of each year, that in which plant life cannot exist.

What we are most concerned with here, however, is the higher phases of these myths, those which link them with the Pelasgian developments of Greek religion. These were in large degree superseded by the Olympian pantheon, its rituals and its beliefs, during a considerable period; but, when the belief in Zeus lost its power, there was a revival of the old Pelasgian rituals and beliefs in a new form. It is true that the agrarian festivals and rituals never wholly died out, but now they came back with an added suggestiveness and with a far broader meaning. The tribal social development had broken down or disappeared in the course of time, and there was a demand for something to take its place, which in part was afforded by the guilds or orgeones. More especially, however, as connected with religion, there was a large growth of the Dionysian rites which provided something in the way of satisfaction to the emotional nature, in its ecstacy, and its personal inspiration from the god.

What became most important in this development was the Eleusinian Mysteries, their impressive symbolisms, their initiations into a form of life preparatory for the other world, their majestic dramatic presentation of the adventures of the goddesses, and their assurance of the forgiveness of sins and entrance upon the higher life when death presents itself. The 


\section{THE SOCIAL EVOLUTION OF RELIGION}

basis of these mysteries was found in the old nature-worships, which had been transformed, added to from foreign sources, and grown into great rituals of initiation into the world of the gods, and assurance that by means of them immortality was made certain to all the initiated. Since an expanded exposition of these cults may be found in the works of Frazer, Farnell, Harrison, and many other writers on Greek religion, it is not desirable to attempt any account of them here.

The mysteries, without doubt, had a considerable influence in the evolution of the Christian church and in the formation of its theology. Traces of them may be found in many parts of western Europe, and even in so remote a region as Ireland. As indicating the degree to which such rituals and myths may survive, and the great number and degree of the transformations through which they may pass as they proceed in their development, and in the accession of other and. related ceremonials and legends, it may be noted that Jessie L. Weston, in her paper on The Grail and the Rites of Adonis, published in FolkLore during 1907, and more fully interpreted in her two volumes devoted to The Legend of Perceval, published in 1906, is of the opinion that the legend of the Holy Grail had its origin in the customs connected with the Syrian myth of Adonis. This myth interpreted the succession of the seasons, the growth of plant life, and the symbolisms which grew out of these. In the tenth chapter of the Perceval volume Weston says of the origin of the symbolisms of the Grail:

"The incidents of the story; the dead body on the bier, with its pomp of ritual accessories, the weeping women (who figure persistently throughout the Grail story); the commonfeast with a mysterious vessel; the question as to the significance and use of which results in the restoration of vegetation to a land waste by reason of the death of him who lies on the bier 


\section{THE SOCIAL EVOLUTION OF RELIGION}

(whose identity is never declared); all suggested the rites celebrated in honor of the god of vegetation, known in different lands by different names-Tammuz, Osiris, Attis, Adonis.

"In these rites the death of the god, and resultant death of vegetation, were mourned with solemn ritual in which women took a prominent part; with his restoration to life fruitfulness was restored to the earth. Not merely did the incidents correspond, but also the object of those incidents; it is a parallel alike of action and intention."

As is pointed out by this interpreter of the Holy Grail, much of the Grail ritual and legend turns around the eucharistic nature of the Grail legend, that is, the eating and drinking of the products of nature as containing the qualities and virtues of the god. In this manner the worshipper takes into his being the virtues and the powers of the god, and he is made godlike, at least for the time. This phase of many of the older cults was taken up by Christianity, and finds a striking expression in the Grail narratives. The slaying of the god of vegetation also connects itself with the crucifixion of Christ and with that which resulted therefrom.

It has been suggested by William A. Nitze, in a paper appearing in the Publications of the Modern Language Association for 1909, under the title of The Fisher King in the Grail Romances, that the Holy Grail had its origin in the Eleusinian Mysteries or in that worship of the productive powers of nature symbolically presented in that dramatic representation of the adventures of the goddesses. He gives a quite elaborate account of the resemblances between the ancient myth and the mediaeval legend. After describing the mysteries at Eleusis, as well as those connected with the worship of Osiris, he carefully interprets the Grail legends. If he does not demonstrate a survival and greatly modified form of the Eleusinia, yet he makes out 


\section{THE SOCIAL EVOLUTION OE, RELIGION}

a very strong case for that conclusion. The resemblances are too numerous and too intimate to be ignored, and make it most probable that in the Holy Grail we have a mediaeval form of the much older vegetation festivals and rituals. The probability is that the survival is from the mysteries of Eleusis rather than from the myth of Adonis, though the two have many very close connections.

"The Holy Grail,", says Nitze, "by the mediaeval romancers often conceived in terms of a quest, is au fond an initiation, the purpose of which is to ensure the life of the vegetation spirit, always in danger of extinction, and to admit the 'qualified' mortal into its mystery. I do not believe we can go far wrong in insisting on both its agrarian and its mystic features. For though both may be present to the same degree in the romances in which the ceremony has been handed down, it is at present difficult to state where the one feature ceases and the other begins. Like the Eleusinia, the Grail rites may have been agrarian and mystic from the start."

Nitze points out that the Fisher King of the Grail legends is the symbol of the creative, fructifying force in nature, especially associated with water or moisture. As a representative of the otherworld, he is the guide to it. The Grail knight, whether Perceval, Bors, Galahad, Gawain, is the initiate. $\mathrm{He}$ must specially qualify in order to become such, and it is he who is responsible for the success of the Grail service. The father of the Fisher King is his double, and stands for the life-god himself. As in the case of Adonis, Dionysos, and Osiris, he lies dead on the bier, with a sword by his side. The Grail, sometimes called the Rich Grail, is essentially the same as the kiste or holy box of the mysteries, and is the receptacle for the divine food, the wafer or the blood, through the partaking of which the mortal comes into communion with the god, and a bloodbond 


\section{THE SOGTAL EVOLUTION OF RELIGION}

is established between them. "Thus it comes naturally to possess talismanic properties," says Nitze, "primarily providing food, but also preserving from disease and decay, distinguishing the faithful from the sinners, and even ensuring victory in battle. This leads by easy stages to its identification in the twelfth century, through the medium of the holy blood legend, with the relic of Calvary, and thence with the cup of the Last Supper." The lance is the instrument of sacrifices, which is vicarious. The lance and the sword have no direct connection with the mysteries, but they have been borrowed from other western legends and myths. The final conclusion at which Nitze has arrived he has stated in these words: "Though the Grail ceremonies and the ancient mysteries have the same leit-motiv, there exists no reason for claiming any direct connection with them. While the fundamental concept of the Fisher King is doubtless a Mediterranean cult, it is quite possible that in the Grail romances it descends in direct line from the primitive Celts in Gaul, Wales, and Ireland. As we have seen, the underlying fact is the identification of Life and Fertility with the creative power of moisture-and this idea is well-nigh universal."

Whether the Grail legend descended more or less directly from the Greek mysteries, or whether it had a more definite origin in Celtic myth, it is evident that the same ideas, the same ritual motives, are to be found in the two. It is impossible, however, to dismiss the conclusion that the mysteries, as ritual romances and legends of initiation, were passed down through the centuries, and reappeared in the legends of the Holy Grail. At first the Grail legends were regarded by the Christian church as pagan and heretic, and were shunned or condemned. So persistent were they, however, that they were slowly Christianized and adopted into the extra faiths of the church. They took on, at last, a distinctly Christian character, and have so been inter- 


\section{THE SOCIAL EVOLUTION OF RELIGION}

preted by all their recent expounders, including their use by Richard Wagner in his music-dramas.

What stands out most emphatically in both the Mysteries and the Grail legends is their slow growth, and their development through many centuries. It cannot be supposed that the Dionysia or the Eleusinia, in their cult or ritual form, and in the form of the myths connected with them, were the products of any one or any number of gifted Greeks. No one has put forth such a theory, but every interpretation of them at least tacitly assumes that they "grew as grows the grass," to use Emerson's word in regard to such creations, which means that they were age-long social developments, the products of the collective genius of the people of the Greek lands.

We cannot suppose that it was otherwise with the Grail legends and romances. We know that these were interpreted by one or another poet or prose narrator; but behind their works appears the more important and more highly creative genius of the legend itself. Although it doubtless had its inciting motives in the great nature-myths and mysteries of the eastern Mediterranean peoples, we cannot for a moment suppose that the Celtic or the Teutonic peoples were less capable of creating myths and mysteries to fit their own conceptions of the world and of life. If the western peoples received traditional hints and stimuli from the Greeks and the others, they were quite competent to produce equally valuable creations, as is seen in the northern sagas, the Nibelungun-lied, and many another ballad or epic production. Their myths, though less highly elaborated, did not attain the same poetical perfection; but this may have been the result of the incoming of Christianity before their full development had had an opportunity of being reached. 


\section{THE SOCIAL EVOLUTION OF RELIGION}

\section{$\mathrm{X}$}

No one has as yet made it quite clear how it is that individual and communal genius succeed in working together or how we are to reconcile personal and collective processes of development. It is the fashion now to assume that all invention, discovery and creation are results of individual talent or genius. A study of the culture-growth of the early ages, and especially those forms of it expressed in the evolution of religion, does not by any means confirm this judgment. Quite the contrary, it nearly compels us to accept the theory of a group mind, a collective soul; and that all true creation comes from the communal activities of mankind.

Most of the great creations of the early world, in the form of myths, hymns, rituals, laws, have no personal names attached to them. This may, of course, be because history had not yet begun; but even after the definite beginnings of writing and history, the situation is much the same. We may be referred to Moses, to Homer, and to Manu; but these names are almost as mythical as the stories contained in the books with which their names are connected. The higher critics in regard to all early literatures, not only religious, but poetical and historical, as well, do not justify us in insisting on the attaching of personal names to the Rig-Veda, to the myths of Babylonia, Syria, Egypt or Greece, or to such poetical collections as the Mahabharata, the Nibelungun-lied, and many another work of the same kind.

It may be that we shall never settle satisfactorily to all persons such problems as these; but we cannot doubt that there was something at work in the early ages by means of which myths, tales, legends, rituals, and religions, were developed on the part of rude peoples, and even by those races which had advanced considerably in culture. We cannot question the fact 


\section{THE SOCIAL EVOLUTION OF RELIGION}

that the myths of Babylonia, Egypt, and Greece, were wonderful creations. We are not disposed to question the fact that the religions of India, Persia, Syria, and Arabia had in them elements of great advancement for the peoples by whom they were created, and by whom they were received as revelations from the gods. If we deny to these peoples the gifts of inspiration and revelation, as the Christian theologians are in the habit of doing, how shall we account for these marvellous productions? In the sheer weight of mental power they manifest they must claim candid consideration as human productions, and our admiration for the loftiness and the greatness of the tales they tell, and the morality they inculcate. It is not enough to say that they were the inventions of priests, as was the custom in the eighteenth century, or that they are mere delusions of the corrupted mind, as is too often the case in our own day. Rejecting the theory that Homer created the Greek myths, as the prodigious result of his personal genius, what shall we say of those mythological creations which have come to us from the world of the ancient Greeks ?

The answer to this query, and to the problem as to the origin of the many religious developments throughout the world in all ages, that many persons have found to be most satisfactory, is that expressed by the conception of a group mind or a collective soul. Behind all individual genius is something greater, more creative, more powerful, more intimately in touch with the sources of life; and this is the collective mind. We may say of all the mythologies and religions we have referred to, that they have grown out of the life of man in his communal relations. The gods of these peoples are reflections of the communities who create them, not merely of their highest personal life, but of their group life. In a word, the gods of the Navaho, as of the Greeks, were intimately and essentially 


\section{THE SOCIAL EVOLUTION OF RELIGION}

reflections of the collective life of these peoples, projected into the earth or into the heavens in the form of the divine beings they worshipped in ritual, and interpreted in myth. The myths recited the doings of the gods, which in minute degree were the doings of these peoples themselves, not, it may be, as their lives were actually lived individually from day to day, but as the community aspired to live, and therefore prayed to their higher selves, as embodied in the rituals and the myths, that they might in future be able to live out their communal existence.

What may impress us in the history of religion, as in the connected and interrelated developments of literature and art, is the greatness and the majesty of the creative power of the communal mind. It may be an extravagant conception to entertain, but one may be more and more impressed, as he comes into more intimate knowledge of the processes by means of which culture and civilization have been gradually developed, with the marvellous inventiveness of man in his collective capacity to create myths, religions, and poems of the highest art. The really creative mind in all ages is the collective mind, though it may always work in harmony with personal genius. What we are to consider is, that the creative mind is still dealing with the problems of religion, and that greater things are yet to break forth from this creative source. What it has done in the past it can accomplish again in the future. It has brought into existence all religions now known to us, and it can create truer and nobler ones in the future.

This leads us to the conclusion that most of the religious inspiration to be found in the history of mankind, and all of the revelation, is of this collective nature. The Sacred Books of the East, as of all other parts of the world, had their origin in the period when the communal life was strong and vigorous. 


\section{THE SOCIAL EVOLUTION OF RELIGION}

While the epics, and many another work having its origin in the creative capacities of the collective mind, cannot be regarded as being possessed of the nature of revelation, yet these books often have the qualities attributed to sacred literature. All works for which a sacred character has been claimed, from the Navaho ritual to the New Testament of the Christians, have on them this character of collective power. They are profoundly emotional, are marked by an elevation of thought, and speak as from a deep subconscious insight into the world beyond the immediate vision of individual man.

In recent years both inspiration and revelation have been referred by many thinkers to the subconscious activities of the mind. This phase of human activity gains greatly in its significance when it is interpreted from the collective, and not merely from the individual, sources as to its origin and nature. Its loftiness of expression, its sublimity of thought, its pro. fundity of emotional insight, all give to such works an impressiveness and a grandeur which bring to them the weight and the worth of an assumed revelation. If they are often trivial, bearing about them the marks of their early origin and their crude views of nature and of human life, as well as much of moral grossness, yet they have a daring assurance in regard to the nature of the supernatural world, and a confident tone with regard to God and immortality, which appeal with convincing power to those who have been educated to accept their sacred character. All of this, without doubt, they owe to their communal origin, to the fact that they are creations of the collective mind.

The question may arise as to whether, with such an origin, these sacred books can be regarded as in any real sense answering to the conception of revelation. In the old sense the reply must be in the negative; but with the modern conception of the 


\section{THE SOCIAL EVOLUTION OF RELIGION}

creative power of collective man, we need not hesitate to answer in the affirmitive. It is no individual judgment, no personal conception of life and its greater meanings, which we have in these works; but something really great and stimulating because of the nature of their origin. In their origin we find their sanction and their worth, their capacity to invigoraate the mind and to satisfy the heart, this origin being that of the social consciousness in all its breadth and might. This is the real meaning of revelation, whatever the claims made by tradition, or in the name of supernatural communication. Such an interpretation of it may take away something of the old dogmatic spirit connected with the idea of a revelation direct from God; but it fits more adequately into the demands of the present day, and gives a fresh meaning to the sacred books of the world. It explains their puerilities, their superstitions and their credulities, as well as their gross moral conceptions. At the same time it explains the relations of the sacred books to the developing culture and civilization of mankind. 


\section{CHAPTER III}

\section{Communal and Tribal Religion}

TWO influences were at work in the origin and early devel1 opments of religion. The first of these is to be found in the nature of man, in the relations of the body and the mind, in the functioning of what we call the objective and the subjective. Probably from the very first man recognized in some crude way this duality of his nature, that the mind functioned in one manner and the body in another. He must have had some dim comprehension that his own inward life was other than that of nature or the world of his environment. From the time that he was able to make any definite use of language he must have had at least a feeble comprehension of this doubleness of his being; but could not apprehend their ultimate unity.

The other influence which worked for the ereation of religion was the communal or gregarious nature of his life as a social being. At no period since man became man has he lived in other than a social world, a world bounded by the limits of a food-group, it may be; but a world in which he was one of a community, a fellowship, a corporate body of friends and relations. It was pertinently said by George Henry Lewes, in the first volume of The Foundations of a Creed, that all attempts to explain mind without taking the social functions into account have been signal failures; and it may be said with equal truth, that any attempt to explain religion without recognizing the social functioning of all human life is doomed 


\section{THE SOCIAL EVOLUTION OF RELIGION}

to miss the mark of sound reasoning on a great subject. Religion is one of the phases of man's sociality, a result of his living invariably as a member of a human community. At first he does not think his own religion, but feels it; it comes to him as an emotional manifestation of the fact of his human fellowship. The fellowship gives him his religion as a child, impresses it upon him, makes it a primary phase of his existence. If we could conceive of him as living apart from a social fellowship, we should also be obliged to think of him as without religion.

Man as having a duality of nature in the form of mind and body, and man as living in a communal fellowship with his kind, these two forces must explain for us the origin of religion, and the earliest phases of its development. However any of its manifestations are given, they are invariably socialized for the primitive man, for the reason that his life is a life of fellowship - a limited fellowship, it is true, but one that creates and dominates his mental being.

\section{I}

The study of the most primitive of existing peoples has led to the conclusion that early man must have thought of all other beings and things in the world as having like nature with himself. In precisely what manner he regarded his own being we do not know, but we surmise that he realized in a faint way that there was in him something not seen, - intangible, subtle, ethereal. These words, of course, he did not know, or what they represent to us; but there came to him a dim perception of what we regard them as representing. He came to this conclusion as the result of his dream experiences, his observations of the shadow, echo, reflection as in water, 


\section{THE SOCIAL EVOLUTION OF RELIGION}

breath, and eye-image. All of these made him think of something in him which is not of the body, and of a shadowy but material nature. When he dreamed he found himself in places distant from where his body was resting, and he met those he knew were not in his immediate vicinity, and even those who had been dead for months or years. To him these experiences in dreams seemed as real as those of the waking life, and he could but conclude that they were of as true a nature. This conclusion was confirmed by his shadow, which followed him almost constantly, especially in regions where sunshine is nearly uninterrupted. The echo suggested that there was some one unseen in his vicinity, who could speak to him or answer his call. Looking in the eyes of his companions he saw there an image of a man, very small, but having all the characteristics of a human being as known to sight. His breath, too, was something on which his life seemed to depend, something unseen, but vital; and suggestive of the same kind of being as that given in the dream-experiences.

Many of the aborigines of North America, it is well known, make use of the dream in determining to which of their several societies they shall belong; and these societies often originate in dream experiences. The dream was announced to the tribe, by means of a performance which indicated its nature; and it allied the dreamer to those who had received similar dreams. Very frequently the dreams related to animals, and those who had dreamed of the same animal belonged-to the society of which this animal was the patron or guardian. The character of such dreams about animals, and the character of the societies which resulted, have been described in a recent bulletin, number 61, of the Bureau of American Ethnology, being Teton Sioux Music, by Frances Densmore.

We are told by Densmore that "the obligation of a dream 


\section{THE SOCIAL EVOLUTION OF RELIGION}

was as binding as the necessity of fulfilling a vow, and disregard of either was said to be punished by the forces of nature, usually by a stroke of lightning." The same writer informs us that many of the songs were produced in dreams, and the oldest songs were thus composed. "This means that they came in a supposedly supernatural manner to the mind of a man who was hoping for such experiences and who had established the mental and physical conditions under which they were believed to occur. In this we have the native concept of what we call 'inspiration.' The Indian isolated himself by going away from the camp, while the white musician or poet locks his door; but both realize the necessity of freedom from distraction. A majority of the songs said to have been thus received by the Indians have a rhythmic and melodic unity which is not always present in songs said to have been 'made up.' "'

This account of the origin of songs and dream-societies among the aborigines of America will aid us in comprehending how religious ideas, institutions and rites may have come into existence in other regions. The dream seems to the primitive man to introduce him into another than the every-day world. In it he seems to come into direct relations with the world of the dead and with an order of experiences which is not only other, but more real, than those of his waking moments. These manifestations of the subconscious take on for him the nature of revelations, in the sense that they introduce him to a world of spirits which is permanent, because he comes to think it subsists before his birth and after his death.

Not only does the dream greatly aid the primitive man in enlarging his religious rites and beliefs; but there can be little doubt that the image affords like constructive aid. If the image-shaping power of the imagination in present-day man had any real counterpart in the experiences of primitive man, 


\section{THE SOCIAL EVOLUTION OF RELIGION}

as was most probably the case, it is quite certain that it afforded a large originative source for the production of spirits, heroes, and gods. The image may be regarded as the wakingdream or the dream may be regarded as a series of images produced in sleep. In some persons the capacity for day-dreams is very great, and many a scene, person, and experience seems by that process to stand out as of the very nature of reality. The imagination pictures another world in such realistic form that it not only seems tangible, but distinctly concrete. Much present-day evidence from ghost-seers, believers in the occult, crystal-gazers, spiritists, and others, makes it certain that the primitive man could see, as it were, fauns and dryads in the woods, spirits in the dark-time of the night, and gods behind the greater phenomena of nature. Not only did the animistic tendency give a basis for such conceptions; but the imaginative mind could see these beings in many a waking experience. He not only believed in them because his animistic conception of the world gave him a reason for their existence; but he actually saw them, even with his own eyes, as he thought.

Not only did the individual create another world in this manner, that seemed to him as real as the world of tangible experiences; but more especially was this gift for image-creation product of the collective capacity for beholding what the senses do not report. Once beheld in this manner such creation enters into tradition, legend or myth, and is retained for many centuries.

If we take into consideration the fact that the primitive man had no science, no accumulated results of observation and experimentation through many thousands of years, we shall recognize the inevitableness of these conclusions, at which he arrived, that he had in his body a something not the same as the body, but intangible and spiritual, and that this something 


\section{THE SOCIAL EVOLUTION OF RELIGION}

could go away and return. When death came the something was no longer in the body, which then became inert, subject to decay. That something must have departed from the body, and had taken its flight, as seemed to be true in dreams, to some other region, though it might remain for a time about its old abode.

Such experiences as these led the primitive man to think that there was in him what we know as the soul, a being other than the body, that could leave the body in dreams, fly away from it at death, and show itself in the breath and in the shadow. This soul, when it had gone away at death, became a ghost, and had its place elsewhere than in the body. Even in the more advanced nations of the ancient world these conceptions survived, and the soul was conceived under the form of breath, as in the ruach of the Hebrews, the pneuma of the Greeks, and the spiritus of the Romans. The breath was that which lived in the body, and gave it animation, gave it working capacity, and gave it power to think and will.

\section{II}

Giving attention to the manner in which the soul acted on the body, and seemed to command it, and to make it subservient to its wishes, it was natural that the primitive man should see a like force or power in the world around him. The soul or breath or pneuma within him made his body move from place to place, accomplish work, and dream of scenes unseen to the waking eye. Whatever in the outward world moved, produced results, led to change and growth, seemed to result from a cause similar to that which acted in himself. Something in himself made him breathe, dream, act and think; and something in the world about made the wind blow, the ocean 


\section{THE SOCIAL EVOLUTION OF RELIGION}

toss up waves and beat against the shore, trees live and grow, the stars move in their courses, and all animals live and breathe like men. What other inference could there be than that there was a soul or spirit in all of these, and that a life was in them similar to that in men?

This primitive conception of the soul in man, and of all other creatures and things as being also possessed of souls, was first described and named by Edward B. Tylor, in the eleventh chapter of his Primitive Culture, published in 1871. He said that so far as we can judge from the immense mass of accessible evidence, the belief in spiritual beings appears among all low races with whom we have attained to thoroughly intimate acquaintance. This belief he called Animism, which he described as "the deep-lying doctrine of spiritual beings, which embodies the very essence of spiritualistic as opposed to materialistic philosophy."

Although Tylor devoted seven chapters to the interpretation of animism, and to the tracing out of its manifestations in all parts of the world, and in all ages, the substance of it he described in these words: "Animism is, in fact, the groundwork of the philosophy of religion, from that of savages up to that of civilized men. And although it may at first sight seem to afford but a bare and meager definition of a minimum of religion, it will be found practically sufficient; for where the root is, the branches will generally be produced. It is habitually found that the theory of animism divides into two great dogmas, forming parts of one consistent doctrine; first, concerning souls of individual creatures, capable of continued existence after the death or destruction of the body; second, concerning other spirits, upward to the rank of powerful deities. Spiritual beings are held to affect or control the events of the material world, and man's life here and here- 


\section{THE SOCIAL EVOLUTION OF RELIGION}

after; and it being considered that they hold intercourse with men, and receive pleasure or displeasure from human actions, the belief in their existence leads naturally, and it might almost be said inevitably, sooner or later to active reverence and propitiation. Thus animism, in its full development, includes the belief in souls and in a future state, in controlling deities and subordinate spirits, these doctrines practically resulting in some kind of active worship."

This interpretation of the origin of religion, which Tylor defines, in a minimum form, as the belief in spiritual beings, has been very generally accepted by the students of origins. Some investigators, however, think it is of too advanced a nature, and that it assumes for the earliest men a degree of mental development which could not have been theirs. Some of these more recent inquiries, as $R$. R. Marett, in The Threshold of Religion, are of the opinion that there was a preanimistic type of belief, when the primitive man merely thought that all things around him were animated. This conception of animatism, or that all things and beings are alive as man is alive, may be regarded as an early form of animism, and not to differ from it, except as an early stage in any development is ruder than the more advanced ones. This type of animism has been defined by W. H. Hudson in his reminiscences of his boyhood, entitled Far Away and Long Ago, as "the tendency or impulse or instinct, in which all myth originates, to animate all things; the projection of ourselves into nature; the sense and apprehension of an intelligence like our own but more powerful in all visible things." He describes certain boyhood experiences as of the nature of animism, and he is of the opinion that many children pass through a period of mental experiences similar to those of the primitive man. He says that what he was taught in regard to religion did not 


\section{THE SOCIAL EVOLUTION OF RELIGION}

touch his heart "as it was touched and thrilled by something nearer, more intimate, in nature, not only in moonlit trees or in a flower or serpent, but, in certain exquisite moments and moods and in certain aspects of nature, in 'every grass' and in all things, animate and inanimate."

In his book on The Idea of the Soul, A. E. Crawley assumes that he has proven that the doctrine of animism is false, and that he has displaced it by a truer interpretation of the phenomena described by Tylor. Most investigators, however, hold fast to the conclusions of Tylor, and find his theory sound as an interpretation of the facts. In his book on Body and Mind, William MeDougall claims that animism is not only true, but that it may be traced through the whole of the history of religion down to our own time, and that it remains, even now, the truest account of the relations of the mind to the physical organism. To whatever extent the definition given by Tylor to animism, has been modified by subsequent investigations, his conclusions have stood so far uninpregnable as defining the religion of early man, and as a sound explanation of many of the phenomena presented by the history of religion even to our own day.

It is not to be supposed that dreams, shadows, echoes, the breath or reflections can give the whole substance of religion, even to the primitive man. Though animism, preceded by animatism, as in large degree growing out of these phases of human experience, interprets the primary nature of religion, there are many other experiences which enlarge and justify the animistic conception. These include all phases of experience which are abnormal, pathological or of an unusual nature. Widely over the world stimulants and narcotics are made use of to bring on conditions of ecstacy or highly exalted states of the mind. Insanity, epilepsy, and the hypnotic state, are ac- 


\section{THE SOCIAL EVOLUTION OF RELIGION}

cepted in the same manner. The insane or idiotic person is regarded as possessed, not merely of some unusual power, but as being the possessor of powers of a spiritual or super-natural nature. Twins are looked upon as uncanny and abnormal, and one or both of them, in some tribes, is made a medicine-man or a priest.

Powerful agents in the development of early religions are all forms of trance and the hypnotic state, hysteria, unconsciousness, hallucinations, clairvoyance, apparitions of the dead, telepathy, and the exercise of the imagination. In one or another degree all of these manifestations are to be found among primitive men, and they give sanction to the idea of the soul and its powers. Children amuse themselves with finding in the burning wood or coal of an open fire, images of animals or persons; and they may exercise the same gift in seeing in cloud or water shapes that seem to resemble one or another object. Without doubt the primitive man saw such shapes in the same places, and in many others. He differed from the children of today, in that these shapes were to him real. What he thus saw he regarded as justifying his belief in spiritual beings as manifested in all the phenomena of nature. Especially was this gift for discovering something supernatural in his environment made effective, and largely increased in its certainty and impressiveness, by the communal or contagious character of these experiences. It has been shown again and again that large numbers of persons, whole clans or tribes, will see apparitions or hear music or oral communications, which have no existence save in the imagination. This power of collective suggestion is one that frequently manifests itself, and gives assured sanction to the beliefs on which these experiences rest for their basis of interpretation. 


\section{THE SOCIAL EVOLUTION OF RELIGION}

It has been shown that auto-suggestion is an effective means of convincing the seer and prophet of the validity of their beliefs; but when we find communal-suggestion at work we have the force that is more powerful, perhaps, than any other in leading to one or another phase of religious development. Psychologists are not as yet agreed as to the nature of subconscious mental action or how it is that it manifests itself in mysticism, the feeling of divine presences, demoniac possession, and many another phase of religious manifestation. Many means have been employed in bringing about experiences of this nature, such as crystal-gazing or any fixture of sight for prolonged periods on single objects; fasting, solitude, repetition of single chords or rhythmic expressions - these, and many other, aids have been employed in bringing about ecstacy, rhapsody, trance, and spiritual intoxication. Most effective of all these aids to supernatural insight or experiences is the contagion of communal action in ritual or other collective manifestations of religious belief.

Another of the aids to growth in spiritual attitudes of mind amongst primitive peoples is nervous instability. The people of Siberia are in a large measure susceptible to any form of excitement, and are in a remarkable degree given to what we call "superstitions." Any sudden noise or unusual sight will throw them into a hypnotic state, when they lose consciousness or manifest symptoms of delusion or even of a state bordering on insanity. Persons thus highly susceptible become shamans and deal in magic, or priests and lead the religion of a community.

Of a higher type is that phase of religious expression growing out of the use of language, and the recognition that it represents something not material, but intangible and spiritual. In many parts of the world words seem to be regarded 


\section{THE SOCIAL EVOLUTION OF RELIGION}

as having something uncanny and mysterious about them, and they are accepted as in some way related to the soul, and perhaps as themselves of a spiritual nature. At least, many peoples are not willing to reveal their names, change the name of a child after initiation or refuse to give the secret name of the spiritual beings they reverence or the gods they worship. It is often thought that to possess the name of a person is to possess power over him, and to become the ruler of his destinies. The curse is greatly dreaded, and it is assumed to have a mystic and powerful influence over the one against whom the curse is spoken. The word is often almost regarded as a definite spiritual being in itself. The idea, as in the philosophy of Plato, is thought to be something real, the most definite thing there is. In higher types of religion the word of God becomes as God himself. We read that in the beginning was the Word, which was but God in another form.

All of these types of religious manifestation seem to grow out of animism. It may be desirable, therefore, to return briefly to that mode of expression of the mind in its individual and collective activities, and inquire somewhat more specifically as to its nature. Alice Fletcher, writing in the Handbook of American Indians, says of the Omaha, one of the Siouan tribes, that to them nothing is without life; the rock lives, so do the clouds, the tree, the animal. The Omaha, she adds, "projects his own consciousness upon all things, and ascribes to them experiences and characteristics with which he is familiar; there is to him something in common between all creatures and all natural forms, a something which brings them into existence and holds them intact; this something he conceives of as akin to his own conscious being." The Omaha calls this power Wakonda, and to him it implies intelligence as well as power. This concept is vague, and it has in it an element of the myster- 


\section{THE SOCIAL EVOLUTION OF RELIGION}

ious, the incomprehensible; and spiritual strength as well. Whatever is unusual is wakonda, as well as whatever is a manifestation of mind or will. Wakonda is invisible, says Fletcher, and therefore allied to the idea of spirit. Objects seen in dreams or visions partake of the idea or nature of spirit, and when these objects speak to man in answer to his entreaty, the act is possible because of the power of wakonda, and the object, be it thunder-cloud, animal, or bird, seen and heard by the dreamer, may be spoken of by him as wakonda. Though it is extremely difficult to define wakonda, as it is to define animism, there can be no doubt that the power exerted over the individual and the group is very great, and that it makes for the development of religion.

On the other side of the world, in Melanesia, wakonda appears under the name of mana, though it has much the same characteristics, and is but another phase of what Tylor called animism. R. H. Codrington, in his book on The Melanesians, defines mana as everything that is beyond the ordinary power of man. The Melanesian mind is entirely possessed by the belief in a supernatural power or influence, and this is what he names as mana. It is, we read in the pages of Codrington, "present in the atmosphere of life, attaches itself to persons and to things, and is manifested by results which can only be ascribed to its operation." This power, although it is impersonal, is always active through persons, who direct it. It is a part of the life of the soul, and it is manifested by all spirits. Some persons are full of mana, such as kings, and those who have special religious gifts. The Melanesians believe in beings who have a great deal of mana, but are personal and intelligent, though of a higher nature than men. These beings are of the nature of spirits, but are of another character than ghosts, who are the disembodied human beings who are able to return after death. 


\section{THE SOCIAL EVOLUTION OF RELIGION}

These spirits are invoked, and their aid is sought. The ghosts are also supposed to possess mana, but not to so large an extent, and are therefore not regarded as in the same degree powerful.

Mana or wakonda is found in some form as accepted by nearly all primitive peoples. Each language has its own name for it, but the thing itself, though it varies considerably in its manifestations, is fundamentally the same everywhere. The Iroquois called it orenda, the Algonkins manitou, the Shoshoni pokunt, the Salish sulia, and in Mexico it was called nagual. In Fiji the name is kalou, among the Dyaks of Borneo semungat, while the Malagasy of Madagascar called it andriamanitra. In Africa the Masia called it nyai, the Bafiote of the lower Congo named it lunyensu, and the Boloki of the upper Congo described it as likundu. The idea embodied in these names was by no means absent from the higher peoples, and the Greeks knew it as teras. What was thus expressed, as has been suggested, has many resemblances to the Christian idea of the Holy Ghost, which has been often regarded as impersonal, and as a pervading, mysterious, and subtle communication of the life of God to the believer. Such, in no small degree, was the mana of the Melanesian and the manitou of the Indian of America.

In the Handbook of American Indians, Alice Fletcher describes the Iroquois conception of orenda as "a fictive force, principle, or magic power which was assumed by the inchoate reasoning of primitive man to be inherent in every body and being of nature and in every personified attribute, property, or activity, belonging to each of these and conceived to be the active cause or force, or dynamic energy, involved in every operation cr phenomenon of nature, in any manner affecting or controlling the welfare of man. This hypothetic principle was conceived to be immaterial, occult, impersonal, mysterious in mode of action, limited in function and efficiency, and not at all 


\section{THE SOCIAL EVOLUTION OF RELIGION}

omnipotent, local and not omnipresent, and ever embodied or immanent in some object, although it was believed that it could be transferred, attracted, acquired, increased, suppressed, or enthralled by the orenda of occult ritualistic formulas endowed with more potency."

Such was the nature of orenda, wakonda, mana, or whatever the name by which this potent force was designated. To comprehend fully the significance of this force this additional statement by Fletcher must be taken into consideration: "As all the bodies of the environment of primitive man were regarded by him as endowed with life, mind, and volition, he inferred that his relations with these environing objects were directly dependent on the caprice of these beings. So to obtain his needs man must gain the goodwill of each one of a thousand controlling minds by prayer, sacrifice, some acceptable offering, or propitiatory act, in order to influence the exercise in his behalf of the orenda or magic power which he believed was controlled by the particular being invoked. Thus it came that the possession of orenda or magic power is the distinctive characteristic of all the gods, and these gods in earlier times were all the bodies and beings of nature in any manner affecting the weal or woe of man. So the primitive man interpreted the activities of nature to be due to the struggle of one orenda against another, put forth by the beings or bodies of the environment, the former possessing orenda and the latter life, mind, and orenda only by virtue of his own imputation of these things to lifeless objects."

It is important to recognize the universality of this conception of mana or orenda amongst primitive peoples, and that it is at the basis of the first forms of religion of which we have any knowledge. This fact is stated by Franz Boas in the same work, in treating of religion, when he says that the fundamental concept of the religious life is "the belief in the existence of 


\section{THE SOCIAL EVOLUTION OF RELIGION}

magic power, which may influence the life of man, and which in turn may be influenced by human activity." This recognition is all the more important because it is from this potent magic force that there is developed the idea of the soul, spirit, and God. The very foundations of religion, therefore, are to be found in this conception of mana, in so far as it manifests itself in the life and thought of primitive man.

\section{III}

Even with primitive man, as he presents himself to us in various parts of the world to-day, religion is not confined to magic, mana, or any other single and limited manifestation. It takes on many forms, and one of them, known to the Melanesians as tabu or tapu (in English taboo), is intimately connected with mana. The fundamental idea of tabu is of things sacred, and also of things impure or unclean. To the primitive man these two phases of tabu are nearly alike, the uncleanness being intimately related to the sacredness. That which is tabu is that which is forbidden; the child being taught in its earliest years that certain things and acts are an abomination, not to be touched, seen or eaten. The reason for this is that these objects are the abode or the manifestation of a ghost or spirit, in whose name, or in reliance on whom, it is pronounced; the tabu being a prohibition with a curse implied in it or expressed by means of it. In Melanesia the ghost is known as tarunga, but a spirit is a tindalo. The ghost may belong to animals as well as man, but the spirit or tindalo is that of man and not that of animals. A tindalo that is connected with superhuman power and intelligence is, in one of the islands, at least, known as vui. Evidently, the spirits and the vui are on the way to becoming gods; and it is from these that the higher powers are developed. 


\section{THE SOCIAL EVOLUTION OF RELIGION}

In all these conceptions the will, or the functioning power in man, that by means of which he accomplishes results and becomes a creator according to his own gifts, being regarded also as belonging to all objects, plants, animals, and whatever else is in man's environment, acquires for the primitive man a magical, spiritual and sacred character. What is thus set apart by special gifts becomes either unclean, not to be touched or handled or it becomes sacred, to be propitiated, reverenced, and it may be, worshipped. In defining the soul, in the Handbook of American Indians, Boas says it has been developed out of the concept of the power of acting as resident in the body, the concept of subjective feelings connected with imagery, and the concept of objective impressions developed from memory images. To these must be added the conception of will power, accepted as being in some manner dissociated from the physical activities of the body. When these concepts are associated with the greater phenomena of nature, such as the sun, mountains, the ocean or the earth itself, there appear great and powerful spirits, far above man, whom we know as gods.

If a man after death, or even before, in some instances, has a large measure of mana, and ability to make things or persons tabu, he is regarded as sacred. In a degree he becomes a god. If these same powers are found in any other being or object, these, too, become gods in one or another degree, in proportion to their mana. Every being and object possessing un. canny, unusual or conspicuous qualities is regarded as possessed in large measure of mana, and is therefore a god. Most interpreters of early religions find these qualities of godlikeness in what is vast among the great phenomena of nature, and emphasize the god-qualities of the sun, moon, sky, ocean, mountains, thunder, and similar objects. Without doubt these more majestic and conspicuous natural phenomena are regarded as gods, 


\section{THE SOCIAL EVOLUTION OF RELIGION}

even by primitive men; but the full development of such god appears to come later, and are not assigned their highest manifestations in the earliest periods. Really primitive man prefers to see what is powerful and godlike in what is nearer and more familiar.

A venerable Indian one day said to Alice Fletcher: "The tree is like a human being, for it has life and grows, so we pray to it and put offerings on it, that the mysterious power may help us." The tree has wakonda or mana, and it can give of its power to those who approach it in the right manner, that suggested by this Indian. In all parts of the world trees have been venerated as sacred, as being possessed of magical or sacred qualities, or as being the abode of a spirit or god. In his recently published lectures, entitled The Ascent of Olympus, Rendel Harris has shown that Dionysus may have been, in his beginnings, nothing else than the ivy; Apollo the apple-tree and the mistletoe which grows on it, and Aphrodite to have been the mandrake or love-apple. Classical students are very likely to dispute these theories, but Harris gives much evidence in favor of them. At any rate, it is evident that all kinds of trees, plants and vegetables were regarded, in one time and place or another, as possessed of mana and the gift of tabu.

Why should plants be regarded as possessed of souls, to be the abode of spirits or to be in some manner the manifestations of godlike powers? It is because they possess mana, and mana means that they serve the purposes of man. Probably they are revered primarily because they furnish food, and man finds himself dependent on them for the sustenance of his life. Having mana, when they are eaten, that mana enters into those who partake of them, and it is communicated to those who eat. Here we have the primary form of all those communal sacraments when man partakes of plants or their juices as giving 


\section{THE SOCIAL EVOLUTION OF RELIGION}

him mana, that is, its power. Often it is thought that no such access of power is secured by the ordinary partaking of vegetables, fruits or other forms of plant-life; but when these are eaten or partaken of by the community in a festival especially established for the purpose, not only is the individual who partakes made stronger, but the whole fellowship is brought into intimate relations with the mana in the food eaten or the juices drunk.

\section{IV}

The complete development of this phase of man's relations to the vegetable world comes at a later stage in the progress of culture; and we may now turn aside to consider another expression of the same power of mana or wakonda. Strange as it may seem to us of to-day, there can be little doubt that man's contact with the animal world came into play at a very early period in his history as shaping the outward manifestations of religion. Reverence for and worship of animals appears in some form in connection with every religion, from the lowest to the highest. The only adequate study of this subject is that by Northcote W. Thomas, which appears in the first volume of the Encyclopædia of Religion and Ethics. He shows that all the qualities possessed by man are attributed to animals, that animals are but men clothed in another form, and that there is something uncanny, miraculous, magical, and even supernatural, possessed by them.

The distinction between men and animals is not recognized by early peoples, evidently because they possess many of man's abilities, can think, act from motives, express their desires, and make use of a slyness, a cunning, a subtlety of will-power which man envies and respects. Early men attribute the power of speech to animals, and they assign to them a reasoning power far beyond their own. When they will, the animals can cast 


\section{THE SOCIAL EVOLUTION OF RELIGION}

off their animal form, as a snake its skin, and appear as what they are, human beings in disguise. Not only may they transform themselves into human beings, but men may assume the animal form; and these races or orders may intermarry, live happily with each other, and bear children partly animal and partly human. Many religions, and more especially Brahmanism and Buddhism among those of the higher races, believe that men may be transformed after death into animals, in order that their karma, or force resulting from conduct, may be worked out to its legitimate conclusions. Many primitive peoples accept this view of the relations of men and animals, and hold that men may be born as animals and animals as men, in order to work out the expiatory results required in securing moral advancement and growth. In every religion of the ancient world there were animal gods, as Hanuman, the monkey-god of the Hindus; and Sebek, the crocodile-god of the Egyptians. Even a god of the high type of Zeus appears as a horse in one of his many transformations, and as other animals in the pursuit of his amours or in order to disguise himself. This undoubtedly means that he was either originally one or the other of these animals or that he had taken over the attributes of these animalgods in the regions where his worship had been established.

Animals hold a very large place in the early mythologies. They appear as bearers of the earth on their backs, as in the Hindu conception of the tortoise or the elephant. These supporting animals may cause the earth to quake when they turn over or move in order to secure a more restful position. An animal may watch over the entrance to the other world, as in the instance of Cerbebus, the three-headed dog who protects the way of entrance to the lower world of the Greeks. The animal has magical powers, as we have seen; and it is this gift which attaches him to witches, and makes the cat the inevitable com- 


\section{THE SOCIAL EVOLUTION OF RELIGION}

panion of the European witch. Wherever we find the wizard or the witch, we find his or her familiar, an animal into which these beings may be transformed. If the animal is wounded, the witch is wounded in the same manner. The werewolf is a familiar object in European folk-lore, and may be found in nearly every part of the world. This belief, it has been assumed, has quite died out; but here is a book on Werewolves, by Elliott O'Donnell, published in London by Methuen, in 1912, which assures us that such creatures really exist, and may be found at the present day by those who know how to seek for them. He assumes that these creatures are emanations from the dead or phantasms of those who have been of a cruel, savage and treacherous nature.

Again, it is in some tribes assumed that the life of a child is bound up with that of some animal, that its life-index or power of life, has been located in an animal, and that as the animal prospers, suffers or dies, such will be the fate of the human being. Some animals have a great power of fascination, and they will charm birds to their destruction, and even human beings are not able to resist this power in the serpent. The snake and the serpent are regarded with awe everywhere, partly because of their manner of movement, and partly because they are to be found often about graves and cemeteries, leading to the conclusion that the dead have taken up their abode in these creatures.

One of the most remarkable phases of this regard for animals is the acceptance of one or another of them as the creator. The northern Algonkins gave this place to the Great Hare (or rabbit), while the Tlingit of the northwest coast of Canada attribute it to the raven. These and other peoples do not suppose that the ordinary rabbit or raven is capable of creating the world or of accomplishing any other unusual task. All the 


\section{THE SOCIAL EVOLUTION OF RELIGION}

peoples who attribute supernatural powers to animals regard the actual animal they hunt as no more than a mere type of that greater animal which takes the same form, but is, as it were, the comprehensive phase of all the animals of the given species. This supreme or supernatural raven exists in the heavens as a great and powerful being, full of magic, a supernatural foree, of which the ordinary animal is but a mere resemblance or manifestation. It is this great animal, this quintessence of the powers of all the members of the species, which is the creator, the being full of magical power, a vast reservoir of orenda.

One other form of the reverence for and worship of animals must be considered. This is what is called totemism, which, in some respects, is the earliest form of what has become known as the doctrine of spirits, in this instance being animals, and not dead ancestors. It may take the form of an animal guardian for the individual, but much more widely it is that of a guardian, protector or ancestor of a communal group. Andrew Lang, in the Encyclopædia Brittanica, says that the totem "denotes the object, generally of a natural species, animal or vegetable, but occasionally rain, clouds, star, wind, which gives its name to a kindred actual or supposed, among many savage and barbaric races in America, Africa, Australia, Asia and the isles. Each child, male or female, inherits this name, either from its mother (female descent) or from its father (male descent). Between each person and his or her name-giving object, a certain mystic rapport is supposed to exist." In some tribes the individual is supposed to have as his first ancestor this particular animal which is the totem, and some tale is told of the manner in which the descent began. At the same time, the whole of the group or chan taking the totem name, and owing descent to the anima? represents, is descended 


\section{THE SOCIAL EVOLUTION OF RELIGION}

from this totem, which is its guardian and protector, as well as the source from which it originated. In some instances this animal is regarded almost as a deity, though this is not often the case.

In four large volumes, of a total of more than two thousand pages, under the title of Totemism and Exogamy, J. G. Frazer has dealt with every phase of this subject. He shows that totemism is not universal, that it is confined to certain regions and countries, and that it is not to be found in any of the higher stages of civilization. Frazer finds totemism in Australia, New Guinea, Melanesia, Polynesia, Indonesia, India, Africa and America. Outside the aborigines of these regions totemism does not exist, except in some possible survivals here and there.

Frazer's definition of totemism is that it "is an intimate relation which is supposed to exist between a group of kindred people on the one side and a species of natural or artificial objects on the other side, which objects are called the totems of the human group. To this general definition, which probably applies to all purely totemic peoples, it should be added that the species or thing which constitute a totem is far oftener natural than artificial, and that amongst the natural species which are reckoned totems the great majority are either animals or plants." The origin of totemism is found in ignorance, on the part of such peoples as the natives of Australia, as to the causes of childbirth, it being assumed by them that the child comes to the mother from some ancestral center, where the ghosts of the dead are waiting to be reincarnated again in human form.

With much trepidation one may differ from an investigator of such vast knowledge and ample resources for sociological interpretation as J. G. Frazer; but the nature of totemism would suggest that it has its origin in animism, and in the reverence paid to animals b peoples who have any of them 


\section{THE SOCIAL EVOLUTION OF RELIGION}

living in their immediate environment. Totemism is to be found only in regions peopled by backward races; but reverence for animals is found everywhere, on the part of primitive peoples, and on the part of those the most highly civilized. It seems probable, if it may not be regarded as certain, that totemism had its origin in the animistic manner of regarding animals and to a lesser degree plants, as possessing powers similar to those possessed by man, and as having magical gifts far surpassing any that man possesses.

This means that totemism is merely a phase of the reverence for animals; but its special characteristics are developed when a tribe reaches a stage of social organization demanding some means of designating groups, clans or gentes, not only for the purpose of distinguishing them from each other as a flag distinguishes a nation; but also for the purpose of definitely indicating those who may marry and those who may not marry. Where totemism exists it is a practically universal rule that those of the same totem shall not marry, as that a bear shall not unite with a bear or a fox with a fox. This rule, called that of exogamy, means that a bear may marry a fox or some one of another clan within the tribe. Generally, but not invariably, totemism and exogamy accompany each other. Evidently, therefore, the reverence for animals, and the idea of the animal origin of groups, is made use of, at a certain stage of social development, in order to designate those who belong to a group, and those who may marry.

Frazer is of the opinion that totemism has no definite connection with religion, and in this he is probably right. However, the reverence for animals, in which totemism has its origin, has an intimate relation with the early forms of religion, and even with those which are highly advanced. Thomas says that animal worship covers facts ranging from the worship of 


\section{THE SOCIAL EVOLUTION OF RELIGION}

the real divine animal, commonly conceived as a 'god-body,' at one end of the scale, to respect for the bones of a slain animal or even the use of a respectable name for the living animal at the other end. Certain animals are regarded as sacred, either as individuals or as a total species. What particular form the worship shall take, or what shall be the nature of the cult devoted to the animal or animals worshipped, is determined by the nature of the society worshipping or the nature of the animals worshipped. Pastoral and hunting tribes reverence animals in ways peculiar to their social development or their manner of securing food, that is, the character of their chief industry. Dangerous animals are regarded in a manner quite different from those which have been domesticated, and have become permanently serviceable to man.

Another phase of the reverence for animals is to be found in the respect paid to them when they are killed for purposes of food. The good-will of the slaughtered animals is sought, and methods of propitiation are made use of to this end. Animals are offered in sacrifice to the dead, and not wholly used for the benefit of the living. It is assumed that the dead depend on food as when they were living, and suitable food must be provided for them after they have entered the other world. To this end, when the dead are buried, food is placed in the grave, that the ghost may be sustained, at least for a time. Food may be placed on the grave at regular intervals for the same purpose. When the food is found where it was placed, it is said that the ghost consumes only the aroma, the spiritual substance of the food, and that its material part remains. The worshipper may consume this remainder, and he may eat of a communal meal on the grave, sharing the food with the ghost, and even with the higher powers who may desire to partake of this sustenance. 


\section{THE SOCIAL EVOLUTION OF RELIGION}

Very crude are these means of communication with the dead, and these helps in providing for their wants. When a man is placed in the grave, if he has been a warrior, his horse, weapons, and accontrements are buried with him, on the supposition that he will need them, and use them, in the ghostland to which he goes. Assuming also that he will not wish to be companionless there, and that he will especially desire the presence of his wife or wives, one or more of them are buried with him either alive or slain, that they may accompany him on his far journey. Since he is a chieftan, and will need attendants, one or more of his slaves are required to accompany him into the other world.

Here we have the primary origin of sacrifice, in the providing of the dead with the food and the services which they will hereafter require. The continued offering of food and other gifts on the grave grows from stage to stage into the providing of similar services to the spirits and then to the gods. Since the gods at first are either deified men or beings having the same physical needs, food is brought to them regularly, and such other means of sustenance as it may be thought they will require, in order to the recuperation of their powers as beings of mana or orenda. This is a very crude and materialistic phase of the development of sacrifice, but there can be no doubt that its savage beginnings are in customs as crude as these. A lowly origin of this kind does not detract from the higher developments which come in time; but the recognition of them enables us to comprehend how customs of this nature originate.

IV

Having passed in brief review the psychological causes leading to the development of religion, as well as its successive stages of animatism, animism, animal reverence and worship, totemism, nature-worship, mana, tabu, and sacrifice, we are now 


\section{THE SOCIAL EVOLUTION OF RELIGION}

prepared to consider its organized forms in the attempt to control the forces in the environing world of man. The first of these is known as shamanism, which is but another form of magic, though magic definitely used for human purposes. The shaman is often known as a medicine-man, and this name describes one of his chief functions. In the cure of disease the medicine-man makes use of magic to overcome malign influences working against the patient; and he employs prayer to the benign spiritual powers, in order to secure a recovery of health. To the same end, rituals, which develop potent orenda, are made ase of frequently in the more advanced phases of the career of the medicine-man.

The great center of what is known as shamanism is to be found in Siberia, and it is indeed from that region the name has come to us, though it is of European origin, but as applied to conditions existing in the north of Asia. The most elaborate account of this form of religion is to be found in the work on Aboriginal Siberia, by M. A. Czaplicka, which summarizes the information contained in numerous Russian volumes. This author attributes shamanism in no small degree to the climatic conditions existing in Siberia, with its intense cold, prolonged absence of the sun, fierce snow-and wind-storms, and the hunger which often results from these conditions. These conditions bring on hysteria, resulting in paroxysms of nervous strain, and in intense excitement and complete collapse. The peoples of northern Siberia are extremely susceptible to nervous excitement, and unusual noise, prolonged drumming, fasting, or other similar cause, throwing them into conditions of hysteria or prolonged sleep. Under these circumstances they acquire their magical powers, and feel a call to the magician's or shaman's career. On this subject Czaplicka says, quoting two or three Russian investigators: "To the believer the acceptance of the 


\section{THE SOCIAL EVOLUTION OF RELIGION}

call means accepting several spirits, or at least one, as protectors, by which means the shaman enters into communication with the whole spirit world. The shamanistic call manifests itself through some animal, plant, or other natural object, which the person comes upon at the right time, i. e. when very young, often in the critical period between childhood and maturity (or else when a person more advanced in age is afflicted with mental or physical troubles). Sometimes it is an inner voice, which bids the person enter into intercourse with the spirits. If the person is dilatory in obeying, the calling spirit soon appears in some outward visible shape, and communicates the call in a more explicit way."

Among the more northern tribes of Siberia shamanism is largely limited in its operations to the family, any member of which may exercise its functions in behalf of the family group. In this region there is no special class of persons devoted to this calling, and it is open to anyone to exercise it. Professional shamanism is only in its infancy; but in the more southerly region it has become a stated and definite profession. It is in this region that the shaman is not only called, but he is trained by other shamans for the exercise of his functions. The shaman believes himself inspired, and he uses the drum, with its monotonous beat, accompanied with song, in order to work himself into that hypnotic or ecstatic attitude of mental excitement in which he is able to exercise the functions of his calling. $\mathrm{He}$ uses many devices for impressing his audience, and for giving them confidence in his powers. The medicine-man of aboriginal America resorts to many tricks, sleight-of-hand performances, forms of jugglery, in order to inspire confidence that he is able to bring about the results he assures his hearers or patients he is capable of as one inspired. 


\section{THE SOCIAL EVOLUTION OF RELIGION}

There can be no doubt, however, that the shaman believes in his wonderful gifts; and, though he may use deception to make an impression, not one whit the less is he assured that he is in direct communication with the spirits, and that they give him the powers he possesses. His attacks of hysteria, his periods of unconsciousness, his dreams and his visions, his ability to bring about auto-suggestion, and his telepathic power, it may be, all combine to give him the utmost confidence in his inspiration by the spirits. In fact, he regards himself as one in immediate communication with the spirit-world; and the means to this end are those which have been enumerated.

Shamanism and magic are by no means confined to Siberia, but may be found in all the northern regions of Asia and Europe, as has been shown by Domenico Comparetti in his work on The Traditional Poetry of the Finns, and by John Abercromby in The Pre- and Proto-historic Finns, both Eastern and Western, with the Magic Songs of the West Finns. All the Ugro-Finnic peoples are shamanists, including the Lapps, Siryanians, Votyaks, Cheremisians, Mordvinians, Voguls, Ostyaks, and others. The Finns were also shamanists, and they did not wholly discard this practice when they became Christians. A large degree of faith in magic continues to exist in the religion of Russia.

According to Comparetti, shamanism in these northern regions "differs from other religions in this: that, in addition to prayer and sacrifice, it believes in the coercive influence which man or some specially endowed men (shamans) exercise by means of acts, by secret operations, or by words, over nature or over the divine or demonic beings which represent and rule nature. Magic, therefore, which in other religions is outside religion and contrary to its spirit, being despised as superstition or condemned as impiety, is in shamanism the very essence of religion; what we shall call the magic word is in it no less 


\section{THE SOCIAL EVOLUTION OF RELIGION}

legitimate, lofty and noble than are the hymn and the prayer in any other religion. The shaman is more than a simple priest, he is the seer, he is the medicine-man, he is wise and powerful above all others and is capable of miraculous actions. With his action and his word he dominates things and men and animals and spirits; he cures ills or prevents them; he can propitiate superior beings and obtain benefits; can ensure good luck for the hunt, the fishing, the journey; can raise winds and storms and clouds and fogs and tempests, and can lay them, scatter them, disperse them; he can transform himself and others; he can rise in spirit into the realms of air, go down into those of the dead and carry off their secret."

These shamanistic powers, in one degree or another, are to be found in connection with all the early phases of religion and in every part of the world. They are often found in survival into quite advanced phases of civilization, and it is by no means certain that they have wholly disappeared from those religions which are the most advanced. Nor are they to be found only in connection with religion and the art of healing. The northern peoples of Europe, and those of other regions also, saw something magical and shamaristic in song and poetry, music and the dance. Their runes, their ballads, and especially their epic poems, often acquired qualities which were divine. Inspiration in any form or in regard to any art was of a supernatural character, the result of the incoming of some god into the soul of the singer, poet, or musician. The Greeks regarded love in this manner, and thought of its excitements, its absorption in infatuation for one person, its forgetfulness for all else than its own object, as manifestations of a demoniacal presence. Infatuation, excitement, ecstacy, absorption in one object or interest, was accepted as of this nature, and was regarded as 


\section{THE SOCIAL EVOLUTION OF RELIGION}

proof that something divine had entered into the individual showing any of these symptoms.

Conclusive proof has now been afforded for the origin of the aborigines of America in the northeast of Asia, and it is not therefore surprising that they have developed many of the characteristic features of Siberian shamanism. This proof comes in considerable measure from the investigations of Ales Hrdlicka, who says of the American medicine-men and women, that they make use of magic prayers, songs, exhortation, suggestion, ceremonies, fetishes, and certain specific and mechanical processes. He adds that these persons were regarded as the possessors of supernatural powers that enabled them to recognize, antagonize, or cure diseases. They might make use of herbs or the sweat-bath, or the manipulation of parts, or other natural curative means; but their real power was that obtained through magic, that is, the compelling of the forces of the spiritual world to accomplish that which they desired to bring about for the benefit of the sick.

The shaman, magician or medicine-man made use of magic, which may be best described as mana or orenda; and he exercised his gifts largely for the benefit of individuals. While his power was accepted by his group, and its members made use of it in their behalf, he did not acquire it from his fellows or through their direct sanctioning of his gifts. He was called of the spirits, in a word, his power was individual, and exercised for the benefit of individuals. It might also be used to injure others, or only for the benefit of the individual making use of it.

Shamanism may be regarded as a development of the social conditions existing before social organization had advanced to the clearly defined clan and tribe. The climatic conditions in Siberia made it impossible that any considerable number of persons should be banded together in one group, the food-supply 


\section{THE SOCIAL EVOLUTION OF RELIGION}

forbidding that degree of social advance. The same conditions existed in the northern regions of America, among the Dené and the Algonkins. These tribes were hunters, roamed over considerable regions, were without any definite tribal organization, and were governed by a head-man or chief. They were grouped into bands rather than organized into tribes, which might increase or decrease according to the popularity of a chief or the opportunities for securing food. It is such peoples who develop shamanism, though it may extend, through survival, among much more advanced peoples. Even into medieval Europe it continued as a social force of no small importance, and was then known as black magic if it was used for individual evil purposes, and as white magic if it did not antagonize religion, and was beneficently employed.

The shaman heals the sick, foretells the future, and controls the spirits; but it is the priest who functions as the leader in the rituals of religion. In The Golden Bough Frazer regards magic or shamanism as belonging to a pre-religious period of human culture, and describes the shaman as exercising his powers in behalf of the individual rather than the social group. When the priest appears, it is after tribal organization has begun to develop, and he acts in its behalf. He does not deal in magic, as does the shaman; but he is especially concerned with the performance of those dances, ceremonies, dramatic interpretations of myths, which take the form of religious rituals. Since these ceremonies, in tribes at all advanced beyond the most primitive forms of ritual, are likely to be elaborate, and of considerable extent, to include many songs, festivals, and ceremonials of various kinds, he must devote much time to their mastery, and become a tribal functionary, a professional interpreter of religion. 


\section{THE SOCIAL EVOLUTION OF RELIGION}

\section{VII}

The religious rituals of primitive peoples are dramatic representations of the doings of the spirits and the gods, and by this means bringing them into direct contact with the people, and for their benefit. As Frazer has very definitely pointed out, the shaman as a rule employs his gifts for the benefit of individuals, but the priest recites his rituals for the aiding of the clan or the tribe. Religion among primitive men is religious because it functions socially, and for the reason that it serves the community rather than the individual. As the priest grows in importance to the group he serves, the shaman becomes of less influence, and his activities become, it may be, more and more hidden, occult, and evil in their nature and methods. In his book on The American Indian, Clark Wissler says that there takes place a differentiation of the priest from the shaman wherever ritualism is highly developed. Though there is no rigid demarkation between the two, yet as rituals increase in importance there comes a positive separation between them, and the priest grows in dignity and power.

To primitive peoples the rituals of religion are the myths interpreted as in action. Some interpreters of myth have claimed that all myths are the product of rituals, that is, that the ritual is first developed as an interpretation of the acts of spirits and gods, and that the myths are merely these actions put into narrative form. It is probable that some myths originate in this manner, being first acted, and then narrated. Other myths, not being expressed in ritualistic form, cannot originate as this theory suggests. A myth is an account of the doings of those beings which we have seen come into existence through the action of what is called animism or the recognition of all objects in nature as alive and acting their part in the great drama of the world's existence. The definition given by J. N. B. 


\section{THE SOCIAL EVOLUTION OF RELIGION}

Hewitt, of the Bureau of American Ethnology, is one of the most explicit, and may be cited here: "Among savage tribal men a myth is primarily and essentially an account of the genesis, the function, the history, and the destiny of a humanized fictitious male or female personage or being who is a personification of some body, principle, or phenomenon of nature, or of a faculty or function of the mind, and who performs his or her functions by imputed inherent orenda, or magic power, and by whose being and activities the inchoate reasoning of such men sought to explain the existence and the operations of the bodies and the principles of nature. Such a being or personage might and did personify a rock, a tree, a river, a plant, the earth, the night, the storm, the summer, the winter, a star, a dream, a thought, an action or a series of actions, or the ancient form or prototype of an animal or bird."

When a myth was dramatized for religious purposes, acted in its several details, presented by persons disguised by masks, and other means of representing the spirits or gods concerned in the myth, it became a ritual. Such a ritual, in order that it might serve its religious purposes, was not to be regarded as a dramatic performance, but as a ceremonial means of communication with the supernatural beings represented in it. Such ceremonial had a magical power, and the representation of the spirits or gods, had the effect of bringing them, as it were, into the presence of the spectators, and of securing their aid for the benefit of the community. The magical power of the ritual not merely invoked the presence and support of the gods, but compelled them to answer the prayers of the community as voiced through the priest. The priest, indeed, was the man or woman who could thus insure the beneficent presence of these supernatural beings, and their being made subservient to the community's needs. As a result, the priest became the most im- 


\section{THE SOCIAL EVOLUTION OF RELIGION}

portant man or woman in the tribe, and the exercise of his powers through the ritual gave him a large and commanding place in the tribal life.

With the growth of religion under ritualistic and priestly influences symbolism became a more and more important feature of it. In our own day there are many attempts to express and interpret what is spiritual and supernatural by means of symbols; but they have largely lost their significance and deeper meanings for the life of our time. No effort to revive what does not belong to the culture of a period can be more than temporarily and spasmodically successful. Symbolism belongs to the age of ritual, to the days of the priest, that is, to the intellectual period of the higher type of animism. Then was it intimately bound up with religion, and was used to interpret and explain all its manifestations. The symbol not merely represented the god in outward form, but made sure that he was present when he was needed. This is what gives meaning to that form of animism or religion known as fetishism. Any object made may become a fetish, the abode of a spirit or a god. The bundle of most miscellaneous articles tied up by a negro of Africa into a fetish was not in itself anything more than a number of sticks and other objects; but the spirit came into it and remained there for the benefit and the protection of its owner, and it became of great importance. Sticks and stones as such had no meaning to the fetish-man, but when a powerful spirit was present in his bundle or other object nothing could be more valuable to him. The fetish was merely the symbol of the presence of a powerful spirit. So it was with all other symbols, that they represented a power of magical potence brought to the aid of the worshipper.

If we study the several peoples of America, or of any other continental region, we shall find that shamanism, with magic 


\section{THE SOCIAL EVOLUTION OF RELIGION}

as its basis, presents itself amongst the most backward tribes, those in the hunting stage or those inhabiting inclement and unpropitious regions. As we move forward towards the more advanced tribes, those which are gaining a definite form of social organization, we shall find religion in more definite forms, taking on the character of rituals and elaborated ceremonials, with a priestly class for their presentation and interpretation. Myths grow, and become a more and more clearly defined statement of the actions of the gods, and explain, in the form of narratives of the doings of the higher spiritual personages, the creation of the world and of man, the origin of the rituals, the advance of the different phases of culture and the advent of the culturehero himself. Sacrifices become more numerous and more effcacious, they are developed into great systems of contact with the gods, and responses to their needs. Symbolism grows, and is perfected in marvelous ways. Rituals develop apace, and they are regarded with a more confident faith. As yet there is no creed, no dogmas, except those which find expression in the symbols and the rituals. Man does not think, but he feels and he acts. He has no science, but he does have symbolism and ceremonial.

Here we have the roots, as it were, of religion. Primitive enough, surely, but all the possibilities of it are in animism, symbolism, and ritual. At the basis we find man's own recognition of his mental powers, that he is in some sense a being other than physical, and with gifts of will, creative power, ability to master the world, and to make it subservient to his wishes. If he sees himself reflected in a world of spirits and gods, it is that he may bring these to his aid, and that he may become more a man than is possible without them. 


\section{THE SOCIAL EVOLUTION OF RELIGION}

\section{VIII}

In the preceding pages it has been suggested that the developing phases of religion passed in review have a positive effect in controlling conduct. Tabu may be regarded as a form of moral law, and exogamy is very distinctly a method regulating marriage and the relations of the sexes. The initiations, the secret societies, the rituals, and the manner in which the spirits are regarded, have a large influence on individual and social conduct. In fact, in primitive society there is no differentiation between religion and ethics. Ritual makes for morality, and morality finds its origin and sanctions in religion.

This union of religion and ethics is a result of the distinctly communal nature of all social development in tribal communities. Belief and conduct to the man of the tribe are not separated as they are in modern society. Not only does morality develop with religion and as a phase of it, but so also does law and jurisprudence. It is true that nothing of positive law is to be found in tribal society, but custom is varied and powerful, and it is but another phase of religion. Custom is the practice, the conduct, of the tribe, what every one of its members regards and obeys because all the other members act in the same manner.

Tabu has been presented as of a religious character, as defining what is sacred and what is evil in its nature. With as much truth it might have been interpreted as a law defining conduct, for such it is in its practical results. If it takes a negative form, and defines what may not be done, because sacred, or, on the other hand, unclean, it is also affirmative as to what is conducive to the tribal advantage. It must be recognized also that totemism, clan organization, and many another phase of tribal society, carries with it rules of conduct for the clan as a clan, and also for each and every one of its individual members. 


\section{THE SOCIAL EVOLUTION OF RELIGION}

In this regard tribal society follows other ethical rules than those known in modern communities. It is not the individual as an individual who is required to obey ethical requirements, but the clan itself. That is, the moral law of the clan is that of custom, the traditional and collective manner of conduct which belongs not to individuals but to the whole fellowship. What one does all do, the custom for one being the custom followed by every member. All act together, in the same spirit, to the same ends.

This may be seen, perhaps, to best advantage in what is known as the blood-feud in the higher phases of tribal life. This custom requires that all the members of a clan shall be responsible for the conduct of every one of its members. All are held to be equally guilty for any act committed by an individual of the clan. If an act of an individual member of a clan has done an injury to a member of another clan, the offended clan requites itself on any member of the offending clan, whether the one causing the injury or not. It is not so much the individual as the clan as a whole which is responsible. This law is that of an eye for an eye and a tooth for a tooth. The offending clan is punished in exactly the same manner and extent as was the nature of the crime committed.

Custom dominates in tribal society, therefore, and custom has always behind it the sanction of the ancestors or the gods. Custom is law in its first stages, but law intimately unified with religion, which prescribes its demands. At this stage in its evolution law has no separate existence, and does not know itself as law. It is no more than custom, the social practice of a clan or a tribe.

While the ethical life of the clan is intimately bound up with religion, in the form of custom, it controls every phase of the life of the individual. In fact, there is in the clan no 


\section{THE SOCIAL EVOLUTION OF RELIGION}

individual freedom as concerns conduct, and every departure from custom is severely punished, either by beating, mutiliation or death. In all the more advanced tribes something in the nature of commandments or a code may be found, brief but explicit statements as to what is to be done or what is to be left undone. These brief summaries of the laws of conduct often cover many or all of the ethical demands of a primitive form of society. Some of them, at least, might be very well enforced in modern communities, so fundamental are they. 


\section{CHAPTER IV}

\section{Feudal Religion}

NCE again it needs to be stated that religion in the early ages is not separated from the other phases of human life. Differentiation from social and political conditions, from industries, the arts, conduct, and other phases of development, has not as yet taken place. Everything that is human is concerned with religion, and it is intimately related to everything that man experiences. The hunt is prepared for with religious ceremonies, and other ceremonies follow the hunter's return. It is the same when the warrior goes forth to battle, and when he returns victorious or defeated. When the ground is prepared for the seed, and when the seed is cast into it, ritual observances are required. The reaping of the harvest calls for thanksgiving and festival, often of an elaborate character. When a child is born, when it is named, when the boy or girl is initiated or married, and when death comes, religion is invoked to give its sanctions. Even the most trivial events may lead to some ritual observance, to a festival when the gods are invoked or to a prayer for guidance.

What this means, at least in one direction, is that religion is dependent for its manifestations on the industrial, social, and political developments of a people. As these change the religion changes to meet the new conditions. The religion of a hunting band or group is other than that of a pastoral tribe or an agricultural clan. The hunting band will give its attention chiefly to those conditions which favor the capture of the 


\section{THE SOCIAL EVOLUTION OF RELIGION}

animals it seeks, and its rituals will be of a nature conducive to that end. The agricultural clan will be chiefly concerned with the growing of an abundant harvest, and it will adapt its ceremonials and its rituals to bringing about that result.

In the study of early religion, therefore, it is desirable that recognition should be given to occupations, to forms of social organization, and to the manner in which a group de. velops its customs and its laws. In the beginning it would appear that man is dependent for his food supply on nature, and he gathers such plants and fruits as afford him subsistance. Since he evidently began his career in tropical lands, he could easily subsist in this manner. The gatherers also were likely to become hunters, for nearly everywhere animals are found. When he moved away from the tropics he became more and more dependent on hunting, as he advanced into regions remote from the abundant natural products of that region. As he came into more favorable regions he became a tiller of the soil, and this occupation gave him the opportunity to settle in permanent localities, and to cease from the life of the nomad. As in India, he might develop a village community of tillers of the soil, with hunting and pastoral conditions subsidiary thereto. The village might grow into a city, with the beginning of industries, the arts and commerce. Or, the development might take the form of bringing together groups into a tribe, each group becoming a clan, if female descent was the rule, or a gentes, if male descent prevailed. In the formation of a tribe two processes appear to have been followed. The one resulted when the group became too large for the food-supply, and it divided into two or more groups, each occupying a separate territory, but continuing as far as possible their old relations. This appears to have been the process followed in the formation of the tribes of the Iroquois. The 


\section{THE SOCIAL EVOLUTION OF RELIGION}

sub-groups might again divide, and in this manner from two to twenty or more groups might be formed. The bond uniting these groups grew to be in time that of blood-kinship, and the ties this constituted. The bond of blood, kinship or hereditary descent is one of the most powerful known to men, and it acted very effectively in the formation of the tribe in all the phases of the developing life of early communities. Such groups, united by the kinship tie, grew into tribes and then, it may be, into a city-state, as appears to have been the case in Greece and in the northern Italy of the mediaeval era.

The other process in the formation of the tribe was that of separate groups gradually coalescing for protection, and for the promotion of their common interests. This was the manner in which the forty or more clans of the Navaho came together, from many sources, perhaps even from tribes speaking other languages than the Dené. In India this process was followed, as well as in Greece. In time the separate groups might become so far welded together as to become convinced of their common origin, and to insist on the blood-bond as existing from the beginning.

Briefly we have explained the manner in which tribes were formed, with their constituent clans or gentes. The process of coalescence and unification did not stop here, however, but went on to far higher expressions. When the tribe, with its communal territory, came under the direction of a chief, who in some degree was regarded as a representative of the ancestral rulers of the community as a whole, it might come to pass that he, in the name of the tribe, and as the representative of its communal interests, would become the putative owner of the land, all the members of the tribe becoming in some degree his subjects. Under these conditions feudalism appears, with its attendant domination of the chief over all other members 


\section{THE SOCIAL EVOLUTION OF RELIGION}

of the community. Under him would be subchiefs, subject to his will; and other minor officials, enforcing his commands. The great mass of the tribesmen, however, would become in some degree subordinate, freemen perhaps or mere serfs, bound to the soil. What we have to note is, that the feudal community grew out of the tribal, and that it carried forward to higher issues those conditions which the tribal life began.

\section{I}

Feudalism, even in its higher forms, retained very much of what had originated in the tribe; and it may be regarded as tribal society more perfectly organized, and reaching towards that which is political. Owing to migration, frequent wars, the development of the early stages of the industries and commerce, it came about that the old kinship relations were sometimes violently broken up, and in other instances this change came about quite slowly; but in one way or another geographical relations were established in place of those which originated in the family. War in itself had little other effect than that of destruction; but one of the consequences which followed from it was that the old kinship ties were disrupted, and men were thrown together who were not of the same family or clan, and found it necessary to live together as best they could. Migration in some instances had the same effect. In these and other ways it came about that communities were formed on another basis than that of kinship, namely, that of geographical proximity or the fact of living on the same territory, and being more or less dependent on each other. At first they might pretend to an origin in some putative ancestor, and such could be readily devised for the occasion. 


\section{THE SOCIAL EVOLUTION OF RELIGION}

Gradually, however, it came about that territory in itself became the basis of social and political union, and the ties of family ancestry and clan organization were broken down. It was a very slow process by which tribal was developed into political society. It required hundreds of years to bring about the change; and in its more pronounced phases this development is known as feudalism. Found wherever the tribe has given way to the state, the process has been greatly varied in different parts of the world. In some regions it would seem that it has been wholly the result of conquest, and the process of the subjection of one tribe to another. Elsewhere it would appear to have been wholly the product of migration, and the gradual coalescence of peoples by the mixing process which resulted. In other regions it may have been the result of the diffusion of culture conditions, the spread of ideas, and the extension of the processes making for civilization.

However feudalism was brought about, it includes several marked phases, and among them the development of the chief of a democratic community into an autocratic lord, with control over the lives and fortunes of his subjects; the ownership of the land occupied by the community on the part of this chief or king, and the right to portion it out to his subjects; and the king as lawmaker, leader of the tribal armies, with the right to determine war whenever it might please his autocratic will to do so. One phase of this process was the development of a class devoted to war almost exclusively. In connection with these developments there usually followed a distinctive type of social custom, a large degree of progress in song and ballad and lyric, the creation of new forms of art, and an added emphasis on ritual and all forms of ceremonial in the domain of religion. As the chief or king became an autocrat, so did the priest become the bishop or overseer of 


\section{THE SOCIAL EVOLUTION OF RELIGION}

priests. In both the secular and the sacred fields of development authority greatly increased, society was organized with marked elaborateness, grades of classes were slowly established, with all power in the hands of the rulers, while the great body of the people were subject to the autocratic will of those above them.

This phase of social and political progress did not appear everywhere; and in some favored regions, such as the Greek lands, this era of advancement from the tribe to the state was marked by the growth of village communities and then by the appearance of the city-state. Even in Greece, however, the other type of feudalism appeared, as it is presented in the pages of the Iliad. It is true that feudalism of the distinctive type did not work itself out to the extent in which it appeared in western Europe, and it did not last for as prolonged a period or so it would seem from the imperfect knowledge we have of this stage in Greek culture. It would appear, also, that it came at an earlier period, and was more quickly succeeded by the growth of the city communities.

With these changes in communal and industrial organization religion took on new forms, and the spirits or gods ac. quired fresh attributes. Not all processes of development, however, took the precise directions here indicated, and we must for a time turn aside to consider other phases of social and religious progress. One of these had its origin in the more distinctly industrial developments of early communities. The discovery or invention of the simplest arts, what Tylor has called the "arts of life," such as pottery, weaving, tanning, and the cultivation of the soil, led to results of the greatest importance. 


\section{THE SOCIAL EVOLUTION OF RELIGION}

\section{II}

Much discussion has been indulged in with regard to what Bachofen called the matriarchate, and what is now generally known as mother-right. To understand how this form of society took its origin we must briefly review again the several stages in social and industrial development. Frequently it has been asserted that female descent or mother-right was the earliest form of society known to humanity, and traces of it have been sought for amongst all early peoples. The evidence, however, does not bear out this theory, and indicates, if it does not prove, that mother-right is not to be regarded as a universal stage in human evolution, and that it is by no means to be found in connection with all primitive communities. It results from industrial conditions, and it is not likely to appear until these have prepared the way. As we have already seen to have been the case, man began his career as a gatherer or as a hunter. Under these conditions the form of social organization was that of control by a headman or chief of the persons gathered into a band. In this band the father was the ruler of the family, and his will was law within its limits, both over wife or wives and children. This form of society may be described as the paternal. It is found widely in Siberia, in the northern parts of America, and in many other regions where the chief means of the food-supply is hunting, the keeping of reindeer or other similar occupation requiring the active exertion of the energies of men.

When men were occupied as gatherers and hunters, in such regions as made it possible, women became the first tillers of the soil. This conclusion is now nearly universally accepted by anthropologists, and by the students of the early forms of the industrial life. Probably it was not by design or through 


\section{THE SOCIAL EVOLUTION OF RELIGION}

inventive skill, that women found they could place seeds in the ground, and secure a harvest near their huts or tipis. This knowledge was probably the result of a happy accident, in connection with the other activities of women; and it was arrived at, probably, in several different regions. This discovery or invention, whichever we may choose to call it, had results of the greatest importance for the developing life of mankind; and for religion, as well.

In many parts of the world, when women began to produce plants, and thus to supplement the labors of men as gatherers and hunters, results followed that were of large social significance. One of these was that the product of their labors belonged to the women, and that they became the owners of the soil, its produce, the granaries in which the results of their toil were stored, and also of the houses in which they lived with their husbands and children. Under these circumstances, the woman asked the man to live with her and to share in her labors and her possessions. She became, consequently, in many tribes, the head of the family, descent being reckoned through her, her children inheriting her property, and more especially this was true of her daughters. The Iroquois and the Zuni in North America, the Khasis of Assam, and the Nayars of India, are instances of such mother-right peoples. To what extent mother-right existed in early India, Babylonia, Syria, Anatolia or Asia Minor, Egypt, and Greece it is impossible to say with historic definiteness. Many anthropologists believe that it did exist at an early time in all these regions, and that its presence had a determining influence on the development of religion. Many phases of the growth of customs in these and other lands can be best explained by the supposition that mother-right once existed there. We know that widely in tribal society women took part in the rituals of 


\section{THE SOCIAL EVOLUTION OF RELIGION}

religion, having the same right as men to fill the offices of shaman, priest and prophet. While they were rigidly excluded from the ceremonials of religion in many regions, this was rarely the case where any form of mother-right had come into existence.

Under the conditions of mother-right, or something kindred to it, there appeared mother-gods or goddesses; and these were numerous and powerful in the ancient world. We have already had occasion to mention Ishtar, the great mother-goddess of Babylonia and Syria. In some respects the greatest, or, it may be truer to say, the best beloved of the Egyptian gods, was Isis, partly because of her motherhood and her relations to Horus. The Great Mother of Asia Minor was the leading divinity of Lycia, Lydia, and the neighboring lands. Athena was the protecting divinity of the city of Athens, and in this capacity was preferred to all the other gods.

One of the reasons why most of the mother-gods may be assumed to have originated in the conditions attendant upon the cultivation of the soil by women, is that they were either personifications of the earth or of the plants cultivated by women. All the cereals and fruits of the early time were regarded as the abodes of a mother-spirit or goddess, as mothercorn or mother-rice. In some regions wheat or maize or rice were received as in themselves mother-divinities, and in others a goddess gave origin to them, and gave them into the care of the women who cultivated them. Such myths as these are not likely to have originated except under conditions which made them historical or descriptive of actual events. When women cultivated the cereals or fruits indigenous to the several regions of the earth, it is natural that they should animistically ascribe divine powers to those plants with which they came into intimate relations, and on which their tribes were closely 


\section{THE SOCIAL EVOLUTION OF RELIGION}

dependent. Any other explanation of the origin of these goddesses, with their agricultural settings, in nearly all instances, seems to be quite wide of the mark as a genuine interpretation.

Another phase of this development is to be found in connection with the animistic or anthropomorphic conception of the earth as a great divinity or mother-goddess. Widely over the world this interpretation of the relations of the earth to the needs of man is to be found. The cereals and the fruits cultivated by women grow out of the earth, therefore to the primitive mind it was natural to regard the earth as a mother, the nurse and nourisher of all who live.

The earth as a Divine Mother was united to the sky or sun as a Divine Father. The earth gave to men an abode, the food which enabled them to live, and the nurturing care of a world goodly and beneficent. The sun and sky made the earth fruitful with light and heat, rain and dew. Therefore they stood in the relations to each other of husband and wife, and to all earthly creatures in that of father and mother. In many regions this relation is to be found in myth, in legend, in ritual and in belief. Even in the highest religions may be found survivals of this belief; it is frequently found in art and poetry, and is not wholly absent from philosophy.

The myth-making capacity of early peoples for personifying the earth, and the cereals which grow out of it, by no means interprets every phase of the growth of goddesses in the early religions. While it is true that this phase of religious development is largely connected with the cultivation of the soil by women, it has also its incentive in the facts resulting from the relations of the sexes in courtship and marriage. Such myths assume that the process of creation is a process of generation, and that man owes his parentage to the intimate relations of Father Heaven and Mother Earth. In the United 


\section{THE SOCIAL EVOLUTION OF RELIGION}

States and Canada many tribes, which are not yet advanced to the industrial stage of the cultivation of the soil, have the myth of the two divine parents. The intimate relations of the sun or sky to the earth are such that even the primitive man and woman must have come to recognize them; and this would naturally lead to the conception of them as the great begetters, the father and mother of all who live. In the stage of advancement when women were beginning the cultivation of the cereals, this relation would obtain added recognition and convincing proof.

In many of the more advanced tribes of America the worship of Heaven and Earth may be found, and in Mexico and Peru this belief had developed to a high stage of perfection. In the first volume of his History of the New World called America, Edward John Payne says of the worship of the earth: "The motherhood of the earth was in aboriginal America no mere figure of speech, but an article of positive belief. In Peru it was so far a matter of universal faith that every tribe could point to a place where its ancestor had actually emerged from the soil. The earth, however, was chiefly worshipped, both in Peru and in Mexico, as in the Old World, as the universal provider of subsistence. By the Mexicans she was called 'mother of the gods' (Teteoinnan) and 'our grandmother' (Tocitzin). ... The great mother is everywhere at hand.... For the same reason [in Peru] Pachamama was not usually worshipped in temples. The world of animated things is her temple : the upper world or firmament is its roof, the underworld its foundation."

In western Africa, in Polynesia, in Indonesia, and in Japan, China, and India, this worship of Heaven and Earth as a wedded pair is to be found. In India they are known in the earliest times as Dyaus-pitar (the Jupiter of Roman myth- 


\section{THE SOCIAL EVOLUTION OF RELIGION}

ology) and as Prithivi; and these names reappear in many of the Aryan languages. Gods and men alike are born of this divine pair by the process of generation. In early Greece, according to Hesiod, this pair was Uranus and Gaia; and he says that all the deathless gods were born of Earth and starry Heaven. In Egypt, where mother-right in large degree prevailed to a later date than the conquest of that land by the Romans, the earth was the primal male deity, Seb; and heaven was the female divinity, Nut. On the primal waters before creation they were married to each other, and from them came all things that are.

\section{III}

Heaven and Earth were regarded by many peoples as not merely animistic or anthropomorphic deities, but as the primary principles in the universe. This may be seen finding emphatic expression in China, where they are known as Yang and Yin, the fundamental types of life, the great energizing principles in all existence. J. J. M. de Groot, in his lectures on The Religion of the Chinese, says of these principles: "The oldest and holiest books of the empire teach that the universe consists of two souls or breaths, called Yang and Yin, the Yang representing light, warmth, productivity, and life, also the heavens from which all these things emanate; and the Yin being associated with darkness, cold, death, and the earth." In his lectures on The Religion of China, de Groot explains that Yang is male and Yin female, and that they respectively represent man and woman.

These two energies are largely of the nature of mana and orenda, lacking in distinct personification, forces rather than persons. According to the Li Ki, however, man is the result 


\section{THE SOCIAL EVOLUTION OF RELIGION}

of the union of Heaven and Earth; and here it would seem that they partake in considerable degree of individuality. Under the influence of Taoism they became actually deified, and appear as gods rather than as creative principles. What is to be noted, however, is that these two principles are the male and female parts of the universe, that their union has given origin to all which exists, that they are never separate from each other, and that they in union are at the sources of the individual human being, as they are of the whole universe, in all its parts.

Essentially the same animistic conception is to be found in India, where purusha is the male principle and prakriti the female principle. When they are personified or deified they become Heaven and Earth, though they always remain the primary manifestations of mind and matter. In many of the Hindu philosophies it is this union of mind (or spirit) and matter which constitutes the fundamental basis of the universe. In his History of Aryan Medical Science, Bhagvat Sinh Jee says that the Hindu doctrine of creation is the result of the coming together of Purusha and Prakriti, spirit and matter. $\mathrm{He}$ adds that spirit is infinite, immortal, sentient, and blissful; but that matter is lifeless, though possessed of creative force and properties of goodness, passion, and apathy. Some Hindu philosophers are of the opinion that matter, the female principle, is without energy or creative power, that its union with spirit is essential to any productiveness on its part. Others are of the opinion that matter is merely an illusion, with no reality in itself, and that it becomes creative only when in union with spirit. And yet others deny all real existence to spirit, and find in matter the one real power in the universe. Thus it will be seen that all modern philosophies found an existence in early India, and often in forms more 


\section{THE SOCIAL EVOLUTION OF RELIGION}

logical and effective than those of their modern co-workers in the fields of speculation.

Some of the Hindu thinkers, as Bhagvat Sinh Jee informs us, are convinced that Prakriti or Nature (and not merely matter) is the cause of all things, and the one universal material cause (prima matrix). A much larger number of them, however, assign creative power to Purusha, spirit or soul, which is essentially the creative force in the world of man and of nature. In the human world the origin of life comes from Purusha, as the father principle, the principle which is creative. On the other hand the mother is Prakriti, the receptive principle, that by means of which the child is nourished and given its life.

In Babylonia it is probable that in the very early time every god was accompanied by a goddess, who was his counterpart, and in the truest sense his helpmate. In the later period the goddesses declined in importance, and became the mere shadows or reflections of the gods. Through many centuries of the Babylonian religion a radical change went on, which resulted in the concentration of all the feminine qualities in Ishtar, who became in a supreme sense a mother-goddess, the mate of all the other gods, or, rather, the source and origin of them all. In the beginning Ishtar was a goddess of fertility, the reproductive principle in supreme expression; but with the development of the military spirit in that land, she became a warrior, the type or symbol of war and the fighting spirit.

Whether in Babylonia as Ishtar, in Phoenicia as Astarte, or by other names in the other Semitic lands, this goddess represented primarily the great principle of fertility, reproduction, and the generational succession throughout the ages. The individual passes, but the race continues; and it is because of this principle of reproduction, the genetic form of life, personi- 


\section{THE SOCIAL EVOLUTION OF RELIGION}

fied as a great mother, that this is true. In Syria, Arabia, the Hittite land, Anatolia, Egypt and Greece this feminine principle of fertility had recognition as that which is primary to all other energizing forces. The gods in time may become supreme, but in all the ancient world this tradition of the supremacy of the feminine principle was never wholly forgotten. From time to time there was a renewed recognition of the idea that motherhood is the one eternal creative force, the great energizing power in the universe.

In the early religions and philosophies of Greece we find this principle of sex working out in a form possibly somewhat different from that expressed elsewhere. The primary conception of the union of two great principles reappears in all its strength and universality; but they are placed in opposition to each other, rather than being regarded as one in their primary union. Through the union of principles which act contrary to each other, are in opposition, and even antagonize each other, the work of generation proceeds, and by means of the processes of creation. The operation of these antagonistic principles is not one of destruction, but one of creation; and they therefore generate through their very antagonism the whole world of things and beings known to man. In particular, we can discern, says Francis Macdonald Cornford, in his From Religion to Philosophy, "that the prototype of all opposition or contrariety is the contrariety of sex." This appears in the mythological separation of Heaven and Earth, which, though they co-operate in the process of creation, are more or less distinctly in opposition to each other, not only in their essential nature, but in their creative activities. In the very beginning there was chaos or an undifferentiated mass, without internal boundaries or limits. This primeval chaos separated into two parts, which were in their fundamental nature op- 


\section{THE SOCIAL EVOLUTION OF RELIGION}

posed to each other, and they became male and female. Through the intervention of Eros, these two were united and reconciled, and by birth gave origin to gods, men, and things.

This brief survey of the manner in which sex, and the activities of women, were regarded in the early civilization may call for some interpretation as to how they originated, and why they disappeared from the higher phases of ancient religion and philosophy. The active cause is to be found in the creative forces establishing social institutions, and those other causes at work for their gradual modification. As already suggested, when women were developing the primary arts, agriculture, and the basic moralities of home and family life, it came about that the feminine creative principle was in the ascendent in all processes of cosmic and human interpretation. They continued to operate in behalf of women until there was developed a dominating activity of men, through the growth of slavery, war, and the autocratic principle.

While the industrial separation of the sexes continued, largely the result of the division of labor between them, men devoting themselves to hunting, the care of domesticated animals, and to war; women to the primary arts, and to the cultivation of the soil, which probably in large degree gave origin to the idea of their opposition and antagonism, there was a large measure of freedom for women, and mother-right continued in active operation. When men gave to their captives the task of cultivation, thereby largely increasing the permanent food-supply; and when war became largely the occupation of the superior class among men, with the result that all other members of the community were brought into subjection to them, there gradually came about a change from maternal to paternal descent, the ownership of land and house by men, the passing of the woman on marriage into the house- 


\section{THE SOCIAL EVOLUTION OF RELIGION}

hold of her husband, and her being held as in his hand, to use the Latin term, implying that she was in the fullest sense subject to his will and authority. In China and in Rome this change in the organized forms of society became in the largest degree dominant and universal. In other countries it did not reach the same logical subjection of the woman to the dominating will of the man. However, under every form of what has been called patriarchalism, the woman has been regarded as inferior, and as needing to be controlled. This change in the status of women led to a change in the relations of the goddesses to the gods; and in all patriarchal lands the goddesses became subordinate to the gods, were merged in them, or wholly disappeared.

We have seen that in China, India, and elsewhere, the feminine principle is connected with the earth, that it is in some measure regarded as inferior to the masculine principle, in as much as that it is symbolized by matter, while the masculine takes the form of mind. It being held that mind is productive or ereative, and that matter is receptive, and can originate nothing of itself, it follows that the man is superior to the woman, because his nature is supremely that of mind, while hers is that of matter. This means that reproduction originates in the masculine principle, and that the role of the feminine is merely subordinate, in that she does no more than to afford a matrix in which the child may develop. In all the higher civilizations this conclusion, that the origin of the child is with the father and not with the mother, finds a place, and is accepted with unwavering faith.

In all the developed Greek philosophies, whether it be that of Plato or that of Aristotle, we find the assertion of the primary nature of form and matter. If we read closely enough, we discover that this duality represents fundamentally the dis- 


\section{THE SOCIAL EVOLUTION OF RELIGION}

tinction of sex, or that this dual distinction had its origin in the relations of the masculine and the feminine. In the Timaeus, Plato pertinently says: "We must conceive three kinds : first, that which comes into being; second, that in which the first comes to be ; third, that from which the first is copied, when it is born into existence. And we may fittingly compare the recipient to the mother, the model to the father, and that which springs into life between them to the offspring." Nothing can be plainer than this statement, which corresponds to that which may be found in the Hindu Code of Manu, that the child is the offspring of the father, and that the mother merely serves as a means of its coming into being. In his work on The Generation of Animals, Aristotle is even more explicit in his statement that the originative cause in generation is the male, and that the female is without any creative power or fundamental concern in the reproductive process.

It may be doubted if female descent was universally accepted everywhere in any period of man's social evolution. Not all primitive peoples accept it at the present time. In Australia it is to be found in the eastern and southeastern tribes, but not in those of the central and northern regions of the continent. In those tribes where it is found there is a considerable degree of advancement in the economic life, and in social evolution, over those of the regions where it is not present. Nowhere in Australia is mother-right to be found, female descent not being, in itself enough to create the larger social force in behalf of women.

Practically the same situation is to be found in North America, so far as concerns the development of both female descent and mother-right. In the northern and western tribes, which are in all respects the least advanced in industries and in social organization, neither of these social institutions is to 


\section{THE SOCIAL EVOLUTION OF RELIGION}

be found. Mother-right appears only in those regions where the greatest progress has been made in all directions. It appears, therefore, that female descent and mother-right are not characteristic of the lowest phases of social development, but of those where agriculture has been to some degree developed by women, and where the deeper meanings of sex, as a process of creation and the continuity of the generations, has come to some measure of recognition.

\section{IV}

The change from mother-right to father-right or to patriarchalism, to use the word commonly employed, did not come about suddenly or from any one cause. It may be said to have had its origin in industrial or economic causes, which was largely the case; but other influences were at work to give sanction and force to this operative influence. Religion also afforded a potent motive working in the same direction, and giving a deeper and more effective sanction than any immediately afforded by economic influences. Behind slavery, war, and the control of property by men, was the potent power of divine requirements enforcing the demands of industrial activities.

We need not dwell upon the greater opportunities men have for leading a stirring and dominating life, since they are not restricted in any degree by childbirth and child-care, and are always free to pursue interests outside of the more limited duties of the home and its immediate concerns. In this sense the anabolic or constructive capacities of men are greater than those of women; but perhaps in this social sense only. This may mean that men may have more of those qualities which are of an individualistic nature, are more rebellious against 


\section{THE SOCIAL EVOLUTION OF RELIGION}

mechanical limitations, more inclined to a stirring and assertive life, and less willing than women to assent to the demands of the immediate environment, that of the family circle and its routine requirements. It may be said, therefore, that man is more interprising and explorative than woman, partly because he craves excitement, and partly because he is not limited as she is by physiological conditions. On the other hand, woman is nearer the life of the race and its demands than is man, physiologically more constructive, and more willing to abide by the great energizing forces that make for the upbuilding of society. In her is to be found what is genetic in a much larger degree than in man, what more truly makes for the continuity of the generations, and for the unifying of the race in all its more permanent interests. Her life is more nearly that of the child, and therefore more assuredly prophetic of the future.

In this manner we may hint at what it is which gave men in the early civilizations a control of women which now seems brutal and wholly unnecessary. Through whatever causes this domination came about, it undoubtedly had a very large effect on religion. Not less true is it that religion had a large influence in bringing about this domination, and, when it was once established, of giving it approval and sanction. As already suggested, the female gods slowly disappeared, and the male gods came to occupy a much larger place than before, to become the true creators, and the enforcers of morality and social requirements.

In many tribes of the more advanced type, and widely in the early civilizations, women were barred from the ceremonies of religion. Tabu proved, in this respect, a powerful influence in restricting their relations to the rituals of religion, to its initiations, and its festivals. They were not wholly refused 


\section{THE SOCIAL EVOLUTION OF RELIGION}

admission to these; but in one degree or another they were shut out from them. In this respect, their position was very different from that accorded them under the conditions of mother-right, when they were free to exercise every religious function, and when they were often the leaders in all rituals and other duties connected with religion.

No other one change which the evolution of civilization has brought about shows more truly than this of the relations of women to religion and social conduct, to what an extent religion is a reflection of the social or collective life of a people. In this age of the developing freedom of women, it is often remarked that a civilization may be judged, as to its advancement and its merits, accordingly as it gives women rights as well as duties, liberty as well as morality. Religion may be also tested by the same standard, not always to the credit of those which most boast of their superiority in other respects.

\section{V}

The causes leading to the worship of ancestors are many and complicated. Perhaps no one or two statements will give anything more than a mere hint as to their nature. Slavery, war, and property, representing the growing interests and activities of men, may probably best serve to suggest what it was which brought about the change from reverence for the genetic principle to worship of ancestors, the change from the superior rights of the mother to those of the father, the superiority of the woman in the family to that of its domination by the man, and the disappearance of mother-right before the growing social assertion of the patriarchal principle.

Two theories in regard to the origin of the social phases of religion are now contending with each other as interpretative 


\section{THE SOCIAL EVOLUTION OF RELIGION}

motives. One of them asserts that religion first finds expression in animism, the recognition of soul or spirit present in all objects of nature, - in plants, animals, remarkable phenomena, and in heavenly bodies; and that these are worshipped either as superior beings to man or as gods. The other asserts that all recognition of spirits and gods comes through interest in, and reverence for, the dead; and the belief that they continue to exist after they have passed out of this life. Not merely do they survive, but they become powerful influences controlling the affairs of men.

That phase of religion known as ancestor-worship was regarded by Herbert Spencer as the earliest form to appear, and that out of which all succeeding religions have been developed. In the first volume of his Principles of Sociology he interpreted this explanation of the origin of religion in much detail. He maintained that animal- and nature-worship originate in reverence for ancestors, and that out of this tendency grows all the gods, from lowest to highest. He states this belief by saying, that "behind the supernatural beings of all orders, there has in every case been a human personality." Summing up his extended studies in support of this conclusion, he says, in his chapter on the primitive theory of things: "After finding that the earliest conception of a supernatural being, and one which remains common to all races, is that of a ghost; and after finding that the ways of propitiating a ghost were in every case the originals of the ways of propitiating deities; the question was raised whether the ghost is not the type of supernatural being out of which all other types are evolved. The facts named in justification of an affirmative answer were of several classes. From the lips of primitive peoples themselves, were quoted proofs that out of ghostworship in general, there grew up the worship of remote an- 


\section{THE SOCIAL EVOLUTION OF RELIGION}

cestral ghosts, regarded as creators or deities. Worship of deities so evolved, we found characterized ancient societies in both hemispheres: co-existing in them with elaborate worship of the recent dead. Evidence was given that by the highest races as by the lowest, ancestor-worship, similarly practised, similarly originated deities; and we saw that it even now survives among the highest races, though overshadowed by a more developed worship. Concluding, then, that from worship of the dead every other kind of worship has arisen, we proceeded to examine those worships which do not externally resemble it, to see whether they have traceable kinships. ... Even deification of the greater objects and powers in nature has the same root. ... Further, the hypothesis to which the ghosttheory leads, initiated by anomalous occurrences, extends itself to all phenomena; so that the properties and actions of surrounding things, as well as the thoughts and feelings of men, are ascribed to unseen beings, who thus constitute a combined mechanism of causation."

Since Spencer published his work on Sociology in its first volume, in 1876, a very considerable change in opinion has taken place with reference to the origin of religion. Most anthropologists, and interpreters of the comparative phases of religious evolution, are of the opinion that the ghost theory belongs to a comparatively advanced phase of the development of religion. Instead of being primitive, it appears in many of the phases interpreted by Spencer only after a considerable growth in civilization, which brings the man into the ascendency in the family, and the king in the state. However, considerable evidence remains in favor of Spencer's contention; and much of this has been brought forward by William Ridgeway, in his book on The Origin of Tragedy with special reference to the Greek Tragedies, 1910; and The Dramas and 


\section{THE SOCIAL EVOLUTION OF RELIGION}

Dramatic Dances of Non-European Races in special reference to the Origin of Greek Tragedy, 1915. These works are devoted, as their titles indicate, to quite other than problems of religious origin; but they deal, nevertheless, to no small extent, in what is more or less definitely religious in its character. As already more than once remarked, religion in its early phases treats of the whole of life, and, therefore, it is not surprising that it has intimate connections with the origin and development of tragedy. When we remark that most of the great Greek tragedies are intimately related to the phases of the religious life of that people, we may feel sure that nothing that is human is alien to the religions of all early peoples. Ridgeway says, in his first-mentioned volume, that Aeschylus, Sophocles and Euripides "continued to the last to give great prominence to the doctrine of ancestor-worship and the potent influence exercised on human affairs by the spirits of the dead." In the introduction to his second volume he says that the Hindus, Greeks, and Latins found their own gods in human beings deified after death. Wallis Budge, in his work on Osiris and the Egyptian Resurrection, says that the idea of the god-man, Osiris, was developed naturally from the cult of the ancestor, who, having been a man, was supposed to be better able to understand the wants of living men than the great unknowable God, whose existence was but dimly imagined. $\mathrm{He}$ also says of Osiris that he was a typical god-man, who died and rose again, is represented in the form of a mummy, or at all events in the form of a dead body, which has been made ready for burial. This form is a development of an ancient presentment of a dead chief or ancestor, for Osiris took the place of the tutelary ancestor-god who was honored and worshipped in every village of the Sudan of any size from time immemorial. 


\section{THE SOCIAL EVOLUTION OF RELIGION}

Here we have the two theories as to the origin and early development of religion. One finds the spirits and the gods in animals, plants and objects of nature animistically conceived, and the other finds them in the dead who are supposed to live on in another life, and to have a controlling influence on human affairs. A great amount of evidence has been brought forward in support of both theories, neither has as yet been able to overcome its rival, and to take exclusive possession of the field devoted to origins. Perhaps for the present the one theory may supplement the other, that of ancestor-worship being regarded as of later origin and development than that based on animism. Whichever theory we regard as the most helpful in securing a comprehension of religious origins, there can be no doubt that ancestor-worship had a great influence on the later progress of religion in all the early civilizations. The two countries in which it appeared in its complete expression were Rome and China.

In Rome ancestor-worship and patria potestas expressed the patriarchal conception of society in a most logical and perfected form. In the family the father had the right of manus, that of directing and controlling every other member of it. He held wife, children, and slaves in his hand, had the right to direct their conduct in every particular. He might even take the life of children and slaves, after consultation with the other members of his family, it is true; but without right on their part to protest. Though the wife joined with the man in family worship, which could not be carried on without her aid, yet she was also subject to the will of her husband, who might banish her from his side whenever he chose to do so. In nearly every particular this was true of the relations of husband and wife in China and India. 


\section{THE SOCIAL EVOLUTION OF RELIGION}

The worship of ancestors in these lands, as in many that were less advanced in civilization, led to one important social demand, that the father should be succeeded by a legitimate son, who would follow the father as the head of the family religion. Only a son born of a pure wife, and in direct paternal descent from the first father of the family, could become the guide in the ancestral worship. In case there was no such son, one might be adopted from some other family; but he must, by means of religious ceremonies, become as if he were born into the family of which he became a member. This demand for a legitimate son about whose birth there could not be the slightest doubt, required of woman the most absolute chastity; and even a suspicion to the contrary was enough to cause her divorcement. The chastity of the father was not essential, only that of the mother.

Fustel de Coulanges, in La Cité Antique, translated as The Ancient City; William Edward Hearn, in The Aryan Household, as well as Erwin Rohde, in his work entitled Psyche, and devoted to the cult of the soul, have given us extended studies of ancestor-worship, as developed in India, Greece and Rome. Coulanges deals more especially with the religious aspects of the subject, and this is also true of Rohde. Hearn gives more attention to the developments connected with jurisprudence, though he shows how intimately the growth of custom and law were bound up with the evolution of religion. The Aryan household, but more especially so in Rome, was intimately related to the interests of religion, and its sanctions were those of the sacra which held it together with indissoluble bonds, at least when it perfectly fulfilled its functions. There could not be a family without worship of the ancestral spirits of its head, and, in turn, that head, the father of the household, after his death became one of the spir- 


\section{THE SOCIAL EVOLUTION OF RELIGION}

its his son would in due time worship. In this manner the family here, and the family beyond, were intimately bound together, the living and the dead constituting one household, one family succession. In heaven and on earth there was but one family, the dead being to the living as if they were alive, and to the household spirits the watchful care and protection of the living was of the utmost concern. In this belief that the family, both present and absent as concerns the interests of the living moment, was an organism, one household with no real breaks in it, no vacant places at the sacred hearth, was basic to the religion of all peoples who had reached the stage of a developed ancestor-worship. In his first chapter Coulanges says that the members of the ancient patriarchal family were united by something more powerful than birth, affection, or physical strength, and that this was the religion of the sacred fire as symbolizing the dead ancestors and the relation to them of the living.

In the presence of the fire on the hearth the family worshipped the ancestors upon whom its members were dependent for health and prosperity. The worship of ancestors, according to Hearn, in his third chapter, had for its practical object the proper performance of the sacra - that is, of the worship peculiar to the household. The machinery by which the sacra were maintained was the corporate character of the household, and the perpetual succession of the house-father. His further interpretation of this worship is of much importance to the history of religious development: "It was a worship of males by males, of past fathers by present fathers. After his death, not less than during his life, the Pater represented in the spiritworld all those who on earth had been under his hand, and required that the offerings due to him should be made by his successor and representative alone. Thus the house-father for the 


\section{THE SOCIAL EVOLUTION OF RELIGION}

time being was the visible representative and head of the household; and was bound not only to administer its temporal affairs; but to perform the ceremonies of its religion, and to maintain the purity of its ritual."

\section{VI}

Two other phases of ancestor-worship ought to receive recognition. The first of these is that of the development of guardian-spirits, which appears everywhere in connection with the worship of the dead. We have already seen in the third chapter, that animals, whether totems or not, were frequently regarded as having a guardianship over those who revered them, and sought their powerful protection. This respect for the animal-guardians was evidently transferred to the ancestral spirits, when ancestor-worship came into vogue. The idea and the need were the same, however, whether the protector was an animal or a spirit. Not only did each household have its guardian spirit, its lares or its penates, but each individual had his Genius or her Juno. To the protecting care of these spirits individuals owed their welfare and their prosperity. Socrates had such a daemon, who admonished or checked him when he attempted to do or say anything which would not be for his advantage. The genius of other men, however, not merely gave negative advice, but also that which was constructive and affirmative.

The worship of ancestors led on, in time, to the deification of living men, but rarely living women. If a father might be worshipped when he was dead, it might also be desirable that he should be reverenced, and even worshipped, while he was living. Men of striking character, of indomitable will, who held priestly or kingly positions, might during their lifetime 


\section{THE SOCIAL EVOLUTION OF RELIGION}

have accorded to them some of the functions of a god, and receive some measure of worship. This tendency finally led to the assumption that kings and rulers were born of divine parentage, and that even while living they were gods in the flesh. In many lands, as in Rome, this tendency led to the deification and worship of kings and emperors. The Emperor of China was in our time regarded as of direct descent from the Heaven-god, and, even now, the Emperor of Japan is of the ancestry of the Sun-goddess, Amatérasu. Descent from a deity, however, does not necessarily imply worship of the one with such an ancestry, though in many instances this result followed.

It has been pointed out by J. G. Frazer, in his Lectures on the Early History of Kings, second lecture, and in the first part of the third edition of The Golden Bough, entitled The Magic Art and The Evolution of Kings, that kingship had its beginnings in magic and the conception of the relations of the magician to the world of the spirits. A higher development of the same tendency was that of the recognition of the priest as having direct means of communication with the supernatural world and its divinities. Because of this capacity on the part of the priest, he was often regarded as of divine birth, as actually the son of a god. Having this godlike nature, he was accepted as a fit person, not merely to conduct the rituals of religion, but to preside over the social and political destinies of the people. Because of his gifts as a magician or a priest the king was regarded as a rain-maker, as having control over the vegetation cultivated by the tribe, and as the master of the forces of nature. In his fifth lecture Frazer says that "most of the higher savages at least possess a rudimentary notion of certain supernatural beings who may fittingly be called gods, though not in the full sense in which we use the word. That 


\section{THE SOCIAL EVOLUTION OF RELIGION}

rudimentary notion represents in all probability the germ out of which the civilized peoples have gradually evolved their own high conceptions of divinity; and if we could trace the whole course of religious development we might find that the chain which links our idea of the Godhead with that of the savage was one and unbroken."

Intimately linked with the growth of the idea of the god was that of the king and his powers as the representative of the god or as the god himself in human manifestation. Frazer has shown that the magician or medicine-man was the earliest differentiation of a professional member of the tribe, that this class itself produced a variety of special activities, and adds: "the most powerful member of the order wins for himself a position as chief and gradually develops into a sacred king, his old magical functions falling more and more into the background and being exchanged for priestly or even divine duties, in proportion as magic is slowly ousted by religion. Still later, a partition is effected between the civil and the religious aspect of the kingship, the temporal power being committed to one man and the spiritual to another."

Interpreting the process by which the magician develops into a priest, Frazer says that "the king, starting as a magician, tends gradually to exchange the practice of magic for the priestly functions of prayer and sacrifice. And while the distinction between the human and the divine is still imperfectly drawn, it is often imagined that men may themselves attain to godhead, not merely after their death, but in their lifetime, through the temporary or permanent possession of their whole nature by a great and powerful spirit. No class of the community has benefited so much as kings by this belief in the possible incarnation of the god in human form." 


\section{THE SOCIAL EVOLUTION OF RELIGION}

Ancestor-worship exists today in China in a form more elaborate and complete than in any other country, and in a form surpassing in many of its details that of ancient Rome. In the seven volumes of de Groot's The Religious System of China, published in Leyden, is given a detailed account of every phase of this religion, as it is there now in active operation. On one side it is a pure naturism, a worship of all the powers of the physical universe. It is called by de Groot Universism, and such it is in fact; but this phase of it belongs to the state, which alone is entitled to conduct the rituals by means of which it finds interpretation.

The religion of the Chinese family, however, is an ancestorworship, and is kept up with great assiduity even at the present time. This was the religion of Confucius, and, though he did not originate it or in any essential sense add to it, his approval and sanction were given it. This may have served in some measure to keep it very much alive to our own day. This worship is justified, to the Chinese mind, because the fundamental powers of Yang and Yin find manifestation, not only in every part of the universe, but also in every human being. The soul in man is a part of the divine universe itself, and manifests all its qualities. Therefore, the universe-worship and the ancestor-worship are essentially of the same nature, except that the one belongs to the state and the other to the individual man, or, rather, to his family.

When the Chinaman worships his ancestors he is also, in fact, worshipping the universe as it expresses itself in them. The microcosm is here directly and intimately related to the macrocosm; and the adoration of the father is in fact a worship of the primary principle of creative power manifested in the universe in the form of Yang, the all-comprehensive masculinity. Ancestor-worship in China is not merely a reverence or 


\section{THE SOCIAL EVOLUTION OF RELIGION}

worship paid to the dead, but to the universal principle of life and power found in the universe, and consequently in man himself. The truth is, says de Groot, that the dead of a family are its patron divinities, worshipped and sacrificed to like all other gods, with quite similar incense, spirits, food, and dainties, quite similar genuflections and khotaos, all with the plain object of obtaining their blessing.

Chinese ancestor-worship is a form of animism; and it is connected with the belief that all forms of life are possessed of spiritual power, and have in them some kind of spiritual essence. The whole world is filled with spirits, and the Chinaman might be said to be the most convinced spiritist to be found in any land or time. Daemons are present everywhere, some of them good, more of them bad. A large measure of the ancestral religion of China consists in seeking to escape from evil spirits, and the ills they bring upon man. Demoniacal possession is a reality in China, and the exorcism of such powers of disease and harm demands much attention and much effort. Not only does the Chinaman believe in spiritual powers, but he believes in far too many of them. They work him harm on every hand, both day and night, and throughout every phase of his existence.

There is a good side to ancestor-worship in China, as well as one that is unpropitious. The bad spirits may be always present, but so are the good ones; and it is through the good that the evil are driven out, and made ineffective in their efforts to cause harm. Were there nothing but evil in this worship it would soon disappear; but the benefits are many, according to the ancestor-worshipper. He therefore continues to adore the dead of his family, and to trust in their readiness and their capacity to give him the aid he needs. He may be sometimes deceived, and sometimes the ancestors may fail to 


\section{THE SOCIAL EVOLUTION OF RELIGION}

afford him succor; but for the most part they are as powerful as they are beneficent, according to his way of thinking.

The Chinaman has had the opportunity to accept the teachings of Lao-tsze, which has confirmed him in his reverence for the dead. He has also been offered Buddhism, which he has to a large extent added to his more primitive form of religion; but he has not, therefore, found it necessary to discard the old worship. Islam has come to him, but he has not been greatly attracted to its strict and dogmatic theism. Christianity has knocked at his door, but, as yet, he has only heard the knocking, but without willingness to admit it into his house of life. Something in the reverence for ancestors, the linking together of the generations in a great bond of reverence and. worship, still wins his admiration and his faith.

\section{VII}

It has been already mentioned that feudalism appears when tribal society is in the process of growth into the organized and developed state. The incipient stages of this process may be studied among the Maori of New Zealand. It found expression in Japan down to the revolution of a half-century ago. In India it found its manifestation at the period when the Aryans were conquering the indigenous races of that peninsula, and settling down as the dominating race in the northern portions of it. What it was in that region may be best studied in the Mahabharata, and in the episode of it known as the Bhagavat-gita. In Greece it found its interpretation in the epics attributed to Homer. The first stages of it in western Europe claim attention in the Nibelungen-lied; and those which were later may be found defined in the codes of the early peoples of that region, in the great body of lyrical 


\section{THE SOCIAL EVOLUTION OF RELIGION}

poetry then produced, and in the various phases of chivalry, perhaps also in the crusades.

Feudalism in western Europe reached its highest manifestation in many respects; and nowhere else did it develop all the phases which it there presented. In that region it appeared largely as a lordly control of the great mass of the people, by men living in castles, holding all the land about them, and by military organization dominating common life, politics, commerce, and religion alike. The social basis for this type of development may be regarded as having its foundation in ancestor-worship, which gave sanction to the idea that some men are born to rule over others by right divine. The feudalism of western Europe had outgrown the more material phases of that worship; but its spiritual implications remained, and they were effective in creating a class ruling as if appointed of God.

The divine right of kings had its beginnings in the belief that rulers are the direct descendants of the gods or that the gods have endowed them with superhuman qualities, in order that they may fitly govern others. Other causes operated to give working power to this belief. One of these was the organization of society for purposes of war, and the demand that all men hold themselves in readiness to heed the war-call of the king or the lord. Society was so organized in ranks or grades as to bring about this result with least delay and in the most effective manner. Another influence leading in the same direction was the theoretical ownership of all the land by the king, who parcelled it out to his followers in proportion to their ability to furnish warriors for his conquest of other states.

Under feudalism religion becomes feudalistic, with belief that all rulers of church and state alike are sent of God, and are free to direct the affairs of others according to their will. 


\section{THE SOCIAL EVOLUTION OF RELIGION}

In Japan Shinto recognized this grading of the different orders of society according to their spiritual rank. This appears most definitely in India, where caste was not merely a social institution, but also a most important phase of religion. Status rules under such conditions, one is born into a certain grade in society, and has no power to remove himself from it, whether it be a low grade or a high one. To a large extent this was true in western Europe, where feudalism ranked society into lords, freemen, and serfs as concerns labor and political duties; and into saved, probationed, and damned by birth as concerns religion.

As we pass up through the several stages in the processes of social and political evolution, from the primitive band or group to the developed state, we may discover a movement towards the modification of religion, in harmony with these industrial and social changes. This process of change is not everywhere harmonious, and the intimacy of religion and social processes is not uniform in all regions. Modifying causes are many, and they prevent an even march of progress through all stages of this evolution. It appears, however, that as the group enlarges the progress is more rapid, for that means a wider connection of tribe with tribe and city with city; and that there is a larger process developed of intercommunication, and of the amalgamation of ritual with ritual and belief with belief. The primitive band has little intimate contact with other groups; but when the stage of the city-state has been reached, as in Greece or northern Italy, many modifying developments of society and religion appear. Commerce is much extended, men travel to other lands, rituals are freely borrowed, and a synthetic process takes place, which widens all phases of life, both as concern social and spiritual interests. Early men live largely in their emotions, and in gratifying 


\section{THE SOCIAL EVOLUTION OF RELIGION}

the primary needs of existence. But as society develops, and there comes a wider touch with other peoples and forms of social and industrial expression, men become thinkers, and speculate about causes, the origins of things, and the fundamental nature of what they see and are. Philosophy slowly advances to an interpretation of nature and life, crudely at first, but with more and more of boldness, and with a firmer grasp on realities. Since the social processes are those with which men are most familiar, they naturally at first read these into the world around them, and find them a measuring rod with which to determine all other phases of the world they know. Very slowly speculation newly interprets religion, broadens its sanctions, and more clearly defines its gods.

In the advance of society from the tribal to the feudal form of organization, there was a corresponding growth in religion from animism to anthropomorphism. Animism grew out of the industrial conditions existing in the clan and the tribe, and it reflected the mental attitude of the gatherer, the hunter and the early agriculturist. Not the less, it was bound up with the early stages of the evolution of the arts of life, those arts of a practical nature which concerned the immediate needs of a primitive communal form of society. In such a community everything in man's environment was of a like nature with himself, and animism reflected this reading of man himself into the whole of the world around him. When death came to have some degree of thought expressed in its interpretation, and it was sought to relate it to the interests of the living community, then animism developed as a world of ghosts and spirits impinging upon man's interests and determining his welfare here and hereafter.

The social advance to feudalism or to the highest stages of tribal organization and rule, which slowly led on to the forma- 


\section{THE SOCIAL EVOLUTION OF RELIGION}

tion of the state, had the effect of gradually supplementing animism by anthropomorphism. The animal gods became human gods. The vague mana and orenda gave way to a definite conception of human-like powers as working in every phase of the environing world. With the appearance of ancestorworship, and the development of the chief and the king, the spirits took on a human form. They ceased to find their chief expression in an undefined animatism or in the form of animalbeings of supernatural powers, and became fathers, that is, genuine human powers residing in a world beyond that of the living. In this manner animism gave way to anthropomorphism, the spirits and the gods becoming more and more human in all their characteristics.

This process went on slowly, and required thousands of years for its full development. It did not go before, but followed, the process by which the tribe was changed into the feudal form of society, first, perhaps into the city-state, and then into the developed nation. This was a greatly important advance for religion, which gave to the gods a definite form and a truly human manifestation. In the early phase of evolution the god might abide in a tree, an animal, a thunder-stroke or a star; but now he became as a man, with all the properties and abilities of a man. In becoming man-like he came nearer to men, and his power was vastly increased.

We may rightly assume that anthropomorphism or the man-like conception of the gods has never wholly superseded animism or even that religious phase known as animatism. Undoubtedly these early phases of religion, and of cosmogonic interpretation, were more nearly universal than any that have succeeded them. The law of social heredity or the working principle of tradition has kept them very much alive down almost to our own day, and has by no means banished them from 


\section{THE SOCIAL EVOLUTION OF RELIGION}

the higher phases of religion and philosophy. They live on in all but the more developed phases of religion, those which have come most under the influence of the methods and the spirit of science. No higher religion has escaped the powerful influence of animism, and under Christianity the belief in spirits as yet holds a dominating sway in controlling the popular conception of the world and life. Even about the conception of God lingers much of what is animistic. It has been said that we never know how anthropomorphic we are, and we may assert with equal truth that we never realize how animistic we are, even at the present day, and in the highest phases of religion.

Nevertheless, it was a great advance when the tribe grew into the state, and when the vaguely defined ghost grew into a definite conception of a human-like spirit. The limitation of this advance was that the god was conceived of as in the form of a chief or king, that is, an autocratic and dominating spiritual ruler. Society ceased to be democratic, as it was in the early tribe, and it became aristocratic, with the father, the chief, the king or the emperor as a theocratic ruler over the society with which he was mainly concerned. This was undoubtedly an advance in the conception of the nature of the ruler, but it was also an increase in a dominating and often vexatious authority. It was no longer the group with which the individual was concerned, with its spirit of democratic authority, its equality of all the members on a basis of common needs and mutual interests; but subjection to an autocratic ruler, with power of life and death.

Every phase of this progress from animism to anthropomorphism, from a religion of ghosts to a religion of spirits, from shamanism to priesthood, was a reflection of the changes going on the industrial, social and mental life of the human 


\section{THE SOCIAL EVOLUTION OF RELIGION}

community. Indeed, we must assume that the basis of this change is to be found in the progress of the arts, in the changing sources of the food-supply of the community, and in its forms of social and political organization. We might truly say that it is a reflection of the progress made from a social to a political form of organization; that is, from a communal or tribal form of society to one that is feudal or political.

It is at this stage in the evolution of religion that myth finds its highest expression, its most perfect development. Myth is of the very nature of anthropomorphism, since myth is the conception of the action of all world-processes as result of the doings of persons. Religion always remains in the mythical stage of evolution while it attributes the origin of the universe, the advances of civilization and culture, the invention of morality and the arts, to the work of personalities or a personality with supernatural powers. This is the essential characteristic of myth, and of all religion which is of a mythical origin. Only when religion sublimates its conception of God, rids him of his personal attributes, sees in him no longer the weaknesses and the caprices of the personal, is it enabled to escape from the domain of the mythical. While it is mythical it is impossible for it to cast off the animistic, and to escape from the thralldom of primitive traditions.

\section{VIII}

The evolution of feudal society had a very effective influence on morals and all ethical conceptions. It was the period when the moral codes came into existence, when the decalogue first took form (though in different regions, and under other religions, the number of commands might be less or more), and when ethical precepts took on a distinct tone 


\section{THE SOCIAL EVOLUTION OF RELIGION}

of command for the individual. The system of tabus did not as yet disappear, but it was gradually replaced by such ethical principles as might be applied to individual conduct. Morality became more and more such as the priest and the king would approve, and such as would promote the enforcement of their authority. It became autocratic. The tabu element remains in the negative form of the decalogue of the Hebrews, commanding what should not be done, rather than what would be most conducive to the welfare of the community and the individual.

In this period of transition the blood-feud underwent a change, and crimes could be compounded for by the payment of money. The tribal demand that all deeds injurious to the tribe should be punished by the community, all members of the offending tribe being held responsible for the acts of each of its members, in no inconsiderable degree remained in force. Such offences, however, though dealt with by the community, were subject to compensation by other processes than those of exacting a tooth for a tooth. Sometimes the offender was handed over to the community against which he had offended, and he was adopted into it in place of the man he had slain. Again, a graded system of compensation in goods or money was devised, by which offences were atoned for. Another method of dealing with crime was that of providing places of refuge to which the criminal might escape, and would there be free from molestation until his friends might compound for his evil deeds.

Gradually customs grew into laws, and jurisprudence found its feeble beginnings. This change indicated that the individual was having recognition as being alone responsible for his evil deeds, that motives as well as acts were coming to have appreciation, and that tabu was developing into definite 


\section{THE SOCIAL EVOLUTION OF RELIGION}

moral principles, enforced in a systematic manner by the community. Though it may appear that these changes indicate a growth in mildness and sympathy in dealing with offences against the community and the individual, yet the fact remains that punishment was of a harsh and often of a cruel nature. If the slave was sometimes treated with leniency and humanness, he was often regarded as no more than a beast, and dealt with accordingly. The criminal was too often regarded as a wild animal, a viper, and used in the most brutal manner. $\mathrm{He}$ was stricken down without mercy, it might be, or he was immured in dark and foul dungeons, fed only that he might continue to live and suffer, or forgotten until death brought release. One result of these methods of punishment by autocratic authority was the conception of the torturing punishment to be meted out to the offender against God in the future world.

Undoubtedly the ethical systems which grew up under feudalism were in some respects more advanced, and socially more conducive to human progress, than those which appeared under the conditions of tribal society; but in other phases of them they were less advanced and less humane. The growth of autocratic power placed the offender and the worker, as well as woman, under conditions making life less kindly, more difficult to carry through with success for all who are below the governing ranks in society. The development of property gave power to those who possessed it, and made their lives ampler and happier; but for those who did not accumulate it, and they were the great majority, the ways of the world were dark, and happiness often a meager shadow. 


\section{CHAPTER V}

\section{National Religion}

T $\mathrm{N}$ his volume on The History of Religion, C. P. Tiele 1 speaks of the great influence of national character on religion; and he refers also to the difference in the character of races, the nature of their home and occupations, and the historic relations in which the various religions stand to their neighbors, as having a considerable influence in modifying their development. He also points out how the mingling of races, by means of migration and conquest, and the transition from the wandering life of hunters and fishermen to the settled tasks of agriculture, and the establishment of regular states, have deeply affected the evolution of religion wherever these changes have come about.

Without doubt the formation of states, and the acquisition of a permanent national life, have been among the most widereaching causes influencing the modification of early religions, the abandonment of animism, and the acquisition of theistic beliefs. As we have seen, there has been a growth in religion corresponding to the changes which have brought about the evolution of the hunting band into a tribe, with organized clans; and the beginnings of the arts and methods of culture. A further advance was made when tribes were amalgamated to form confederacies, city-states or the earlier stages of national organization. The same causes which transformed the band into a tribe, and the tribe into a feudal autocracy, also in time brought about the enlargement of feudal into national society. This process was brought about by peaceful federation and by 


\section{THE SOCIAL EVOLUTION OF RELIGION}

conquest. The Iroquois afford an instance of the union of tribes into a confederacy by the friendly agitation and solicitation of Hiawatha, though he was vigorously opposed in this effort. In time it was brought about by this personal influence, and because it became apparent that a union of tribes would secure many advantages. However, at a later time the Iroquois made use of force in compelling other tribes to join their confederacy. Probably the Iroquois, in the course of a few centuries, would have developed a state organization had not their evolution been disturbed by the coming of the whites.

In Mexico one of the most successful states in America was organized as the result of conquest, though peaceful amalgamation was also a potent influence in the formation of the Aztec nation. The same statement will apply to the kingdom formed in Peru under the Inca influence and capacity for organization. Not too much emphasis, however, is to be placed on individual genius in this respect, for there can be no question that climatic and other similar external causes were in one or another degree favorable to the development of the early states. All the advanced civilizations in America originated in the region extending from Mexico along the Pacific coast as far south as northern Chili. The political development in this narrow though much extended region was not continuous; but here were all the most advanced growths, and the presence of the only genuine states. In Mexico, Central America, New Granada, Colombia, and Peru, tribes had been combined, political power had begun, and had advanced to a considerable degree of perfection. In Peru, especially, one of the most highly organized states along communal lines had been secured.

When we consider the rudimentary industrial development attained to in America, the rudeness of the tools and weapons, the slight degree of advancement in the military art, and the 


\section{THE SOCIAL EVOLUTION OF RELIGION}

almost entire absence of commerce, methods of travel and transportation, it may be recognized that no considerable progress could be made except in the localities most favorable for the cultivation of the soil, on which these peoples almost entirely depended.

When we turn to the eastern continent we find that similar conditions led to similar results. Almost without exception the early civilizations grew up along river valleys or in other most favored regions as concerns climate, soil and opportunities for commerce. One of the earliest of these was that which appeared in the river valleys of China, and was to a considerable degree shaped by the conditions there afforded. The Aryan civilization in India began along the Indus, and then spread eastward down the Ganges. Every step in its progress through northern India was by means of armed conquest; and for centuries this people was under arms in forcing back the native population, and in their subjection. Another great civilization grew up in the valleys of the Euphrates and the Tigris, which was not only one of the earliest, but in many respects one of the most important. The other very early civilization was that which appeared in the valley of the Nile, which has held a great place in the world's history. Other centers of states, proceeding from a time very remote, was that eastward of the Persian gulf, and those bordering on the Mediterranean. The valley of this great inland sea acted on the peoples who settled in it in much the same manner as did the rivers to those of the more eastward regions.

No claim is here made that the early civilizations were the results of the conditions mentioned but that these favored climatic regions, and their advantages of location, merely afforded the opportunities which aided in developing race, political organization, and social genius. Such opportunities led to the 


\section{THE SOCIAL EVOLUTION OF RELIGION}

migration of the most capable races into these regions, and to their being utilized in behalf of an advancing civilization. Not one of the races settled in the regions mentioned appears to have been indigenous to them, but were attracted to them because of the facilities they offered for agriculture, industries and commerce. Some of them were won by conquest, some by peaceful amalgamation with the original inhabitants; others appear to have had successive invasions, and to have developed a highly mixed population, which finally led to an amalgamation into a distinctly new race.

Migrations were the result of the changes in climate, the failure in the productiveness of the soil, owing to the oncoming of those conditions which produced the deserts of the eastern continent, and the ensuing failure of the food supply. Another cause, though less frequent, perhaps, was the result of over-population and the consequent inadequacy of the soil to produce food in sufficient quantities. Under these conditions a part of the tribe or the feudal community divided off, and sought unoccupied or more productive regions. The results produced by these processes were essentially the same.

War and conquest played a considerable part in these developments; but it is doubtful if they were in any degree more important than the results which were produced by peaceful migration, the amalgamation of peoples, the coalescence of cultures, and the fusion of religions. The chief value of war in the advancement of civilization was the bringing together of races and cultures, their assimilation to each other, and the mixing of religious rituals and beliefs. These results were of frequent occurrence, it would appear; and the effects were often permanent and beneficial. At the same time, it is not to be forgotten, that populations were ruthlessly destroyed, that women were carried from their homes in great numbers, that 


\section{THE SOCIAL EVOLUTION OF RELIGION}

they were cruelly made to serve the purposes of their captors, and with little regard to their own welfare. If in this way peoples were mingled and newly created, culture assimilated to culture, and civilization broadened by mingling with civilization, it can only be said that this was the worst of all possible means which could be followed for the advancement of human welfare. Good came, but evil followed with uncompromising certainty.

It is designed here to suggest that the causes which furthered the progress of civilization were also those which promoted the advancement of religion. No higher religion ever grew on a barren soil or under conditions where art, industry, morality and civilization could not progress. The religion of the tribe is that which naturally grows out of that type of social organization, while feudalism produces a widely different type of ritual and faith, largely because the social and political forms of organization are of another variety. When the state is reached we come upon still another kind of religious movement, with rituals largely modified, and a fresh quality of moral conduct.

It must not be assumed, however, that there is any sudden break in development or that fundamentally the religion of the state is of another type than that of the tribe. A continuous advance goes on, though not without rapid movements of change during shorter or longer periods, and not without times when an actual degeneracy appears; but the general trend is along the same lines which lead to social and political modifications. Without doubt a lower religion may be modified by a higher one, even without large regard to those movements which change the nature of the state; but this is assuredly not the case in the early periods. What this all means is that mankind advances, not in sections, but in the whole of its characteristics; and as 


\section{THE SOCIAL EVOLUTION OF RELIGION}

a totality. When a tribe or a state is modified in one direction, the ultimate outcome is a change of the whole life of the people in question.

Under all the early civilizations the religion follows the lead of national development. As the state is, so is the religion. Social progress indicates religious advancement. Political growth leads to a modification in the character of the religion. Because the early states largely grew up in a considerable degree of isolation from each other, the religions developed largely in independence. Probably no state was without influence from some other or wholly failed to impress itself in some degree on those in its immediate vicinity. In the absence, however, of means of communication and transportation, most states were not in immediate touch with their neighbors, as is now the case; and they were not directly and immediately influenced by what was proceeding outside their own borders. There resulted a religious growth largely conditioned by the inward life of the state, and according to its material, ethical, and cultural progress.

\section{I}

What has been just said will apply especially to the religious progress of China. One of the most isolated of all the early civilizations, it was not wholly shut off from outside influences; but was comparatively little affected from outside its own borders before the time of the invasion of Buddhism. China was to a large extent geographically isolated, because of the extensive desert to the westward, and the mountain barriers to the south and south-westward, with few avenues of transit into the regions beyond. The result was that in China we find a more independent development of religion than in any other part of 


\section{THE SOCIAL EVOLUTION OF RELIGION}

the world, unless it be in the instance of Mexico and Peru. For this reason, it may be, the religion of China was very conservative, closely adhered to the primitive animism, natureworship, and reverence for ancestors.

Chinese traditions give us only the most limited intimations as to the beginnings of the civilization which grew up in that land. We infer, however, from such knowledge as we possess, that the state developed from a condition of tribal society, through feudalism, to a federal monarchy of the loosest possible type. In the time of Confucius there were many states, and these were in almost constant contention with each other. His life was largely devoted to the task of reconciling these states with each other, and to the bringing about such unity of the people as would promote morality and the general welfare.

At first there appears to have been a tribal society, each tribe having a number of clans, with exogamy, and animism, reverence for animals, and worship of the powers of nature. With the growth of ancestor-worship, which came with the later stages of tribal society, and an advancing patriarchalism, there appeared, under feudalism, a perfected type of naturism. The family being the most primary and the most important of Chinese social institutions, its political and its religious life alike partook of the type thus created. The state became an enlarged family, with gradings upward from the household, through the village, the province, to the kingdom itself. The political methods employed were essentially those suggested by the organization and government of the family. The king or emperor was only the father of the state; and as the head of the family managed its affairs, so the emperor and his government managed the interests of the state. The result was that the religion of China was a family religion, with Heaven and Earth as the great universal parents, with the Emperor as 


\section{THE SOCIAL EVOLUTION OF RELIGION}

their heir and representative in the human world. The worship was essentially that by the family of its ancestors, conducted by the head of the family, in the family mansion or in some place especially connected with it. The village worship was that of a group of households, probably all related to each other; but of the same essential nature. On behalf of the state the Emperor led in the imperial worship of Divine Heaven; but it was also of the family type, a recognition of the kinship of the lowest family all the way up to the Emperor as at the head of the great family of the nation, and then still higher up to the one imperial family of all the dead and all the living under the supremacy of Shang-ti, Father Heaven.

The Chinese religion has, perhaps owing its early isolation, remained distinctly animistic and of the ancestral type. It has no developed mythology, no pantheon of great gods, and, consequently, no priesthood. The religion being throughout distinctly of the family type, there has been no demand that the rituals and the ceremonials, as well as the prayers to Imperial Heaven, should call for a distinctive class in order to their administration.

If the Chinese have felt no need for a great number of gods, and their religion is in no inconsiderable degree a monotheism, yet they have repaired this limitation, if such it is, by the vast number of the nature- and ancestor-spirits in which they believe. Nowhere has daemonism and spiritism been so nearly universal. The whole world is peopled with these beings, mostly beneficent, but also very often evil in nature and intent, needing frequent propitiation and exorcism.

What we find in China we find also in Corea and Japan, for these countries were a unit as to their culture, the Chinese carrying at an early time their civilization into both of these other lands. The Japanese having proved themselves highly 


\section{THE SOCIAL EVOLUTION OF RELIGION}

intellectual and progressive in our day, we naturally assume that they have always displayed the same qualities. The early religion of this people, however, shows a paucity of those higher characteristics we anticipate discovering in an alert and advancing people. The gods are not distinctly anthropomorphic or individualized, not even to the extent we find in Polynesia and America. They are nature-powers with no positive personal qualities. The mythology is primitive, almost degenerate, and with no large phases of action and energy displayed. In this respect the Kojiki and Nihongi, the early books in which it was presented, show it to have been one of the rudest and least advanced to be found among any people progressing toward civilization. As in China, the religion was largely a worship of nature and of ancestors. Every natural object had its god and all nature was a dwelling-place of spirits innumerable.

Advancing, however, through a prolonged feudal period to statehood of an imperial type, the religion of Japan has been gradually modified, and in the direction of a priestly class administering the rites devoted to the family gods and to the great powers of nature. Animism has not disappeared, ancestorism remains prominent and the regard for nature, as the dwelling-place of powerful spirits, continues with almost unabated effectiveness.

\section{II}

Turning to Egypt, which has many characteristics similar to those found in China, we may observe that religion in the Nile valley has been modified in intimate connection with the growth of the social and political evolution of the land. We know little of the primitive conditions, but we may infer that they were those of a stone-age people, with animism of the usual type, probably quite similar to that found in many parts of Africa at the present time. Then came tribal society, with 


\section{THE SOCIAL EVOLUTION OF RELIGION}

its growth from primitive bands of the hunting type, its advance to a form of feudalism, then the formation of two states, a northern and a southern, and finally the unity of the whole of the valley in one mighty empire. In the early time the valley was settled by tribes along the greater part of its length, perhaps in the totemic stage of development, with each tribe having an animal ancestor or guardian. When the state form of organization was reached the country was still divided into districts, each of which was named after an animal. Probably these nomes, as they were called, were the territories of the original tribes. What had taken place, then, was the unification of a considerable number of tribes under one general political organization. This process of growth from bands and tribes to an empire marks also the general direction of the gradual unification of the religion of the people of the Nile valley, its development of larger conceptions, and of higher grades of divinity.

As in China, Egypt in the early period had no priestly class, and the king was the head of the national worship. Beginning in animism, passing up through ancestor-worship to an elevated form of theism, the Egyptian people retained throughout their belief in many gods. As in most other ancient lands, this was owing, to no small extent, to the fact that each tribe had its own divinity, and each of these was incorporated into the national system when that came into existence. This tendency was forwarded by the fact that Egypt was in intimate relations with the Berber peoples on the west and the Arabs on the east. In the period of its highest political development it made war in Syria, Babylonia, and in the Hittite land. This brought the people into relations with the religions of these nations to the eastward and northward, and to the assimilation of their rites and beliefs to a considerable extent. In time came the Greek and Roman conquests; and still other religious 


\section{THE SOCIAL EVOLUTION OF RELIGION}

changes more or less assimiliating the products of these later political developments.

The Egyptians, however, were very conservative in regard to all which concerned their religion, and were always reluctant to make anything more than superficial changes in their mythology and ritual. The old religion remained through all the centuries of Egyptian history, and the changes made were of the nature of additions rather than of assimilations. In some respects more truly than any other people they venerated the dead, partly because they most firmly believed in the resurrection of the body, and partly because they had attained to a firm conviction that the soul is to live immortally. Great monuments were erected to enshrine the mummies of the dead, and in order that the proper respect might be paid them.

In however large degree the Egyptians resembled the Chinese in various particulars, they greatly differed from them in others. Their mythology was far richer and more elaborate, and their gods were of a far more definite personal type. However, as in the case of the Chinese, they venerated animals, and even worshipped them; and they included the great powers of nature as gods in their pantheon, even the Nile itself. The sun-god $\mathrm{Ra}$ was theoretically the chief of their divinities, and the other gods were largely grouped around the principle of sex, including Osiris and Isis. None of the gods were infinite, omnipresent or omniscient. There inhered in them all the limitations of humanity, with its weaknesses and defects.

Naturally, the character of the country, the dependence of the people on the Nile and its annual inundation of the land, and the agricultural pursuits of the whole country, had a very important influence on the evolution of the religion and the development of its mythology. The principle of fertility, the necessities of growth for plants and animals, the anxious wait- 


\section{THE SOCIAL EVOLUTION OF RELIGION}

ing for the round of the seasons, found their intimate expression in many of the phases of the religious life. Light became of the utmost importance, and was recognized in the worship of the sun, its overcoming of darkness and the attendant evil. This found expression in the corresponding idea that life is able to overcome death, which plays such a great part in the remarkable Book of the Dead. $\mathrm{Ra}$ as typifying light, and warmth, and growth, overcomes the serpent Apap, the embodiment of darkness and whatever it represents for man.

Every interest of life came under the influence of the Egyptian religion. Worship was domestic as well as public; and it included alike birth, marriage, and death. There were lucky and unlucky days, dancing had a religious significance, music played a considerable part in the religious services, magic retained its part in the religion; but the festivals of sowing and harvest were in many respects of the greatest importance. The two ceremonies which were the most popular were those of fertility, which took place in connection with planting, and that celebrated at the harvest period. The first of these festivals was connected intimately with Osiris as the god of fertility, and his images or representations played a large part in its symbolisms. There were other festivals, some of them connected with the kingship, one of them coming once in thirty years, and celebrating the deification of the king as Osiris.

A remarkable exemplification of the manner in which the union of nomes into states affected the religion may be seen in connection with the myth of Osiris. In the tribal period the three personages of this myth were quite independent deities, with no connection with each other whatever. Each was the deity of a separate nome; but when these nomes were brought together and unified in a higher political organization, the three gods were amalgamated and grew into a family. In his 


\section{THE SOCIAL EVOLUTION OF RELIGION}

article on the Egyptian Religion, in the Encylopædia of Religion and Ethics, Flinders Petrie says of this process of coalescence: "Thus the best known triad of Egypt was compounded of the gods of three independent tribes, Osiris, Isis, and Horus, who were linked as a family when the tribes were fused together." The same process undoubtedly went on in many other directions, and the gods grew, and the religion developed with the changes in the social and political evolution of the Egyptian people.

It would be interesting to follow the Egyptian religion through its several stages of growth and decay, to enumerate its numerous gods and their attributes, to indicate how the rituals and festivals grew as the religion unfolded, and what social purposes to which they answered. To accomplish this task however would require more space than it is possible to assign it here, and would not directly serve the purpose had in view in these chapters. In a brief way it has been intimated how the Egyptian religion was in large measure the result of the fortunes of the Egyptian people, and reflected their life and their social ideas. This method of interpretation might be carried much further, but space forbids any extension of the treatment accorded it in these pages.

\section{III}

We may proceed to a brief survey of the Semitic religions, with the same object in view, that of suggesting a close relationship between the religions of these peoples and their forms of social and political organization. The Semites included the peoples of Arabia, Palestine, Phoenicia, Syria, and those of Mesopotamia, together with the Chaldeans and Assyrians. The Egyptians were closely related to the Semites, as also were the 


\section{THE SOCIAL EVOLUTION OF RELIGION}

Ethiopians, though in both instances there was an ethnological basis in the native African tribes, with infusions from other sources.

The Semitic peoples afford a good illustration of the manner in which religions change with political evolution, since they included the Arabs, who were before Mohammed in the tribal stage of evolution, and were passing slowly upward to the feudal stage. On the other hand, the peoples of the Euphrates valley had reached a very high stage of industrial and political development as far back as 4000 years B. C. Even then they had attained to large and prosperous cities, a highly elaborated art and architecture, an advanced stage of writing and literature, and to one of the most highly developed mythologies and systems of worship. Regarding the beginning of Chaldean, or what is usually known as Babylonian, religion, the monuments afford us only the faintest intimations. It is probable, if not certain, that the Semites in the valley of the lower Euphrates, or in its near vicinity, followed a people of Mongolian or Turanian origin. Since the Semites originated in Arabia, and migrated to the great river valleys at a very early period, it is by no means impossible that they were preceded by a people of other race and religion. As this appears to have been the case, it cannot be doubted that the Semites assimiliated the culture and the religion of this people; and there are some important reasons for believing this to have been true in a period far remote, perhaps approximating 5000 B. C. This people is usually known as the Sumerian.

The religion of the primitive Arabs, as probably that of all the early Semites, was animistic and of the nature of shamanism, that is, largely given to magic and the propitiation of spirits. In no small degree this was the character of the religion of the early settlers of Judea. They came from northern 


\section{THE SOCIAL EVOLUTION OF RELIGION}

Arabia into that region, gradually overcame the Canaanites, with their worship of Baal and the other gods of a harsh and somewhat cruel religion, probably also of Semitic origin. At first this people, whom we know in their successive stages of advancement as Israelites, Hebrews and Jews, were in the tribal period of culture, with the usual characteristics of such peoples. They were probably animists, made use of magic, worshipped plants and animals, revered the powers of heaven and earth, and were polytheists. When the sacred books of the Jews came into their final shape, in the period two or three centuries B. C., they were edited with the purpose of convincing their readers that these phases of the old worship were wild aberrations of certain elements in the population; but that they had no real place in the beliefs of the great majority of the people. That assumption we can no longer accept, for we find mythology, legend, folk-lore, and witchcraft woven into the very texture of the early developments of this religion. In the three volumes, extending to seventeen hundred pages, of his Folk-Lore in the Old Testament: Studies in Comparative Religion, Legend and Law, J. G. Frazer has most elaborately dealt. with the folklore and legendary elements in the Jewish scriptures. He deals with the legends of the early ages of the world, the patriarchal age, the time of the Judges and the Kings, and the origination of the Law. From every part of the world he gathers illustrative materials showing that this great body of folk-lore and legend is to be widely parallelled elsewhere on the part of many savage and barbarous peoples. In a word, he makes it fully apparent that there is nothing peculiarly Jewish in the earlier books of their collection of sacred writings.

The national god, Yahweh, was of late origin or greatly changed in character with the evolution of the Hebrew state. At first borrowed, very probably, from another people, and 


\section{THE SOCIAL EVOLUTION OF RELIGION}

when first taken over by the Hebrews was a god of thunder or of storm, he gradually came to supersede Baal and Chemosh, the gods of the preceding peoples in Palestine. In the books describing the early phases of Hebrew life in Canaan, we find that a prolonged struggle took place between these gods and Yahweh, with the result that he became greatly victorious. It may be recognized, however, that this acceptance of Yahweh was only by a small class, and that the winning over of the whole body of the people did not come for many centuries.

It was through the work of the prophets that Yahweh finally became the national god. The early members of this class were essentially polytheists, and recognized Baal, and the gods of the neighboring peoples, as also existing, and as real as their own. At first Yahweh was no more than a national god, the exclusive divinity of the Hebrew people. Almost certainly he did not become in any true sense a universal god, the one real Divine Being, until after the return from captivity of those who had been in exile because of their fidelity to their own divinity. The contact with the religions of Persia and Babylonia, both of which had theistic phases of much importance, and especially the former, undoubtedly had a considerable influence in developing the conception of Yahweh as the one universal God. Probably, also, the bitter experiences of exile, and of weeping by the willows of Babylon on the part of these exiles, had an effect in creating a new devotion to their own god. Many an individual cares little for religion until some great disappointment or sorrow comes upon him; and this may also be the experience of peoples. Exile made these men believe that they had been faithless to their own true god or they would not have been crushed as a nation. Therefore, they returned to preach and practice a more ardent loyalty to Yahweh, and to accept as never before the conclusion that they belonged to the chosen 


\section{THE SOCIAL EVOLUTION OF RELIGION}

people of this god of theirs. Tried as by fire, they came to the developed faith of the Hebrew in one exclusive and jealous god, the Lord of Heaven and Earth.

The claim often put forth that the Hebrews had revealed to them the faith in monotheism, which they gradually came to accept, might be made also of most of the other great religions of the ancient world. Monotheism is not the exclusive idea of any one people or religion, but may be found in one or another phase of its evolution in nearly every part of the world. The clans or gentes in tribal society worshipped one exclusive god as their very own, and they might probably be called monotheists, and especially since they likewise believed that this god had been revealed to them. Polytheism results because, when clans are federated into tribes, tribes into feudal communities, and these into states, there is a constant process of coalescence of the several gods, and of the rituals and worships connected with them. In nearly all communities, and especially those of the higher type, there is the distinct recognition of some one god as superior to all the others, and as the great essential force that controls the ongoings of the universe and humanity.

\section{IV}

If we turn back to the Babylonians, we shall find in an early period that Marduk was the high lord over all gods and men, though there were many subordinate gods reigning over various phases of nature or human affairs, but subject to his will, as dukes and earls are under the control of kings. What this means is, that as the social and political affairs of the people were reduced to order, a king placed at the head of the state, and the subordinate ranks, grade after grade, made subject to his final authority, so in religion order and system grew in 


\section{THE SOCIAL EVOLUTION OF RELIGION}

the same manner and to the same ends. As men obeyed the laws, which grew to be more precise and specific, so did the gods also obey the dictates of the great imperial sanctions and purposes of the Supreme God, from whom emanated all order and law. As men grew into a more definite and systematic conception of ethical principles, and into a more definite acceptance of theories of conduct, so did the gods become more and more ethical in their relations to one another and to the nation they served.

The myths of the Babylonians were perhaps midway in their display of creative power between those of China in their paucity, and those of India and Greece in their brilliancy and their elaborateness. The creation story is somewhat rude, but it has for us the interest that it was at the basis of that we find in the Hebrew book of Genesis. It has come now to be an accepted conclusion, that the Hebrews adopted their myths from the Babylonians or that they were the generally wide-spread and common Semitic attempts at an interpretation of the origin of the nniverse and of man. The manner in which the Hebrews reconstructed these myths, and brought them into conformity with their advanced theism, undoubtedly belongs to that period when all the history of this people was being reconstructed to meet the demands of the more advanced beliefs of the later time. We cannot to-day regard the story of creation, the origin of man, the garden of beauty, the fall of man, the casting out into the darkness of savagery, the flood and the rescue of one family, the condemnation of Sodom and Gomorrah, the talking of Abraham with his god, the fall of the city of Jericho, the standing still of the sun, and many another folk-tale of the early time, as other than mythical. These legends are of essentially the same nature as those which may be found in every part of the world, and are to be interpreted in the same manner, as expressions of 


\section{THE SOCIAL EVOLUTION OF RELIGION}

the expanding nature of the human mind under the influence of industrial, social and political phases of evolution.

Some of the myths and epics of Babylonia are of great interest, especially that of the going down of Ishtar into the world of the dead, and that of the adventures of the culture-hero Gilgamish. These show the great literary power that had been developed among the Chaldeans, and the nature of their constructive genius. These epies may be studied in connection with the developments of the relations of Tammuz or Adonis, Aphrodite, Hyacinth, Attis and Cybele, Osiris and Isis. In such myths as these we find the early Semitic religions interpreting themselves in their largest intellectual capacities.

These myths make it certain that the Semites, as well as the more barbarian peoples like the Chinese, and the more advanced of the Aryans, regarded the gods as of both sexes; and that they were bound together by ties of affection and marriage. The love of Adonis and Ishtar was of a romantic quality, and symbolized those forces of nature which gave spring and winter, growth and decay, life and death. In several of these myths the wife is the older of the two, and appears to be the mother of her lover, as well as standing to him in the other relation. The mother who marries her son, as is in several instances the case in the Mediterranean religions, is not to be assumed to mean that this was a direct interpretation of human relations. Mother-nature or Mother-wheat may bring forth a son who symbolizes the plant which grows from the earth as the result of the coming of spring and summer. For these myths are interpretations of the processes of nature, of the eternal round of spring and summer and winter. The upspringing vegetation of spring appears as one god, that of the perfected growth of summer, one of the different character, and the death that comes upon all things in winter, still another. This last 


\section{THE SOCLAL EVOLUTION OF RELIGION}

stage, however, is usually represented as the death of a god, and his resurrection when the spring comes back again.

If we choose to study the several stages in the evolution of the Semitic religions, from that of the primitive Arabs to that of the most advanced Babylonians and Hebrews, we shall find them keeping pace with the social and political evolution constantly proceeding from century to century. Such a study must convince us that, while no one of these religions may be a direct creation of the social process in every phase of it, yet that the two developments are intimately connected, and that it is the social evolution which precedes the other. As are the laws, so are the gods. The nature of the people determines the nature of the religion. The worship reflects the standards of the tribal or national life. The myths are no more than the inmost life of the people translated into the actions of great personalities.

\section{V}

The evolution of the Aryan religions proceeds in the same manner as those of the Semites, and those of the other savage and barbarian peoples. In all of them, even the very highest, we find the presence of animism, magic, animal- and ancestorworship, a multitude of contending and brutal gods, a vast world of ghosts and spirits, and developing rituals and festivals. The myths of the Aryans are more elaborated, with personalities more distinct and real, and expressing greater artistic and epical power, than those of most other races.

The Aryans include the Persians and Hindus, Greeks, Romans, Slavs, Teutons, and Celts. Probably the lowest religion found among these races is that of the early Slavs, which was thoroughly animistic and magical, crude in the extreme, and without a mythology at all developed. In the earliest period 


\section{THE SOCIAL EVOLUTION OF RELIGION}

of which we have any historic knowledge, they appear to have been at about the same stage of advancement as the pre-Islamic Arabs. From this stage in the evolution of religion the Aryans advanced to the highly elaborated religions found in India and Greece.

When we first know of them, all the Aryan religions remained animistic, magical, in the stage of animal-worship, and beset with ghosts and spirits. In some of them, it may be, these phases of religious expression were in the form of survivals; but for none of them had they been cast aside as no longer serviceable. What enabled the Aryan peoples to turn away from them was not so much the higher thinking of the philosophers, the Platos and the Aristotles; but that the state was developing, that tribal society was being outgrown, that greater communities than the city-state were coming into existence, that feudalism was being superseded, and that the several states were coming into contact with each other, that myths, religions, and philosophies were being communicated from one nation to another, and that a world-unity in this direction was being formed, albeit a world-unity extending only a little way outside the valley of the Mediterranean, reaching from Persia to Rome, and including Egypt.

What the tribal religion was among the Aryans may be seen in the case of the Teutons, who worshipped great nature powers, had a mythology of a somewhat advanced type, believed in a world where the evil were cruelly punished, and accepted an animistic conception of the soul, ghosts and spirits. As with most of the other Aryans they believed in human beings who possessed godlike powers, and in some instances were actually gods in their own nature. Charms, incantations, magical processes were made use of in order to control the spirits and the gods. Among the Vikings of Scandinavia the gods were of 


\section{THE SOCIAL EVOLUTION OF RELIGION}

like nature with the men of that bold and warring race, great heroes, born fighters, daring adventurers, and cruel haters of those who offended them or refused to obey their commands. Very human gods were these, even if, as in the instance of Thor, they were nature-powers, such as thunder, raised to superhuman expression.

The religion of the Celts may have been in some degree less fierce and cruel than that of the Teutons; but it included all the features which may be found among the Germanic tribes, and widely over the world, as we have seen elsewhere. Its basis may probably be found in nature-worship, including the worship of animals, rivers, trees, and plants. As with all the other Aryans, much of their ritual, as well as many of their festivals, circled around the growth of vegetation, and the securing of good crops by magical aids. In fact, with both the Teutons and the Celts, magic was regarded as a most potent force, and was largely employed. Witchcraft extended far down into the middle ages, and has by no means been outgrown as yet. It played a great part in the life of western nations for many years; and nothing in the whole history of religion was more brutal, barbarous, and fearful than the persecution of witches by the Christian church, when many thousands of women lost their lives.

Here, as elsewhere, a process went on which is often met with in the history of religion, by which the old gods were transformed into saints or devils by the newer and more progressive faith of the later time. Isis became the Virgin Mary, Demeter was transformed into a male as St. Demetrius, and many a Teutonic and Celtic god or goddess lived on in a fresh form as a power capable of aiding the peasant or of serving the ends of the church in keeping alive under the new forms the old beliefs. The church canonized more than one heathen divin- 


\section{THE SOCIAL EVOLUTION OF RELIGION}

ity as a Christian saint. The witches were often no more than the old goddesses modified to suit the new conceptions in regard to the nature of divinities and spirits. Both the Celts and the Teutons worshipped goddesses who were often quite equal to the gods, and also worshipped women possessed of divine qualities or born of divine parentage. These goddesses, as usual, were connected with fertility, the productiveness of the earth, as well as the growth of plants and animals.

The old religions of the Teutons and Celts have by no means as yet disappeared from the life of to-day. They may be now described as "survivals;" but they live on vitally in the life of the peasants and those of little education. In the folk-lore, the folk-customs, the festivals, and even in the actual beliefs of great numbers of persons in all the countries of Europe, these old religions are even now very much alive. On this subject, J. G. Frazer, in the preface to the first edition of The Golden Bough, pertinently observes: "The primitive Aryan, in all that regards his mental fibre and texture, is not extinct. $\mathrm{He}$ is amongst us to this day. The great intellectual and moral forces which have revolutionized the educated world have scarcely affected the peasant. In his inmost beliefs he is what his forefathers were in the days when the forest trees still grew and squirrels played on the ground where Rome and London now stand."

Where the Aryans originated we do not positively know; but it was probably not far from the Baltic sea. Wherever it may have been, the Aryans were much given to migration, wandered widely in Europe and Asia, and did not entirely refuse to invade Africa. They wandered widely to such an extent that it has been claimed by various investigators that the Veddahs of Ceylon, the Todas of southern India, the Ainus of Japan, and the Maotzi of China were of this racial origin. Nor have the 


\section{THE SOCIAL EVOLUTION OF RELIGION}

peoples of the Pacific Islands been left wholly out of this connection, some of them, including the Australians, presenting features warranting the Aryan designation. These claims have not been substantiated, and probably will never be fully justified. From whatever source they originally came, one of their great migrations was into central-southern Asia, and finally into India. In some prehistoric period a considerable body of them appeared to the eastward and northward of the Persian gulf. In this region they appear to have remained for several centuries, it may be, and then they divided, one part remaining in that region as the Persians of history, and the other passing southward and invading India.

\section{VI}

We may justly assume that the religion of this undivided body of Aryans was similar to that of the Slavs, and of the Teutons and Celts as first known to us. Primarily it was animism, with shamanism prominent, a worship of animals and the great forces of nature, and with a gradual development of a world of spirits and elemental gods. In Persia the Aryans developed a worshipful regard for fire, and either accepted it as a god or as a symbol of divinity. They also worshipped the heavenly bodies, and came to have an occult regard for the stars. In this respect they followed the leading of the Babylonians or developed a kindred interest in the heavens and their nightly display of constellations. In both regions there grew up the beginnings of the science of astronomy; and men felt that their destinies in all their affairs were determined in large degree by the occult powers exercised by the heavens over them.

There appeared in Persia a reformer by the name of Zarathustra, usually known as Zoroaster, who gave a quite new 


\section{THE SOCIAL EVOLUTION OF RELIGION}

form and meaning to the old religion. In no small degree he was a creator, as well as a reformer. Probably it would be truer to say that around a reformer there gathered social and intellectual influences which in time produced a remarkable religion, not wholly new, but making a quite distinct advance on the old nature-religion of the Aryans. It is by no means certain that such a person existed as is described under the name of Zoroaster, though it is probable, if not wholly certain, that such a man lived and brought about changes in the ancient rituals and beliefs.

Zoroaster did not claim to have been a god, but to have been commissioned to purify the old religion, and to bring it into conformity with the new needs of his people. Behind this claim of divine sanction to bring about required reforms we may rightfully assume that there were to be found social and political causes demanding modifications that would bring the religion to a condition of harmony with the newer phases of the national life. The people of Persia had advanced from a congeries of tribes into a nation moving forward towards a much higher civilization than that of the Aryans when they migrated from the northward into the territory of Persia.

The most distinctly marked phase of the religion usually designated as Zoroasterianism or that of the Avesta, was its dualism, the belief in two gods, one good and one evil. Whence came this conception of duality running through all the affairs of nature and humanity, it is not now possible to say. Many students of this religion assume that it is to be found in the superior moral conceptions of Zoroaster, that he saw clearly. the ethical distinction between the good and the evil, righteousness and sinfulness. Without doubt, the religion of the Avesta is one that places great emphasis on the contrast between right conduct and sinful behavior. 


\section{THE SOCIAL EVOLUTION OF RELIGION}

The claim, however, that Zoroaster was superior to his time in this respect does not appear to be fully maintained; and we may question if what is attributed to him was not developed at a later period. Was it rather, as in Egypt, that there was a recognition of the distinction between light and darkness, life and death? Many of the phases of the Avestan religion would appear to confirm this conjecture, though we may accept the conclusion that there had arisen in Persia a fresh insight in regard to ethical problems, with a greater emphasis on conduct beneficial to the state and to the individual.

Not wholly to be turned aside from, however, is the idea that the Persian dualism arose in those primitive conceptions we find in the Chinese Yang and Yin, the Greek Father-heaven and Mother-earth, and the principle of sex as fundamental to all interpretations of the origin and nature of the universe.

A great amount of evidence might be brought together in favor of the suggestion that the evil side of the dualism on which the Zoroastrian religion was founded had its origin in the nature of the receptive or non-creative element in the universe. This conclusion is more probable than that it was purely a metaphysical or even an ethical consideration which was at the foundation of this dualism. It may be that no such distinction was in the mind of Zoroaster, but in those ages of growing folkconceptions it may probably be found a basic hint at the dualism which formed a large element in this religion of the Persian people.

Zoroaster was, if not distinctly a monotheist, at least closely approaching that type of belief. His Ahura Mazda or Ormazd, though opposed by Angro Mainyash or Ahriman, was finally to triumph; and the whole universe was to come under his rule of beneficence and righteousness. On the whole, this was one of the most noble and ethical of all the Aryan religions, and 


\section{THE SOCIAL EVOLUTION OF RELIGION}

had a very considerable influence on the growth of the religions of the Hebrews, the Greeks, and even of Christianity.

\section{VII}

Turning southward, we follow the other branch of the eastern Aryans into India. They invaded that peninsula along the valley of the Indus, and then, passing eastward, entered the valley of the Ganges. When they entered India they had not left behind the tribal form of social organization, and, they have never quite outgrown it, as the Chinese have not. In India they retained also a large measure of the old Aryan animism, a no inconsiderable measure of the methods of magic, and had by no means outgrown animal- and nature-worship.

As they passed eastward in their conquest of India, they were a band of warriors, always armed for war, for invasion, and for the subduing of the native populations. In the epic poems we find fully described this phase of the Indian life, its constant readiness for war, its heroic attitude to all phases of life, and its determination to allow nothing to hinder the aim to bring the whole of the peninsula into subjection to their arms. Even the high gods, as we read in the Bhagavat-gita, were with them in their great exploit, and made it certain that their aims should never permanently fail of their object.

As they moved forward to their successive conquests, these Aryans developed their religion, newly conceived their gods, and saw in the whole of nature the presence and the voice of these divine beings. The heavens, the nightly sky, the sun, the planets and the stars, thunder, mountains, dawn, the growing world of vegetation, the earth itself, were accepted as having divine powers or as being the abodes of mighty supernatural beings. To these powers they danced, sang, made festival, of- 


\section{THE SOCLAL EVOLUTION OF RELIGION}

fered incense, or performed ritual ceremonials. All of this was reproduced in the Vedas, hymns written in praise of the gods, which came to be sung at their services of worship. More than a thousand of these hymns were composed during the several centuries that the conquest of northern India was proceeding - composed but not written - for this people did not as yet possess the art of recording their compositions. At a later time these hymns were brought together in the collection known as the Rig-Veda, the last book of which was composed under the conditions following the completion of the work of conquest. The hymns of the Rig-Veda were rearranged for ritual and sacrificial purposes into the Yajur-Veda, together with a number of hymns especially devoted to this purpose. The Sama-Veda consists of the hymns arranged for chanting. In the Atharva-Veda we find another, and more primitive, phase of the religion of these Aryans. The hymns are here edited with the intent of using them for magical purposes, as charms, incantations and conjurations.

The hymns of the Rig-Veda represent or express a very high type of religion, in some instances rising into a lofty theism or a profound pantheism. In the Atharva-Veda we find a religion that is almost primitive, that has advanced but a little if at all above shamanism. It would be difficult to say in what manner or degree it differs from the shamanism of Siberia or North America. If it has advanced at all, it is in its systematization, and its ability to bring a higher form of ritual to its aid. We may be rightly puzzled in an attempt to comprehend how a religion so far advanced as that of the Rig-Veda can bring forth one as primitive and as magical as that of the AtharvaVeda. Possibly, we may be inclined to believe that the magic and the shamanism are much older than the more spiritual re- 


\section{THE SOCIAL EVOLUTION OF RELIGION}

ligion of the Rig-Veda, though it may seem to be later in the relations of the two collections.

As the hymns were gradually added to, were used as prayers to the gods to whom they were addressed, and were then developed into rituals, they grew to have a constantly greater meaning to the Aryan invaders. At last they were accepted as a body of revelation, and to them were ascribed a sacred character. It is because of this growth in the conception of their sacredness, perhaps, which finally, in the Atharva-Veda, gave them their magical nature, their shamanistic power. As the centuries passed, and the conquest had come to an end, these hymns grew to have an ever enlarging significance, as embodying the religion of this people. Having come from a period far in the past, and having lost much of their meaning for the new age, the hymns required explanation, and a large body of commentary grew up about them. This is what is known as the Brahmanas, which largely added to, or grew out from, the Rig-Veda, the larger and in some respects more spiritual and more philosophical phases of religious expansion. There followed the Upanishads, the epies, and a great number of other works, in which the successive stages of the Vedic religion grew into that of Brahmanism and then into Hinduism. No brief statement can make it wholly clear how and why these phases of development succeeded each other; and the manner in which they expanded out of the primitive animism with which the Aryans began. Brahmanism followed Vedism when the people had settled down permanently in India, became adjusted to its tropical climate, especially in the central and southern regions. Hinduism followed the advent of Buddhism and Jainism, and the new adjustments they compelled the old religion to make, and as resulting from the efforts for the expulsion of the former. 


\section{THE SOCIAL EVOLUTION OF RELIGION}

One of the results of the conquest of India by the Aryans was the production of caste as a rigid system of social and religious distinctions. The prolonged task of conquest brought about the development of a compact body of warriors, who gave themselves wholly to the demands of that occupation. Since the constant presence of the enemy compelled the warrior class to be alertly on their guard day and night, ready to meet attack at any moment, and ready always to push forward their conquests, it is evident they could have no other occupation. They were obliged to depend for their subsistence on a cultivating class. As has been the case nearly everywhere, a warrior class despises those who become cultivators, artisans, and are given to any kind of mercantile pursuits. These classes were not only despised, but they were in large measure excluded from the interests which were those of the warriors.

At this stage of social development the interests of religion, at least so far as concerned the warrior class, were in their own control. In time, however, it became necessary that the hymns should be remembered, recited, used for magical and religious purposes. Gradually there grew up a priestly class devoted wholly to these offices. The brahman, as the priest came to be called, made a third class, and one who, in time, came to regard himself as far superior to the other classes. With the conquest and subjection of the native population, who were much darker than the Aryans, there appeared a fourth or servant class. Here we have the four original castes - the Brahmans, the Kshatriya, the Vaisya, and the Sudra, - the priest, the warrior, the farmer and merchant, and the servant. In time a great number. of other castes made their appearance, as these four were amalgamated, and as new occupations arose. Nowhere else in the world have such rigid and exclusive distinctions been made between social classes as in India, though in its essentials caste 


\section{THE SOCIAL EVOLUTION OF RELIGION}

is to be found widely elsewhere. The distinction of caste is primarily social, but it enters deeply into every phase of the religion of India, making it difficult, if not impossible at present, to secure any genuine unity of the people in the acceptance of one comprehensive faith.

The religion which grew out of the Vedas, and which regards the hymns as a revelation, is known as Brahmanism. Many are the gods adored or worshipped by the followers of this religion; but the leading characteristic of it is that it is chiefly a religion of ceremonies and observances. This statement may be made of practically all early religions; but the Aryans of India greatly elaborated their ceremonials; and in the ritualistic books the most detailed accounts of them may be found. Perhaps the leading features of these ceremonials were those connected with sacrifice. These were of a magical character, and were regarded as more potent than the acts of the gods themselves. According to H. Jacobi, in the article on Brahmanism in the Encyclopædia of Religion and Ethics, sacrifice "is not offered to a god with the view of propitiating him or obtaining from him welfare on earth or bliss in heaven; these rewards are directly produced by the sacrifice itself, i. e. through the correct performance of complicated and interconnected ceremonies which constitute the sacrifice, and which are more of the nature of magic than of worship. Though in each sacrifice certain gods are invoked and receive offerings, the gods themselves are but instrumental in bringing about the sacrifice or in completing the course of mystical ceremonies composing it. Sacrifice is regarded as possessing a mystical potency, superior even to the gods, who it is sometimes stated, attained to their divine rank by means of sacrifice."

This manner of regarding sacrifice, and of its control by the priest, places the brahman in a position superior to that 


\section{THE SOCLAL EVOLUTION OF RELIGION}

even of the gods themselves. By means of the mystic potency of the sacrifice, he controls the gods, and compels them to serve his purpose. It naturally follows, therefore, that the brahman became the leader in religion, and that Brahmanism shaped itself around this dominating influence of the priest. The tropical temperature of India, its enervating climate, the absence of facilities of rapid transportation, led to the development of industrial and political conditions which bred a spirit of peace and stagnation. The peninsula was divided into many small states, and a very large aboriginal population remained throughout the land, against which the Aryans felt compelled constantly to protect themselves. Under these circumstances asceticism grew into great proportions, and many men went away into the wilderness to think of god and to develop their spiritual powers. All of these conditions gave the brahman a dominating position in the life of the Aryan people, and shaped in large degree the nature of the religion which came to be known as Brahmanism. This was the religion of a people who were chiefly concerned with spiritual interests, and with those things which would bring them into harmony with the gods.

When the aborigines had been completely subdued, and the Aryans settled down to the life of farmers, artisans, and herders, they gave much of their time to speculation; and this was especially true of the ascetics. Many forms of philosophy were developed, no less than six leading systems being produced. These ranged all the way from the most extreme idealism to materialism. The nature of being,- the qualities of the soul, the relations of man to the spiritual world, engaged the attention of these thinkers. Practically all modern forms of philosophy were anticipated by them, and with great elaborateness and subtlety. Some of the systems regarded mind or spirit as the only reality, others found it in matter. Perhaps the favorite 


\section{THE SOCIAL EVOLUTION OF RELIGION}

idea was that of one Supreme Self, of which all individual selves are phases or manifestations. This conception is worked out in great detail, requiring the closest attention to follow the lofty but intricate speculations which gave it meaning to those who accepted it.

Justice would not be done to the Aryans of India, however, if we regarded them as mere dreamers and ascetics. In fact they produced a comprehensive body of customs, and developed to the fullest extent a code of family and community law. In the Code of Manu, compiled at about the beginning of our era, we find a detailed system of family conduct, connected with a high morality, but mixed with many crudities and superstitions, as they seem to us. This body of customs and laws, dealing with the duties of householders, heads of families, students, rulers; and, in fact, all the members of the community, gives a remarkable picture of the life of this people in the several centuries after the permanent settlement of the Aryans. More elaborate works on law, such as the Yajnavalkya, Narada, Mitacshara, were also written dealing more comprehensively with the duties of rulers, and with the management of states; but not neglecting family and household affairs. In many respects these works form the earliest treatment of the principles of jurisprudence; but always in connection with religion, and with the obligations owed to the gods. All students of jurisprudence feel obliged to go back to these books in order to secure an intimate knowledge on which the basic principles of that science historically rest. Here was the beginning of Roman, as of all later, law on a comprehensive basis.

The struggles of Brahmanism with Buddhism, from the sixth century B. C. onward for several centuries, led to the development of Hinduism, which varied greatly from Brahmanism, and in many particulars. The gods were different, and 


\section{THE SOCIAL EVOLUTION OF RELIGION}

the rituals were greatly modified. Essentially, however, the religion of India remained the same, even if new gods came into existence. To the Hindu dharma is of chief importance, and is that body of customs, laws, institutions, rites, and festivals which shape the conduct of the Hindu. After caste, the most distinguishing feature of Hinduism is the belief in transmigration or metempsychosis. The origin of this conception may be found in the recognition by many primitive peoples, that the child resembles its parents and others of the members of its family. In Australia, west Africa, and in other regions, heredity means the return of the soul of the dead to inhabit a new body. The Aryans of India developed this conception into a systematic interpretation of the nature of the soul, and that which determines its future destiny. According to the deeds of the individual was the nature of the life he lived hereafter, whether he returned in an animal, a bad man, a woman, or in some state superior to that of man. Hinduism came to hold to the doctrine that the soul passes through an eternal round of existences, which was described under the symbol of a wheel, every point of the circumference of which returns again and again to the same position. It was against this theory of a continuous succession of existences that Buddha chiefly directed his religion, and sought for a means by which the wheel might be abandoned, and the succession of lives brought to an end.

Hinduism has become in some measure a missionary religion, is drawing into its fold many of the aboriginal tribes, thus giving them a higher social position, as it invaded Indonesia centuries ago and made its presence greatly felt.

\section{VIII}

The most highly developed, the most intellectual, and the most artistic of the Aryan religions, was that of Greece. We 


\section{THE SOCIAL EVOLUTION OF RELIGION}

cannot doubt that it began in animism, and that it passed through stages of magic, fetishism, and possibly totemism. We know that it worshipped animals, and many of its gods were of a plant or animal origin, and that some of them, from time to time, passed into animal forms. In the animistic manner, it found its higher gods in the great powers of nature; and it had regard to a great world of spirits and daemons. In the early periods the religion of the Greeks was mainly ritualistic, and found expression largely in ceremonials, festivals, and sacrifices.

The first phases of the Greek, as of most if not all other religions, circles around the demand for the productiveness of the earth and of those plants and animals which afford food. To secure the products of fertility the first rituals appear to have been developed. Since the earth was cultivated by women, perhaps wholly in the beginnings of agriculture, these rituals were theirs, and such as they found conducive to the results desired. The Thesmophoria and other rites were of this nature, all of which had a basis in the conditions of agriculture. This phase of early religion gave origin to the great sowing and harvest festivals, and to the personification of the forces expressing themselves in the growth of plants. To invoke the nature-powers, which would fertilize the seed placed in the earth, that would bring the necessary rains to promote the growth of the plants, and that would bring forth abundant harvests to the farmer - these were the phases of the early religion which seemed most deeply to impress the people. These demands led to the greatest of all the rituals, that connected with the Mysteries enacted at Eleusis. The great productive forces, in their two phases of the growing plants in spring, and the maturing plants before the time of harvest or 


\section{THE SOCLAL EVOLUTION OF RELIGION}

at that period, personified in Persephone or Cora and Demeter, formed the most striking of the Greek myths.

The phase of the Greek mythology and religion which usually claims attention is that found in the great pantheon of which Zeus was the head. We may perhaps feel convinced that the agricultural rituals represent a matriarchal period in the industrial and social development of the Greek peoples; but it seems most probable that the gods on Olympus interpret or result from the later patriarchal social growth. The Olympian pantheon or system of gods does reflect the conditions of a people who accept the father as the head of the family, and the king as an autocrat in the state. Olympus is a family, a group of related and intermarried gods, all under the rule of the dictator Zeus, who is himself subject to that fundamental law of nemesis which is superior to all gods, because impersonal and eternal. Even the supreme god must bow to this principle of fate or of fundamental necessity, that is, of the law which underlies and gives meaning to all existence.

The Greek race was never coordinated into a central state, but remained largely under the conditions determined by their tribal history, and were grouped into city-states, with loose confederacies of these from time to time. This failure to reach any higher phase of nationality may account, in no inconsiderable measure, for the failure of the people as a whole to reach the monotheistic stage of religious evolution. Though the gods in all the communities were much the same, there was no religious centrality, because there was no federation of the cities into one effective nation in its political institutions. When Sparta fought its long war against Athens, and conquered, all chance for a unity of the many cities came to an end; and with this failure came the last Greek opportunity for a perfected theism. The philosophers could reason their way to a unitary 


\section{THE SOCIAL EVOLUTION OF RELIGION}

conception of nature and life, but in the absence of a national organization this became impossible for the great mass of the people.

In the writings of Plato and Aristotle the philosophical thinking of the ancient world reached its highest standards. In the later centuries, when the Greek states had lost their autonomy, and had come under the rule of the Roman empire, the teachings of these men came to have a great influence; but it was under another than the Greek religion that this extension of larger ideas found acceptance. The unification of the world about the Mediterranean, brought about by Roman conquest, prepared for the teachings of the neo-Platonists, the Stoics, and other broadening movements of thought.

In connection with these movements it is interesting to note the remarkable revival of the earlier phases of religion which appeared under the influences of Macedonian and Roman political developments. The Olympian religion was distinctly masculine, patriarchal, autocratic, and intellectualist. With the political changes there came a despair of the world as it then existed, a call for some interpretation of life that would satisfy the emotional nature, and that would unify human interests in the spirit of brotherhood. These results could not be attained by means of the state or with the aid of the Olympian religion. There followed a great revival of the old agricultural religions, the religions connected with the interests of women as to their origin. This may account for the remarkable increase of interest in the Eleusinian Mysteries, and in other cults bringing considerable bodies of persons into fellowship with each other. Even more than this, perhaps, was the demand for some assurance in regard to the future of the soul. The mysteries, in a series of rituals, dramatic presentations, and elaborate initiations, gave the required faith in re- 


\section{THE SOCIAL EVOLUTION OF RELIGION}

gard to the destiny which the soul might expect. At Eleusis men and women alike were received into the fellowship, as were slaves and foreigners. What could not be secured by means of the state, what the Olympian religion failed to give, was brought to the people in a manner the most impressive and convincing - to them.

The phase of Greek religion, as distinct from philosophy, which has most impressed the modern world is that which found expression in art, including the drama and poetry. For many years it was assumed that Hesiod and Homer created the religion they describe, but it is not in their writings that we find the best interpretations of what religion was to the Greek people. This may be found in the dramas of Aeschylus, Sophocles and Euripides, and in various of the minor poets and later writers. The great creations embodied in the myths find expression in these dramas in a manner which brings the religion home to us as to what the Greek believed, how he felt, and what were the motives controlling his life. This cosmic order of the gods and heroes, of godlike-men and of manlikegods, with their world controlled by supreme principles of moral order, justice, friendship and fellowship, is one understood by the dramatists, as it was not understood and interpreted by the philosophers.

In the plays we see the great traditions, which had grown into shape through many centuries, receiving a presentation that was masterful and convincing to the hearers as to the true principles of life and conduct. These plays brought out a supreme religious expression, presented in the most impressive manner, and with an interpretation of the doings of the heroes and gods who determined the ethical conduct of men and states. 


\section{THE SOCLAL EVOLUTION OF RELIGION}

The other phase of the presentation of the Greek religion, that of the artistic, supremely presented by the architect and the sculptor, brought directly before every eye and mind the real nature of the gods and the heroes. The best work in these directions of Egypt, India, and Babylonia was crude compared with that of Greece. Here was perfection of harmony and beauty. Zeus here stood forth in all his majesty as the thunderer and as the law-giver. Apollo reached the very height of manly beauty and dignity. Aphrodite gave the ideal of womanly beauty, as Hera did that of motherly care and fidelity, and Artemis that of one who loved the free and the wild.

The religion of the Greek in the early period largely found expression in dances, festivals, rituals, music and dramatic presentations; but that of the later time was embodied in architecture, the drama, and sculpture. In the theatre, on the buildings which came to greatly adorn a city like Athens, might be daily heard or seen the best interpretations of the religion of the better portion of the people. The old dances, rites, and festivals had not been abandoned; but in the city the gods were brought very close to the lives of the people, and made to appear as real beings.

Yet, with the changing times, loss of political autonomy, failure of the spreading life of the Greek people into new colonies, there came a questioning of the old beliefs and the old gods. Philosophy satisfied some, tradition pleased many more; but there was a desire for new gods, and these were brought from many lands. In this manner a great syncretist movement was developing, with increasing acquaintance with the civilizations of Babylonia, Syria, Phoenicia, Egypt, Anatolia and Rome. The Greeks were an alert-minded people, free from the conceit that nothing more was to be heard or known; and they were constantly widening the borders of their faith, 


\section{THE SOCIAL EVOLUTION OF RELIGION}

the depth of their philosophical thinking. Here in this land began the work of science, and here for the first time arose the spirit of free inquiry into the causes of the changing phenomena of nature, with a search for underlying and eternal principles, capable of an interpretation which would satisfy the inquiring spirit of men. 


\section{CHAPTER VI}

\section{International Religion}

T $N$ the international religion two factors are of very conL siderable importance, the commingling of religious tendencies and ideas from various national sources, and the influence of individual originators. The first of these developments is probably much the greater of the two, though it usually receives but a small degree of recognition. When we give attention to the fact that there can be no international religion until the preceding stages of tribal, feudal and national developments have been passed through, though not all of them may be absolutely essential, it will be recognized that this phase in the history of religious evolution carries with it great significance.

Until national governments have definitely made their appearance, and have gained a stable and independent form of organization, it is impossible that there should be anything approaching internationalism, either for the state or for religion. The king precedes the god in any really monotheistic sense of the word. Recognizing the fundamental law of all religious history, that the world of spirits and of the supernatural is a reflection of the world of social and political and industrial activities on the part of man, it follows that there can be no unitary conception of the other world and of god until there has been developed a state in which there is one law and one ruler. In the ages when the state is growing to have a definite 


\section{THE SOCIAL EVOLUTION OF RELIGION}

and wide-reaching influence on human affairs, it is for the first time possible to conceive of divinity as having a personal and a thoroughly law-giving power.

When the state had come into existence, and there had begun the process of the federation of states or when they had begun to have frequent intercourse with each other in the interests of commerce, exchange of ideas and customs, or when conquest had brought scattered communities under one widereaching national spirit, then began the process of the amalgamation of religious rites, customs, and institutions. Perhaps the most distinctive phase of this process was that of the growth on the part of the votaries of a religion of a desire to make their rites and beliefs known for the good of the peoples of other states than their own, even when conquest had not taken place. In this way the religion of China spread to Corea and Japan along with its laws and its institutions. It was not in a missionary spirit that this process was brought about nor was it with any idea that the religion of itself had a special and saving merit; but as a part of the Chinese culture, without which the educational methods and the philosophical principles could not be conveyed to another people. Religion and culture in this instance were one and the same.

In the same manner, and in the same spirit, the religion of the Aryans in India spread to the eastward, and pervaded the whole of Indonesia, at least in all those regions where there was a sufficient degree of enlightenment to appreciate it. In this instance, it was not so much conquest as commercial penetration, which served to propagate Brahmanism in other lands. 


\section{THE SOCIAL EVOLUTION OF RELIGION}

In much the same manner Zoroastrianism was diffused westward, and came in time to penetrate the Roman empire to some extent. Here the process was an intellectual one, rather than one of conquest or commercial activities.

We cannot study any of the more advanced regions of the ancient world without coming upon the fact that, slow as were the methods of transportation, and few as were the number of travellers, yet there was going on a constant process of communication from one people to another. The recent explorations in western China indicate that the people of that region were receiving one or another influence from as far west as Greece, and no doubt Chinese ideas and customs were in some measure reaching into western lands. This was certainly the case so far as concerned Persia, with its deification of fire, star-worship, dualism, and its emphasis on what became in the west the Mithraic cult. To some extent, also, the teachings of Buddhism penetrated into western lands; and it has often been suggested that the birth-tales told about Gautama were influential in developing those connecting themselves with the birth of Jesus, especially in the apochraphal writings.

\section{2}

Perhaps no more significant instance of this influence of one civilization and religion on another is to be found than in that of the Jews. From the very beginning of their career, even as a tribal people, they were in close touch with the surrounding nations. The situation of their country not only brought them into intimate relations with the tribes and nations inhabiting the sea-coast, the mountain regions eastward and northward; and the desert regions southward and westward; but also the great nations which passed through their 


\section{THE SOCIAL EVOLUTION OF RELIGION}

country or along its borders on their way to other regions. The Egyptians, Babylonians, Syrians, Hittites, and later on, the Greeks and Romans, penetrated their country as conquerers or settlers.

The diffusion of the Jews to Babylonia, Egypt, and into various parts of the Roman empire, mark different stages of their career. After the time of Alexander the Jews became in large numbers inhabitants of the city in Egypt built by him and which was given his name. Here was in many respects the chief center of Jewish culture and influence; and, soon after the beginnings of Christianity, the Jews were to be found in Rome in considerable numbers. Wherever they penetrated they had an influence on religion, though probably not of any great extent. Far more important is the fact, that this contact with other peoples marked important and considerable changes in the religion of the Hebrew people. From the Babylonians they took the origin myths on which their religion was based, from the Persians their dualism, and from the contact with the Greeks no little portion of their later and more progressive culture and religion.

The period when Buddhism, Christianity, and Mohammedanism were originating was one of the penetration of culture by culture, and of the wide diffusion of social contacts throughout the ancient world. Had it not been for this growing intimacy of peoples, the increasing diffusion of the most fundamental phases of their religious and cultural life, no new religions would have come into existence. F. B. Jevons, in his Introduction to the History of Religion, has suggested that a very considerable change in religious development took place at this period. Before this status or birth determined the religion of a person, for he accepted without choice the tribal or the national faith of his community. At this period, 


\section{THE SOCIAL EVOLUTION OF RELIGION}

Jevons remarks, in his twenty-third chapter: "we find in the ancient world new rites and cults arising which differ from all previous ones, first in that they were open to all men, and next in that membership was voluntary and spontaneous. They were not always or necessarily new religions, for in them the old gods of the nation might still be worshipped, though with new rites. They can scarcely be called sects even, for their members were not required to give up the ordinary hereditary worship of the state to which they belonged. But the idea was now for the first time expressed in action that a man could belong to a religious community which was distinct from the state. The possibility of choice between the worship to which he was born and another was now before him."

This choice as between one and another religion was directly the result of the diffusion of religions through contact of one people with another, and through the origin of new religions, and gods not hitherto known. Until such changes had come about there was no opportunity for choice, for there was but one religion, that of the tribe or that of the nation. More than one religion within a state meant that it should make no choice between them, that it should accept them all as of equal importance, or that it should prefer one to the others, and give that its special protection. In either event the choice was open for the first time to the individual to make his own preference count as regards the form of worship to which he should give his adhesion.

\section{3}

In the Roman empire we well know that many religions found acceptance. The religions of all the Mediterranean countries found reception there. Mithraism was given wide dif- 


\section{THE SOCIAL EVOLUTION OF RELIGION}

fusion, though it originated in Persia. Isis was regarded with a devotion rarely given to any other god. The Jewish faith won the acceptance of a few of the more ethically inclined men of the philosophical type, and who were disposed to receive a distinctly monotheistic religion.

There spread through all nations at this time a form of religion sanctioned by the social needs of artisans of all classes. The clan and tribal forms of religion had largely disappeared, and their place was taken by guild or community cults. Not ties of blood held these together, but occupations of craftsmen, who felt the need of associating themselves in a fraternity for the protection of their common interests. Each guild was a church or religious association, as well as an artisan union for the securing of whatever best concerned the interests of the individuals belonging to it, and of the fraternity as a corporation. Such communities are widely to be found in China, India, Greece, and Rome; and they probably existed in every ancient nation. Each guild had its own god, its own form of worship, and its own cult.

Of a similar nature, in many respects, were many developing new forms of religion widely found in all the ancient states. The highest type of this kind of religion was to be found in the Mysteries of Eleusis and the cult developing around Dionysus. The state protected these cults, and to some extent they were of a national character. But at the heart of them, at least in their more advanced forms, despite their crude origin, they became international. The worshipper was initiated, and was not born, into these religions. They had most solemn rites, and they sought to give the worshipper admission to a more spiritual conception of the world, and to insure entrance to a diviner state beyond death. Such were some of the consequences of the growth of internationalism in the an- 


\section{THE SOCIAL EVOLUTION OF RELIGION}

cient world, and of the wide diffusion of cultural and religious ideas.

Throughout the whole Mediterranean region, probably extending as far east as Persia, and as far west as Gaul and Iberia, it may be said that in no inconsiderable degree there was but one religion. Over all this vast territory the same beliefs and rituals were being diffused, and there was a constant process of intercommunication. This at least may be said, that all the nations of this region, and all their religions, were influencing each other, and there was a process of amalgamation going forward for several centuries. This syneretist process finally culminated in the origin and diffusion of Christianity. In the very nature of this revolution in Hebraism, syncretism was at work, result of the contact of religions and cultures. Had this process not been in active evolution Christianity would not have come into existence. At first a development from Judaism, it rapidly took on a much wider phase, and unified all the faiths of the Mediterranean region.

One other phase of religious evolution must be taken into consideration in connection with a study of the international religions. Without doubt all advanced religions have owed much to individuals of genius, and to those who have been known as prophets and founders. This phase of religious evolution has been undoubtedly too greatly emphasized, owing to the theory that all religions result from the inspiration of these men directly from God. What is the true nature of genius is not usually discussed in this connection, nor is it sought to discover the exact character of the inspiration and revelation in which the developed religions have originated. 


\section{THE SOCIAL EVOLUTION OF RELIGION}

Genius appears to be a heightening of the emotional and mental powers, and a concentration of them in some one or more directions. Most men of genius focus their gifts on some special faculty, and are often lacking in most or all other directions. The man of religious genius is rarely broad-minded and catholic in his ideas. If he is strong in one direction, he is weak in all others. Such men appear to concentrate a strong personality into a single channel of interest and expression. More often than otherwise, they know nothing outside religion; and care not for science, art, law, or culture. They live with God, abide in an ideal realm, are ascetics or given to miracles. In large degree they are quite incapable of estimating wisely and justly their own teachings or of criticizing them from the basis of a large knowledge of other spiritual ideas or beliefs. Therefore, they are fanatics, bigots, dogmatists, and greatly credulous with regard to all that is supernatural. In fact, they are rarely able to distinguish clearly between what is natural and what is supernatural, subjective and objective. Their own emotions, aspirations, visions, even their dreams, they regard as objective phases of what takes place in the world of spirits.

Without doubt some men and women live in a world of spiritual realities, penetrate to the abodes of the spirits and the gods - so it seems to them. The common world, the world of sense impressions, and of objective realities, is to these persons far from being the world of spiritual beings and essential truths. And it is to these persons, as William James has abundantly shown in his Varieties of Religious Experience, that religion owes its force, reality, and assurance. There is always to be recognized in regard to such persons, however, that they are never quite normal in the wider human sense. They belong, in no small measure, to a world apart; 


\section{THE SOCIAL EVOLUTION OF RELIGION}

and form a class by themselves. Reassurances in regard to religion come from these persons, who keep alive the old beliefs, and kindle new ones at the torch of this inspiration of theirs.

We owe much to genius in all its forms - artistic, moral, scientific. It penetrates through the old truths and gives them fresher meanings. It quickens thought, formulates new truths, brings to light fresh discoveries, and makes inventions of great practical benefit. Something daring, courageous, audacious, rebellious is to be found in all true genius, that is, the capacity for breaking away from old leading-strings, for facing realities and not conventions. Most men repeat what they have been taught; but genius penetrates a step or two beyond this, and finds new meanings under what has been inherited.

As has already been said, religion is of all forms of life and thought the most conservative, the least able to break out new paths, and to penetrate far into the wilderness beyond the village or the city. Were it not for the fanatic, the man of an intensely egoistical thought, who can see but from one angle at a time, there would be no religions, at least in the earlier ages of civilization. Therefore, we find that all new religions of the higher type begin with such men, and grow out of one of the old religions. No religion ever arises without such connection with the past, whatever the genius of its founder or whatever the claims put forth in regard to his inspiration or his divinity. Whatever may have been claimed for revelation in regard to any or all religions, the fact remains that religion everywhere is the result of evolutionary processes, that it has its basis in the past, and that it cannot rise higher than the civilization from which it has grown. 


\section{THE SOCIAL EVOLUTION OF RELIGION}

All religions have claimed to be revelations, even those the rudest and the most primitive. This claim is fundamental to the very nature of religion, and gives no superiority to one over another. From the earliest times we find it claimed that the tribal ritual is of a sacred nature, that it has power to control the spirits, and that it must not be in the least degree departed from in its repetition. If even the slightest mistake is made, if its words are not given in their proper order, or if the rite itself is not presented in the orthodox, that is, the prescribed manner, all must be repeated from the beginning. Here we have the beginnings of things sacred, and of even those books which have been regarded as divine. This demand as to the sacredness of religions, - its rites, ceremonials, books, and persons, still remains, - and dominates the interpretation which is to be given them.

It follows, therefore, that religion is regarded as something more than the result of genius, unless we accept this word in its original meaning, as the indwelling in the mind of a spiritual or guardian being other than the true self. Such claim cannot be allowed, and we must insist that religion must come within the laws of mental activity, as to its origin and nature. In the demand that we shall accept it as communicated from some other world than our own, by an order of beings known only to those of religious genius, we find what has not been proven, and what religious history does not justify.

The reasons for this conclusion have been already suggested, in saying that religious genius is of the same nature as other forms of genius; and that all the more advanced religions have their roots in social and political conditions, that is, 


\section{THE SOCIAL EVOLUTION OF RELIGION}

in the nature and needs of man. Whatever the claim made for any religion, what it really is may be found in the constitution of man, both as an individual and in his social nature. Most of the claims made in regard to revelation, and the special nature of religion, have been owing to neglect to study the conditions determining the social and correlated activities of the groups of men described as tribes, and as feudal or national states. Man thinks collectively as well as individually; and this collective thinking is largely accepted as of a sacred or divine nature. In this collective character of emotion and thought most of the sacredness lies. Beyond it most of the claims made are exaggerated or result from a failure to recognize the true nature of human mentality.

\section{I}

If we turn to Buddhism, the oldest of the great international religions, we find that we have before us the problem of a great religious personality, and also the problem of the cultural origins of the religion which came into existence in connection with his name. The most fundamental of these problems is the last, and one without the full recognition and appreciation of which Buddhism cannot be understood. In his time, the sixth century B. C., the Aryans had invaded a greater portion of India and established their supremacy. In fact, the conquest having been completed, they had settled down to a life, partly of industry and agriculture, but largely devoted to questions of ritual and philosophy, and to asceticism. In a degree they had stagnated or come to be content with the conditions afforded by a rich and prosperous country in a tropical climate.

The teachings of the Vedas and of the Brahmanas had 


\section{THE SOCIAL EVOLUTION OF RELIGION}

reached a stage when they were not developing, but had become highly specialized in the directions of ritual, magical practices, and attempts to gain religious truth by means of contemplation and retirement from the world. Into this world was born, to a princely house in northeastern India, a son to a family of the warrior or Kshatriya caste, though caste had not as yet taken on its more rigid phases. This family belonged to the Sakiya elan, and lived not far from Benares, in the small eity of Kapilavastu. He was named Siddhattha, but his family name was Gautama, by which he is oftenest known. The title Buddha is an officicial one, and means the enlightened, signifying that he had attained to Buddhahood or complete knowledge.

In a measure Buddhism was a reaction from the most emphatic phases of Brahmanism, and especially against its many gods and its extreme claims in regard to the nature of the soul. On the other hand, in every phase of its earlier developments may be seen its relations to the older types of religion in India. Gautama became an ascetic and wanderer, when a young man, leaving wife, child and family relations, in order that he might find the true way of life. After consulting many wise men, and after a long period of search for inward quietness and truth, he finally attained to Buddhahood, during a period of contemplation under a tree. Accepting the teaching of Brahmanism, that life in this human world is determined by the wheel of existence, the round of transmigrations from one stage of being to another, he reached the conclusion that it is possible to escape from this vicious circle, and to attain to a condition of calm, serenity, and inward peace. Having reached this condition of freedom from the round of human evils, Gautama had become an Arahat, one free from the wheel of rebirth and evil. This stage of enlight 


\section{THE SOCIAL EVOLUTION OF RELIGION}

enment having been reached, Gautama became the Buddha; and might have passed on into Nirvana (now written Nibbana by Indian scholars) or the state of perfect bliss, and emancipation from all evil and degradation. Gautama preferred to turn back to the human world and its sufferings, in order that he might teach others the means of escape.

The fundamental teaching of Buddhism, that on which rests all its other doctrines, is that suffering is inherent in the life of man, and that it is universal. This teaching is embodied in the axioms known as the Four Aryan Truths, that there is suffering, that it has a cause, that it can be overcome and suppressed, and that this may be done by means of the "path." "It is the will to life," said Gautama, as quoted in Ananda Coomaraswamy's Buddha and the Gospel of Buddhism, "which leads from birth to birth, together with lust and desire, which finds gratification here and there; the thirst for pleasures, the thirst for being, the thirst for power." To bring about the extinction of suffering, therefore, is the great aim of Buddhism; and to secure emancipation from desire, egotism, and the insistance on self-expression. This is to be reached by the eight-fold path, the path of faith or of right attitude toward the sufferings incident to humanity. Rhys Davids quotes from the Vinaya or Samyutta, the words of Gautama himself in regard to his teachings, in this form:

There are two aims which he who has given up the world ought not to follow after - devotion, on the one hand, to those things whose attractions depend upon the passions, a low and pagan ideal, fit only for the worldly-minded, ignoble, unprofitable; and the practice on the other hand of asceticisms, which is painful, ignoble, unprofitable. There is a middle path discovered by [Buddha] - a path which opens 


\section{THE SOCIAL EVOLUTION OF RELIGION}

the eyes, and bestows understanding, which leads to peace, to insight, to the higher wisdom, to Nirvana. Verily! it is this noble right-fold path. ....

Now this is the noble truth as to suffering. Birth is attended with pain, decay is painful, disease is painful, death is painful. Union with the unpleasant is painful, painful is separation from the pleasant; and any craving unsatisfied, that too is painful. In brief, the five aggregates of clinging (that is, the conditions of individuality) are painful.

Now this is the noble truth as to the origin of suffering. Verily! it is the craving thirst that causes the renewal of becomings, that is accompanied by sensual delights, and seeks satisfaction now here, now there - that is to say, the craving for the gratification of the senses, or the craving for a future life, or the craving for prosperity.

Now this is the noble truth as to the passing away of pain. Verily! it is the passing away so that no passion remains, the giving up, the getting rid of, the being emancipated from, the harboring no longer of this craving thirst.

Now this is the noble truth as to the way that leads to the passing away of pain. Verily! it is this noble eightfold path, that is to say, right views, right aspirations, right speech, conduct and mode of livelihood, right effort, right mindfulness and right rapture.

Such, in brief, was the teaching of this warrior turned monk. For when Gautama came to organize his religion it was by means of an order exclusively devoted to its interests. He did not ignore the great mass of the people; but he sought to give permanence to his teachings by ordaining bodies of men and women who should, for at least a part of their lives, live exclusively the life of religion. In this respect Buddhism greatly resembles Roman Catholicism, and also as concerns its rituals and its ideals. In Siam, and in other Buddhist countries, boys enter the order, are educated there, serve a period of apprenticeship to their religion, and then go forth again to the duties of daily life in the world. The Buddhist monk lives on the generosity of the people, who secure merit for the future by contributing to his necessities. In the time of Gautama himself, he and his disciples went forth once each 


\section{THE SOCLAL EVOLUTION OF RELIGION}

day carrying a bowl, from which they ate when the generosity of the people had given as much as was needed. In this way they were wanderers from place to place, preaching the gospel of emancipation from pain and evil, and devoting the rest of their time to meditation and prayer. After the earliest period, however, the monks and nuns were no longer wanderers, but remained in their households, except when gathering food from door to door.

Gautama is usually represented to have discarded belief in God and in a future life. In a limited sense this is true; but, on the whole, it is far from stating his exact position in regard to these religious beliefs. $\mathrm{He}$ did discard the great pantheon of animal and nature-divinities which Brahmanism had accepted; but he did follow the teachings of some of the more philosophical Indian teachers, in that he believed in an underlying reality interpreting and giving meaning to the universe. In China and most other Buddhist lands, the teachings of Gautama have probably been followed by regarding him as a divinity or by the creation of a great number of other beings who rule the universe and its several manifestations. In a word, if he was, as is so often claimed, an atheist, the Buddhists of to-day are very far from being of that type of thought, since they believe in, and worship, a great number of divinities.

What Gautama rejected was the limited and imperfect gods, the gods who were but men in another guise, with all their passions and weaknesses. To what extent he believed in the immanence of God or in an impersonal divinity or in a pantheism of a philosophical type, as did many of the Brahmans, it is difficult to say. At any rate, he did not teach any definite opinions in regard to deity; and with reference to that belief 


\section{THE SOCIAL EVOLUTION OF RELIGION}

he had almost nothing to say in his teachings, probably quite ignoring such a being, but without asserting that he existed or did not exist.

With reference to the future life Gautama's teaching was far more definite, though by Christian scholars he has usually been assumed to have rejected that belief also. Probably both beliefs, that in God and that in immortality, had their basis, so far as he was concerned, in his conception of the soul. He discarded the popular notions in regard to the idea of there being in man an essential nature other than the body and the mind. The idea of the soul, as held in India at the period when he lived, was an evolution from primitive animism; and this was not acceptable to Gautama. An entity unlike all else he could not accept; but his idea was that of the continuity of the results of all past experiences, the karma which has been produced by the round of existences through which the individual has passed in the endless cycle of being. To get rid of all that result of conflict with earth and its sensualities, was his desire. This was the great emancipation.

Buddhism has no cosmology, no theory of origins as regards the universe or humanity. Desire, lust for sensation, craving for the expression of self, has made the world as we know it; and to suppress self is to secure unity with the eternal nature of things, harmony with the infinite realities. This is what the Buddhist calls Nirvana, which is not extinction, but emancipation. It is a freeing of self from selfhood, from all that clogs one's nature, from all that binds one to the round of pain and suffering. Following the higher teachings of the philosophical schools, the individual comes back to the great Self from which he emanated; and he is, as it were, absorbed into the great reality of being. In large degree this is what the Christian, and especially the mystic, has often sought for 


\section{THE SOCIAL EVOLUTION OF RELIGION}

in his conception of heaven, that lust, sin, and wrong would be worn away, and the inner self made free for complete union with the eternal nature of God. Many persons will regard this as nothing less than annihilation or so nearly like it, that they are not able to distinguish between the two. Undoubtedly, however, to the devout Buddhist it means nothing of the kind. Rather does it mean the sloughing off of what is limited, earthly, imperfect, and the gaining, in union with what is permanent, that eternal emancipation of the mind which is perfect bliss. Release from worry, fret, care, sickness, pain, and all individual desire, this was union with the higher Self, and therefore entrance into Nirvana, that is, into quietness and peace. A highly mystical idea, but one found wherever mysticism makes its influence felt in the history of religion.

Buddhism had a great career in India, spread widely over the northern states, then southward, and into Ceylon. In later centuries it passed onward into all the countries of eastern Asia, and notably into Siam, Tibet, China, and Japan. What is most characteristic of it in all these countries is its teaching of the spirit of peace and harmony. No other countries than those accepting Buddhism have been so little given to war. No wars of religion have ever been waged in Buddhist lands. In these lands religious persecution has been almost wholly unknown. This means that Buddhism has been to some degree of a quietistic nature, that it has not been pushing and energetic in the modern western sense; and that the Buddhist lands have been stagnated from the industrial and commercial point of view. It means also that it has been one of the most tolerant of all religions. 


\section{THE SOCIAL EVOLUTION OF RELIGION}

After something like a thousand years in India, Buddhism gradually disarpeared from that peninsula, as a result of the revival of Brahmanism, except in the island of Ceylon, where it has always remained very strong. As it spread northward and eastward, and came into contact with the previously existing religions, largely animistic and polytheistic in their nature, Buddhism showed its conciliatory spirit, and readily adapted itself to the old faiths of the peoples who accepted it, thus largely corrupting it as regards the real teachings of Gautama himself.

As in the case of all other founders of religions, a great body of legend, folk-tale, and myth, grew up about Buddha. The birth-legends are many in number, miracles came to be attributed to him, marvellous tales were told of his early life, and his birth was of a virgin nature and of wondrous import. What was true in regard to his history seems to be very little, but what was told of him, and his conversations with his disciples, forms a considerable body of literature. He wrote nothing, and no part of his numerous conversations was put into writing while he was alive, though he lived to the age of eighty, and frequently preached to, and conversed with, his disciples. After his death his sayings and his sermons were remembered and put into written form. His frequent repetitions, forming a large part of what he had to say, evidently greatly facilitated this process of reducing his words to writing. These works are numerous, and comprise, as they now exist, two groups of books, those in Pali, known as the lesser vehicle or Hinayana, and those in Sanscrit, known as the greater vehicle or Mahayana. The first of these is that of southern Buddhism, as found in Ceylon; and is regarded as giving more correctly than the other the teachings of the Buddha. The Mahayana represents the new or accommodated 


\section{THE SOCIAL EVOLUTION OF RELIGION}

type of Buddhism, that modified and adapted to the needs of the more northern nations, such as the Chinese, who have adulterated the teachings of Lord Buddha to harmonize with their earlier forms of religion. Chinese Buddhism has been drawn from many sources, not only from India, but also from Persia, central Asia, perhaps from Babylonia, and even from more western lands.

\section{4}

The remarkable resemblances between Buddhism and Christianity have puzzled many persons; but they may be best accounted for by that process of diffusion of cults and faiths referred to at the beginning of this chapter. Recent writers on Japanese and Chinese Buddhism have recognized that these resemblances have not been the result of direct borrowing, but of that process of the diffusion of religious rites and beliefs which has gone on widely throughout the world, and especially so in the period when the great religions were in process of evolution. Lloyd, an Anglican missionary in Japan, says in his Creed of Half Japan, in explaining the resemblances between the two religions, that "it is perhaps enough to recognize that these thoughts were in the air." Timothy Richard, a missionary in China, says in The Awakening of Faith, that "these common doctrines of new Buddhism and Christianity were not borrowed from one another, but both came from the common source." He regards this common source as Babylonia, and adds that from "this centre those great life-giving inspiring truths were carried like seeds into both the East and the West, where they were somewhat modified under different conditions." To the same effect is the statement of Reginald Fleming Johnston, in Buddhist 


\section{THE SOCIAL EVOLUTION OF RELIGION}

China, where he says that both religions "had access to the same sources of doctrinal inspiration - sources which in themselves were not specifically either Christian or Buddhist." "We may admit," he says again, "the possibility that some of the characteristic doctrines shared by Christianity and the Mahayana - such as the efficacy of belief in divine or superhuman saviors incarnating themselves in man's form for the world's salvation - were partly drawn from sources to which the builders of both religions had equally ready access. We may accept the view that each of these creeds incorporated certain ideas which had long fascinated the religious imagination of a considerable portion of south-western Asia."

Johnston has pointed out, in this work on Buddhist China, some of the particulars in which Buddhism and Christianity resemble each other, as the result of their dependence on the same common sources for their origin. Jesus and Sakyamuni were both deified, not at first, but as the result of the growth of their religions, and their contact with other faiths. Buddhism emphasized the efficacy of faith as much as has ever been done by Protestant Christianity - and especially in China. Some of the Mahayanist sects have regarded it as allimportant. "Faith in Amitabha [the source of all the subsequent Buddhas] is of itself sufficient to ensure an eventual birth in his heaven, and without faith good works are of no avail; but the candidate who has virtue and good works to his credit, as well as a strong faith, will be placed in a higher class than one who has gained paradise through faith alone."

The repetition of the name of Amitabha, the supreme Buddha, is of great efficacy in securing salvation; and in this respect some of the more ignorant Christians seem to agree in their frequent repetition of the names of Christ, the Virgin Mary, or the saints. To the Buddhist the lotos is a symbol 


\section{THE SOCIAL EVOLUTION OF RELIGION}

regarded in quite the same manner as the Christian does the cross. The Buddhist believes that the severest punishment of the sinner consists in his exclusion from the presence of Buddha, just as some Christians maintain that the real pain of hell consists in exclusion from the vision of God. The Buddha is not to be judged from the historical point of view, for he is above all that belongs to time; and the Christian maintains that Christ was from all eternity, that he was eternally one with the Father.

The Christian mystics have frequently presented the idea that heaven is a condition of unity with God, in which all that is selfish, merely individual, and of an earthly nature, is sloughed off, and only what is of the nature of pure personality is retained. The Buddhist mystic holds to the same conception of the future life. "Nirvana is a state of blissful tranquillity attainable in this life (not necessarily terminable with this life), and is conditioned by a passing away of all egoistic lusts and cravings." The Buddhists greatly resemble the Christians of the earlier types in their fondness for pilgrimages; but this development has been common to all the higher religions.

In one of the Chinese sacred books Maya, the mother of Sakyamuni, is called the "Holy Mother," and she is also mentioned as "the eternal Mother of all the Buddhas." However, by most Buddhists, Maya is regarded as of an exceptional purity and holiness, but she is not called a divinity. In China she is sometimes identified with the Taoist "Queen of Heaven." There has developed in China, nevertheless, a pronounced faith in a female deity of the highest importance, who is regarded by the Chinese Buddhist as superior to all other divinities. This is Kuanyin, known to Europeans as the "Goddess of Mercy." She is an idealization of motherhood in quite the same manner as the Virgin Mary is an almost exactly 


\section{THE SOCIAL EVOLUTION OF RELIGION}

similar idealization. "She has gained popularity because the ideal is one which touches people's emotions and lessens the gap between the merely human and the unapproachable divine." This female deity is merciful, loving, motherly, tenderly caring for and consoling those who call upon her. The Chinese speak of her as the "One who looks upon the world and hears its cries." "If any living creature who is in trouble or in pain addresses a prayer to this pusa [divine being], and in true faith calls upon her name, then will the pusa immediately hearken to his cries and bring him deliverance from his woes. If any living creature clings for support to the potent name of Kuanyin, he may be thrown into a raging furnace, but the flames will leave him unscathed; he may be in peril from sharp swords, but the steel will break in pieces; he may be in danger of death from drowning, but the blessed pusa will come to his rescue and set him in a place of shallow waters." It is quite apparent that Mary and Kuanyin have many close resemblances, though the one may have derived nothing directly from the other.

Although Buddhism was obliged to abandon the mainland of India, and the regions of its origin and early developments, many centuries ago, it has lost little of its vigor; and yet remains the dominant religion of Siam, Burma, Tibet, China, and Japan, and most of the countries of eastern Asia. When westerners have come into contact with it, who are ready to study, to understand, and to appreciate its merits, it has been received with enthusiasm. In a number of books and especially in that entitled The Soul of a People, Henry FieldingHall has written most eloquently on, and appreciatively of, Buddhism as he found it in Siam. The charm of it, the graciousness it develops in those who truly accept it, and the inward peace and outward harmony it cultivates, Fielding-Hall 


\section{THE SOCIAL EVOLUTION OF RELIGION}

has described in a manner to delight a great number of readers. If they have not been inclined to turn Buddhist, they have certainly gained a more appreciative acquaintance with one of the world's greatest religions.

\section{II}

Christianity, which comes next in historic order, was more largely influenced in its formation by social and cultural conditions than any of the other great religions. This was due to the fact that it originated in the midst of wide-reaching environing influences, which brought it to the very focus of most of the great developing conditons of the Mediterranean world. As we have seen, the Jews were in touch with many parts of the world about them, and through their borders passed the great armies, along their shores wended much of the commerce, which the world knew in the time when Christianity took its rise. Greek culture and civilization were gathered about the sea of Galilee, in Jerusalem was a seat of Roman government, along the Mediterranean coast were those great centers of commercial activity, Tyre and Sidon, and northeastward not far distant was the civilization of Syria, which was then under Roman dominion.

Probably no other great religion was less influenced by its founder than was Christianity, for about him, as about the Buddha, gathered legend, folk-tale, and myth. We have but to read the books called the Apochrapha to realize to what an extent they correspond to the similar legends which gathered about the beginnings of Buddhism. If the Buddha was sometimes assumed to be virgin-born, and wonders attended his advent into the world, they were not surpassed by those which accumulated about the Christ, the anointed or heavenly en- 


\section{THE SOCIAL EVOLUTION OF RELIGION}

dowed, as Buddha was the enlightened. Marvels, displays of the supernatural and miraculous, predictions and anticipations of a marvellous birth, belonged to the one as to the other. If the mother of Christ was declared to be of virgin-birth, and brought forth so as to be afterwards known and accepted as the Mother of God, something of the same kind attended the birth of Buddha.

In the ages when these founders came into the world, such portents and supernatural displays were accepted as necessary to give eredit to any great man; and not merely those with whom new religions originated. Miracles were thought to insure the divine origin of the men so attested, though to-day it demands a Buddha and a Christ to give sanction to the miracles. Many Christians now assert that miracles cannot take place, that they give no credit to religious truths, and that their presentation shows a tendency far too great towards what is superstitious, incredible, and unbelievable. No truth gains in any degree by their presence, or any claim made in connection with them.

An intimate study of the age and environment in which Christianity arose shows that it was supersaturated with the supernatural, that it was seeking for something incredible and marvellous, that it was in a condition of mind fit for the reception of a religion based on the miraculous and magical. The old animism and fetishism had not been wholly sloughed off, but were too often received as if they were worthy of the most vigorous reception. Not all men were of this type, nor was the whole of the civilization of the world given to the ready acceptance of the miraculous or inclined to see portents in the heavens, marvels in every passing phase of the sky. Those who may be inclined to open Pliny's Natural History will find abundant evidence in regard to the mental attitude 


\section{THE SOCIAL EVOLUTION OF RELIGION}

of the time. In the Metamorphoses of Apuleius may be found many a hint as to what was the religion of even cultivated men in the Syria of the days of the advent of Christianity. It is not to be forgotten that the emperors of Rome were divine men, and that they were saluted as sons of god. They were worshipped, the worst of them as well as the best. It did not seem ridiculous that such men should be regarded as gods, and prayed to for cures and for divine aid. Wherever there was a man bold enough to claim that he was a prophet or a god, from wherever he may have come, or whatever his character, the crowd received him on the basis of his own assertions. The records of the age tell us of many such, that they were gladly welcomed, and that the bolder the claims the more honor was given to the one coming forward in this manner.

It has been claimed that the Buddha described in the sacred books of early Buddhism could not have lived, that the stories told of him are too largely constituted of the incredible to have any authentic historic basis. The same claim is made in regard to Christ, and by an increasing number of the ablest scholars. Undoubtedly archaeological material has been found of one kind or another authenticating one or another event in the early history of Christianity, that manuscripts in considerable numbers have come to light in recent years validating various events; but these cannot be taken as support for beliefs that depend not on such materials as these, but on their conformity or nonconformity with reason and the nature of man.

We may accept it as probable, perhaps as certain, that there appeared in Palestine, at about the time of the origin of Christianity, a prophet or reformer, who claimed to answer 


\section{THE SOCIAL EVOLUTION OF RELIGION}

to the Jewish conception of the messiah. It is by no means incredible that such an enthusiast should make the assertion that he was the promised one sent of God to redeem his people, and that his claim should be widely accepted. More than one such reformer and claimant appeared in Jewish history; and that a certain Jesus or Joshua made such claim is by no means incredible, or that he should be a peasant, a carpenter or other artisan. As we have seen, this was a time in which the artisan world was awakening religiously, as well as socially. Those who claim that in its early developments Christianity was largely an artisan movement are by no means unlikely to be correct; but, on the other hand, their contention may be accepted as most probable. Not only the traditions in regard to the occupation followed by Jesus, and the other traditions, which connected the early Christians with the working-class, rather than with those who were prosperous and educated, would possibly point in this direction. Naturally enough, it was not those trained in all the wisdom of the time, who had come into closest touch with the older learning, and who were connected with the higher social and political interests, who would first turn for satisfaction to the new religion. Not many in high social circles, came into the company of the first converts; but, rather, the poor, the manual workers, the artisan class, were found in the first believing circles. Sinee Jesus appealed especially to the poor, to the outcast, to those broken by life's conflicts and struggles, it is most likely that these persons and these classes first drew towards the consolations he offered. His condemnation of the rich and the prosperous would give support to the same conclusion, though it is now these same classes who most zealously seek the religion offered in his name.

The claim is frequently made that Christianity is the [254] 


\section{THE SOCIAL EVOLUTION OF RELIGION}

greatest of all the religions of the world, that it is most in harmony with the more advanced civilizations, and that it is divinest in its nature. The old assertion was that it alone is true, and that all other religions are false. Many of its advocates and defenders to-day, however, are ready to admit that there is good in the other great religions, and that they present much of truth to those who accept them. Some will go so far, even, as to assert that in Buddhism and Islam salvation may be found, perhaps not so perfectly, but quite as surely as in Christianity.

It is evident that the exclusive claim in behalf of Christianity grows out of the spirit of sectarianism, and is defended with metaphysical rather than with historical evidence. It may satisfy those who are concerned to uphold that with which they are familiar, and that which has traditional associations with childhood and youth; but it can be of little importance to those who truly desire to find what is the truth, and who have no other end in view in their investigations.

Starting forth in our quest for the facts, we soon discover that Christianity, as in the instances of all other religions, has its historic basis in the religions which preceded it, and in the mental attitude of the age which produced it. About every phase of its early history folk-lore, legend, and myth gather; and they cling there with the utmost tenacity. J. G. Frazer has published three big volumes on Folk-Lore in the Old Testament, and he has by no means exhausted the subject. As many and as large volumes might be written in regard to folk-lore in the New Testament, and in the history of the first two centuries of Christianity. The Apocrapha alone would fill 


\section{THE SOCIAL EVOLUTION OF RELIGION}

more than one of these volumes, and it ought to indicate what was the mental atmosphere in which Christianity had its origin.

In the introduction to the present chapter it has been indicated to what an extent the ancient religions were influenced by common traditions, legends, myths, and beliefs, which spread throughout western Asia and eastern Europe. "Ideas are propagated from school to school and teacher to teacher," says Percy Gardner, "less often by direct borrowing which comes of admiration than by the parallel working of similar forces in various minds. When ideas are in the air, as the saying is, men eatch them by a sort of infection, and often without any notion whence they came."

We have seen how this process operated in the formation of the new or Mahayana Buddhism, especially as it appears in China. Undoubtedly the same process went on in the formation of Christianity, which had its basis in Judaism, but which was also influenced from Babylonia, Persia, Syria, Asia Minor, and Greece. Back of it had been growing for many centuries throughout all Asia, and along the Mediterranean lands, those rites and beliefs which finally culminated in the Christianity of the fourth and fifth centuries. The sources were many, working together in the background of history, rarely coming out into a definite presentation; but none the less effectively growing up the religion which the modern western world regards as the best mankind has as yet come to know. Every phase of Christian rite and belief has been affected by this prehistoric or this subconscious back-ground of developing religious feeling and thought.

Writing of the manner in which religions in the ancient world influence each other, R. F. Johnston, in his Buddhist China, says that "it is now a matter of common knowledge 


\section{THE SOCIAL EVOLUTION OF RELIGION}

that Christianity and Mithraism were in many respects amazingly alike; yet the best authorities assure us that at the root of those two religions "lay a common eastern origin [Persian and Babylonian] rather than any borrowing.' " To the same effect is Louis Duchesne, in his Early History of the Christian Church, where he says that "the religion of Mithras contained elements - in theology, morality, ritual, and in its doctrine of the end of all things - bearing a strange resemblance to Christianity." Not only is this true of Mithraism, in so far as we know it to-day; but in no inconsiderable measure the same statements will apply to a great number of religious movements and sectarian developments preceding and following the beginnings of Christianity. Regarded as heresies by the church, and condemned to extinction in the selective processes going on in the later periods of the Roman empire, yet they all testify to that teeming religious life of the period, and the working together of many forces to the making of Christianity.

The development of Mithraism affords an excellent illustration of the manner in which religion was growing and extending itself, in this period when Christianity was originating. Originating in India, modified in Persia, gaining new elements in Babylonia, it passed onward into the Roman empire, where it acquired little or nothing, but became for a time the leading religion. As in the instance of early Christianity, it was largely accepted by the humbler classes, and especially by the soldiers in the Roman armies. Its appeal was that of a mediator between suffering humanity and the inaccessible god of all being. "The rapid advance of Mithraism," says Grant Showerman in the eleventh edition of the Encyclopaedia Brittanica, "was due to its human qualities. Its communities were bound together by a sense of close fraternal relation. Its democracy 


\section{THE SOCIAL EVOLUTION OF RELIGION}

obliterated the distinctions between rich and poor; slave and senator became subject to the same rule, eligible for the same honors, partook of the same communion, and were interred in the same type of sepulchre, to await the same resurrection." Showerman says that the resemblances between the two religions were very numerous, and he proceeds to indicate what they were:

"The fraternal and democratic spirit of the first communities, and their humble origin; the identification of the object of adoration with light and with the sun; the legends of the shepherds with their gifts and adoration, the flood, and the ark; the representation in art of the fiery chariot, the drawing of water from the rock; the use of bell and candle, holy water and the communion; the sanctification of Sunday and the 25th of December; the insistence on moral conduct, the emphasis placed upon abstinence and self-control; the doctrine of heaven and hell, of primitive revelation, of the mediation of the Logos emanating from the divine, the atoning sacrifice, the constant warfare between good and evil and the final triumph of the former, the immortality of the soul, the last judgment, the resurrection of the flesh and the fiery destruction of the universe - are some of the resemblances which, whether real or only apparent, enabled Mithraism to prolong its resistance to Christianity." Showerman adds that at their source is a common eastern origin.

Undoubtedly there were wide differences between the two religons, some of them of a fundamental nature. Looking at their resemblances, however, it is evident at once that they reached back into other religions, and that they came from a somewhat remote past. A goodly number of them may be found interpreted in Frazer's work on the Folk-Lore of the old Testament. 


\section{THE SOCIAL EVOLUTION OF RELIGION}

In the Hibbert Lectures of 1888, on the Influence of Greek Ideas and Usages upon the Christian Church, Edwin Hatch has pointed out the large degree to which Christianity was affected by Greek custom and thought. Many of the higher natures in the Greek world were drawn into Christianity by the kinship of ideas. In the western communities Christianity took over the greater part of the Greek inheritance, and it formed the basis of the later creeds. To a considerable extent, also, Christianity was influenced by the mysteries growing out of the earliest religious developments in Greece. "During the earliest centuries of Christianity," says Hatch, "the mysteries, and the religious societies which were akin to the mysteries, existed on an enormous scale throughout the eastern part of the empire. There were elements in some of them from which Christianity recoiled, and against which the Christian apologists use the language of strong invective. But, on the other hand, the majority of them had the same aims as Christianity itself - the aim of worshipping a pure God, the aim of living a pure life, and the aim of cultivating the spirit of brotherhood. They were part of a great religious revival which distinguished the age."

Hatch points out rather conclusively, that to a very large degree Christian ritual, and the manner of ecclesiastical organization, were influenced by the mysteries. In the origin and early history of Christianity it was profoundly influenced by the common religious development which had been proceeding in Asia for many centuries; but in its later developments it owed very much to Greek thought and ritual and custom.

To the same effect is the statement of F. Crawford Burkitt, in his book on the Jewish and Christian Apocalypses, in which 


\section{THE SOCIAL EVOLUTION OF RELIGION}

he says: "The period between the eras of Alexander the Great and the Emperor Constantine, those six centuries during which Christianity grew up, was an age of syncretism, of the mingling of religions, a period during which European civilization was especially influenced by Oriental beliefs. It was the age of the Mystery-religions, the religions of Isis, of Mithra, of Attis. The dominant philosophies, as we are more and more coming to see, were the result of the blending of Greek thought with Oriental beliefs and teachings. Oriental Astrology was in itself a religious philosophy; it was an attempt to formulate the influences which to a certain degree moulded the lives of all the dwellers under the roof of heaven."

Biblical scholars have now come to emphasize the fact that there was no real break between the Old and the New Testament, that there was at this time no period of silence, and none when religion was not in an active process of growth. This is proven by any genuine study of the Old Testament Apocrapha and the other Jewish literature of the period, this statement especially applying to the works of Philo. The change from Judaism to Christianity was distinctly the result of those powerful syncretist movements which were transforming all the religions of the age, and acting as a ferment in the creation of the new faith. In no period of the ancient world was there in operation such an active process of the transfusion and amalgamation of rituals and beliefs. The Jews were greatly influenced by their contact with the religions of Babylonia and Persia, as they were to a lesser extent by those of Egypt, Greece and Anatolia. At Tarsus, where Paul, the real founder of theological Christianity, had his early training, was a focus of these many culture influences from both east and west. Alexandria, as already indicated, was another center of these world- 


\section{THE SOCIAL EVOLUTION OF RELIGION}

developing tendencies, and there Philo lived and wrote.

A powerful intellectual, religious and ethical ferment was in operation at this period; and it unified in considerable degree all the religious developments of the ancient world. It brought them to a focus in Christianity, the product of several centuries of growing thought and belief. This was recognized by Augustine in the first book, thirteenth chapter, of his Retractions, where he says: "The very same thing which is now called Christianity existed among the ancients, and was not absent in the beginning of mankind, until Christ himself appeared in the flesh, whence the true religion, which already existed, began to be called Christianity."

It is not necessary to ignore in any degree Jesus and his personal influence in order to reach this conclusion; but it does transfer the center of gravity from a personality to great social forces operating through long periods of time and over wide regions of the ancient world. In order to reach this conclusion it is not essential that we should dismiss to insignificance the personality of Jesus and its effective operation. Both tendencies must be recognized, it is very evident, if we would fully understand the forces at work in the production of Christianity. Hitherto the culture tendencies, the social developments, the ethical movements, and the intellectual processes have been almost wholly ignored in the attempts made to explain the origin of Christianity. Now we are coming to see that no merely personal influence could have been great enough to produce this powerful movement had it not operated in the direction of those world-wide tendencies which were focussed and concentrated in the new religion. In Christianity were culminated the growth-processes of a thousand years of human evolution, especially in the direction of ethical and religious developments. 


\section{THE SOCIAL EVOLUTION OF RELIGION}

3

When we consider in a scientific spirit the claims made in regard to the virgin birth of Jesus, we find that they have their real basis in the corresponding stories in regard to the birth of various divinities, as well as the great men of the ancient world. When the claim was then made that a man was of superior qualities of mind, that he possessed genius, it was asserted that he had been supernaturally born.

Such a claim was not exceptional, reserved for only a few of the divinest persons; but was very commonly made, as often as is now that in behalf of individual genius. In the three volumes of The Legend of Perseus, Sidney Hartland has brought together a great number of such legends and folk-tales, proving beyond doubt that such births were accepted as common, as in a degree natural, and to be found everywhere, especially wherever men rose to any prominence in the several walks of life. In the concluding chapter of his highly interesting and instructive work, Hartland says: "The supernatural birth we found related in various forms, not merely for amusement, but as sober fact, over so large an area of the world as to justify the belief that it was universal. Every nation has its heroes; and in the popular mind the mightier the hero, the greater the need for providing him with a worthy entrance upon his mortal existence." As we have already seen, the intent of animism gives warrant to the notion of supernatural birth; and this idea is supported by the theory of transmigration, as well as by that of the fathering or mothering of children by divine personages. This was no casual idea of the ancient world, but one of daily occurrence as an interpretation of every form of genius and authority.

Only one conclusion could be reached by such an extended 


\section{THE SOCIAL EVOLUTION. OF RELIGION}

study as that given to the subject by Hartland, which he presents in this form: "If these legends be universal, if they must be rejected in every case but one as the product of an inevitable tendency of human imagination, then why not in that one case also? Assuredly that one case can be regarded as exceptional, only if it stand upon historical evidence totally different in kind from the others, and of inevitable cogency. But can anyone who sits down (as it is the duty at least of every educated man to do) calmly and, so far as he can, with scrupulous impartiality to weigh the evidence, say that the testimony of ecclesiastical tradition, or even of our Gospels, is different in kind from, or of greater cogency than, that which we reject, without hesitation, in the case of Sakyamuni, or of Alexander the Great?'"

This statement in regard to the virgin birth of Christ is that of a scientific investigator into the origins of folk-customs and beliefs, and into the causes developing those great fundamental ideas which lie at the bases of all religions. We may, therefore, properly turn to a Biblical critic, one of the ablest of our time, T. K. Cheyne, in his little book on Bible Problems. He regards the birth-story as being borrowed from Babylonia, and, modified or supported, from Egypt. "It arose," he said, "out of a misunderstood title which originally implied something very far from the thoughts of Christians, and the narrative, to a historic and therefore reverent mind, is by no means disparaged if taken to stand in some connection with the Egyption theory of the divine generation of kings, and the Philonian belief in the divine generation of certain favored personages of the Old Testament." On a succeeding page he says that the legend is a Christian transformation of a primitive story, derived ultimately, in all probability, from Babylonia, which has 


\section{THE SOCLAL EVOLUTION OF RELIGION}

passed through an oriental phase, a Jewish phase, and then a Jewish-Christian phase. He defends this manner of interpreting the birth-legend by saying that it was a means of expressing the ancient longings of the human heart for a redeemer of men from the evils incident to a human world. When we find that it was precisely for a similar reason that Buddha was assumed to have been virgin-born, and that supernatural events attended his birth, we are in a position to estimate the Christian narratives correctly.

When we press our inquiries a stage further on, and discover that the virgin-birth leads the way to the doctrine of the incarnation, and that the two are intimately related to each other, we are prepared for estimating the latter belief historically. What we find is, - that the conception of incarnation is nearly, if not quite, as wide-spread as that of the virgin-birth, and that it arose from the same or similar causes. What we have already seen in previous chapters, that the gods might be born into human form, and that gods might be the fathers or mothers of human children, prepares us for the recognition of the idea of incarnation as characteristic of most religions, and as having no exclusive connection with Christianity.

\section{4}

The belief in incarnation began at a very early period, and may be traced through the religions of the American aborigines and those of Polynesia, up through all the higher religions; in those which are fetishistic and polytheistic, onward, to those which have become distinctly monotheistic. When a god assumes the form of a man or even of an animal, incarnation has taken place; and such transformation of the higher 


\section{THE SOCIAL EVOLUTION OF RELIGION}

into the lower is practically universal in all the more primitive religions.

Turning to the eleven articles on incarnation in the Encyclopaedia of Religion and Ethics, evidence enough appears to convince the unprejudiced mind, that the belief in incarnation is in no sense peculiar to Christianity; but that it was introduced into that religion because it was essentially known to all the religions to be found in the civilized world when Christianity came into existence. The founders of Christianity probably did not reason to any great extent about this belief, but found it in existence, and unconsciously (perhaps we may say subconsciously) accepted it as necessary to any religion in that age which had meaning and purpose. That it should remain the cardinal doctrine of Christianity to our day proves to what an extent even the highest religions are based in myth and in the traditional.

The extraordinary conservatism of religion carries forward such a belief as this, which roots back undoubtedly into the most primitive conceptions ; and enables men of the largest knowledge and powers of reasoning to cling to it with the utmost insistance on its value and its truthfulness.

In the Buddhist sacred books we may find in fullest details the story of the incarnation of the Buddha. He is not soiled by birth, his mother was a pure virgin, and he was therefore an incarnation of a heavenly being. Many of the Christian speculations in regard to the incarnation of Christ may be found in quite similar statements regarding that of Buddha; and the authenticity of the one seems to be as great as that of the other, so far as history throws any light on the subject.

According to A. Wiedemann, incarnation in the religion of Egypt was very common, though not distinctly in the form known to Christianity. On the Egyptian theory he says: 


\section{THE SOCLAL EVOLUTION OF RELIGION}

"The king was regarded as of divine origin, and even as a god. In this aspect, however, he was not merely the incarnate form of a particular deity, but was a new addition to the pantheonone who, clothed in a human form, and born of a human mother, lived as a man amongst men, and yet could associate with other gods on a footing of perfect equality." Likewise in Greece and Rome persons of superior talent, and kings, whether they had any talent or not, were regarded as incarnate gods. Plato, when he had attained to fame, was described as the son of Apollo, not merely by way of flattery or in a poetical sense, but as a truth authenticated by innumerable other instances of a similar origin. In the older religions of India incarnation is a fundamental tenet, and widely, if not universally, accepted by all classes of the population. In the Bhagavat-gita Krishna appears as an incarnation of Vishnu; and in that form he sets forth to much length the mystic faith which forms such a striking feature of that work - one of the episodes in the great epic, the Mahabharatta. Krishna here appears as a man, but is also the Supreme God, incarnate in manlike form. In so many ways is Krishna of Christlike type, and especially is there a great resemblance. in that work, at least in some respects, to the teachings of Jesus, that some Christian scholars have been puzzled by it, and have tried to show that Christian influence had been at work in India, in order that this similarity might be explained. Why not merely assume that similar causes produce similar results in different regions?

5

The doctrine of atonement or expiation is also to be found in all religions which have passed beyond the most primitive phases of development. Wherever it has reached the stage of 


\section{THE SOCIAL EVOLUTION OF RELIGION}

requiring a reconciliation between an offended god and offending man, the doctrine of sin is implied. This phase of it is not to be found in the very early religions, at least only in an embryonic expression. The reconciliation is rather between man and man, as where one injures or takes the life of another, in the instance of blood-feud. Here it is customary that the person who injures another shall make restitution, giving as much as he has taken. If a life is taken then a life must be surrendered, but not necessarily that of the offender. The family of the injured become his avengers, and under the earlier forms of custom, exact to the uttermost. In time compensation in goods or money might be made, and reconciliation might be thus effected.

The forms of sacrifice already mentioned, indicate that there was an effort from a very early time to secure the favor of the dead; and this led on to seeking the aid of the gods. When morality had advanced to a stage where it was thought that the dead might be offended by the actions of men, and more especially when it was assumed that the gods would be inclined to look on the deeds of men with approval or condemnation, there gradually developed from the primitive conceptions of sacrifice, that larger one of the offering to these divine personages of what would appease them, and bring about a reconciliation. Here we may find the origin of the belief in God as capable of looking with dislike upon the evil deeds of men, and of demanding an expiation for them.

In all religions and cultures we find the idea of a culturehero, one sacrificing himself, as in the case of Prometheus, for the good of mankind. In this instance, the hero combats the gods in behalf of man; but in many others he works with the gods to give men advantages they could not otherwise obtain. The cereals, the cults, the higher rituals, the medicines by 


\section{THE SOCIAL EVOLUTION OF RELIGION}

which men are healed, are brought to men at the sacrifice of something on the part of those higher beings who give them benefits. Even such a people as the Iroquois believed in a cosmic being who gave his own life that the world might come into existence, that from his body might be produced plants and animals, and that his life might nourish the life of man.

In most of the more advanced religions, such as the Babylonian, Indian, and others in a like stage of evolution, the theory of sin was that based on magic, and the power of the evil thus expressed was supposed to work harm to man. In the overcoming of such evils the aid of the gods or of superior beings was desirable; and they gave their aid through the priest and the ritual. All the processes of ritual surrender of what men held to be of value, was of the nature of an atonement; and it was made effective by means of the aid of the divine beings. Brahmanism sought expiation in the form of penance, and this is the meaning of dharma, obedience to the law of duty and right conduct, ethical as well as ceremonial.

These statements may hint at the manner in which the doctrine of expiation or atonement came to have its origin. It has had a very long evolution, and probably has not as yet reached the culmination of its development. The idea of reconciliation, of harmonizing, of securing unity and concord between human individuals, and then between these individuals and the higher powers, is one that can hardly be said to have had an historic origin or one that can be definitely determined. In its various stages it has been with man from the very beginning, so far as we can now see. The Christian idea of it is somewhat more advanced than those which preceded it, and it is itself undergoing a process of rapid change.

Two questions present themselves, when we attempt an historic study of the doctrine of atonement. First, why should 


\section{THE SOCIAL EVOLUTION OF RELIGION}

God be offended with man, and seek to punish him or need to have him seek reconciliation? Secondly, why is the sin man commits of a nature or extent to excite the wrath of God, and make desirable man's search for reconciliation? A study of these problems, thus presented, brings us to the conclusion that the god or gods demanding such reconciliation are reflections of human kings, who make similar demands, and punish severely their subjects for any offences against them, even those which are quite minute. To conciliate a king requires flattery, the giving of money or slaves, or the rendering of some service he will value. Otherwise he will cast the offender into the hell (or dungeon) deep under his palace or his castle. To propitiate, to seek reconciliation, to make great sacrifices for life and liberty, are naturally offered by men offending such great personages. Carry this situation up to the relations of men with their god, and we have a true picture of what happened when men thought they had offended deity. They were willing to surrender every thing in order that their sins might be expiated, and that the smile of the god might be secured again.

It was quite natural that primitive men should think that sickness, loss of crops, or death of their friends, was the result of their having offended a fetish, an ancestor or a god. In order that they might put aside the offense, and secure favor once more, they surrendered what was to them precious. In the Hebrew legend Abraham was willing to sacrifice his son in order that his god might no longer look upon him in anger. The story marks a growth in the idea of sacrifice as a means of appeasing an offended god, in that the sacrifice of human beings, very common in all the early ages, was surrendered by the god for an animal. Later on contrition and repentance 


\section{THE SOCIAL EVOLUTION OF RELIGION}

took the place of the animal; and the materialistic forms of sacrifice largely disappeared.

Atonement is an expiation for sin. The god is holy, when ethical ideas have reached a high stage of advancement; and he demands holy worshippers. If they are not holy, free from sins, they offend him, and must seek to appease him. We see the beginnings of this idea in tabu; and sin is an advanced stage of that primitive conception. What it implies is not that men neglect social duties, that they do injury to other individuals, that they fail to regard the great ethical results of human experience or that they disregard the institutions of the state; but that they fail to regard a highly metaphysical demand on the part of God. Sin as theologically conceived is an extreme form of tabu, not as required by a chief or a king, but as insisted upon by deity. That one should seek inward purity, fidelity to one's own conscience, and loyalty to the highest ideal of manhood, is desirable; but what the Christian conception of sin means is an utter abnegation of self in the desire to reach a state of holiness or of absolute loyalty to God.

As just indicated, such a standard is metaphysical and not practical. What characterizes it is disregard for human welfare, and an absence of the humanitarian spirit, in those who most ardently demand that all persons shall attain this standard. Loyalty to God, if it has any meaning at all, is first of all loyalty to man. Without the human fidelity the other has no true ethical significance. Holiness is selfishness in disguise, an attempt to disregard man in order to serve God.

Expiation, therefore, is likely to become ceremonial, - a form, a ritual. The more this phase of it is emphasized, the less ethical does religion become, and the more routine are its methods and its spirit. Nothing can truly take the place of the ethical life; and the greater the emphasis on rites and 


\section{THE SOCIAL EVOLUTION OF RELIGION}

ceremonies, the less is likely to be the practicality of the moral conduct which results.

Regarding atonement from this point of view, it is to be said of that assumed to be offered by the messiahs and christs of the world, that it must be voluntary, and not official, in order to have any permanent efficacy. George Eliot said that the spectacle of Christ offering himself on the cross for the good of others was the sublimest ideal presented to us in the whole history of mankind. As an illustration of the spirit of selfabnegation, of self-surrender for the good of others, this view of the story of the cross may be accepted as true and just. It is doubtful, however, if it is in any degree nobler than the turning back of Buddha from the attainment of Nirvana, in order to aid others in finding the path to peace in the great beyond. In the spirit of it, it is no greater than when a common man gives his life to rescue children from drowning or women from a burning house.

The reason why many persons to-day are turning away from the Christian conception of this sacrifice is that it makes God but a kingly tyrant, and the sacrifice, at least as it is often presented, bloody and brutal. The dwelling on the materialistic features of the dying of Christ on the cross, whatever the historical basis for the narrative, repulses thinking minds, and takes from the story all its poetical beauty as a humanitarian act.

\section{6}

One other phase of Christianity must receive recognition, and that is communion with God. Here again we find something universal, and not a sectarian phase of religious development. The least civilized peoples, such as the American 


\section{THE SOCIAL EVOLUTION OF RELIGION}

aborigines, the Fijians, and the negroes of Africa, all assume that they, too, may have communion with their god. They may seek it by means of magical rites, by means of fasts and continence, with ascetic practices, with the aid of dreams and visions; but they believe they find it, and are as convinced of it as is the Christian by processes known to his religion. By the offering of food, by divination, by charms, by the aid of amulets, the god of many peoples is sought; but the seeking testifies that there is a felt want, and that there comes assurance of response. In the higher religions ecstacy is thought to indicate the presence of the god, and inspiration is believed to be the gift vouchsafed to worthy devotees. The insight or the intuition of prophetic minds marks, perhaps, a still higher stage of the same process. In these and many other ways is man brought into contact with God, and his mind thought to be opened to heavenly truths.

Communion with God is also very often found in eating with him, partaking of the food that has been consecrated to his sustenance. Here also we have a long history, with many phases, at the first crude in the extreme and purely materalistic. We have seen that food was placed on the graves of the dead that they might have provision for their journey to the other world. From this stage, through a great number of refinements, we advance to that where the very God himself is eaten by the person who seeks communion with him. And that brings in another element, which is that of the belief that the individual takes into his system the virtues and the strength of what belonged to the animal or the human being eaten. Probably this idea lay at the basis of cannibalism, that in eating the body of a strong man one becomes himself strong. In this way, to partake of God, in however symbolical a manner, is to become godlike. Behind all this, and within it, is the thought 


\section{THE SOCIAL EVOLUTION OF RELIGION}

that in partaking of God physically we come to have his nature, to become spiritual and holy as he is divine. It is true that this rite largely loses its materialistic interpretation, and becomes spiritualized, as it were. It is accepted in a mystical manner, and therefore appears to lose all or nearly all of its grosser features. It never quite escapes, however, the materialistic origin with which it began. Refine it as we may, the distinctly gross nature of its beginnings will forever cling to it.

It having been stated already that animism and magic survive into the higher and highest religions, it may be desirable here to indicate in what manner these appear in the Christianity of the present day. (a) God is conceived of as a personal will acting throughout the whole of the universe, and controlling its forces according to his individual fiat. The most modern conception of God is that of his immanence in all nature and humanity, a life and law within all phenomena of whatever kind. In many respects it is impossible to distinguish this from the idea of the American aborigines, that there is in the world a universal spirit, a great Manitou or Orenda. It is not surprising, therefore, that the first interpreters of American Indian ideas mistook this belief for that of faith in a Great Spirit, very like the Christian's God.

(b) The Mass or Lord's Supper retains in large degree animistic elements. The transformation of the material substance into spiritual power, has its close counterpart in the animistic processes. Had it not been for animism, it is safe to say, these rites would not have come into existence. The primitive man believes that the food he places on a grave for the ghost is eaten as to its spiritual substance. He believes also that when he partakes of food consecrated to a god, that this food becomes in him a spiritual renewal of his higher 
being. Here are the essential features of the Christian rites, albeit in a crude form. Carry these up to a refined and spiritualized interpretation, and we have the Christian rites in all their significance.

(c) The Holy Ghost has been often recognized by anthropologists as having close affinities with the primitive ideas of mana and manitou. The silent, subtle, pervasive, mysterious action of this divine power is largely of the same impersonal character. It is of close kin and positive descent from that of the primitive manitou of primitive peoples in many parts of the world. The third person of the Christian trinity passed through several stages of development, as did the other members of it. In its origin the trinity partook of the nature of a family of father, mother and son, in which form it is to be found in many countries, at several periods of human history, and in several manifestations. The early Christians frequently regarded the holy ghost as feminine, and as affording the mother element in the triune godhead. The subtleties of Greek philosophy turned the three individualities of the trinity into abstractions rather than personalities, and in that manner secured that there should be one in three, one person with three manifestations. All these processes in creating the Christian God betray their affinities with the primitive phases of thought as to the nature of the god.

In this connection it may not be out of place to say that the reason why the chief personage in the Christian trinity was recognized as male, and why the Christian world worships a Father as the supreme deity, is to be found in the ideas in regard to generation which were everywhere accepted in the ancient world. Aristotle in his Generation of Animals, and in other works, said very distinctly that the origin of life is from the father, who is the real causing agent in the 


\section{THE SOCIAL EVOLUTION OF RELIGION}

production of the child. In the Code of Manu it is asserted that the mother is but as the field in which the seed is sown, fatherhood corresponding to the seed. In more philosophical statement this is the assertion of Aristotle. The same view of generation is to be found in China, in Egypt, and through. out the whole ancient world where paternalism had been established in the family and in social interpretations. Plato voiced the same conception. It underlies the Christian theory of God, whether most conservative or most liberal.

The matriarchal conception of motherhood, however, lingered on in the Christian manner of worshipping the feminine principle in the virgin Mary as the Mother of God. Had it not been for the acceptance of the Roman idea of the dominance of the masculine in the family, in the state, and in religion, it is not in the least impossible that the Mother rather than the Father would have been regarded as at the head of the trinity and the dominating spiritual force in the threefold deity.

It is not possible to pass by the resurrection of Christ as a Christian dogma. No one can have studied it as it is presented in the churches at the present time without recognizing to what a great extent it has its basis in nature-symbolism, which is even now largely retained in its presentation at each Easter season. The awakening of nature in spring is regarded as typical of the arousing of man from the grave, and his ascent to a higher life. When we turn back to this symbolism in the great nature-religions of the world about the Mediterranean, as they have already been presented in these pages, we cannot doubt that the Christian conception of the resurrection of Christ had its origin in these myths. Many of the details of it can be there 


\section{THE SOCIAL EVOLUTION OF RELIGION}

duplicated, as that of the descent of Christ to the world of the dead, in order to offer to them release from the thralldom in which they were held.

As in the case of the other Christian dogmas mentioned, this one was by no means new, but had been, and was, widely accepted in the ancient world. Ancient legend is full of accounts of the descent of the living into the other world out of curiosity as to its nature and location, with the view of liberating some one who had died or that some good might be accomplished for the denizens of that lower world. Then again, ancient legend and myth have many a tale to tell of the resurrection of the dead to a renewal of life on the earth. One of the most remarkable of these myths is that of the resurrection of Osiris, and of his becoming in consequence the lord of the world of the dead. In his chapter on the death and resurrection of Jesus, in his work on Jesus the Christ in the Light of Psychology, Stanley Hall deals to a considerable extent with the doctrine of the resurrection in mythology, and shows rather conclusively that there would have been no Christian doctrine of the resurrection had not this dogma found a large place in the earlier religions. In the myths of Adonis, Attis and Osiris, and to these might be added many another from other parts of world, the resurrection found its origin and all its significance. The basis of this conception was the return of vegetation to new life in the spring, symbolized under the form of a young and dying god. To this may be added the wish for the immortality of the dead, and for reunion with them in some world of the future. With reference to the resurrection of Osiris, and his becoming the lord of the dead, Stanley Hall has this to say, which suggests much in regard to the presentation of this dogma in the pages of the New Testament:

"Orthodox Egyptian tradition says that the grief of this 


\section{THE SOCIAL EVOLUTION OF RELIGION}

dolorous mother [Isis] induced the sun-god Ra to send down Anubis who gathered and swathed the scattered parts of the body, observed all the rites over them, and fanned the clayey remains with wings until at last Osiris revived and returned as king both of the upper earth and among the dead. He became Lord of Eternity, ruler of the lower regions, where he judges and rewards all souls after death according to their merits. The morality of the Egyptian Book of the Dead is very like that of Jesus, and those who are acquitted live in a land of indescribable fertility and beauty where men and animals are young and fair, and there is eternal verdure. In Osiris's resurrection the Egyptians see a pledge of their own immortality: 'As surely as Osiris lives I shall live.' Belief in resurrection is suggested by the custom of embalming, which was physically very like that of Osiris. Mourning for him began when the Nile began to rise. Then the dams were ceremonially cut and the soil became the bride of the Nile. Seed-sowing was in autumn, and was sad; for planting, as among primitive people to-day, suggests the burial, and is often connected with the festival of the dead. Thus representatives of potentates are often killed, dismembered, or burned to increase the fertility of the soil, so that in Egypt special precautions were taken that the bodies be not cut up and their fragments used as talismans for this purpose. Osiris was originally a tree spirit, and pillars solemnly erected to him were symbols of resurrection. Even from this so bald sketch we can glimpse the culture atmosphere which pervades so much of Christianity, and can see that not only in the regions which Jesus knew but perhaps still more in those which Paul knew and where the church first had its development, these cults were developed in both their higher and lowest forms, and their influence was very pervasive." 


\section{THE SOCIAL EVOLUTION OF RELIGION}

Stanley Hall insists that the passion and the resurrection must to-day be discussed in view of a vaster background than the Old Testament affords, for he sees in them the culminating expression of the central theme of many cults far older than they, all about the eastern Mediterranean, each of which contributed its best elements to the Christian beliefs clustering about these features in the Christ story. He goes on to show that, had it not been for these older products of the folk-soul, there would have been no Christian belief in the resurrection from the dead. In its inmost core, in its essential character, this belief of Christianity originated in these old myths, and in them it finds all its assurance and all its beauty.

In his study of the resurrection, Stanley Hall has sought its meaning for the Christian believers of our own day. By means of a questionnaire he has tested its significance for present-day Christian faith with the conclusion that it no longer affords a large measure of comfort or faith for the believer in immortality. There may be set down here the conclusions which he reached as the result of his investigations:

"(a) Many think they believe in it as a literal fact because they have never candidly examined the nature of their affirmation of it. This few can do, and still fewer do. Some fear disillusion or dread the labor of reconstruction. As Albertus Magnus and Aquinas carefully reserved certain dogmas from the sphere of philosophic thought, so this psychic process is set apart as too sacred for investigation. (b) Many have some degree of faith in too crude a form of it even to be able to attain the full conviction they crave, and so are unhappy, halting and praying for more faith when they ought to reinterpret it into a form the mature modern mind demands.

(c) Others think they find aid to their own faith by vociferous and dogmatic affirmation of some form of it, or find their own 


\section{THE SOCIAL EVOLUTION OF RELIGION}

belief reinforced by censuring what they deem shortages or errors in the belief of others, on psychic laws akin to those which make young Mormons suspected of doubt reclaimed by faith by being sent on missions to preach their doctrines among heretics, and who by becoming advocates instead of judges convert themselves if no others. (d) Yet others with, and surprisingly often without, any knowledge of Kant's critique of the practical reason and its postulates, hold to the conventional form of belief because they think its effects on the conduct of thought, life, or both, are a higher criterion or sanction than any which reason can supply. The highest truth is that which works supremely well. (e) Many hold to it esthetically. Art has embodied it in many forms that edify and give a true hedonic narcosis, and so they have grown indifferent to historical validity. It is venerable, hallowed by association and by a consensus so wide as to be itself sublime. Moreover, poetry is often truer than fact. (f) Many think it essential to the young, and while they feel that it is outgrown in their own experience deem it vital, saving truth for children and youth, to the needs of which they subordinate not only their own lives but their convictions, and find a pedagogic virtue in so doing that they reconcile with personal standards by often elaborate accommodation theories. (g) Finally, a few devout souls whose private lives are consecrated to the imitation of Jesus's life, and who live for good works, distinctly and consciously reject all forms of resurrection. Of these, some, chiefly women, were shocked to first realize their unbelief and are more assiduous in practicing the Christian graces as if to atone for a defect, while others, more often men, have found great satisfaction in their éclaircissement, but believe they can do most good by conforming and working in the harness of conventionality, or perhaps think this an article of faith best left to lapse 


\section{THE SOCIAL EVOLUTION OF RELIGION}

from the Christian consciousness quietly, as they believe it will do... But few, if indeed any, held to a belief in the resurrection that would satisfy the conventional standards of orthodoxy in the denomination to which they belonged. This shows a wide chasm between the latter and the true facts of inner religious life."

Here is evidence enough as to the mythical origin of the belief in the resurrection; and it is not surprising, in view of that origin, and considering the fact to which Stanley Hall refers, that the New Testament report as to the resurrection of Christ is by no means authentic and historic, that a very large degree of skepticism exists in regard to it. It belongs to another age than our own, and it now survives almost wholly because of traditional causes. We believe in it, if we believe at all, because men long ago found it satisfactory, and because we have not dared to slough it off as no longer worthy of modern thinking.

Negative as this interpretation of the origin of Christianity may seem to be, its purpose is to emphasize the syncretist nature of that religion, that it has its foundation in what has gone before, and that it is in no inconsiderable degree a culmination of the religious strivings of mankind through all the preceding ages. In this sense, if in no other, it may be regarded as the noblest and truest of all the world's religions. Without the preceding religions it could not have come into existence; and it is also dependent on all the social, political and philosophical advancements of the preceding ages. In no inconsiderable degree its limitations, as well as its excellences, are owing to its growth out of the past life of mankind. Especially its ethical ideals and its social purposes had their origin in its capacity to grasp and to emphasize what was best in the earlier ages. 


\section{THE SOCIAL EVOLUTION OF RELIGION}

Stripped of his legendary and miraculous settings, the Christ may be regarded as the purest, loftiest, and most human figure in the history of religion. His moral teaching, his human sympathy, his fellowship with the poorest and meanest, his boundless compassion, his fidelity to his own convictions even to the bearing of the cross, gave him a character above that of any of the gods of the ancient world.

We cannot doubt that, as Emerson said, there has been a vast exaggeration of what is artificial and unbelievable that has gathered about the person of Christ. Nevertheless, many a thinker and reformer of the present day finds in him, when the legendary has disappeared, a figure most attractive and most trustworthy. Rejecting all the theological and metaphysical beliefs which have been inherited from the old religions, and which have been added to in the course of the Christian centuries, we may admire the character of Christ, and we may seek to conduct our lives in the spirit of his ethical teachings. Many a man who accepts none of the dogmas of Christianity admires and loves this gentle teacher, and believes in his boundless sympathy with suffering and toiling men and women. Here is his greatness, and the worth of his ethical precepts.

\section{III}

When we give our attention to Islam, the religion founded by Mohammed (Muhammad), we may be more than ever convinced that the physical, social and political environment has a dominating influence in the formation of any and every religion. It is by no means enough to say, that the desert conditions of Arabia, the nomadic and pastoral life of its population, gave Islam its true character; but we cannot doubt that the one had its effects in shaping the other. We must also take into 


\section{THE SOCIAL EVOLUTION OF RELIGION}

consideration the fact that many Jews were living in the Arabian cities at the time of Mohammed, the sixth century, and that Christianity was known there, though in some of its more perverted forms. There yet lingered in Arabia, to a very considerable extent, the old nature-worships; and many of the rites and beliefs of the older types of the early Semitic religion. All of these had their influence on Mohammed, and on the manner in which Islam came to its development during his life, and for two or three centuries after his death. Islam, too, had a true syncretist origin.

In a few cities like Mecea and Medina Arabian culture had reached a considerable degree of advancement. We know that many centuries before an advanced type of civilization had appeared in the south of Arabia, but this had not been permanent. The tendency was that the desert should assert itself against all advancements made into its borders, and that the desert populations should migrate to more favorable regions. In this manner Babylonia, Syria, Ethiopia, and to some degree Egypt, had been populated from the Arab peninsula. In the time of Mohammed the Arabians were tribesmen, keeping their clan organization, their clannish habits and living largely the life of nomads. Outside a few cities they roamed the desert, bred their camels and their horses, attacked the caravans whenever opportunity offered; and lived largely the life of marauders and highwaymen.

\section{1}

Into such a world as this came Mohammed, born in Mecca in the year 632 , June 7 . Of him it may be said that he is the only great founder of a religion of whom we know the year of his birth or have any definite historical evidence in regard to 


\section{THE SOCIAL EVOLUTION OF RELIGION}

his family, manner of life, daily pursuits, and how his religion grew in his own mind. Even the life of Mohammed, however, is lacking in many details, and many difficulties present themselves in regard to its more important episodes. Tradition, if not folklore, gathered about his life; and we find much that is obscure in his acts as in his teachings. This may be said, however, that his life stands out in clearer historic perpective than in the instance of any other great religious founder. The impress of his mind is marked deeply on his religion; and we must know him, and the conditions amidst which he lived, in order to comprehend the beginnings of the Mohammedan religion. "No religious code extant," justly remarks Emanuel Deutsch, "bears so emphatically and clearly the marks and traces of one mind, from beginning to end, as the Koran." Deutsch goes on to remark that it is next to impossible to separate the man from his book. "True," he says, "the more than twenty years which its composition occupied are embalmed in it with all their strange changes of fortune, with their terrors and visions, their curses and their prayers, their bulletins and their field-orders. The Koran does indeed illustrate and explain its author's life so well that hitherto every biographer (and there have been many and great ones) has suggested, in accordance with his own views, a different arrangement of that book."

It is because Mohammed composed the Koran, and because it was extant from the very beginning of his religion, that we may regard its foundations as standing forth historically as in the instance of no other religion. Whether Mohammed could write or not is not quite certain, though it is probable he could not. In that case he dictated to a scribe his inspirations, visions, ecstatic thoughts, and his revelations. These were thrown into a heap, and were not always carefully 


\section{THE SOCIAL EVOLUTION OF RELIGION}

considered or copied. In time, however, when he had become a great man, these scraps of writing were brought together and shaped into the Koran. No record had been kept as to when each verse or sura had been composed. Consequently, when the book was edited, a somewhat mechanical arrangement was resorted to, the chronological order of composition not being remembered, even by Mohammed himself. This is the reason why, though the life of Mohammed is largely embedded in the book, and though it gives the unfolding of his spiritual experiences and growth in theological beliefs, no one has ever been able to determine these with any definiteness. Consequently, each historian arranges the suras in such order as he thinks best explains the development of the biographical and historical events. Here is history, as in the instance of the origin of no other religion; but history confused and chaotic.

Mohammed was born of an important clan in Mecca, but his early life was lowly, until he married a rich widow, much older than himself; and by her and an uncle he was enabled to give his time and his interest to religion. An epileptic, he had visions, sought out a cave where he had mighty dreams of the presence of angelic beings conversing with him, gradually came to the idea that God was calling him to a great task. When, however, he began to preach of one god, and to claim to be in some way the prophet or voice of that god, he was laughed at, hated, persecuted, and threatened with death. His uncle, a powerful man in the tribe, who was a sceptic in so far as concerned Mohammed's visions, at least, protected him. At last, though he had made a number of converts, beginning with his wife and other members of his family, he advised his followers to flee to Ethiopia, where the Jews would protect them. He himself went to Medina. This flight or 


\section{THE SOCIAL EVOLUTION OF RELIGION}

hejira was the greatest event in the history of Mohammed, and became the date of the beginning of the Mohammedan era.

\section{2}

At Medina Mohammed sought the favor of the Jews and the Christians, and soon made a compact with a part, at least, of the people of that city, that they should accept him as their prophet, and that they should give him their support in the spreading of his religion. Soon he reurned to Mecea with an army, conquered that eity, and brought the people to accept the faith of Islam. From this time on he was king, judge, leader of an army, and a conqueror, whose arms spread through Arabia, and into other countries. What is most notable in this successful spread of Islam is the remarkable awakening it brought about in the Arabs. From being nomads and shepherds, they became in a few years the conquerors of southern Asia and northern Africa, spreading into southwestern Europe. Even more remarkable was the awakening of their mental natures, so that from being mere herdsmen and marauders, they took the lead of the world in culture, in science, and in all phases of intellectual advancement. In a century or two they had mastered the culture of Greece, knew Aristotle, and became the leaders in all forms of philosophy and science. When they broke into Europe, through Spain, it seemed more than probable that they would become the intellectual and religious, as well as the military, leaders of mankind. More than one historian gives them the credit of saving the old culture of the Roman empire, and carrying it over to the period of the renascence and passing it on to modern times.

When it is said that Islam is the one religion that has been propogated by the sword, it is true in no inconsiderable meas- 


\section{THE SOCIAL EVOLUTION OF RELIGION}

ure; but these other facts deserve also to be remembered, and given just recognition. Nor is this criticism on the part of Christians wholly justified, in view of the facts connected with the crusades, the persecution of the Cathari and Albigenes, and the war lasting for a hundred years after the Reformation, which devastated and largely depopulated all Germany. What Christianity has done in the way of waging religious wars, and in the persecution of those who did not agree with one or another set of its tenets, is by no means an excuse for Mohammedanism; but those who are without fault in this respect should be the ones to cast stones.

No apology should be offered, however, for the darker side of the career of Mohammed, though we need not condemn him in order to praise another religion, as has been the custom very generally resorted to by the eritics of Islam. D. S. Margoliouth, the chief authority on Islam, says of the life of Mohammed: "In order to gain his ends he recoils from no expedient, and he approves of similar unscrupulousness on the part of his adherents, when exercised in his interest. $\mathrm{He}$ profits to the utmost from the chivalry of the Meccans, but rarely requites it with the like. He organizes assassinations and wholesale massacres. His career as tyrant of Medina is that of a robber-chief, whose political economy consists in securing and dividing plunder, the distributing of the latter being at times carried out on principles which fail to satisfy his followers' ideas of justice. $\mathrm{He}$ is himself an unbrideled libertine and encourages the same passion in his followers. For whatever he does he is prepared to plead the express authorization of the deity."

We may suspect that this severe criticism, undoubtedly based on facts, has taken on at least a tinge of sectarian preference, and readiness to condemn what did not match with the 


\section{THE SOCIAL EVOLUTION OF RELIGION}

author's accepted beliefs. Recognizing what is good and what is striking in the religion taught by Mohammed, we may reach the conclusion that Islam presents us with the only unequivocally monotheistic religion the world has known. The Jews became monotheist, but after a struggle of many centuries, and only at the very end of their sacred books. Christianity, with all its claims as to monotheism, has retained, in its doctrine of the Trinity, no inconsiderable remnant of the old polytheisms. Mohammed said that there is no God but God, and that Mohammed is his prophet only. He refuses to accept Jesus as in any sense the son of God. He added, It is not fit that God should have a son, for he is neither begotten nor begets.

Mohammed was an ardent believer in immortality, though his paradise has in it too many sensual pleasures to make it wholly attractive to men of a high ethical temper. Much of the old Arabian animism and fetishism clung to his teaching, as was natural in such an environment as his. He believed in a world peopled with jinns and afrits, diabolical beings; and in angelic hosts without number. It must be said of Mohammed, however, that he made less use of the miraculous than any other great founder of a religion, though he by no means discarded this supernatural element. In this respect primitive Christianity was saturated with the miraculous compared with what we find in the history of early Islamism.

In two respects, at least, the moral teaching of Mohammed was sound, in that he abolished gambling and drunkenness. In respect to woman his attitude was far less advanced, for he regarded her as largely a mere instrument of man's 


\section{THE SOCIAL EVOLUTION OF RELIGION}

pleasure, and as his servant. He continued polygamy, and permanently fastened it upon his religion. He did abolish infanticide, and especially that of girls, which had been very common in the Arabia preceding his time. He inculcated honor to parents, and he gave emphasis to the spirit of toleration.

In theology, as might be anticipated when we consider the stage of culture which had been reached in the Arabia of Mohammed's time, he was distinctly anthropomorphic; and it has been truly said that Allah is a magnificent oriental despot. The angel throng about him is that of a splendid court, with its ranks one above another, and its autocratic tendencies in all directions. Very distinctly materialistic is the heaven and the hell of Mohammed, though not wholly lacking in spiritual and ethical significance. His teachings in regard to the resurrection of the body, probably taken over from his religious predecessors, is most materialistic, the actual body being that which survives the grave.

Two simple doctrines formed the whole substance of the teaching of Mohammed - that God is one, and that Mohammed in his prophet. He added other doctrines to these; but this was all that was essential, the whole of the creed of Islam. In his Mohammed and Mohammedanism, Bosworth Smith, the most apologetic of all Christian interpreters of Islam, says of this creed: "The essence of Mohammedanism is not merely the sublime belief in the unity of God, though it is difficult for us to realize the tumult of the feelings and the intensity of the life which must be awakened in a polytheistic people, who are also imaginatve and energetic, when, on a sudden, they recognize the One in and behind the Many. Mohammed started indeed with the dogmatic assertion that there was but one God, the Creator of all things in heaven and earth, all powerful, knowing all things, every where pres- 


\section{THE SOCIAL EVOLUTION OF RELIGION}

ent. He reiterates this in a thousand shapes as the forefront of his message; and, sublimely confident that it need only be stated to insure ultimate acceptance, he deigns not to offer proof of that which, in his judgment, must prove itself."

Any attempt to follow the history of Islam would be impossible here; but it may be suggested that any fair-minded survey of that history will show many bright spots. The accusation often made that Islam is sensuous and materialistic almost exclusively, is not justified in regard to some of its more ethical and spiritual developments. In the teachings of the Sufis, and in their poetry, highly mystical as they are, may be found many a phase of noble religious import. The same is true of that more recent development, originating in Persia in the last century, at first known as Babism, but now as the Bahaist movement. Highly spiritual in its nature, it is at the same time very positively humanitarian.

This survey of the greater religions of the world, and especially those which have had individual founders, may lead us to the conclusion that even these religions have grown out of those which preceded them, and that none of them owes its origin without qualification to a great personality. As was hinted at in the second chapter, religion is in large degree an organic growth, human in origin, and whose evolution is determined by social and intellectual phases of the progress of culture. No religion in its origin can go beyond the stage of civilization in which it arises, and no one of them has as yet prought to man truths he could not have himself discovered by other means than those of inspiration and revelation.

As we have already seen, all religions claim to be revelations, to have explored the heavens and to have brought back to man what he could not ascertain by his unaided faculties. 


\section{THE SOCIAL EVOLUTION OF RELIGION}

The aboriginal inhabitants of America, as of all the other continents, have made the same claim; and it appears to be as valid for the savage as for the most civilized. We have no means of knowing that there is something hidden from the common man which only prophet and priest can make known to him. Rather is it probably true that humanity, in its onward march, in its great unfolding evolution, is step by step finding out the secrets of God, and coming slowly to follow the path which leads to the good of the race, and to a great confidence in what lies beyond the present ken of man. 


\section{CHAPTER VII \\ Universal Religion}

7 HE international religions have claimed to be universal, 1 or have sought to become so; and this is more especially true of Christianity. Some of the Christian churches have taken the name of Catholic, and in that manner have emphasized their claim to universality. Such a claim, however, is rather prophetic than historical, for no religion has ever yet become in any true sense universal. Christianity, according to the most recent estimates, based upon such statistics as are accessible, is accorded a larger following than any other religion; but it does not have amongst its adherents a majority of the population of the globe. It is only in anticipation of what may come, therefore, that any religion can be called universal; and because Christianity has been extended into every part of the world alone justifies its being called catholic.

Buddhism is confined to eastern and southeastern Asia, and has only the smallest following on any other continental division of the earth. Islam extends across Asia, far into its northern regions, over many of the southeastern islands, and also over northern and central Africa. It has no following on the western continent. Christianity is universally accepted in Europe, except in the southeast. It has churches in southwestern Asia and northeastern Africa, reaching back almost to its beginnings; and it has missions in many other parts of those continents. In America it is almost universally accepted; and in the Pacific islands it has made great prog- 


\section{THE SOCIAL EVOLUTION OF RELIGION}

ress, as it has in some parts of Africa. Only in the sense that it has been preached in every part of the world, and zealous efforts have been made for its propaganda, can it be claimed as universal. Certain tribal peoples have never yet been brought into the acceptance of its rites and its beliefs; and it appears to represent too high a type of culture to enable it to win such peoples. On the other hand, it has met with only a moderate success where the civilization was of a high type, as in India, China, and Japan. The religion of these lands has grown out of the people's life, is in harmony with their culture-development; and they resist a religion coming from another type of culture, and representing another form of civilization.

When we survey the whole of the history of religion, so far as our sources of information will permit us to do so, and consider it in all the periods of its evolution, it is apparent that it has undergone many changes, and that it has been modified by numerous revolutions, in the form of new rites and new beliefs. One of the most important of all these causes of change has been the contact of one religion with another, brought about by war, slavery, and migration. Probably the most potent of these causes of change has been migration and the contact of cultures.

As we have seen in the preceding chapters, mankind has advanced from tribal through feudal to national political organization; and there has then followed the grouping of nations to form great empires. Religion has been profoundly modified by these social and political evolutions. In its origin it belonged to the food-group, then to the hunting band, fol. lowing that to the tribe, and the succeeding phases of political evolution. That is, in all early forms of society, the religion belonged to the group, whether it was a band, a tribe or a 


\section{THE SOCIAL EVOLUTION OF RELIGION}

nation, and did not extend beyond its limits. This development may be seen more clearly in the instance of the Jews than in that of any other people, for Yahweh was emphatically their God, and could belong to no other people, since he had chosen the people of their nation, as they believed, as his especially beloved and faithful adherents. In lesser degree this was the conviction of each tribe and nation throughout the world in regard to its own divinities, that they belonged particularly to those who worshipped them. Since each nation had its own gods, it must follow that the people and the gods were of one company or family, forming, as was often said, one household or fellowship.

\section{I}

A process went on from a very early time by which those changes were brought about that may be described by the use of two words, migration and affiliation. Man is the most restless and forward-pushing of all animals. All other animals, at least those which are feral, have a local habitation, a certain range of territory, which is most highly fitted to their needs, and to affording them the necessary food-supply. But man has great adaptability, far more so than any other animal, and has fitted himself to all climates and to all geographical areas. His.invention of tools, implements, clothing, shelters in the form of tents, huts or houses; and his ability to domesticate plants and animals, and to bring himself into subjection to customs and laws, as well as to add the arts and sciences to his equipment, has enabled him to live in mountain regions, on the steppes that seem to spread out endlessly, and even in desert regions that give almost no promise of affording subsistence to his life-needs. He finds himself at home in the 


\section{THE SOCIAL EVOLUTION OF RELIGION}

burning tropics and in the freezing arctics, and in all the regions that come between.

From the earliest periods man has been migratory, hunting new lands, ever pushing out into new regions, seeking fresh adventures with the world in which he lives. In our own day we have seen this tendency largely at work, peopling the great west of our own country, subduing the wilds of Canada, and finding habitation in Australia, New Zealand, South Africa, the islands of the far-off seas, and in many a land all around the globe. So far back as we know anything of man he has been the self-same seeker for new worlds to conquer, partly pushed on by the spirit of adventure, and partly because of the loss of fertility to regions he had inhabited for centuries, and partly by the push of other peoples led on by these or similar causes.

Whatever has brought peoples, at any stage of their devel. opment, into close contact with each other, has had the effect of modifying their religion. Internal resources, the influence of original minds or the natural growth resulting from the general advance of a people, have not usually been sufficient to account for those changes in culture and religion, which we see taking place wherever there is anything which can be denominated as progress. Much of this advance everywhere has come about by means of contact of tribe with tribe, nation with nation, either as a result of war, trade, strife for the possession of territory and resources or as resulting from friendly affiliation by coalescence. This latter tendency has had more permanent and wider results than any of the other processes, though trade and commerce may be described as of the same nature.

Affiliation or amalgamation comes about by several different processes, one of which is the conquest of a weaker nation 


\section{THE SOCIAL EVOLUTION OF RELIGION}

by a stronger. In that case it has often occurred in the history of the past that the weaker nation has given its culture and its religion to the physically stronger, thus finally conquering the conquerer in all that most concerns the higher interests of nations. Another process is that of the adoption of the art, the traditions, the culture, and the religion of a more advanced people by one that is less advanced. This is not always the result of conquest or pressure of material interest, but may result from the readiness of the less advanced people to assimilate what they had not themselves discovered or invented. This process goes on widely in all stages of tribal society and beyond it. Over considerable areas we find the same customs extending, passing over tribal barriers, thus preparing the way for the union of tribes into confederacies. The same process goes on after the national stage has been reached. In this manner the same culture, and essentially the same religion, found expression in China, Corea and Japan; throughout the Mongul tribes and nations of central Asia; in all the region in Europe and Asia occupied by the ancient Greeks; and in all the countries to which the Semites had extended.

Some of the results of migration have a great meaning for the history of religion. Though the Semites originated, probably, in Arabia, yet because of the scanty fertility of their land, and its small resources even for grazing, they spread out into all the neighboring more fertile lands. The result was that their culture, to no small extent, spread with them, into Egypt and neighboring regions in Africa, and throughout all southwest Asia. An even more remarkable instance of the results of migration may be seen in the spread of the Aryans. Originating, as scholars are now generally agreed, in northern Europe, a large body of them crossed western Asia, and ap- 


\section{THE SOCIAL EVOLUTION OF RELIGION}

peared, perhaps 3000 years B. C. in the region of Persia. After a considerable period had passed they divided, and one part proceeded to the conquest of India. Another movement of this same people was into the eastern coast-land of the Mediterranean, and were the enemies of the Hebrews as the Philistines. Yet one more small group invaded Asia Minor and are known to history as the Phrygians, having settled in the central mountainous region of that peninsula. The traditions of the Greeks tell us of several invasions by this same people into the continental regions in Europe and Asia, as well as the islands of the Agean, which were occupied during the historical period. Other movements of this race may be seen in the history of the Romans, Celts and Teutons. All these peoples were offshoots from the primitive Aryans; and their languages, their religions, and their literatures, have close affiliations with each other. One of the most remarkable of historical discoveries in the eighteenth century was that of the fundamental unity of these peoples, and the tracing out of their language and other affinities.

What the migration of peoples has done in connection with the history of religion has been to bring the otherwise distinctly tribal or national religions into touch with each other, thus modifying them in one degree or another. In the early periods, as we have recognized more than once, religion was distinctly tribal or national, shut up largely within the limits of one social and political unit. The religion was coterminous with the tribe or the nation, a veritable part of its life, growth of its growth, and known only within its limits. When such a religion was brought into intimate relations with another religion because of the amalgamation of tribes or nations, the religion also took on wider limits and grew to greater proportions. In this process all the gods 


\section{THE SOCIAL EVOLUTION OF RELIGION}

of a nation were carried over to the larger political unit, as those of the tribe had been retained, along with those of other tribes, to form the pantheon of the nation. It was by such a process that polytheism came into existence. This may be seen at work in all its phases and modifications in the history of religion in Greece and Egypt.

\section{II}

An unprejudiced and unsectarian study of the origins of the great religions makes it certain that they came into existence by the same process, that is, as the result of the contact of civilizations and religions. Buddhism was evidently born of the clash of religious tendencies in India in the period when it came into existence. In a degree it was a protest against the philosophical, ritualistic and theological developments of the time, and an attempt to escape from the dogmas which bound man to the eternal round of rebirth. The many philosophies which had grown up in India testified to the tireless process of speculation in which men had entangled themselves, and to the need for some way to escape from dogma and from the round of being. Gautama solved the problem in the only way possible under the given conditions, by ignoring much philosophical speculation, and by assuring himself that rebirth can be escaped. If he reached his emancipation with the aid of an agnostic attitude as regards the soul and God, denying the existence of both in the old theological and philosophical manner of their acceptance by his predecessors, it was that way lay hope and progress.

No one to-day undertakes to interpret the origins of Buddhism without an extended study of the Vedic growth of religion in India, and its evolution into Brahmanism, and 


\section{THE SOCIAL EVOLUTION OF RELIGION}

finally into Hindusism. Back of these, and essential to any large perspective view of Buddhism, must be studied the Aryan invasion of India, and the varied phases of the civilization thus produced. In a word, Buddhism is a product of the Aryan culture developed under conditions of invasion, intimate contact with the native population in the process of their conquest, the spreading of that culture over the peninsula, and the resulting growth in all the varied arts of civilization. Its more specific features may have resulted from its having had its origin in the Kshatriya or warrior class, the demand that caste should no longer override all social and religious interests, and the wish to escape from merely metaphysical speculation into a life of practical service in behalf of genuine human interests.

Any study of Islam, however sympathetic it may be, must take note of the conditions under which it had its origin. To assume that it sprang full-born from the brow of Mohammed, armed and equipped for every effort life may demand, is to quite misapprehend its real significance as representing a most interesting and important human movement. We cannot regard Mohammed as anything more than a torch from which was lighted a continental conflagration of great proportions. The way for this movement had been preparing for many centuries, and Mohammed did no more than give the initial incentive which precipitated it at the time when he lived, rather than at a somewhat later period. We cannot doubt that within a century or two of his birth such a movement as he inaugurated would have developed in the peninsula of Arabia, had he not lived. In a word, Mohammed was not necessary to a new Arabian revolution, such as had broken out at the time of the origin of Judaism. Moses is but a name connected with that earlier revolution; and very nearly all that we read 


\section{THE SOCIAL EVOLUTION OF RELIGION}

of him in the Jewish literature is traditional, when it is not mythological. What is historical belongs to the desert people who came out of Arabia and settled in Palestine, and not to the man who is assumed to have existed behind the name of Moses.

Students of the early Jewish writings now generally recognize their legendary character, and that the patriarchs or fathers of the race, as there described, represent tribes and not individuals. Read in this light these narratives give an interesting account of the migrations of the early clans, and of their efforts to find a suitable habitation for their people. These migrations are those of a nomadic and pastoral people from the desert regions of Arabia into the richer and more variagated country of Palestine. In his lectures on The Early Poetry of Israel in its Physical and Social Origins, George Adam Smith says that this poetry, embedded in the early Jewish writings, reflects many of the phases of this migration from an arid to a fertile region. "According to all the traditions of Israel," is Smith's remark, "the forefathers of the people came up from the Arabian desert into possession of the fertile lands of Syria; and in common with the early prose narratives the poetry reflects every phase in the change of physical environment through which such a passage necessarily brought them, every stage in the economic and social developments which it involved."

The primitive desert habitat, and the migration to a more attractive region, left their mark on the history of this people throughout their career, as recorded in their sacred writings. Their customs and their institutions, the manner in which they regarded civilization, and their attitude towards religion and its rites, were in no small degree influenced by their early history as a people of the desert. In their religion, as in their 


\section{THE SOCIAL EVOLUTION OF RELIGION}

poetry, were reflected "the desert circumstances and shepherd life; the desert tropes and figures; the desert theophanies; every phase of the inevitable transition to agriculture on a fertile soil with its effects on the nomad's appetite and imagination; the long survival of the nomadic habits and tempers; the purely tribal ethics and interests, the ferility of the tribe, its genealogies, its pride and its hatreds, its loyalties and sympathies, its relentlessness to enemies, its savage scorn and exultations; and, not least, all the nomad's strange silence."

It is impossible to ignore the suggestion that these early experiences of the Hebrews had a large influence on the development of their religion, and more especially on their conception of God as one, and as intimately their own protector and guardian. It is a most suggestive fact that the only two distinctly and unequivocally monotheistic religions came out of the Arabian desert, and from very nearly the same part of it. While it cannot be assumed that a desert region has any. thing especially religious about it or that it must tend towards a monistic conception of nature and life, yet it cannot be doubted that such an experience for a people as the desert afforded had a concentration of interest, an absorbing attraction to the central facts of life, and an unitary direction of thought to single impressions of the phenomena of nature, that as a whole facilitated the conception of the underlying causes of the world and of life as one, and as personal in its nature. No other people than these of Arabia seem to have had an experience of the same limited nature or such as to direct attention to the unitary character of the world known to them. In all other lands where great religions originated the phenomenal world appeared in far more variagated forms, 


\section{THE SOCIAL EVOLUTION OF RELIGION}

and as suggesting a diversified cause or causes behind the appearances it presents. Certainly, however much or however little the desert may have done for religion, we cannot but be impressed with the fact that the two primitive monotheistic religions came from the great desert region of Arabia.

When we compare Arabia with India, the barrenness and monotony of the one with the richness and diversity of the other; and then reflect that the great monotheisms originated in the one region and the richest polytheisms in the other, we may have cause for serious pondering on the problems thus presented. It cannot be assumed, as was done by Buckle, that the desert and its peculiar phenomena have led to the production of a monotheistic faith; but the social conditions induced by such a land as Arabia may favor the conception of the cause of the world as one and indivisible. Arabian life throughout the history of that peninsula has been tribal almost wholly; and, as we have already had occasion to recognize, the tendency in the tribe is to the acceptance of a tribal chief and a tribal god. Whether that god is a totem plant or animal, a great ancestral founder of the tribe or a being of a powerful natural manifestation in sky or earth, he is very likely to be one and alone. When tribes are welded together, when something of the nature of a state comes into existence, in so far as desert conditions permit of such a unity, the unitary conception first finding expression in the tribe is continued and intensified. The god of the tribe then becomes a greater totem, a more devoted guardian of his people, a more kindly and efficient protector of their interests. What the totem was to the tribe, and what the guardian ancestral father was to the patriarchal family, that was Yahweh to the Hebrews and Allah to the Mohammedans. Regarded in this manner, it is not quite 


\section{THE SOCIAL EVOLUTION OF RELIGION}

surprising that the two desert peoples came to believe in one god, and to regard themselves as chosen by him as his own especial favorites.

Any attempt to prove that the traditional Moses was the originator of monotheism, even as regards the Hebrews, is but a futile speculation or the result of sectarian presuppositions. The Hebrew writings themselves indicate rather definitely that this belief was the result of a long-continued process of growth, that it fluctuated from age to age, that it was only at first accepted by a few of the more zealously religious men of the nation, and that it required centuries of exhortation, discussion and protest to bring the people to its general acceptance, which did not occur until many years after the exile and the return. The prophets were as voices crying alone in the wilderness, insisting upon the oneness of God, that Israel had been chosen of him, and that he alone was real as a divine being. After many centuries of their exhortations and incisive protests the nation came to their way of thinking. It would seem, therefore, that even to the Hebrews, called emphatically the people of one God, there was no natural affinity for that idea, no inevitable demand for the worship of a unique and solitary divinity.

\section{III}

Probably it will never be possible to state in emphatic terms the causes resulting in the acceptance of monotheism. The originating causes lie in the background of pre-history, in that far-off time when the nations were forming, when as yet there was no history and no growth of definite tradition. In the nature of their habitat, in the psychology of the race itself, in the character of the life they came to live and the 


\section{THE SOCIAL EVOLUTION OF RELIGION}

ethical principles they accepted, and not the less in the long line of heroic souls who represented a developing idea, and adhered steadfastly to it, are we to look for the originating causes of the faith in one God. Evidently, such causes, in their diversity, their illusiveness, their subtlety, and their intimate oneness with the life of the nation itself, cannot be put into definite propositions. Therefore, we are not able to state how or when the idea of monotheism came to the Hebrews or to any other people. We must be content with saying that these causes were less individual than social, that they did not spring from a single brain; but were the product of ages of human experience.

When we contrast the religions of Arabia with those of India, we are compelled to recognize the wide variation between them, and that there is a divergence corresponding, in no small degree, to the differences in their environment, and to the character of the experiences of the two races. The richness and diversity of the one environment, and the poverty and sameness of the other, seem to be intimately reflected in their religion and in their ethics. When we recognize that this diversity is one of temperament and quality in the lives of the two peoples, we have some clue to the variation in their beliefs and their rituals. All the more emphatically does this contrast stand out before us, when we consider the fact that the Hebrews left the desert at an early time, and migrated into a rich diversified land, with a corresponding result on their religion. Perhaps it was this very fact, their frequent contact with other peoples, and their more mythological and imaginative religion, which made it so very difficult for them to confine their faith to the one God they had come to know in the desert. In this respect it is interesting to compare the history of Mohammedanism with that of the Hebrew faith. 


\section{THE SOCIAL EVOLUTION OF RELIGION}

When Mohammed proclaimed that there is no God but Allah, he asserted what the desert had taught him, and what the lives of his people had made possible of proclamation and acceptance. The same faith in the beginning seems to have been that of the Hebrews, but because of their migration away from the desert, it took them a thousand years or more to accept this faith in confidence and assurance.

We may query why a people of such intellectual calibre as the Greeks, with such a gift for philosophy and for high thinking, should not have come at a very early period to the acceptance of monotheism. In more than one direction they seemed likely to reach a unitary conception of life and of the world, and therefore to come to the belief in one God. Plato and the other thinkers reached this idea theoretically; and sometimes the belief in Zeus or another god, seemed leading to this conception. With them, as with the Hindus and other peoples, the tendency was towards the recognition of one or another god as concentrating in himself all the qualities of the whole pantheon. The worshipper, whatever the god to whom at the moment he was offering sacrifice or prayer, regarded him as if he alone existed. In this sense all the higher religions were monotheistic; and the several gods were no more than attributes or qualities of the one Universal Being. It was with this meaning that Brahmanism believed in the Eternal Self, of whom all men and gods are but manifestations or intimately related as of the same nature. However, in India, Babylonia, Greece, Egypt, and Rome, the diversities of nature and life made too strong an appeal to the human mind to allow of a concentration of attention on the unity of nature and life.

Great as was the influence of the migration of peoples, and of the diffusion of ideas and beliefs, the ancient religions 


\section{THE SOCIAL EVOLUTION OF RELIGION}

grew up to an extent isolated from each other. If these two causes had a great effect on the later stages of their development, this was not the case in the earlier periods, when they were in the process of formation. At that time they were most emphatically isolated from each other and they grew out of, and represented, the tribal life in its most distinctive qualities and characteristics. To a very large degree this has been true of the whole of the history of some nations and their religions. This was true of the Chinese, the Hindus, the Babylonians, and the Egyptians. None of these peoples were quite apart from the rest of the world or developed their religions in utter isolation. Even the Chinese, more truly isolated for many centuries than any other people of the ancient world, were by no means wholly so, though they did not come into definite relations with the more western nations.

In the study of the ancient religions, as in that of social and political institutions, we are compelled to recognize the fundamental fact that the individual was born into his religion, that he had no choice as to the ritual he should use or as to the religion with which he was connected; but these were determined for him by his racial inheritance and by his family associations. In his Ancient Law Henry Maine stated very definitely this fact, when he said that in ancient society the position of the individual was determined by status. It was one of the greatest of all human revolutions when the individual came to have the right to choose for himself to what ritual he should accord his acceptance, and to what religious fraternity he should owe his alliance. As in the case of most revolutions this one came about very slowly and it was only when it had been fully accomplished that it was recognized as having been revolutionary in its nature. 


\section{THE SOCIAL EVOLUTION OF RELIGION}

\section{IV}

Another fact of much significance is to be recognized, if we would understand the full meaning of religion as a phase of the evolution of civilization. Some religions of the ancient time are yet alive, and others have long since ceased to exist. One of the most remarkable of all the religions in this respect is Judaism, which reaches back to the prehistoric time, and yet is full of vigor at the present day. No other religion has ever passed through such vicissitudes, been persecuted to so great an extent, and yet has thriven in spite of the ghetto and the most perverse social ostracism through many centuries. In a less marked degree has been the fate of the religion of $\mathrm{ZO}_{0}$ roaster, which still survives in India, though with greatly diminished numbers. Its followers, however, rank high in culture, morality, and nobility of living.

Several of the great ancient religions have ceased to exist, including those of Egypt, Greece and Rome, together with those of the Celts and Teutons. Other religions disappeared from the knowledge of the western world, and when they came to be known again the surprise was very great. For many centuries the religion of Babylonia had almost passed out of the knowledge of men, buried under the drifting sands which had overwhelmed the cities where it once lived with great brilliancy. In the last century or more it has been revealed to the knowledge of the world once again through the uncovering of the monuments, with their cuneiform inscriptions, which recorded the history, the laws and the religious rituals and beliefs of this ancient people. Not less great was the surprise when the religion of Egypt once more came to the light, and all its striking characteristics, in many respects differing from those of any other land, were brought to our knowledge. Much 


\section{THE SOCIAL EVOLUTION· OF RELIGION}

that we should be glad to know escapes us as regards many phases of Egyptian religion and history; but it would appear , that the great essentials have been deciphered, and the history in a fairly clear outline revealed to us.

If the religions of India, China and Japan continued to live, and were in some degree known for many centuries, it has not been until the last century or two that our knowledge of them has been in any degree extensive and intimate. During the past century their sacred books have become known to the western world, and they have been translated into many of the European languages.

In addition to this increased knowledge of the great religions of the past, and of those which have survived to our own day, we have gained a knowledge of the religions of barbarian and savage peoples in every part of the world. As yet we have no intimate acquaintance with many tribes and peoples on all the continents; but a vast mass of information has been brought to light during the last half-century in regard to the religions of the aborigines of Africa, America, Oceania, Asia, and many an island around the wide world. In the reports of travellers, missionaries, ethnologists, and other scientific investigators, a vast body of knowledge has been accumulated, which is being intimately studied, weighed, assorted, and presented in systematic scientific interpretations of the origin and early developments of religion in all its varied phases. These studies have added greatly to our knowledge of the meaning of religion as a social force, as an attempt to explain the origin of the universe and man, and as a moral incentive and an ethical stimulus. At the same time, it has given us a larger and truer insight into the psychological causes operating to give religion its widely varied developments. If the definitions as to the nature of religion which 


\section{THE SOCIAL EVOLUTION OF RELIGION}

are usually given, even in works seeking to interpret religion in a scientific spirit are by no means broad enough, yet it has become certain that its influence in all ages has been very great.

Such studies have made it known to us that the early religions were not concerned with beliefs, but with rituals. They did not present creeds, but ceremonials and sacrifices. In this respect the earlier religions, including all those known to the ancient world, were of this type, concerned with conduct and not with belief. Salvation in the thought of early man was not the result of what one believed about God, but what ceremonials one observed and what sacrifices one offered. To no small extent that remains true to-day in regard to all but a few of the most developed phases of religion, even in Christian lands. It is emphatically the case in India, and with what there appears as the most widely spread religious developments. Creeds there may be, but it is ritual and ascetic practices which count.

Another marked difference between early and ancient religions and those of our own day is to be found in their attitude in regard to progress. Truly orthodox religions everywhere do not accept the principle of progress, for they assert the conviction that the past is better than the present, that God once revealed himself to the world, and that no fresh revelations are to be anticipated in the present or the future. Almost without exception the great ancient religions looked back to a happier past, a paradise which has disappeared, a golden age which no longer exists, or to a time when God walked with men in the cool of the evening or sat with them in the door of their tent conversing freely. To the same import is the belief that in the early time God revealed himself to men, and that remnants or survivals of that primitive revelation are to be 


\section{THE SOCIAL EVOLUTION OF RELIGION}

found underlying all that is good and beautiful in the religions of savage and barbarian peoples. In a word, this conception of religion is backward-looking, facing the past and not the brighter time that now is or that which is to come.

On the other hand, we may find many religious developments which are progressive, which do not look back to the past, but which face the future with hope and expectation. Such religions do not believe that the truth has been exhausted or that religion has as yet reached the utmost of which it is capable. They believe with John Robinson that more truth is yet to break forth from the revealing word of life. They also agree with Emerson, that man is not yet old enough by a thousand years to write a creed. They do not look to a paradise behind, but to a nobler life for man in the future. They are not much concerned about the old beliefs, but are deeply solicitous as to the most helpful truth man can acquire at the present time. Those who take this attitude in regard to religion are usually known as heretics; but it is probable that they are the true prophets of the coming time.

In the unfolding of the history of religion from the earliest time, we find that, on the whole, in its higher types it has progressed. While it has remained too often unmoved by the advances of the world about it, being more interested in retaining the old rituals and beliefs than in serving the higher interests of mankind, yet there has been progress, and a progress that is very great from primitive animism and polytheism to the most developed manifestations of the religious spirit in our day. There has often been retrogression, and some phases of the most abject degeneration, yet the general tendency has been upward, and toward what is more ethical and rational. Even now there is frequent reversion to what is magical and superstitious, to dark and forbidding beliefs, and to ceremonials which are de- 


\section{THE SOCLAL EVOLUTION OF RELIGION}

grading and gross; but the general march is sunward; and towards a broader acceptance of what will make for the elevation of man.

What is claimed to be a new interest in relgion, about which much is being written-it being claimed that no one is now critical of its tendencies, and that there are no doubters and no skeptics-means that the occult, the mystical, and the supernatural have been revived in no inconsiderable degree. Credulity, superstition, and fanaticism, if they do not by any means control the religion of the day, have over it a very large dominion. Even palmistry, astrology and spiritism, once thought to have forever disappeared from the beliefs of modern men, have their numerous and ardent advocates. Rationalism is condemned, science is ostracized, sanity in philosophy no longer meets with approval; and these are replaced by vitalism, an exaggerated idealism, and an assumption that psychic research is to give us a new faith and a fresh hope.

Whatever there may be of permanent value in these tendencies, how is it possible to conclude that they are more than passing phases of the life of our time! The history of the past assures us that the occult and the mystical are only temporary phases of a religion which abides through all the centuries. The rationalism which is now tabued will inevitably come back in a great revival, we may be assured. Religion divorced from reason and from science cannot be other than credulous, superstitious and fanatical. However attractive the tendency to the occult may be for the moment to many persons, it has not the qualities which are permanent.

It is often claimed that this passing charm of the occult is a reaction against the materialism of science; but it must not be forgotten that there may be a revolt against the occult-and one that will earry rationalism and science to heights they have never 


\section{THE SOCIAL EVOLUTION OF RELIGION}

hitherto reached in the history of religion. Fascinating as the mystical may be to those who come under its attractive influence, it has never had other than a fleeting hold upon the great majority of mankind. We have gone too far in the direction of a clear-thinking view of the world to give other than a passing opportunity to the occult, whatever the name by which it may be known. Its power is steadily waning, however much it may seem to be in the ascendency at this moment; and it can come in our time only to a spasmodic and temporary rejuvenescence. The day for these phases of religion-however great their appeal for the passing day-cannot be other than temporary, and as a mere fashion of the hour.

Great and rapid changes in the nature of religion are taking place at the present time. Never before in its whole history has it been at such a stage of revolutionary progress as in our own day. This is in part due to the great advance, and general acceptance, of science; and to the wide-reaching influence of its facts and its methods of investigation, which have been carried over to the study of religion. Never before has it been possible to regard religion as a phase of the progress of culture and civilization, and to study it in the same spirit in which we study a flower or a star, a chemical element or the processes of social genesis. We are now able to stand away from it, to regard it, as it were, in perspective, with an aloofness that permits of dissevering ourselves from all concern as to what belief or unbelief may mean with regard to our individual destiny.

One of the newest of all the sciences, that of Comparative Religion, has grown up as the result of this new method in the study of religion, which permits of its investigation in the whole range of its evolution, and with absolute freedom. Most of the works which have so far appeared in connection with this new science have been marked with more or less of the sectarian 


\section{THE SOCLAL EVOLUTION OF RELIGION}

spirit, and have felt it necessary to bow to the dictates of Christianity, as if the writers dare not speak their minds with absolute freedom. However, the tendency is strongly towards regarding religion as in itself interesting, of great importance to an understanding of the evolution of civilization, and as demanding the strict application to it of the methods and spirit of science. It does not follow that the investigator must reject all religion, in order to undertake such a study in the scientific spirit, or, on the other hand, that he should apologize to any of the higher religions for his devotion to the demand for the truth, and the whole of the truth, in regard to any and every religion, past and present.

The most important of the changes which have come into the religion of our day is the increase of our knowledge in regard to all the religions of the past, from those of primitive man to those which are the most advanced. We may now study the sacred books of all the peoples which have produced works of that nature, and these include the Japanese, Chinese, Hindus, Persians, Babylonians, Arabs, Hebrews, Egyptians, and Christians. Several other advanced peoples, which have no books which may be called sacred, such as the Polynesians, Syrians, Greeks, Romans, Celts, and Teutons, as well as others, have given the world rituals, sacred songs, mythologies or epical poems, which are of great importance in connection with the evolution of religion. All of these may now be studied, and are included in the materials investigated by the science of Comparative Religion. The very idea of comparing all this vast mass of traditional or written materials, coming from every part of the world and from all ages, is quite new in the history of religion; and is giving it a fresh meaning, as well as bringing us a far broader conception of what it has represented in the history of mankind.

This new knowledge, which has been coming to us during 


\section{THE SOCIAL EVOLUTION OF RELIGION}

the last two centuries, and more especially during the last halfcentury, has immensely widened the conception of religion, and our outlook upon it as a phase of human culture. In one direction it has greatly developed the work of the Christian missionary, made him familiar, if he has so chosen, with the nature of the religion or religions he has to face in his field of labor. It has prepared him for appreciating, and for apprehending, what religion means to savage and semi-civilized peoples. If his field of labor is in a land where exists one of the great religions of the world, such as Brahmanism, Buddhism or Islam, he may go to his task equipped with an intimate knowledge of its origin and development, its ritual and its creed. Even if he is to labor in the heart of Africa or in some remote island region, it is more than probable that he may secure before he goes a large acquaintance with the customs, folk-lore, mythology, and religion of the tribe amongst whom he is to carry on his work. He may know the religion of Australia, of the Andamans and of Borneo, of the primitive races of North and South America, before he sets forth on his work of religious propaganda. Whatever advantage there may be in this knowledge, it is owing to the widely developed interest in all phases of religion which has characterized the ethnological investigations of the last century.

There can be no question that this remarkable recent advance in our knowledge of the evolution and history of religion has developed, and is developing, most important results, the full effects of which will appear only in the future. One effect is that all religions have been cast, as it were, into the melting pot, and are being refined and purified; at least, this is true of all the more advanced religions. Another effect is, that the cruder and least developed are rapidly disintegrating and disappearing. In some respects this is to be regretted, for we should be glad to have more knowledge of some of them than we have as yet been 
able to secure, so rapidly are they passing out of existence, as the result of their contact with the higher civilizations of the world. We would give much to know the true nature, in much of their details, in regard to the religions of Mexico, Central America, and Peru. The fierce onslaught made upon them by Christian nations has forever deprived us of any intimate acquaintance with those characteristic American religions, a knowledge of which would enable us more clearly to understand the civilizations with which they were connected, and to comprehend more definitely whither the less advanced aboriginal peoples were tending at the time of the discovery of America.

\section{V}

Now that all religions have been brought out into the open field of knowledge, and all the great sacred books of the world may be read and studied by whomsoever will, since the most characteristic of them have been translated into English and other European languages, some important results are following. One result is that each of the great religions of other countries has proven attractive to a greater or lesser number of persons in European and American lands. The religions of India have given us Theosophy, a wide reading of the works of Rabindranath Tagore, and an eager study, on the part of a considerable number of persons, of the sacred books of that country. It may be that no great number of persons have been attracted to Theosophy, but there can be no question that it has had an influence by no means insignificant on the tendencies of modern religion. The conception of metempsychosis has proven attractive to a considerable number of persons who have not connected themselves with the Theosophical movement, for the reason that it gets rid of the arbitrary conceptions connected with the ortho- 


\section{THE SOCIAL EVOLUTION OF RELIGION}

dox manner of interpreting the nature of the future life or, rather, of the processes by which the destiny of the individual is determined. The notion that the future brings about a sharp division between the good and the bad, as determined by conventional, ethical standards, and that the fate of the individual is forever fixed by the nature of his beliefs and his ritual actions in this life, has become repellent to a no inconsiderable number of persons; and some of these are attracted by what they regard as the more natural conceptions of karma and methempsychosis. Here the future fate of the individual, whether under Hinduism or Buddhism, is determined by himself, and what he is, what he makes himself to become by his deeds, and determines the kind of life he shall live when he comes to his next birth. However low in the scale of being he may find himself as the result of his actions, he may raise himself to a higher stage at the next rebirth, if he seeks to obey the conditions of the life which is now his, whether that of plant, animal or man.

The results of religious contacts in the last century have not been confined to western lands, but have effected India, China, and most other oriental countries. Not only has Hinduism been led to seek for reforms in its methods, as the result of contact with western civilization; but there have grown up in India several distinctly reform movements, all of which are highly interesting and suggestive with regard to the future. These include the Brahma Samaj,. with its several branches and offshoots. These have sought to bring Hinduism back to its purer phases of the past, to rid it of superstitions and mythologies, and to give it a more distinctly ethical and a monotheistic interpretation. The number of adherents of these movements has not been large, in proportion to the whole population of India; but the influences leading out from European contacts have been much wider-reaching than the number of their followers would 


\section{THE SOCIAL EVOLUTION OF RELIGION}

indicate. Evidently, there is going forward in India a revolutionary movement as concerns religion, partly a result of missionary effort, but much more largely the product of intimate contact with western culture and civilization. As yet the visible results are not great, but they are likely to be progressive, and to develop far more rapidly in the future.

One of the results of the invasion of Mohammedanism into Europe, both into Spain and into the Balkan region, has been an intense prejudice against it in Christian lands. The long and fierce attempts to repel it, and to expel it from Europe, has awakened every possible kind and degree of sectarian hatred and misconception. This hatred and this jealousy have developed among Christians a dislike for Islam which has been shown towards no other religion; and has not made it possible, until quite recently, that Mohammed and the Koran should be viewed in any favorable light. In spite of this distrust and this hatred, a considerable number of Europeans and Americans have quite recently been drawn to Bahaism and the teachings of Baha'u'llah. Abbas Efendi, a most venerable old man, winsome in his manner, speech and teaching, has visited this country and England, leaving behind him a gracious memory. Declaring that the Primal Divinity is unknowable, but that there have been and are various manifestations of the prophetic spirit, the Bahais teach that the Universal intelligence has spoken, and speaks, to mankind through a succession of prophets, that God has never left himself without manifestations of his reality and his presence. What was material in Mohammed's conceptions of the future, or what has been interpreted of his teaching to mean a material hell and heaven, the Bahaists reject, and assert that these are mere shadows of the spiritual nature of the future life. According to their teaching revelation never ends, and God is ever revealing himself. The unity of nature, life and God is also in this teach- 


\section{THE SOCIAL EVOLUTION OF RELIGION}

ing. What most attracts westerners to this new religion, however, appears to be at once its lofty spirituality and its broad humanitarianism. In essence it is a progressive and a reform movement, teaching that men everywhere should live together harmoniously, in a brotherly spirit, and for the advancement of the great common interests of mankind. Teaching a practical socialism, a socialism of brotherhood and mutual service, the Bahaist movement seems destined to have a considerable influence on the future of religion, both east and west.

Other religious movements which have sprung up in recent years, such as Christian Science, New Thought, Ethical Culture, the Modernist development in the Roman Catholic Church, the Progressive Orthodoxy of Protestantism, and the wide-spread revival of mysticism, are to be regarded, in one degree or another, as results of the broadening of our knowledge of the past of religion, and of our greatly increased acquaintance with the religions of the eastern lands. The sacred books of Judaism and Christianity have been subjected to a most searching investigation, as to their origin, their historical character, the quality of their ethics and their theology; and they have not come forth from this ordeal as they were when the testing of them began. They have been, in no small measure, placed through such studies by the side of the other sacred books of the world, and subjected to a critical comparison, which has led many persons to the conclusion that they can no longer be held as in their nature essentially different from the other works of the same type.

These various tendencies of the last century have had the effect of discrediting, at least in a great number of minds, whatever is ecclesiastical and orthodox. Even orthodoxy itself, in all the western churches of Christendom, is no longer what it was a century ago. It has moderated its claims, in some degree has ceased to be dogmatic, has developed a distrust of the sovereignty 


\section{THE SOCIAL EVOLUTION OF RELIGION}

of God as a spiritual autocrat, and has grown more tolerant towards other forms of belief than its own. Holding largely to Christianity, in western countries it is to no small extent in a manner no longer strict, and insistent on mere belief in metaphysical creeds; but even in the most orthodox churches there is taught the immanence of God, the wide-open mercy Christ offers the offender against the majesty of his teachings, and a sweet reasonableness as regards what is essential to the nature of religion itself.

When we view the developing movements of civilization throughout the world, what we must recognize is the drawing together of nations as the result of the extension of means of communication and transportation. Countries that were a few centuries ago quite unknown to each other in any real meaning of the word, have now come into intimate touch, and are largely influencing each others' interests in many directions. The east and the west have been brought into close relations, not merely as the result of the development of commerce, but because of growing intellectual affinities. Travel has brought a great number of persons into a genuine acquaintance with other lands; and all that is best in the arts and sciences, the literatures and eultures of any land has become the common property of all the world, and to no small extent. Japan has become to-day almost as well known as England, and in many respects better known than Russia. China has opened its resources of material, and its other resources of intellectual, riches to western lands; and the old antipathy and exclusiveness are wearing away. The fact that this land of a great population has become a republic, with promise that it will during this century become stable and progressive, marks a vast change wrought in the life of the orient. India, we are told, is seething with unrest, and aspiring to follow the example of Japan and China; but proves to be loyal to the 


\section{THE SOCIAL EVOLUTION OF RELIGION}

west and to its deep-reaching influences, which are slowly modifying the civilization of that peninsula, and in many directions. If it is receiving largely from the west, it is by no means failing to give to the west of the best its centuries have produced.

In the nearer lands of the east vast changes are in progress, with the building of railroads, opening of canals, increase of trade, and penetration of world-travellers and world-commerce. Syria, Mesopotamia, Palestine, Arabia, Egypt, Greece, and all the Balkan lands, as well as that vast continental area known as Russia, give promise of far-reaching changes in the not remote future; and of their being opened to all the progressive movements of our time. If they have received much from the more western countries, there can be no question that they are returning as much as they have received or will do so in a century to come. Russia is a land of vast possibilities, and we may not doubt that it will have a great influence on the future of mankind, not only as concerns social growth and literary developments, but in religious evolution. After a time of what may prove to be a prolonged revolutionary struggle, Russia is likely to come forward, perhaps before this century ends, as one of the most enlightened and progressive countries known to the world. Its religion is now backward and superstitious, but it is possible that in this respect the people will keep pace with their evolution of a truly modern social and political life for the whole body of the people under a genuinely democratic regime.

What we see taking place about us is, that religion is becoming emancipated from its superstitions, its credulities, and its orthodoxies. We are leaving behind, perhaps too slowly, but very surely, the results due to the inheritance of animism, fetichism, and polytheism; we are compelling religion to stand side by side with science, and to make answer to the newest and most assured knowledge man possesses. It need not follow that re- 


\section{THE SOCIAL EVOLUTION OF RELIGION}

ligion will lose any of the deeper meanings which have made it powerful in the past or that it will cease to guide the feet or to cheer the hearts or to illumine the minds of men in the time to come.

Men throughout the world have refused longer to accept the dogma of the divine rights of kings, or they will soon come to do so; and with equal certainty they will refuse to accept the divine rights of sacred books or the authority of autocratic saviors. The conception of Jesus as a Lord belongs to an undemocratic age. His own preference, according to one tradition, was to call himself Friend,- - the friend of the poor and unfortunate, and the friend of mankind. Lord Christ and Lord Buddha are titles belonging to the same strata of aristocratic and autocratic social conditions, when men were not free, when they cringed before their superiors, and when they dared not speak their own minds or lead their own lives. In this age of equality and freedom, when democracy is beginning to dominate the world, lords of every kind are out of place, and should be banished from religion as from politics and national life, from the church as from the state.

The human spirit will be free, and every man and woman will dwell in the house of his or her own mind, as in a castle that cannot be invaded arbitrarily by any other. We shall no longer permit pope or bishop to dictate to us what we shall believe, and no synod or congregation can be permitted arbitrarily to instruct. the individual mind in regard to the great problems of destiny. The day of the lord and his authority has gone by forever, as regards political control or religious conviction.

At the present time there is a demand that the world shall be won over to the interests of democracy and peace; and it is proposed that a league of free nations shall be organized to promote these objects. It seems probable that something of this 


\section{THE SOCIAL EVOLUTION OF RELIGION}

nature will be one of the developments of the near future, and that the nations will be federated together for the promotion of those interests which they have in common. Democracy has made great strides forward in the last half-century, and it is likely to win all progressive nations to itself in the near future. Nearly all peoples are demanding this form of government and the freedom which it promotes. It is the governing and military classes alone which do not favor its acceptance; but the rising tide of working-class demand in all industrial countries, it would seem, will soon compel the acceptance of what the great mass of the people demand, that freedom, the ballot, and industrial equality shall be secured for all; and these ends can be reached only through the promotion of a genuine democracy. An essential to the promotion of democracy and equality is peace and the federation of the nations, in order that the interests of all men and women shall be guaranteed. While it may be possible that humanitarian desires, and the craving for democratic freedom, may anticipate too eagerly the advance of mankind toward these results for all, yet one can hardly refrain from believing that the day of freedom and democracy is at hand. Many a struggle may yet be necessary to their being secured in every part of the world, many a hard fought battle may come before they are fully attained; but can one doubt that they are written in the destinies of mankind in the not remote future?

With the coming of democracy and peace there must also come a great modification of religion, a sloughing off of those creeds and principles of authority which have come to us from the ages of kingship and autocracy. Even at the present day a silent advance is being made in this direction, and we are witnessing on every hand a growth of democratic ideas in connection with religion. It is not that religion concerns itself directly with the promotion of the political aims of democracy; but that 


\section{THE SOCIAL EVOLUTION OF RELIGION}

freedom of thought, liberty of inquiry, the furtherance of individual beliefs, the demand for personal interpretations of all religious principles, are coming more and more into the foreground of the religious life. The priest and the preacher may be listened to with respect, and followed in their teachings with a considerable degree of confidence; but a smaller number with each generation are willing to accept them as in any way authoritative guides in regard to what is fundamental. Even in the older churches, where authority reigns in apparent supremacy, this is coming to be true in an appreciable degree. The pushing forward of democracy to the conquest of the world will, in time, undoubtedly, influence the most reactionary and ultramontane of these churches, and bring them into line with the world-movement. If they cannot be modified in this manner, the life of the new time will sweep by them, and leave them in the corners of the world to live out their little day.

The demand for democracy, industrial opportunity, peace throughout the world, and the federation of the nations for the advancement of economic and industrial ends, with the elimination of the antagonisms of nations for the promotion of exclusively national interests on the part of individual nations or small groups of nations, will inevitably in time lead to demand for the unification of the ethical and religious interests of mankind. It will be seen that, if the nations are federated in behalf of common industrial, economic and political interests, they cannot be permitted to retain the old antagonisms growing out of diverse creeds and religious ideals. This result can be brought about either by bringing all peoples under one religion or by a synthetic acceptance of what is common to all the advanced religions. This means, that what makes for democracy and peace, what promotes an ethical life, what broadens and deepens and universalizes the humanitarian motive, and the things that 


\section{THE SOCIAL EVOLUTION OF RELIGION}

make for fellowship and goodwill, are the truly essential elements in any and all religions.

At the present time there is a growing demand in Christian lands that the antagonisms of sects shall be eliminated, and that they shall federate together to promote the interests they have in common. While the growth of new sects has been in recent years more rapid than the affiliation of the old ones, yet the developing ideal of unity is becoming more and more forceful as a general aim to be sought for and promoted. At the same time, as we have seen, there is an enlarging recognition of the universality of religion, that all religions may be defined under one eategory, and that each religion may profit by the history, the ideals, and the beliefs of all others. Perhaps neither of these tendencies has as yet developed to any considerable extent; but the federation of the nations, in order to promote the interests they have in common, will inevitably lead to a closer intimacy of the churches of the world, by whatever name they may be known, and will tend to bring about a more genuine co-operation of all good men everywhere for the promotion of every humanitarian work and ideal. When this result is reached, it can little matter how the theologians and the sectarians regard the work that has been accomplished.

The liberal-minded Christian should remember that there is the broadest possible contrast between the Jesus of the New Testament and the Christ of the creeds and the theologies. The Nicene and the Athanasian, and even the Apostles' creed represent nothing that is historical; and they are very far from being true to the facts of human experience. One of the results is that the common daily expressions of religion are largely conventional and traditional, merely repetitions of old phrases, catchwords or terms that carry no present-day con- 


\section{THE SOCIAL EVOLUTION OF RELIGION}

viction. Faith in the Lord, and in God the Father, is uttered in the same manner and tone that faith in the influence of the moon on crops is stated. Neither belief is likely to carry with it knowledge or deep conviction.

The religion of the future must more and more develop in the direction of making a better human world, a world in which all persons shall find the highest measure of development possible to them as individuals. Religion does by no means consist in belief in ghosts or spirits or even in gods; but many of its highest expressions are purely human, and concerned with the present-day interests of human beings, as well as with the present-world destinies of mankind, not merely with those of individuals. The conception of the great future of humanity, the faith in large and noble reforms, etc., act as religious motives, inspiring not only enthusiasm, but faith, hope, courage, and steadiness of purpose. This faith has most of the deeper qualities and sanctions offered by the old religious motives.

A higher ethicism is demanded by the new conception of humanity, that the ethical motive shall be that of the nation or the race rather than that of the individual. It will have very nearly all the incentives of religion, an eager desire to serve mankind, and an inspiring faith in the future of humanity throughout the ages to come. In large degree the religious motive will be replaced by the ethical. The moral life has grown with social and political progress, and it is a direct expansion of that progress. Since the feudal era it has been more and more without the mystical and supernatural sanctions of the older religions, but has become distinctly human, concerned with social and individual welfare. It no longer depends primarily on theology and metaphysics. 


\section{THE SOCIAL EVOLUTION OF RELIGION}

Religion is not science, and cannot be identified with it; but it must accept what science declares; and it must have its foundations in the scientific spirit and method. Its cosmology must be that of science, and its conception of human origins, and the quality of human nature, must be also scientific. Its morality must have a truly scientific foundation, no longer relying merely on tradition and customs originating in a far-off past, when human life was quite other than it is now. Some of the directions in which science will aid in the development of the future of religion may be presented here, in briefest statement :

a. A greater recognition of the social origin and functions of religion.

b. In conformity with this recognition a much greater effort will be made to ameliorate human conditions. Without doubt less stress will be laid on what is other-worldly, and far more upon making this world of human conditions a fit place for human habitation. That is, it will become more and more humanitarian, and will clearly set before itself, if it is wise and worthy to continue as a human force, the task of helping to abolish poverty, vice, crime, and ignorance.

c. A growing unity of purpose as between the several religions will be one of the tendencies of the coming years. The Protestant sects are likely to affiliate more closely in all practical efforts for human welfare, and some of them will amalgamate. The estrangement between Protestantism and Catholicism, Roman and Greek, is likely to grow less. A profounder understanding and appreciation of the other great religions of the world will slowly come about, and there will be a larger recognition of each other on the part of all the progressive religious movements throughout the world. It will come to be recognized that all religions are capable of producing good 


\section{THE SOCIAL EVOLUTION OF RELIGION}

men and faithful citizens, and that conduct does not rest primarily on beliefs and creeds.

d. Science will be more and more widely accepted as explaining the methods by which the individual and society can be improved. Evolution will be practically, as well as theoretically, accepted as interpreting the origin and nature of the moral life, its sanctions and methods of enforcement of its dictates. Heredity and eugenies will play a large part in the practical interpretation of human life, and the efforts to advance the ethical interests of mankind.

e. Religion will become more rational. There will be less of submission to the demands of tradition, and to those crude and cruel ideas in regard to the future which have marred and darkened all religion in the past.

f. Religion will become more tolerant, humane, and sympathetic. It will also become more friendly towards aberrant ideas and beliefs. Belief will be seen to be of less importance than conduct; and individual opinion will not only be permitted, but welcomed. In a word, orthodoxy will be less insisted upon than it has been in the past, and it may be even discarded as of no importance. It will be recognized that religion cannot compel by any process uniformity of belief in the modern world; but may secure unity in the desire to promote good works, a more ethical and nobler life, and a wide-reaching spirit of helpfulness and purpose to uplift humanity in so far as possible.

g. That which in the past orthodoxy has most severely condemned - the good life without a strict belief in the creeds - will become the very foundation of future religion. The church has given us too many creeds, and it has asked for beliefs which will be more and more rejected by all thinking and progressive persons. The past of religion proves clearly 


\section{THE SOCLAL EVOLUTION OF RELIGION}

enough that it is not soundness of faith, but soundness of life and character, which advance personal and social religion to its highest expression. The individual may believe in the strictest manner possible, and to the fullest extent, and yet fail in every particular to live an honest, noble, and manly life. It may be anticipated that all the creeds will in time go into the dustheaps of the past, and that religion will gain immensely by the process of elimination. Nearly all the creeds belong to the past, and to old or dead processes of thought.

h. The present demands a more social, humanitarian and tolerant religion - one based on conduct, desire for human welfare, and combined effort to make a better world in which men, women, and children will be helped to live the best life possible to each and every person. This means that caste, class, social barriers, dominations of wealth, and all religious and social restrictions shall be abolished from human relations; and that all shall meet on a basis of fellowship and good-will.

\section{VI}

If we look seriously at this moment at what it is in our own country which truly indicates the nature of the religious convictions of the American people, we shall be the better prepared to believe that a great change is advancing over the world in the realm of religious beliefs. Remembering that in the past, when religion was a great unifying force in the lives of nations and races, and it was a common ideal and motive living in the life of the whole nation, we may inquire as to what it is to-day which is unifying the interests and aims of the American people. The various sects, however much they have talked of unity and the promotion 'of their common aims, have not federated, and are not working together as one uni- 


\section{THE SOCIAL EVOLUTION OF RELIGION}

fied body for the promotion of human welfare. If their old antagonisms are not as strong as formerly, yet they have not come to stand together as a solid ethical force for Christianity or even for the helping forward of the cause of democracy and peace. On the other hand, what has unified the life of the American people in an astonishing degree is patriotism. Christianity has not brought about this result, and apparently could not at the present time bring it about. Patriotism alone has wrought the miracle, has accomplished what was apparently impossible.

No other conclusion, therefore, can be reached than that patriotism is the real unifying force to-day in the life of this, as of all other progressive nations. Apparently the same force operates in all European countries, with the result that there has been, as here, a marvellous growth of patriotism, which is leading to the greatest sacrifices on the part of millions, not because the people are compelled to give of their lives and their substance for the promotion of military interests; but because they have voluntarily, for love of country, thrown themselves into the support of what their country represents and is seeking to accomplish. Can there be any other conclusion, therefore, than that the real religion of the world today is patriotism? What Christianity has not been able to accomplish, the unification of a nation for some great ideal aim, patriotism has brought about with a minimum of effort, and in an incredibly short time.

There was a time when the church stood above the state, and dictated to it its policies and its lines of conduct. Now it has become of distinctly lesser importance than the state, and subject to it. The church continues steadily to recede in its influence, but the state is as steadily increasing in its meanings for mankind. In all democratic lands the church has become 


\section{THE SOCIAL EVOLUTION OF RELIGION}

of minor significance and value, and in large degree subordinate; but where the old autocratic rule obtains the church is more fully recognized, and in proportion to the autocratic rule. However, even under autocracies the people may largely reject the church as an authority, and as having a right to dominate individual belief and conduct. It may support the aristocratic regime, as it often does; but that does not insure its acceptance on the part of the mass of the people, who are becoming more and more imbued with democratic ideas and motives.

The thinkers of the world no longer look to the church or to revelation as giving sanction to ethical principles and conduct. It is seen clearly enough that morality originates in social conditions, the relations of individuals to each other in society, and that it is by no means essential that one or another god shall guarantee the fundamental motives on which it is based. Since it is on the primary ethical principles that the state rests for its right to exist, it is no longer necessary that the state should appeal to the church or take from it any iota of its right to exist. In fact, more and more the state usurps the place once occupied by the church, and makes a more effective appeal to the great majority of the people than it is now possible for the church to present. That is the reason why it is possible for the whole mass of the nation to accept the claims of patriotism, love of country, and joy in the things of the free spirit it represents and promotes. If the state still continues to exercise some of the autocratic power once belonging to the church in a supreme degree, we may be convinced that this tendency must pass away with the growth of a genuine democracy.

Love of country has become a religion, which is slowly broadening out to an international conception of human re- 


\section{THE SOCIAL EVOLUTION OF RELIGION}

lations and obligations. We may not doubt that in time there will develop a world conception, a recognition of the great fact that nothing human can be alien to us. The furtherance of all human interests, the bringing nation into close fellowship with nation, the having regard to the welfare of all who live in whatever land or of whatever color - this will enter very largely into the religion of the future. Love of God, if that is to be retained in any degree of effectiveness, must mean love of all human beings, profound regard for the interests of mankind, and desire to promote, in whatever degree possible to us as individuals, the welfare of all the kinsmen of the human fellowship.

As the fellowship of the church lessens, the fellowship of the state increases. It seems more than probable to-day that the bonds uniting individuals to the church will slowly cease to have any meaning, while those uniting individuals to the state will grow stronger and more effective. In the past men have sought fellowship in the church, now they are seeking it in the state, and finding it coming closer to them, with ties of sympathy and inspiration the church can no longer provide to an ever-increasing number of men and women. True it is that the state fails in many a particular to serve the interests of the individual and the community as it ought; but it is growing in its capacity to serve and to invigorate human interests of all kinds. It seems most probable, therefore, that in the coming time love of the church will be, as it is now, largely superseded by love of country. Patriotism gives a great fellowship, one which unites men of all opinions and degrees of culture, while the church serves more and more to divide men from each other.

The only hope of the church in the future is that it shall put away its disintegrating motives and teachings, its creeds 


\section{THE SOCIAL EVOLUTION OF RELIGION}

and its antiquated beliefs, and seek fellowship with all lovers of what is human and noble and beautiful, in all lands and under all religions. If it cannot do that, its day of doom is read out to it, and cannot be escaped. Mankind is one, and it needs but one religion and one motive for human fellowship.

There can be no doubt that Christianity is to-day in the melting-pot, and that it is being tried as by fire. It is being questioned, tested, and searched to the very foundation of its being. How it will come out from the great world-struggle no one can now answer, and yet it will not be as it went in. It is being tested most thoroughly, and it may come out purified and refined; but it may also lose its power over millions of men and women. These are questioning what there was of defect in it, that it could not prevent the great world-war; and because it could not, or did not, there is something ethically lacking to its claims. The patent fact that all the great Christian nations have been taking part in this desperate struggle for industrial and commercial supremacy can but make all independent thinkers question as to what is the real significance of Christianity as a world-force capable of unifying the nations, and of promoting democracy and peace. Other influences, apparently, are coming forward to bring about what it has not secured during the nearly two thousand years of existence as a world-force.

Will there come a new religion, equal to the needs of this new time? Some indications may be seen that such a development is even now in progress, and that it may attain to rapid growth in the near future. The freer-thinking men and women of all religions are coming into closer sympathy with each other, are holding great world conferences to promote the aims they have in common, and are endeavoring to put the emphasis on what is universal or on what will promote the 


\section{THE SOCIAL EVOLUTION OF RELIGION}

humanitarian development of all peoples. As yet there is no close affiliation, no organizing of a sect, no effort to propagandize for these new movements. The number of those who desire as yet to promote such a unification of the world's religions is not large; but in all lands smaller or larger groups are seeking to bring about the advancement of what will bring good-will between, and genuine affiliation of, thinkers and humanitarians throughout the world. If at present the most spectacular movement toward the religious unification of the world is that of Christian propaganda, with the claim that it alone can save mankind for ethical fidelity and the harmony of nations, we may question if it has any such significance as that of the silent forces which are everywhere steadily working to bring the nations together, and to bring into closest sympathy and fellowship those of all lands and religions who are desirous that all mankind shall work together for what is promotive of permanent human welfare throughout the world.

What political, social or religious force it shall be which promotes the growth of democracy and peace cannot be of great importance, so that these aims shall be genuinely advanced in all lands. The breaking down of the spirit of military and autocratic domination over the lives and interests of the great mass of the people is what it is desirable to have accomplished. Any religion which seeks to hinder that expulsion of the lords and kings must suffer the righteous wrath of the people against it, and its day must end thereby. Any religion which allies itself with the people, which is ready to become truly democratic, wiH have before it a great future. It needs no prophet to assure us that the coming religion must be one growing out of the lives of the toiling millions, voicing their aspirations, assuring them hope, joy of life, and confidence in regard to the future. 


\section{THE SOCIAL EVOLUTION OF RELIGION}

It might appear that the religion which reaches back through countless generations, that has gathered up sanctities and ideals through thousands of years, is "the one most likely to command the future. This might be true, were it not that all such religions carry with them many and many a survival of the old days of tyranny and autocratic power. They are also cumbered with credulities and superstitions which this scientific age cannot tolerate, and will not believe have any genuine connection with religion, at least of the kind which is rational, forward-looking, and humanitarian.

Therefore, we may anticipate that, either some one of the existing religions will be brought up-to-date in its beliefs and its ideals, or that some new religion will come into existence. In the end it cannot greatly concern us as to which of these methods is followed, though we may have a conviction that the second gives by far the greater outlook as to the promotion of a truly ethical life for all mankind. The unification of nations, the working together of all peoples for what will secure the largest amount of human fellowship and sympathy, is what we must ask of any religion to which we give our assent, and our enthusiastic acceptance. That such a religion is growing, that it is already well on its way above the horizon, is the conviction which we have, and which gives us utmost courage and hope.

It may be that it will require centuries for the evolution of the new religion, but already it is in the womb of the future. We cannot doubt that it will be with man in the centuries to come, and that it will give him new hope and courage. It will be scientific, humanitarian, and progressive. At the same time it will be profoundly ethical, and mindful above all else of human conduct and character. The motives it will offer will appeal alike to the individual and the collective man. 


\section{THE SOCIAL EVOLUTION OF RELIGION}

The new religion will have its basis in the past, its hope in the future, its reality in the present. As we look through the past we find that tribal and feudal man was deeply religious, that religion filled the whole of his life, that there was no act of his where religion did not manifest itself. Every act of the man of the clan and the tribe was intimately associated with some religious purpose or act. The feudal man, as in the Islam of to-day, prays often and devoutly. Five times in the day he pauses in prayer, and all his fellows are with him in this act. Even the man under the early forms of national religion was sincerely pious, often sought communion with God, never failed in the ritual requirements of his religion, and believed that which was incredible and hard of belief.

In any city of to-day, in the management of any modern state, religion has no manifestation of itself as in the early life of mankind. On the streets, in the places of business, in the courts, in halls of legislation, in the daily tasks of men and women religion may never give manifestation of its presence. For an hour or two on Sunday it may come, as it were, out of its hiding, and make itself really felt. In this respect it is markedly different from what it was in its earlier manifestations. Then it was ever present and could not for a day or an hour be escaped from in any part of life. Now one may pass through many days, even many years, and see no expression of religion in its outward manifestations of itself. It may enter deeply into the lives of individuals, and even control the motives of their lives; and yet it may have no power to reach and influence the community as a corporate reality. It is for the individual, not for the town, the city or the state. In becoming individual it has lost its capacity to direct and stimulate the communal or the national life. Its deeper mean- 


\section{THE SOCIAL EVOLUTION OF RELIGION}

ings are for the individual and not for the collective life. In becoming distinctly individualistic it has lost its power over a great number of men and women in all human communities where this development has taken place.

When we study critically Christianity as it appears in western lands, what must impress us most emphatically is the wide disparity between the belief and the practice of the professed Christian. This appears most distinctly in the national phases it presents, for in becoming more and more individualistic, a means of private incentive and consolation, Christianity has lost its hold on the social and political and business life of modern western communities. Nothing could more amaze one than to hear of or to see it brought into real manifestation in any of the acts of commerce or industry. The golden rule has lost most, if not all, of its meanings in the relations of those who buy labor and those who sell it as a commodity. In legislative halls prayer is heard at the opening of each session, but religion may be silent throughout the remainder of the day. Indeed, the broader ethical conceptions, and the primary principles of human justice, may appear to be banished from both of these acts of human beings.

If religion is to be retained by mankind, if it is to have any commanding power in the future, this yawning gulf between profession and practice must be bridged over, and made not to be. Religion must again enter into the whole of life or it were better it should pass out of existence. It cannot continue as a pretence, as something for special days or occasions or for a few devout souls. Death must come to it if it cannot recover its collective power, its ethical stimulus for cities and nations, its broadly human capacities. Rignano's idea that it may be retained for a few individuals who have a genius for prayer and worship cannot insure the future of religion. It 


\section{THE SOCIAL EVOLUTION OF RELIGION}

must belong to the acts of every day throughout the whole nation or it were better that it should die as Greek pantheism and Roman paganism have died. A legend of the old time said that Great Pan has died; and we may query if some new legend will not mournfully report, as the word is echoed over land and sea, that Lord Christ has gone the way of all that is outgrown. It will surely be so if religion does not advance away from theology and metaphysics, if it does not seek above everything else the good of all who live, and if it does not enter profoundly and convincingly into the life of all human communities, to secure brotherhood, justice as between man and man, and to bring human welfare to its highest possible estate. 


\section{CHAPTER VIII}

\section{Religion as Cosmic and Human Motive}

RELIGION may be regarded as a process, a growth, an 1 evolution. At the same time it is a ferment, a stir of the mind, a battle for what is just and right. In its older forms always conservative, reactionary, and faced towards the past, in its newer manifestations it is forward-looking, progressive, and rebellious against what is old and effete. More and more it identifies itself with the life of man, and with his aspirations towards a better and happier life for all who live.

Those who think that religion has been outgrown are more concerned with what it has been in the past than with what it may become in the future. Because man has been a savage is no reason why we should reject his childhood as the path which has led to his manhood. Because he has believed in magic is no reason why we should reject what is progressive and humanitarian. The earth was once a fire-mist, and then a great ball of flaming elements in a condition of incandescence; but it is neither of these now. Nor is it necessary to assume that because religion was once cruel and degrading, it is that now or will be that forever. What we are to consider is not what it has been, but what it may become. Granted all the superstition, fanaticism, and brutality which once belonged to it, we have no right to assume that it will retain these to the end of time. Granted that it still clings tenaciously to what belongs to ignorance, mythology, and rejection of science, this 


\section{THE SOCIAL EVOLUTION OF RELIGION}

is not proof that there is no possibility for organizing in its name what is rational, progressive, and humane.

\section{I}

The question presents itself, What is religion? Many have been the answers, though none of them are likely to agree with each other. In the first volume of the third edition of The Golden Bough (volume one of The Magic Art), J. G. Frazer defines religion as "propitiation or conciliation of powers superior to man which are believed to direct and control the course of nature and of human life. Thus defined," he adds, "religion consists of two elements, a theoretical and a practical, namely, a belief in powers higher than man and an attempt to propitiate or please them." He proceeds to show that religion means belief in superhuman beings, and that it consists in governing the life by the individual in the fear or the love of God. Frank G. Speck, in a recent lecture on primitive religions, defines religion "as that which expresses in life the relationship between man and the supernatural realm." These definitions are from men of science, who are students of the earlier forms of religion, and of the races which are the most primitive in their religious development. Their definitions, however, belong to the conventional rather than to the truly scientific results of investigation.

Other definitions dispense with the supernatural, and with an autocratic control of the universe by a divine being. John McTaggart, for instance, in Some Dogmas of Religion, says that it is "an emotion resting on a conviction of a harmony between ourselves and the universe at large." Edward Caird, in the first volume of his Evolution of Religion, says that "a man's religion is the expression of his ultimate attitude to 


\section{THE SOCIAL EVOLUTION OF RELIGION}

the universe, the summed-up meaning and purport of his whole consciousness of things." William James expressed a similar point of view in The Varieties of Religious Experience, when he said that "the religious life consists of the belief that there is an unseen order and that our supreme good lies in harmoniously adjusting ourselves thereto." Henry Bosanquet, defining religion in Baldwin's Dictionary of Philosophy and Psychology, says that a man's religion "is that set of objects, habits, and convictions, whatever it might prove to be, which he would die for rather than abandon, or at least would feel himself excommunicated from humanity if he did abandon." As distinctly excluding all idea of the supernatural may be taken the definition of Thomas Davidson, in an article in the International Journal of Ethics, on the subject of American Democracy as a Religion, where he defines religion as that which places us in harmony with our environment, that we may "attain the highest possible development in knowledge, love, and will." He proceeds to say that "not only is Americanism a religion, but that it is the noblest of all religions, that which best insures the realization of the highest manhood and womanhood, and points them to the highest goal." To much the same purport is the definition of modern religion given by $\mathrm{H}$. G. Wells at the end of God the Invisible King, where he says: "It is a process of truth, guided by the divinity in man. It needs no other guidance, and no protection. It needs nothing but freedom, free speech, and honest statement." On an immediately preceding page he says again: "Religion which is free, speaking freely through whom it will, subject to a perpetual unlimited eriticism, will be the life and driving power of the whole organized world."

Here we have a wide enough variety of definitions of religion to fit any mind or any mood of it, all of them from mod- 


\section{THE SOCIAL EVOLUTION OF RELIGION}

ern thinkers. This variety indicates how widely divergent religion has come to be for the modern mind, and how many the thinkers who depart from the established and inherited conceptions of its nature. However, when we consider the real significance of these definitions, and what they imply with reference to the developing tendencies of modern religious thought, they are far less widely apart than at first would appear. When we read these words in connection with the works from which they have been taken, we may not doubt that a new meaning for religion is growing among men, and one that faces joyously and confidently all the facts of the modern world, believes that they are evolutionary and progressive, and that they mean the outgrowing of all that is dark and forbidding in the religion of the past. This new tendency in religion is turning from the supernatural to the human, from the miraculous to what is natural, and from the mere routine of ritual to the service of man.

\section{II}

A very suggestive, and, indeed, a startling indication as to what is now taking place in the thoughts of intelligent men and women may be found in the book by James H. Leuba on The Belief in God and Immortality. In the second part of that work he presents a statistical study of the belief in a personal God and in personal immortality in the United States. By means of questionnaires he secured the opinions of nearly one thousand students in the non-technical departments of nine colleges of high rank, and also of the same number of American scientists, sociologists, historians and psychologists. As the result of these inquiries he found that 31 per cent. of the men among college students conceived of God as imper- 


\section{THE SOCIAL EVOLUTION OF RELIGION}

sonal and 11 per cent. of the women. Taking together all who do not distinctly believe in a personal God the number of men is 40.5 per cent. and the number of women 15.7 per cent. He found also that, considered all together, as many as from 40 to 50 per cent. of the young men leaving college entertain an idea of God incompatible with the acceptance of the Christian religion, even as interpreted by the liberal clergy.

Leuba shows that only 7 per cent. of these persons hold to a thoroughly anthropomorphic idea of God, that is, that he is manlike and material in his nature. Two-thirds of the men and nearly half the women disclaim any mental picture of God. This means that they do not conceive of God under any form that can be definitely defined in concrete shape. Thirty-two per cent. of the men and 17 per cent. of the women are of the opinion that the non-existence of God would make no difference at all in their lives. Apparently as many as 43 per cent. of the men, and 22 per cent. of the women think themselves morally independent of the existence of God. Summing up the results of his inquiries in regard to the beliefs of college students, and after giving a considerable number of the replies he received from them, Leuba concludes: "The deepest impression left by these records is that, so far as religion is concerned, our students are grovelling in darkness. Christianity, as a system of belief, has utterly broken down, and nothing definite, adequate, and convincing has taken its place. Their beliefs, when they have any, are superficial and amateurish in the extreme. There is no generally acknowledged authority; each one believes as he can, and few seem disturbed at being unable to hold the tenets of the churches. This sense of freedom is the glorious side of an otherwise dangerous situation."

Leuba found that, in regard to both belief in God and 


\section{THE SOCIAL EVOLUTION OF RELIGION}

immortality, the number of believers decreased with the advance from the freshman to the senior years in college, so that the more these men gained of knowledge and culture the less likely were they to hold fast to the beliefs of their youth. The number of believers in immortality, however, was greater than the number of believers in God throughout the whole college course. Some surprise is expressed, as the result of this investigation, that as many as 35 per cent. of the juniors and seniors in a Christian college were unable to believe in immortality, and a considerable additional number indifferent to it. Leuba adds: "This situation points to a very profound change now taking place in the convictions of our educated young people regarding a belief usually considered vital to Christianity." Certainly, in view of the fact that most of the older colleges and universities were founded distinctly on a Christian basis, and with the avowed purpose of preparing young men for the ministry of the Christian church, and that nearly all the graduates formerly entered upon that profession, the change is one of startling significance. Put these facts by the side of the statement in his biography, that John Fiske, when a student at Harvard, was threatened with expulsion because he believed in and promulgated the doctrine of evolution. A little later he failed to secure a professorship because of his acceptance of this scientific belief. Even as late as 1872 he was refused the opportunity to lecture at the Lowell Institute because he did not believe in the divine revelation of the Bible.

Leuba was also desirous of finding what were the beliefs of scientific men in this country; and he selected his inquiry lists with a view to securing the opinions of the leading men, as well as those of lesser note. He found that the men of greater knowledge and attainments were less inclined to believe 


\section{THE SOCIAL EVOLUTION OF RELIGION}

in God and immortality than those who held lower rank. Taking together the nearly one thousand men from whom he received answers, he found that there were 50.6 per cent. of the lesser men and only 49.4 per cent. of the greater who believe in immortality. Those believing in God were 51 per cent. of the lesser and 35.7 per cent. of the greater. These belonged to the first five hundred whom he investigated. In his second group the numbers were 45.5 per cent. and 27.7 per cent. for believers in God; and 52.8 per cent. and 35.2 per cent. for believers in immortality. The number of agnostics or those of indefinite opinions proved to be greater than the disbelievers in regard to immortality. Among the greater scientists the agnostics and doubters were 43.7 per cent., and the disbelievers only 25.4 per cent.

It was found that the physicists furnished a considerably larger number of believers both in God and in immortality than the biologists. Among the greater biologists was found a small number of believers, only 16.9 per cent. believing in God and 25.4 per cent. believing in immortality. Among the historians the numbers were much larger, as might have been anticipated before the inquiry began. Of the sociologists, however, the proportion of believers in God proved to be quite small. The greater psychologists showed only 13.2 per cent. who are believers in God, and only 8.8 per cent. of believers in immortality, the smallest figures secured in regard to any class entering into this investigation.

Leuba regards the figures he gives in his book as actually representing the beliefs of American students and scientists, and that they can be trusted as giving a just estimate of the attitude of these classes towards the greater beliefs of religion. Among the one thousand scientists he says are included all the intellectual leaders of the United States. Since they are teach- 


\section{THE SOCIAL EVOLUTION OF RELIGION}

ers, for the most part, in the higher institutions of learning, they may be regarded as the moral as well as the intellectual leaders of the country. This fact may be placed alongside the other fact he states, that he does not see how it is possible "to avoid the conclusion that disbelief in a personal God and in personal immortality is directly proportional to abilities making for success in the sciences in question." He more fully states the conclusions of his research by saying that it "shows that in every class of persons investigated the number of believers in God is less, and in most classes very much less than the number of non-believers, and that the number of believers in immortality is somewhat larger than in a personal God; that among the more distinguished, unbelief is very much more frequent than among the less distinguished; and finally that not only the degree of ability, but also the kind of knowledge possessed, is significantly related to the rejection of these beliefs."

The tenth chapter of his book is devoted by Leuba to the consideration of the cause of the growing unbelief which he has statistically investigated. He finds that cause in the individualism which has been rapidly growing in modern society, and in the consequent break with the traditions of the past. He finds in the gain in independence among college and university students, as they advance in their studies, the cause of their growing skepticism. When their minds awaken they refuse longer to be bound by what in youth seemed satisfactory because it had been taught them in childhood. The reaction of all growing minds from childish conceptions naturally leads to this growth of the rebellious spirit, the free spirit of inquiry, the demand for what will satisfy the intellect rather than the emotional nature. The recognition also comes, that the knowledge imparted by science and culture is not in 


\section{THE SOCIAL EVOLUTION OF RELIGION}

harmony with the religious teachings received in the years before serious study began.

Leuba inquires why there are among college students 82 per cent. of women who are believers, and only 56 per cent. of men. He points out that they belong to the same classes, hear the same teachers, read the same books, and imbibe the same knowledge. "The main cause of the difference," he thinks, "is to be found in the greater readiness of men to break from tradition." It may be inquired, however, why men break with tradition more readily than women; and the answer is to be found in what is fundamental to sex itself. It cannot be assumed that the mind of woman is merely a duplicate of the mind of man; and in saying this it is not necessary to assume, in the least degree, that the mind of woman is weaker or less capable than that of man. The difference is not one of capacity, but of emphasis, of temperament, of that to which a woman gives the preference. Recognizing this constitutional difference, it is possible to make it of too great importance, and thereby to ignore the social and educational manner in which women have been brought to look at the world in quite another manner than that of men. While there is a natural difference, undoubtedly, the artificial variation has been assiduously cultivated, and makes up most of the manly and womanly characteristics.

It may be seriously questioned whether there is any fundamental intellectual difference between men and women, as such. As just now suggested, the difference is much more truly artificial than natural. What is meant is, that the educational processes used for women are other than those used for men. The wide-reaching and long-continued barring of women from all truly intellectual training has not as $y \Sigma^{+}$been put aside in any degree approaching equality for the two sexes. If boys 


\section{THE SOCIAL EVOLUTION OF RELIGION}

and girls, men and women, are educated side by side, yet to a very large degree the trend of social influences is in favor of quite another sort of intellectual attitude for women than that for men. If educational processes approach in some measure the same training for the two sexes, the standards set up by society, and especially in as far as they have been inherited from the traditions of the past, demand for women another quality of life, another manner of thinking, than that assigned to men as natural to them. Perhaps, it is not going too far to assume that the whole of the difference between the two sexes, as indicated in the above statistics, has its origin in this superimposed mental attitude for women. Society has not yet come to the position of liberating women to freedom of thought, to entire self-direction in all their affairs, and to the forming their own opinions in regard to religion. Until it has done so, women will remain under the domination of the sex consciousness, in religion as elsewhere.

Turning to the causes for the greater unbelief of men of superior knowledge and ability, Leuba finds it in their greater independence, their disposition to think more freely, and their marked individuality. It is not merely greater knowledge in itself, however, which makes these men more skeptical; but rather it is to be attributed "to certain temperamental qualities or energies which make it relatively easy for them to rid themselves of much of the social pressure to which others yield." Such men are also likely to find about them associates who do not demand what is orthodox, and aid them in warding off those traditional demands which compel others to conform to what society regards as truth. More than all else, in Leuba's opinion, is the fact that such men "are, on the whole, distinguish among their colleagues for activity, tenacity, initiative, and self-reliance. Of these qualities, at least 


\section{THE SOCIAL EVOLUTION OF RELIGION}

the last two tend to resist the forces of authority and of prestige, as well as to increase knowledge."

The conclusion which Leuba reaches, in the final summing up of his investigations, is one of great importance. It suggests much in regard to the future of religion. "The situation demanded by the present statistical studies," he says, "demands a revision of public opinion regarding the prevalence and the future of the two cardinal beliefs of official Christianity; and shows the futility of the efforts of those who would meet the present religious crisis by devising a more efficient organization and co-operation of the churches, or more attractive social features, or even a more complete consecration of the church membership to its task. The essential problem facing organized Christianity is constituted by the widespread rejection of its two fundamental dogmas - a rejection apparently destined to extend parallel with the diffusion of knowledge and the moral qualities that make for eminence in scholarly pursuits.",

\section{III}

Leuba's investigations have led him to the conclusion that the desire for immortality is far from being universal. Even some who believe in it have no earnest wish for the continuation of the individual life, and others distinetly prefer that life should come to an end. The Buddhist doctrine of nirvana, cessation of struggle and material interests, with absolute rest and quiescence, is by no means unattractive to persons of western countries. Investigations suggested by F. C. S. Schiller, and carried out by the American Society for Psychical Research, published in the Proceedings of the Society for Psychical Research, in 1904, volume 18, as well as discussed in Schil- 


\section{THE SOCIAL EVOLUTION OF RELIGION}

ler's book on Humanism, fully confirm these conclusions. In reply to this questionnaire, the Society received 3321 answers, and of these 40 per cent. only "had never entertained a doubt, or had trained themselves to regard a future life as certain, and then dismissed the matter from their minds." Many persons were very decidedly of the opinion that they did not believe in immortality or had no desire for a continued future existence. Schiller finds, in his book on Humanism, that "it is just because the religious doctrines of immortality are not ctaken as fact that they are accepted." He goes on to say: "Hence the religious doctrines with respect to the future life form a part of paper currency, inconvertible with facts, which suits people and circulates because of its very badness. Their function is to conjure up pleasing and consoling visions whenever we are in the mood for them, to provide a brighter background for life than sheer extinction; but they are not allowed to grow insistent enough seriously to affect action."

In the statistics gathered by Schiller only 22 per cent. out of 3321 persons had a real desire for a scientific knowledge of the future life; 23 per cent. preferred to accept the future on a basis of faith alone, 12.9 per cent. preferred to remain in a state of ignorance in regard to the other life, while 3.3 per cent. were indifferent. A large number of persons, according to Schiller's report, express themselves to this effect: "At present, belief in immortality plays a very small part in my experience or motives; I leave it indefinite, though I rather feel it is true."

Schiller says that 1314 out of the 3321 report that they find it necessary to their comfort to feel that immortality is true. A majority of those answering, however, report that the desire for a continued life would not add to their satisfaction with life. Schiller subjected the returns from the questionnaire 


\section{THE SOCIAL EVOLUTION OF RELIGION}

to a rigid scrutiny, and, though on the face of the returns a majority, or 1706 out of 3218 , were in favor of having a positive knowledge in regard to the future, many showed themselves negative or indifferent in regard to the subject, who answered in the affirmative. Those who would like to know that there is no future life were 225 in number; those who had but a slight or doubtful desire, 123; those wishing to know but think knowledge impossible, 64 . This reduces the majority to a minority of 1294 , who have a desire to know that man is immortal. The final result of the analysis is, that 681 out of 3218 , or rather over 21 per cent., "may be credited with a real desire for scientific knowledge of the possibility of a future life." To this statement should be added the conclusion that only 22 per cent., or 739 out of 3321 , have a desire for "a future life at all costs." Schiller adds that "it turns out that not only is a real desire for the heaven of what used to be thought orthodoxy decidedly rare, but that a good many actually have so strong an objection to it that they assert they would prefer annihilation."

The purpose of this investigation by the Society for Psychical Research, suggested by Schiller, and the results worked out by him in a lengthy report, was to ascertain what was the probable proportion of the population desiring a scientific knowledge in regard to a future life, such as the Society aimed to secure, if possible. Schiller was of the opinion that there was necessary a social demand for such knowledge or it would be impossible to secure it, however zealous and laborious might be the efforts of a few researchers. The traditional opinion, often repeated from the pulpit and elsewhere, that there is a great eagerness in regard to the future, and that this desire is not only nearly universal, but one that causes much anguish, appears not to be true. Schiller reports "that the returns 


\section{THE SOCIAL EVOLUTION OF RELIGION}

show comparatively little evidence of great spiritual revolutions, and still less of any considerable or lasting mental anguish connected with them. The apparent absence of any widespread spiritual distress is certainly very striking and surprising, though here again this might perhaps have been inferred from the surface indications of general placidity and contentment. It would seem that spiritual crisis and prolonged religious excitements are the prerogative of exceptional temperaments; ordinary persons seem to adjust themselves easily and rapidly to their definitive attitude."

Schiller recognizes that the number of answers procured was too small to make the returns secure a decisive test as to the extent of the desire for immortality in the general population. He also recognizes that, owing to the questionnaire reaching a large proportion of psychical researchers and spiritualists, the figures given are in larger proportion affirmative than would otherwise be the case. He is of the opinion, also, that the returns do not prove that the problem of the future life has always been indifferent to those who are but little or not at all concerned about it at the present time. On this phase of the problem he says: "Some consideration surely is due to those who would sincerely like to know, and to whom the lack of knowledge causes grave distress. I have admitted, and even emphasized, that at any given time they form a minority, it may be a small minority. But there is also evidence to show that at some time or other in their lives a large majority pass through a period when the mystery of existence oppresses their spirits and torments them with fears and perplexities which real knowledge would almost certainly show to be groundless. It is true, no doubt, that such periods of anxiety seem usually to be short, and that after a few years people 


\section{THE SOCIAL EVOLUTION OF RELIGION}

find quite comfortable beliefs which at first had seemed quite unbearable."

In his eleventh chapter Leuba brings together the opinions of a number of eminent men and women of our time, all of whom are largely indifferent to the beliefs in God and immortality or entirely reject them. These include Renan, George Eliot, John Addington Symonds, William McDougall, and others. For instance, McDougall says in his book on Body and Mind: "I can lay claim to no religious convictions; I am not aware of any strong desire for any continuance of my personality after death; and I could accept with equanimity a thorough-going materialism, if that seemed to me the inevitable outcome of a dispassionate and critical reflection. Nevertheless, I am in sympathy with the religious attitude towards life; and I should welcome the establishment of sure empirical foundations for the belief that human personality is not wholly destroyed by death."

Leuba cites the opinions of a large number of the men and women who responded to his questions, showing that they either rejected these beliefs or were of the opinion that they had no direct bearing on their conduct or on their conceptions of human duty and responsibility. Some of these are of great interest because of their frankness, their indications of a disturbed mind or their desire to believe what had become impossible of acceptance.

An interesting indication of the present-day trend of thought and desire in regard to immortality may be found in the Easter number, 1918, of the Universalist Leader, published in Boston. The editor asked a number of representative people who are leaders in their various fields to express for publication their opinions in regard to immortality. Of the nine answers published, three express a very definite disbelief in 


\section{THE SOCIAL EVOLUTION OF RELIGION}

this doctrine. For instance, John Burroughs wrote: "I see no more grounds for belief that I shall live again than that my dog or the grass or the trees will live again. They and we live in our descendants. It is life that is immortal, and not the individual manifestations of it."

There can be no question but that this point of view is being found satisfactory to a considerable number of thinking men and women. This is the answer of Charlotte Perkins Gilman: "Personal immortality may or may not be true, I know nothing about it. It is an idea which has never interested me in the slightest degree. My whole hope, love, purpose and work pours along the line of what I do know - the continuity of the human race on earth ; its boundless capacity for growth, improvement and happiness; and our power to build that splendid future. We shall make better progress in this world when we outgrow our selfish grasping after another one."

\section{IV}

Turning back once again to James H. Leuba's book on The Belief in God and Immortality, we must recognize that no more important work has been published in our time. It does not assert that religion is prospering, as is so often done by those less well informed, and that there has been a complete reconciliation between religion and science, that the skepticisms of a half-century ago have ceased to vex believing minds, or that all the great critics of religion of that time have disappeared, and have no successors. These assertions seem to be made for the same reason that a boy whistles when passing a dark wood, in order to keep up his courage. They have been repeated with such frequency, and with such persistence, that many have come to believe them true. As Leuba has conclu- 


\section{THE SOCIAL EVOLUTION OF RELIGION}

sively shown, they are not true. It might be added, that in a time like ours, when the spirit of free inquiry is abroad, when thinkers are searching heavens and earth for facts and their laws, it is impossible that they should be true. All that can be said is, that such men as Huxley, Haeckel, Matthew Arnold, and their confreres, have had no immediate successors. The reason for this is to be found in the situation produced by the publication of Darwin's Descent of Man, and the necessity for the interpretation and defense of the doctrine of evolution. That great occasion having passed by, with the general acceptance of evolution and what it implies, religiously and socially, there has been no further occasion that the controversy then developed should be prolonged. The successors to Darwin, Huxley, and Haeckel have had other work than to criticize the old religious traditions or to show wherein they no longer fit into the needs of the present time. They have been investigating vast fields of research opened up by the work of Darwin and his associates, broadening the spirit and the conclusions of evolution, and fitting it to meet the demands of all phases of modern life. Therefore, they have not followed Huxley or Haeckel, who did a highly important work for their time; but the newer time has required other methods and wiser conclusions.

The investigations of Leuba and Schiller, as well as several others, are highly important because they show what is the attitude of thinking men in our own day. We have here not mere assertions of those who wish that what they assert may be true; but facts which cannot be turned aside from with mere denial. What do they signify? In what manner are they to be accepted? Evidently they are too serious to be dismissed 


\section{THE SOCIAL EVOLUTION OF RELIGION}

with indifference or to be turned aside from because we dare not face their full import.

Any large and broad-minded study of present-day religious tendencies must bring home to us the fact that men and women are no longer accepting the old beliefs in the spirit of docility and unquestioning trust, such as was characteristic of those of two or three generations ago. If the secularists, freethinkers, and atheists are not now largely organized, or making themselves heard with frequency, and much assertion of their skepticisms, it seems that it is not because their kind has disappeared from modern society. Apparently, if we are to believe Leuba and Schiller, their number has greatly increased, and among the better educated rather than among the more ignorant members of society. What appears to be the actual situation is, that these classes are so far indifferent in regard to the beliefs of religion, that they do not organize or take the trouble to assert or to defend their opinions.

If we turn to a book which has been widely read and much discussed in recent years, Henri Bergson's Creative Evolution, we shall find a new and most suggestive interpretation of life with reference to its fundamental cause. To Bergson this cause is not that of an arbitrary will, a supernatural being, or a God standing on the outside and projecting the universe into space. He sees all life as a process, a movement, a development and an evolution, with its causes in its own nature, ever active, an ever unfolding process. Life, Bergson declares, transcends all the categories of the old manner of thinking, and is something vital, natural, ever proceeding. Nature and humanity are not apart from each other or antagonistic, but parts of one whole, phases of a great proceeding activity, one triumphant march forward of the eternal sources of being. Accordingly, individuality and society proceed together, are 


\section{THE SOCIAL EVOLUTION OF RELIGION}

but phases of one continuing process, ever working themselves out together to higher and higher conclusions. Therefore, Bergson says that God "has nothing of the ready made; he is unceasing life, action, freedom. Creation, so conceived, is not a mystery; we experience it ourselves when we act freely."

Who can object to such a conception of God? If the full significance of such a God were clearly placed before them, probably most of Leuba's skeptics would not turn from him. What they have not been able to believe in is the traditional God, the deity having his origin in animism and supported by mediaeval metaphysics, that is, by abstractions and anthropomorphic interpretations of a visible concrete deity somewhere in the heavens.

It is interesting to place by the side of Leuba's book two little volumes by Francis Younghusband, an English explorer, administrator and soldier, who led the British expedition of 1904 into Thibet. At a later time he was struck down by a motor-car, and for months lingered between life and death. During his period of convalescence he had an opportunity to think about the problems of religion, with the result that he wrote the little book entitled Within: Thoughts During Convalescence, which appeared in 1914. The next year he published Mutual Influence: A Review of Religion. What is remarkable about these little books is their tenderness, their deep human sympathy, their poetical elevation and graciousness, and their highly mystical tone on the part of a soldier and a man of the world. Rejecting all which is usually defined under the name of religion, these books make a profoundly religious impression. Their attitude is constructive, inspiring, 


\section{THE SOCIAL EVOLUTION OF RELIGION}

and humane. The note is not one of skepticism, but one of belief. They touch the deeper emotions, and satisfy the heart as well as the mind.

As many other men have done, Younghusband found in the tenderness and devotion of his wife, during his prolonged convalescence, the basic influence giving shape and meaning to his new religious beliefs. Projecting, as it were, this human sympathy and fellowship into the universe, he found his conception of God. In a word, his God was not that of Christianity or any other historic religion; but that of humanity, as interpreted to him by the devotion of his wife. He does not ignore the harsh and cruel phases of nature, its indifference to human welfare, its readiness to sweep a city out of existence as quickly as a pebble into the sea. Therefore, he finds in humanity his symbol of divinity, and, indeed, his conception of the only God which has any meaning. He finds that there is in the universe a mighty world-spirit, of which each individual is a manifestation. Loyalty to that spirit as manifested in ourselves, true manliness, faith in that life working in our own being and in all other men and women, this is the true religion.

Mutual Influence elaborates these ideas, and gives them a more adequate statement. It has that poetical quality, that mystic tone, that breadth of sympathy, that humaneness, and that lofty piety of the modern type, which must make it attractive to every independent-thinking mind who in any degree feels an interest in what is religious. Rejecting unqualifiedly an anthropomorphic God, Younghusband finds in humanity his aspirations, in his conquests over himself and over nature, in his growing association of himself with his fellows in a great human fellowship, that which gives a satisfying conception of 


\section{THE SOCIAL EVOLUTION OF RELIGION}

God as ever-present in the world and as ever-ready to give the individual sympathy and help. "Any individual human being," says Younghusband in his eleventh chapter, "may feel that he is regarded and cared for by that Power which springs from all individual units in the universe in their mutual influence upon one another." A page or two further on he says again: "The individual may have confidence that God, as herein conceived, though he be no separate person but only the personification of the spirit which animates all individuals as members of a whole, does, in truth, regard, care for, and even love him, and is therefore something in which he may place his faith and hope and trust, and love as surely as he would love his country." Again, in a more explicit statement, at the beginning of the concluding chapter of the book, we read: The view here set forward "is that the power to which any individual man is subjected is not exercised by any separate personal being wholly outside men, but is what results from the mutual influence of all men, and of all the component parts of the universe, however small they may be, upon one another; and which these units are able to exert because they all, whether atoms or men, are self-active individuals with properties and characteristics of their own." We are assured that God is not a separate person any more than France is a separate person, and yet the Frenchman loves and is loyal to France as something ideal, something great and inspiring, something to which he can give his utmost of loyalty and devotion. As France or any other country is not a distinctly personal and concrete thing, but an idea, a symbol, and a tangible fact not the less, so is God, though no more personal than one's country, something that can win and hold our loyalty. We can give that loyalty, not to some intangible mythical being in the heavens, but to our country and to our fellow-men. 


\section{THE SOCLAL EVOLUTION OF RELIGION}

"In this view," according to Younghusband, "things do not consist of God, man, and matter, each separate and distinct from the other. They form rather one single, inter-connected, and intimately related whole; a whole which is in process, in process of betterment, and which is animated by a spirit issuing from the parts, but which in turn fashions and moulds them, making and remaking the same material over and over again, but itself enduring continuously and being continually bettered."

It may seem to those who have been trained to accept the idea of an anthropomorphic God or the God of metaphysics and theology, that Younghusband is giving them nothing more than a shadow for the reality, that his God cannot work miracles or answer prayer or come into the world for the redemption of men. The striking fact is, that having been taught all this, and having heard it from his youth up, and having had great adventures, seen much of men and of the causes which direct the actions of nations, he turns from it all, and under conditions of the utmost distress, when he is face to face with death, finds for himself what he regards as a larger and saner conception of religion, and of the moving forces which control the world and the actions of men. He clearly says that the power he has actually found working in the affairs of men and nations is not the hand of an Almighty God resident in the heavens, but is an influence issuing from men themselves, from the earth from which they spring, and from the whole universe of which the earth and men are only a part.

So far from thinking that this faith of his will make the world dark and the grave forbidding, Younghusband closes his second book on a note of aspiring faith and triumphant conviction. They who have acquired truly this faith, he assures his readers, will be caught up in the rush of the uni- 


\section{THE SOCIAL EVOLUTION OF RELIGION}

versal spirit, and will be filled with a love of their kind which will cause them, with something like maternal instinct, to stretch far forward and sacrifice the best that they can make themselves, for the good of the future it is their part to create.

This is the triumphant note with which he brings to an end his religious interpretation of what may be called a religion of humanity: "When the generality of men have absorbed into their minds what has long been in the minds of great thinkers, that the power which so influences their lives is within the world and within themselves, and that it is on themselves therefore that they must rely; when this idea has saturated the literature, the music, the art, the hymns, the prayers of the people, and when the whole atmosphere in which they are brought up is one of reliance of men on themselves, of faith in the spirit within them and of pride in a destiny which lies in their own keeping, then men will no longer feel the need of the comfort which belief that they are shielded and nurtured by some invisible God affords. They will feel erect and self-supporting, and by a greater reliance on themselves they will have acquired that firmness of purpose so necessary for great achievements, and that strength of character without which it would be impossible to bear the burden of responsibility which the new freedom will entail."

In Mr. Britling Sees It Through, Herbert George Wells expressed himself with some emphasis in regard to the nature of God, declaring that, if there were any such being as the theologians describe, he would bring the great world-war to an end. He went on to say that God is finite, that he struggles as men struggle, and that he is human with love and tenderness 


\section{THE SOCIAL EVOLUTION OF RELIGION}

as men are human. If God is to be anything to men, says Mr. Britling, he must be limited and defined as men are. The young men, on both sides, who had lost their lives in the great struggle of nations, were declared to be with God, and God present tenderly with them.

The reviewers immediately said that H. G. Wells, who had hitherto been indifferent to religion, had now, on account of the war, been awakened to its meaning and its importance. The fact is, however, that in First and Last Things: A Confession of Faith and Rule of Life, published in 1908, six years before the war began, Wells gave a concise statement of his philosophical and religious beliefs. Nothing which has appeared in God the Invisible King or any of his other later books was absent from that one, at least in general outline. Some of his arguments are given in greater detail, and he has elaborated on some of them; but all the essentials are in that earlier work. In that work, writing of belief, he says that the universe must have a meaning, that it must show forth order and co-ordination, and that there is in it an ultimate rightness and significance of meaning.

Wells goes on to say that he is greatly attracted by the phrases in which the personal purpose of the universe is expressed, and is not averse to declaring his belief in God. Yet he immediately remarks that we can occasionally best serve the God of truth by denying him. He confesses, however, that the sense of personality in the universe is very strong. He adds : "If I am confessing, I do not see why I should not confess up to the hilt. At times in the silence of the night and in rare lonely moments, I come upon a sort of communion of myself and something that is not myself. It is perhaps poverty of mind and language obliges me to say then this universal scheme takes on the effect of a sympathetic person - and my 


\section{THE SOCIAL EVOLUTION OF RELIGION}

communion a quality of fearless worship. These moments hap. pen and they are the supreme fact in my religious life to me, they are the crown of my religious experiences."

It is evident, however, that Wells is not here speaking of the metaphysical and theological God of the churches, but of an imaginative being, an ideal of humanity, the projection of the trend of the whole of human life through the ages. The race flows through us, and what God means is that the species lives in us, a continuous flow of a controlling and sustaining life. Wells confesses that this idea may seem vague and indefinite; but he adds that it is mystical, and therefore all the more suggestive and inspiring. He believes that even he may contribute to the forming of that great being, as all men have been doing throughout the ages. In the world of both man and nature he finds beauty, and that is the true revelation of God. There is also power, and that, somehow, is one with beauty. These two are in all the universe, and they give life its meaning. His statement is this: "Things move to power and beauty; I say that much, and I have said all that I can say."

Wells says very positively that he does not believe in immortality, that there is no abiding of the individual apart from the life of the species, and of those things which belong to all men in common. His position on this subject he states in these words: "I am not the continuing thing. I personally am experimental, incidental. I feel I have to do something, a number of things no one else could do, and then I am finished and finished altogether. Then my substance returns to the common lot."

These statements will make it clear that neither Mr. Britling Sees It Through nor God the Invisible King has anything essential to add to what had been written in the earlier book. Few read First and Last Things because it was a philosophical 


\section{THE SOCIAL EVOLUTION OF RELIGION}

work, many read Mr. Britling because it was a novel of great power. Many also read God the Invisible King, because following immediately after Mr. Britling, and being written in a manner nearly approaching the novel, it was widely discussed. In the preface to God the Invisible King, Wells says that he does not believe in orthodox Christianity, and that he does not accept Christianity in any of its forms. He especially rejects the doctrine of the Trinity, and condemns in the severest terms the Nicene creed and those who constructed it. $\mathrm{He}$ rejects all the creeds explicitly and frankly, does not attempt to conceal his indignation at the role which has been played by the Christian dogmas, and the manner in which they have been through all Christian ages obscuring, perverting and preventing the religious life of mankind.

Wells expresses complete agnosticism with reference to God the creator, and calls this the Veiled Being, because of our entire lack of any real knowledge with regard to him. His belief is in God the Redeemer, who is finite, human, growing, and the projection of man's hopes and ideals into a great constructive idea. God is not a person who can be seen and handled, and he is in no sense concrete and physically real. God is youth and God is love; by which Wells means to say that God is at once finite and developing, something not finished, but advancing with the growing life of humanity.

In many places throughout his book Wells presents religion and God as something very real, the greatest things there are. Sometimes the reader may be inclined to think he has gone back to the old beliefs and the old faith, with such apparent enthusiasm and conviction does he use the terms of the churches. However, one need not be for more than a moment deceived by this emphasis laid upon the importance of the religious life, and the joy it may give the struggling 


\section{THE SOCIAL EVOLUTION OF RELIGION}

person. In fact, he is from first to last presenting a great imaginative conception of humanity as the real God, humanity as growing through the ages, and coming more and more to serve the interests of all its aspiring and hoping members. Whoever will read page 61 of God the Invisible King understandingly, in connection with the rest of the book, will have no doubt that Wells means that the true God is the human species idealized. It is not merely the aggregate of the individuals who have lived, and do live, who are symbolized by Wells under the name of God; but the species as an advancing development of the highest life known to our globe. It is the species as one continuous movement, subtly knit together in all its members, as it were, into one organism, one great lifeforce forever moving, expanding, becoming more and more supreme over nature and the forces that hinder its progress. This is Wells' own statement of what he conceives God to be as such a youth and such a being of love: "Modern religion declares that though he does not exist in matter or space, he exists in time just as a current of thought may do; that he changes and becomes more even as a man's purpose gathers itself together; that somewhere in the dawning of mankind he had a beginning, an awakening, and that as mankind grows he grows. With our eyes he looks out upon the universe he invades; with our hands he lays hands upon it. All our truth, all our intentions and achievements, he gathers to himself. $\mathrm{He}$ is the underlying human memory, the increasing human will. But this, you may object, is no more than saying that God is the collective mind and purpose of the human race. You may declare that this is no God, but merely the sum of mankind. But those who believe in the new ideas very steadfastly deny that. God is, they say, not an aggregate but a synthesis. He is not merely the best of all of us, but a Being in himself, composed 


\section{THE SOCIAL EVOLUTION OF RELIGION}

of that but more than that, as a temple is more than a gathering of stones, or a regiment is more than an accumulation of men."

This God who is humanity idealized, and made into a great symbol of power and beauty, Wells believes may be accepted as having a divine imperative, which he is called upon to obey implicitly. These are his words: "I am obeying an irresistible call, I am a humble and willing servant of the righteousness of God." Again, in his fifth chapter he makes more clear his conception of the ethical force the invisible God brings to bear on all who would obey his will: "Its implicit command to all its adherents is to make plain the way to the world theocracy. Its rule of life is the discovery and service of the will of God, which dwells in the hearts of men, and the performance of that will, not only in the private life of the believer but in the acts and order of the state and nation of which he is a part. I give myself to God not only because I am so and so but because I am mankind. I become in a measure responsible for every evil in the world of men. I become a knight in God's service. I become my brother's keeper. I become a responsible minister of my King. I take sides against injustice, disorder, and against those temporal kings, emperors, princes, landlords and owners, who set themselves up against God's rule and worship."

We may query why Wells should think it desirable or necessary to apply theological terms to something quite different from that to which they have been applied through many ages. We may think it confusing rather than illuminating to call idealized humanity by the name of God. We should not forget, however, that it is precisely this very process by which God has been constructed in the past, and that he is essentially a projection of what man is individually and collectively into 


\section{THE SOCIAL EVOLUTION OF RELIGION}

the great spaces of the universe. The history of the unfolding of religion which we have been following proves this to have been the identical process through which all gods have come into existence, and have their meaning for mankind.

Then, it is not to be forgotten that Wells is an artist of great constructive powers, that he makes use of a vigorous creative imagination, and that he has dared to think out the new problems in a fearless manner, with no regard to the wishes or the teachings of the theologians and the metaphysicians. He rightly says that he speaks for many others, that he is not setting forth his own private views, but the constructive ideas which are surging in many minds. For these reasons he has a right to speak, and his message is worthy of the most serious consideration.

We may now give consideration to the religious conclusions of Emile Durkheim, the greatest sociologist of our time, who has died since these pages were written. In no small degree he interprets and justifies the beliefs of $\mathrm{H}$. G. Wells, though the one may have known nothing of the writings of the other. Durkheim is of the opinion that religion is the most fundamental and primary fact in human life, that all other phases of culture, civilization, and science have evolved out of it. He finds religion beginning in the social life of man, a result of his collective activities, and essentially a development from his social interests. It is not a product of individual genius, but of the collective insight, imaginative vigor, and constructive enterprise of social man. Religion is directly a manifestation of man's social interests, a product of his social genius, a construction of his social creativeness. 


\section{THE SOCIAL EVOLUTION OF RELIGION}

In the opening pages of The Elementary Forms of the Religious Life (Les Formes élémentaires de la vie religieuse), Durkheim says that religion is something eminently social. He turns from all the individualistic interpretations of it, and finds that they do not accord with the historical facts, either those of ethnology or those of psychology. "Religious representations," he proceeds to say, "are collective representations which express collective realities." He refuses to think that religious rites are derived from divine personalities. He assures us that religion is more than the idea of gods or spirits, and consequently cannot be defined exclusively in relation to such beings, in this directly contradicting the definition of J. G. Frazer already given.

Religion appears nowhere except as an expression of the central life of a group of men and women. It is always a family, a corporation or a city which celebrates a religious rite, never a solitary individual. In this respect Durkheim regards religion from quite another point of view than that presented by William James in his Varieties. Durkheim, when he defines religion, finds that it is the beliefs and practices which unite into one single moral community all those who accept them or live in accordance with their requirements.

Durkheim accepts this conception of the nature of religion because he finds that it is a developmental phase of man's evolution as an industrial, moral, and intellectual being. The life of mankind grows about a great tradition or a series of traditions, results of human experience, passed on from one generation to another, and received by all growing minds as culture, intellectual training, and moral inculcation. We enter into the life of the community in childhood, find it giving us theories of life which have been elaborating through many centuries, and initiating us into the communal interpretation of 


\section{THE SOCIAL EVOLUTION OF RELIGION}

the world into which we have arrived. We have not to think our way into an explanation of life, its meanings and its duties, but find these already prepared for us by those who have preceded us on the life march. We may in time come to doubt these interpretations; but at first we accept them implicitly and are not able to question their truthfulness. "We speak a language," Durkheim says in his seventh chapter, which is devoted to the origin of beliefs, "that we did not make; we use instruments that we did not invent; we invoke rights that we did not found; a treasury of knowledge is transmitted to each generation that it did not gather itself. It is to society that we owe these varied benefits of civilization, and if we do not ordinarily see the source from which we get them, we at least know that they are not our own work."

It is Durkheim's conclusion that because we feel our dependence on these products of the creative energies of mankind, and do not comprehend definitely how they came to us, we attribute them to spirits or gods, and give them a religious significance. These precious things, that have come to us.out of the past, that have tender sanctities associated with them, we regard as of a divine origin, give them symbolical meanings, and say that they came to us from God. Durkheim is of the opinion, however, that "the sacred principle is nothing more nor less than society transfigured and personified." Accordingly, we have here a means of interpreting sacred things and acts in lay and social terms. The process by which the social becomes the divine Durkheim interprets in these words: "The individual gets from society the best part of himself, all that gives him a distinct character and a special place among other beings, his intellectual and moral culture. If we should withdraw from men their language, sciences, arts and moral beliefs, they would drop to the rank of animals. So the char- 


\section{THE SOCIAL EVOLUTION OF RELIGION}

acteristic attributes of human nature come from society. But, on the other hand, society exists and lives only in and through individuals. If the idea of society were extinguished in individual minds and the beliefs, traditions and aspirations of the group were no longer felt and shared by the individuals, society would die. We can say of it what we said of the divinity : it is only in so far as it has a place in human consciousness, and this place is whatever one we may give it. We now see the real reason why the gods cannot do without their worshippers any more than these can do without their gods; it is because society, of which the gods are only a symbolical expression, cannot do without individuals any more than these can do without society."

Durkheim arrives at the conclusion that society has stamped itself indelibly upon every phase of individual life, as well as on all phases of religion, culture, and eivilization. It is not the individual mind as individual, as possessed of initiative and genius, which has given origin to these great constructive results of the experiences derived from many a generation succeeding one another, and absorbing these products of individual activity. Rather is it the corporate, the organic, more properly the genetic, advance of mankind, which has made humanity what it has become. This means that life has grown out of life, that one phase of society has evolved out of another, and that religion is something ever proceeding, as much a revelation now as it ever has been or ever can become. Religion, therefore, is a process of growth, and when it is not that it is a cumberer of the earth. Truly, it is something that is evolving, that leaves behind the old, that is forever sloughing off the outgrown. It does not so much give us new truth as fresh life. What it may accomplish, if it is vital and dynamic, is to give society new incentives, which shall bring it 


\section{THE SOCIAL EVOLUTION OF RELIGION}

into vital and forceful activity towards making a better humanity. What does not make for the glory of man, what does not lift him and set him more strongly on his feet, is not essential to a genuine religion.

"The real function of religion," is the statement of Durkheim, "is not to make us think, to enrich our knowledge, nor to add to the conceptions which we owe to science others of another origin and another character, but rather, it is to make us act, to aid us to live. The believer who has communicated with his god is not merely a man who sees new truths of which the unbeliever is ignorant; but he is a man who is stronger. He feels within him more force, either to endure the trials of existence, or to conquer them."

Durkheim emphasizes, as perhaps no one else has ever done, the constructive power of society, and that out of it grows every phase of knowledge, art, science, and religion. He refers all these back to it, and finds in it their interpretation. He may seem to give too little credit to the individual genius; but when one follows through his pages that worthy is not missed, and it is difficult to find a place for him, and especially so in the realms of religion.

Not less than in the case of Younghusband and Wells, does Durkheim regard God as a projection of the collective consciousness of mankind. No one can more strongly emphasize the importance of religion than he has done, and he never ignores the meaning and the worth of God as a constructive force in nature and humanity. He makes no appeal to the supernatural, the miraculous, the occult or the mystical; though he makes no attack upon any of them. Rather, he has no use for them as a man of scientific habits, who is inquiring diligently into facts, and not into surmises and theories. $\mathrm{He}$ respects tradition, he expounds its true meaning; but he never 


\section{THE SOCIAL EVOLUTION OF RELIGION}

bows to it as to something infallible. He knows the great power of tradition, but he also knows that new traditions are being created, which will in time supersede the old ones and make them of no account.

An Italian biologist, Eugenio Rignano, has published several important scientific works, and is the editor of Scientia, the international review of scientific synthesis. In his Essays in Scientific Synthesis, he has devoted one of them to religious phenomena, in which he contends as strongly as does Durkheim, that in its beginnings religion is of a social origin; but that in its more recent developments it has lost that character, and has come to be superseded by economics and other practical interests.

Psychologically, according to Rignano, primitive man makes for himself, at the base of all his religious conceptions, an irresistible association of ideas; and the hasty generalization resulting from it, at every unexpected happening in the physical world in which he lives, leads to the opinion that events are caused by one or more wills similar to his own. Man makes use of propitiatory acts in mitigating the anger of his fellowman, and he learns to apply the same method in dealing with the wills he finds acting in nature. In time the community accepts the method of controlling the powers acting against or for man, and a series of rites develops to this end. In ancient society, Rignano assures us, religion constitutes alone the whole psychic scaffolding so indispensable to the solidarity of the social edifice; and it penetrates, regulates, directs, and stimulates the energies of each member of the community at each moment of its existence. 


\section{THE SOCIAL EVOLUTION OF RELIGION}

"Thus it is that religion," we are told by Rignano, "raises and sustains all the social institutions, which serve as dikes, either to contain and canalize the course of certain series of social facts or relations, or to oppose an irresistible barrier to anti-social acts or relations. Every social thing, i. e., that it is of collective interest to fix and to preserve, becomes at the same time a sacred thing, which may not be touched without sin. Civil obligation and religious duty are one and the same thing."

It is shown that law is of a purely religious origin; and of the same source are those regulations which class the members of society according to age, sex, celibacy or marriage, profession, caste, and so on. In fact, every activity of a social interest was controlled by religion. Especially was this true of all the activities which depended absolutely on their simultaneous and co-ordinated character. There was no individual or collective economic fact which was not invested with a sacred nature, and in that manner imposed on society for general observance. The calendar, moral requirements, ceremonies connected with agriculture, the psychic habits growing out of primitive gregariousness, war in all its phases, the derivation and sanctions of government, were all of a religious origin, and the means of expressing and enforcing its rites and beliefs. Rignano mentions war especially as approved by religion, and as one of the most important means of its extension and emphasis.

In the modern world, however, this intimacy of religion and social development has lost its meaning. With the progress of mankind "we see all these causes, which have contributed in the past to the creation and development of the religious organ, growing now weaker and weaker, especially in the civil societies of our own time, and tending one after an- 


\section{THE SOCIAL EVOLUTION OF RELIGION}

other to disappear, because there have been gradually formed distinct organs for these functions, always useful, which religion alone hitherto exercised, or because the need of others for these functions of religion is no longer felt."

Social institutions and law now have no-regard for religion, and develop quite independently of it. The divine sanctions which condemned anti-social acts in the past have now no meaning, and have been replaced by legal processes and secular punishments. 7 The religious bond has been replaced by the economic, and the sentiment of social solidarity succeeds to the influences formerly exercised by religion. Owing to the development of the new industrial and economic forces the old religious sanctions have ceased to function, and religion is condemned to a slow atrophy of its control of human affairs. Dogma is being shaken off and faith is weakening on every hand. "The prodigious development of science in every branch of knowledge, the diffusion of technical culture and of instruction in general, the popularization of the conception of natural laws, immutable, and regulating the various transformations of matter, all these facts, which give to the mind a scientific as opposed to a religious outlook, ultimately exercise a destructive influence on religious beliefs, which becomes more and more efficacious, in proportion as the organ destined to support and strengthen those beliefs has lost from day to day its functional energy."

Not only is the religious organ in a continuous process of atrophy, but the economic and scientific developments which are replacing it are growing stronger with every year. The result is a direct attack upon religion and its several institutions and beliefs. As the workers of the world grow stronger and better organized they find religion less important to them; and some day they will sweep away those social and religious guarantees which underlie much of what has been regarded as of primary 


\section{THE SOCIAL EVOLUTION OF RELIGION}

importance. There is taking place, also, a moral evolution away from religion; and conduct, individual and social, no longer depends on the old sacred sanctions. A collective conscience is being developed, which is having a marvellous growth, and makes religion no longer essential. It is this power which is fighting human evils, and is destined in time to conquer them. "Built up by every means of communication and transmission of thought, by the most varied methods of the propagation of ideas, by all of what we call the organs of public opinion, by every kind of meeting and association adapted to elicit and to express the resultant of many individual wills, by all the representative systems in every department of social activity, this complex apparatus of the collective conscience now allows, with greater and greater facility and perfection, and in an ever-increasing number of cases, of concerted agreement and action between the components of each social group or sub-group, and thus between all the members of society in general. It exercises in consequence an ever-increasing and decisive influence in all domains of social activity, and also in the domain of morality."

The conclusion of Rignano is that religion is slowly dying, but that it is being replaced by what is truer, by what answers more truly to modern needs, and by what is far more effective as an individual and social support. Guided by principles of purely rational order, society is progressing with tranquil serenity towards a great future. As religion loses more and more of its social force, as a guide and support of human communities, in its regenerated form it may become a support to individuals, and especially to those of a mystical tendency. In this purely individual form it may keep alight within its heart the sacred torch of religion, and transmit that light from one generation to another while human life endures. 
Another Italian, Benedetto Croce, is of the opinion that religion is nothing else than mythology, and that it is being superseded by philosophy. Croce's philosophical writings have recently attracted much attention, for he is the author of a series of volumes on the philosophy of spirit, which shows that he has been greatly influenced by Hegel. This system includes Logic as a science of pure concept, Aesthetics as science of expression and general linguistics, and a treatise on philosophy as a practical economic and ethic. He has also published works on what is living and what is dead in the philosophy of Hegel, and one on historical materialism and Marxist economy. $\mathrm{He}$ is also the editor of a philosophical review called La Critica.

In his chapter on mythology, to be found in his Logic, Croce expresses the opinion that religion is identical with mythology, and that its basis is no more substantial. Whatever is real in religion, and with a solid foundation, is identical with philosophy. Therefore, he entirely discards religion as valueless, and as without any substantial meaning for the thought of today. He classes the narrative of Adam and Eve, who eat of forbidden fruit and are driven out of paradise, with the stories of Phoebus, Daphne, and Prometheus, as of the same nature. The Hebrew story of a God Creator is of the same character as the Greek myths of Uranus and Gaea, the birth of Chronos and the Titans. To be classed with these myths are those of paradise, with its immortal life, the son of God who comes into the human world, and the apocalyptic visions of a regenerated earth.

According to Croce mythology results from giving concepts a personified form, and it is the fundamental error of religion. In so far as the revelation on which religion rests is not of the spirit of thought, it is nothing more than mythology, with its 


\section{THE SOCIAL EVOLUTION OF RELIGION}

logical contradictions. Such religion has its origin and its essence in myth, it is necessary that it should be rejected for philosophy, which has its justification and its credentials in the nature of thought. Philosophy is the only true religion, and more and more religion takes on the philosophical form. If it does not make this transition it remains as error, and can be nothing else. Croce says that religion, when divorced from philosophy, degenerates into blind fancy and empty concepts. When religion would save itself from criticism it is obliged to have resort to philosophy, and it is then called theology. "Theology is philosophism," to use the translation of Douglas Ainslie, "because it works with concepts which are empty of all historical and empirical content. Myth becomes dogma; the myth of the expulsion from paradise becomes the dogma of original sin; the myth of the son of God becomes the dogma of the incarnation and of the Trinity.'

In his chapter on the consolations of philosophy, Croce assures us that religion has no comforts which are permanent for the thinking person. Philosophy has made the concepts of God and immortality more exact, and it has liberated them from the impurities with which they did abound. Those who have really thought about them have never found true consolation in their absurdities. No God outside the world, a despot ruling the universe, can lead to anything else than fear; and he may be often the cause of maledictions. The belief in immortality gains nothing from its theological interpretations; and these are more and more called in question by those who think.

Croce recognizes four great fundamental forms of knowledge - logic, esthetics, economics, and ethics. There is no fifth, and therefore religion is in no sense to be regarded as affording knowledge in any form apart from these primary forms of philosophy. Religion sometimes partakes of the nature of esthetics, 


\section{THE SOCIAL EVOLUTION OF RELIGION}

sometimes of logic, and is, consequently a mere hybrid. As mythology it is now art and now philosophy. However, though all that is true in it is of the nature of philosophy, yet as such it is never of the real nature of a philosophical system. Rather is religion of the nature of art, a work of the imagination and of intuition, but without verifying means for correcting its false perspectives and visions.

In that volume of his philosophy devoted to esthetics, Croce says, in the translation of Wildon Carr, presented in his interpretation of that philosopher: "Where there is no knowledge there is no religion, and religion is not a form of knowledge distinguished from other forms, for it is sometimes an expression of practical aspirations and ideals, sometimes a historical narrative, sometimes a conceptual science, dogmatic theology. With equal cogency, then, we may maintain both that religion is destroyed by the progress of human knowledge and that it always persists in that progress. To primitive peoples, religion was the whole patrimony of knowledge; to us our patrimony of knowledge is our religion. Its content has changed, has ameliorated, has become refined; in the future it will contrive to change, to be ameliorated, to become refined; but its form does not change, that is always the same. How those who would preserve religion as a theoretical human activity side by side with art and philosophy would use it, I do not know. It is not possible to preserve an imperfect and inferior knowledge side by side with the knowledge which goes beyond it and invalidates it."

An English interpreter of religion who has been to a considerable extent influenced by Durkheim, as also by Bergson, is Jane Ellen Harrison. Her Prolegomena to the Study of 


\section{THE SOCIAL EVOLUTION OF RELIGION}

Greek Religion, and her Themis: A Study of the Social Origins of Greek Religion, are works of the first importance, being standard authorities on the subjects with which they deal. A more recent, 1915, small volume of essays entitled Alpha and Omega, presents some most interesting interpretations of her religious experiences. Brought up in a strict low-church Anglican family, when she went to London and became a lecturer at Newnham, her early teachings quite dropped away from her, and she became indifferent to church forms and beliefs. Gradually she found herself greatly interested in Greek art and philosophy; but at last it dawned upon her that what she really cared for in her absorbing Greek studies was religion, every phase of which drew and held her with its naturalness and its charm.

In the essay which gives title to her book, she says that "it happened rather oddly that what I really was interested in was, not Greek art, but Greek religion, and even Greek literature held me largely for its profoundly religious content. So, gradually I worked and lectured more and more on Greek mythology, and less and less on Greek art; and then, again, I found it was not mythology really interested and drew me, save for its poetry, but ritual and religion. I was always hankering after that side of things, wanting to understand it, excited about it. ... I was studying a vital and tremendous impulse - a thing fraught indeed with endless peril, but great and glorious, inspiring, worth all a lifetime's devotion.

"And then bit by bit I came to see that the thing I loved, that beckoned to me and drew me irresistibly, was religion; the thing that hampered and thwarted and even disgusted me was theology. Theology is the letter that killeth, religion the spirit that maketh alive, and if the good ship Religion is to live in to- 
day's turbulent waters, we must shrink, we must throw overboard the Jonah of theology."

In these essays Harrison makes it quite plain that she is not only a heretic and an agnostic, but also an atheist. In this same essay she says in plainest terms: "To be an Atheist, to renounce eikonic theology, is to me personally almost an essential of religious life. I say this in no spirit of paradox, but as a matter of deep conviction. The god of theology is simply an intellectual attempt to define the indefinable; it is not a thing lived, experienced; it almost must be a spiritual stumbling-block today.... It is not only that the particular forms of theology are dead, but that the idea of theology - i. e., a science of the unknowable - is, if not dead, at least, I venture to think, dying. God and reason are contradictory terms." Then she avows herself a deeply religious Atheist, who has been largely influenced by Bergson, whose philosophy she regards as having given a shattering blow to theology, "because all theology is but a thinlyveiled rationalism, a net of illusive clarity cast over life and its realities."

In being a heretic Harrison feels that she is assuming an almost human obligation, because the gist of it is free personal choice in act, and especially in thought, and the rejection of traditional faiths and customs. In tribal society heresy was impossible, and even in the time of our grandfathers it made one something of a social outcast. Now it has become an intellectual as well as a social duty. In taking this view of heresy, however, we must recognize that orthodoxy results from the action of herd instincts, hence it becomes an obligation of progressive persons to bring the herd instincts to the side of what is modern and rational. Heresy, being the child of science, while it holds fast to its mother's hand, may run with swiftness and certainty. In her definition of religion Harrison follows Durkheim, 


\section{THE SOCIAL EVOLUTION OF RELIGION}

her statement taking this form: "Religion is not the aspiration of the individual soul after a god, or after the unknown, or after the infinite; rather it is the expression, utterance, projection of the emotion, the desire of a group. Now, historically this is true of the genesis of religion. That I hold is established. Religion, in its rise, is indistinguishable from social custom, embodying social emotion." In the course of time social combinations have enlarged, the individual has come into a right to act and think for himself; but religion largely remains a form of the collective attitude of great bodies of men and women. Freedom of thought has been secured, but essentially religion focuses the social consciousness and aspirations. She accepts the conclusion that the only real forces to-day are the group forces, and these give to religion its meaning and its power.

The conclusion reached by Harrison is that man was never so little theological as he is to-day, but that he was never so profoundly religious, so passionately social, the two words having essentially the same meaning for her. If we would keep religion, we are told, in the essay on Alpha and Omega, we must allow theology to go. It is a chief hindrance to the progress of religion, and its retention means that the two will die together. The basis of theology is the idea of revelation, a body of supernatural truth. In discarding theology, it is evident that Harrison would permit revelation to go with it, as no longer having a real meaning for the thinking of to-day. "It is sufficient," she says in the essay on Darwinism and Religion, "to recall that 'revelation' included such items as the creation of the world out of nothing in six days; the making of Eve from one of Adam's ribs; the temptation of a talking snake; the confusion of tongues at the tower of Babel; the doctrine of original sin; a scheme of salvation which demanded the virgin birth, vicarious atonement, and the resurrection of the material body. The scheme was un- 


\section{THE SOCIAL EVOLUTION OF RELIGION}

folded in an infallible book, or, for one section of Christians, guarded by the tradition of an infallible church, and on the acceptance or refusal of this scheme depended an eternity of weal or woe. There is not one of these doctrines that has not now been recast, softened down, mysticized into something more conformable with modern thinking. It is hard for the present generation, unless their breeding has been singularly archaic, to realize that these amazing doctrines were literally held and believed to constitute the very essence of religion; to doubt them was a moral delinquency."

The whole tenor of Harrison's interpretation of religion and theology in this book would lead to the conclusion that these doctrines are of a mythological nature, as much so as the Greek conception of Olympus, its gods and its beliefs. If Christianity has a meaning for the life of to-day it does not lie in the direction of these mythological conceptions, but in quite another direction. We have discarded the myths of the Greeks, Babylonians, and Hindus; and it is quite time that we rejected those of the Hebrews and Christians. Religion gains nothing whatever by retaining beliefs thinking men and women, as these pages have shown, are coming more and more to reject. We are to recognize the fact that theology is based on myth and metaphysics (myth stated in abstract form); and that it is quite time we turned away from both with scorn. What theology means to Harrison she has well stated in the essay on Darwinism and Religion, in saying that "man has provided himself through the processes of his thinking with a supersensuous world, the world of sense-delusion, of smoke and cloud, of dream and phantom, of imagination, of name and number and image."

In the same essay we read that man worships, feels and acts ; and, as the result of his feeling and action, projected into his confused thinking, he develops a god. Man projects his own 


\section{THE SOCIAL EVOLUTION OF RELIGION}

thought into universe and calls it god, bows before it and worships. Gods are a part of theology, and both are necessarily temporary, constantly giving place to those which are more modern and rational. "We know now that, all over the world, a people of peasants tilling the fields, dependent much on weather and climate and nature generally, will have as their gods vague daemones. But a people vigorous, self-reliant, practically efficient, a people of conquerers, immigrants, colonial, whether Hellen or Teuton, always make their gods in human shape. They believe in themselves, and they project their own images. God is for them what they trust and believe in - that is, their own right arm. Religion is transfigured morality." Again: "Morality is social, due to the reaction of man on man; it is human. But religion is our reaction to the whole, the unbounded whole."

An American psychologist, who to a considerable extent accepts the same positions in regard to the nature of religion as those presented by Emile Durkheim, is James Mark Baldwin. He has published numerous psychological works, and is the editor of the Dictionary of Philosophy and Psychology. In his little book on Darwin and the Humanities, Baldwin says that we cannot rest content with the individualistic theory of religion, the view that it springs up in the individual in the form of rational insight or private intuition; but, as the result of comparative and anthropological studies, we must regard it as of social origin - always an institution of gradual evolution, embodying the results of social intercourse. Always and everywhere it is a social phenomenon, and grows out of the life of the social group. When the group is primitive in its character, such will be the religion, that is, communal and tribal. As the group advances 


\section{THE SOCIAL EVOLUTION OF RELIGION}

in size, in affiliation of its parts, and in co-ordination of its forces, the religion will become more integral and nobler.

Baldwin finds that God is an expression of the ideals of the group and of the individual, for he says that the ideal self is God. As he indicates by his interpretation of the nature of the self, which is a growth from social contacts, he must regard the self embodied in the nature of God as essentially social in its origin and nature. "God is a construction of the imagination," he observes, "beyond the concrete cases of selfhood that we know ; it is an ideal set up and considered as actual. Considered as a factor in experience, God is the supposed or imagined Self, which is the outcome of the self-movement toward perfection the control meaning anticipated by all the partial adjustments which finite selves effect to one another. As the ethical demand or postulate is one of a completed social order, and its ideal is one of harmonious practical relationships on a social community; so the religious demand or postulate is that of a perfect self, a fully realized or complete person, in whom the opposition between private and public interests would be completely overcome."

Baldwin adds that the deity shows the growth of the normal social relations, and reflects their character, because he is the projected personal ideal of the group. The individuals of the tribe think of the deity as apart from themselves because he is personal, yet he is the controlling spirit of their collectivity, the voice, the oracle of the group. In a true sense the deity of the tribe is the tribal spirit, and he is thought of in terms of the tribal self. This holds good through all advancing stages of social evolution, though, as this advances, the individual is less and less subject to the arbitrary control of the collectivity. Accordingly, the deity becomes of a larger and more humane type, and represents a finer and more ethical ideal. 


\section{THE SOCIAL EVOLUTION OF RELIGION}

Baldwin is the author of four volumes devoted to a system of genetic logic, the fourth of which he calls a Genetic Theory of Reality. The second part of this work is largely devoted to the problems of social growth in connection with the evolution of religion. Baldwin regards God as one of the personages in the social relation, and of such a nature as this relation would suggest. He is not an arbitrary, autocratic being in some sphere away from the interests of human beings; but is in actual and intimate connection with their interests. He probably does not, as Durkheim does, regard God as humanity personified and idealized to represent the highest standard to which it can attain; but he evidently is quite unwilling to set God in any place or time apart from the human fellowship in all its meanings. God is a symbol, and while both actual and ideal, is never to be dissociated from human interests.

"Religion of humanity," Baldwin says, "to be a religion, must mean religion of ideal humanity; but this is what religion of divinity also means. For divinity is humanity idealized in both its aspects, individual and social." Religion being always a social ideal, it is not possible that the deity should escape from that character or become something outside humanity and above it. All ideals being products of the imagination, built upon knowledge, but going beyond it, the ideal person, God, must also be a construction of the imagination, and hence receive his nature and his character. "God is the final and comprehensive value of the life of feeling and will," is another statement of Baldwin; "and as reality, this postulate gives concreteness to the ideal contained in the whole series of social and moral values." If the meaning of these statements is fully apprehended, Baldwin is in sympathy with Durkheim in assuming that God in all his phases of development, from the lowest to the highest, is a reflection of the social consciousness of one 


\section{THE SOCIAL EVOLUTION OF RELIGION}

or another human society, the innermost expression of itself as a social body, a fellowship of kindred spirits. So understood God becomes the real meaning of religion, in becoming the ideal of that type of society the group aspires to become, and is organizing its forces to realize. This means that the deity and the religion of a people cannot go far beyond the actual life lived by its membership from day to day.

Roy Wood Sellars, a professor of philosophy in an American university, has published one of the most radical of books, which he entitles The Next Step in Religion. At one time a student in a theological seminary, he has evidently studied widely the history of religion. He has given attention to a wide range of other subjects for he has published books on Critical Realism, The Next Step in Democracy, The Essentials of Logic, and The Essentials of Philosophy.

The chief contention of Sellars is, that religion originates in mythology, his second chapter being devoted to that subject. $\mathrm{He}$ is of the opinion that theology must be superseded by science, which must reconstruct for us the universe, morals, and our social institutions. He insists that the conflict between science and religion has by no means ceased, and he devotes a chapter to that subject. He claims that there is an ever-increasing number of persons who believe that science and philosophy must take the place of religion or give it a thorough reconstruction. The battle waged in the time of Huxley and Tyndall has not ceased to rage, but has shifted its points of contention. He says that the new battle is being waged around psychology and philosophy. Already the struggle is going on between those who defend the theory of an extra-organic soul and those who prove by 


\section{THE SOCIAL EVOLUTION OF RELIGION}

means of the laboratories of biology and psychology, that the mind and body are inseparable. This contention cannot end until the old conception of the soul, born of animism, has been brought to its end.

On the subject of the old dualism of body and mind Sellars gives forth no uncertain affirmation that a unity of conception is demanded. "I am inclined," he says in his chapter on the soul, "to prophesy that psychology and physiology will reach an adjustment of their principles before many years have passed, and that consciousness and mind will take their places along with mass and energy in the scientific view of nature. The old dualism of soul and body will pass away and give place to a flexible naturalism." $\mathrm{He}$ contends, also, that human personality is a function of the sub-lunar life, of the physiological organism, of the sky and soil, and of the restless struggle of man with nature. In his opinion when the mind-body problem is solved, there will go with it the last bulwark of the old supernaturalism. "Man will be forced to acknowledge that he is an earth-child whose drama has meaning only upon her bosom. It is my firm conviction, he affirms, "that the clear realization of this fact will startle men into insights and demands of farreaching import."

In his criticism of theology Sellars is definite and explicit. In treating of the evolution of Christianity he says that the theology of the church fathers, councils and scholastics has in our time been mellowed into a universalistic outlook and a strong ethical trend. "I challenge anyone to develop a really tenable system of theology, a system which is self-consistent and relevant to the world as we know it. I am certain that it cannot be done. As a student of ethics, my growing conviction has for some time been that these traditional controversies and modes of approach to human life are barren and irrelevant, be- 


\section{THE SOCIAL EVOLUTION OF RELIGION}

cause they cast absolutely no light upon human problems, social or personal. Modern ethics and theology have ceased to have any genuine commerce. The one is in touch with the sciences of biology, sociology, psychology and criminology; the other, by its very nature, can gain nothing from these sciences."

Contrasting theology with science our author maintains that the logic of revelation is the logic of the auto $d a f e$; but that the logic of science is tested by fact. Theology cannot bring about agreement among men; but this is the very purpose and spirit of science. The romantic spiritualism on which theology rests must give way to that humanistic naturalism which sees clearly what is man's true place in the world. It will be a great relief when narrow sectarianism, cruel bigotry, and the obscurantism of supernaturalism are purged from religion.

Because of its worship of the Bible Christianity has set too high a value on beliefs which are doomed to destruction. The Bible miracles are uncompromisingly rejected as a part of the mythical and supernatural view of the world and man's relations to it. They lead to all sorts of superstitious beliefs, and have hindered real progress toward a rational conception of nature and life. The miraculous tales of the New Testament have done an incalculable amount of harm, for the basis on which they rest is weak. They do not fit into the world of experience as we know it. "The assertion that God performs miracles, like the similar assertion that he created the world, is purely hypothetical and unverifiable."

The very idea of a personal God, who works miracles, who answers prayers, who directly controls the events of nature, and who works on the side of man through providential agents is in need of justification. In dealing with the stories of creation, Sellars says that "to assign to a hypothetical agent called God, powers sufficient to produce what experience tells us exists 


\section{THE SOCIAL EVOLUTION OF RELIGION}

explains nothing. The primary assumption, of course, is that there must have been a creation; but the conception of evolution has attacked that assumption at its very foundation." We are outgrowing the conception of personal wills acting in the universe, whether interpreted by polytheism or monotheism. The idea of a youthful and developing god appeals to a goodly number of persons now; and in many directions there is an advance to an impersonal conception of the causing agent or agents in all the affairs of the universe. We are coming to explain by means of natural causes all the happenings in nature and humanity, and we need not, therefore, appeal to a supernatural agent. "All of man's ideas are human ideas, and so his idea of his God and the very personality and moral outlook of that God reflect the social standards which are in force around the individual. If human justice is cruel, God's justice is strict and unyielding." In the newer conceptions of deity God becomes a part of the universe in every respect, and the universe is to be regarded as co-existent with deity.

As the idea of God has grown out of social and political conditions at the several stages of its development, so has the belief in immortality. The idea of another life has given a false perspective to the conditions of this one. Sellars is of the opinion that this belief has never been a healthy one for the human race. It serves as a narcotic, and it falsifies the real issues of human progress.

Sellars is appreciative of Jesus and his teachings, but he is not appreciative of the theory of the messianic mission of this or any other great religious person. He seems to have some doubt as to the real existence of the New Testament personage, and apparently attributes the origin of theological Christianity to Paul. The Messiahs, Buddhas and Mahdis he finds to be products of the race imagination, and are to be interpreted from that 


\section{THE SOCIAL EVOLUTION OF RELIGION}

point of view. Christianity was not the creation of a single mind, but was the flowering of religious mythology. The deification of Jesus is certain to be outgrown. What has grown up about him in the way of legend and myth is to be duplicated by nearly all the other higher religions. "He was not born miraculously, nor was he preëxistent as the Word or Logos. These terms do not fit into an outlook dominated by science. To call him the Son of God in an exclusive sense is not warranted by the facts, nor has it any clear meaning for the present age. . . . Jesus was a noble and tender-hearted man with the beliefs of his age. To speak of him as ideally perfect and sinless is absurd just because these terms are absolutes where relatives alone have meaning. Like most theological terms they cut themselves loose from their necessary setting, which, in this case, is human nature and society."

What is to take the place of theology, and what is to give sanction to the developing religion? According to Sellars it is to be found in ethics and science. Throughout his book he emphasizes the importance of science and its fundamental principles. Its spirit and its method are to be everywhere applied in the future, and nothing is to be accepted without its sanctions. This is why we have here a fresh emphasis upon the ethical point of view. Science shows us that the moral life in all its phases and developments is of human origin, and that it needs no sanctioning of theology or from the supernatural. Christianity has given us a vicious interpretation of morality, and one that must be inevitably outgrown. "And the modern thinker is pretty well convinced that morality is a purely human affair growing out of the instinctive tendencies which man has inherited in the course of evolution as these find themselves in various situations. Moral problems are meaningless apart from their setting on this earth." 


\section{THE SOCIAL EVOLUTION OF RELIGION}

In spite of the repeated assertion that morality apart from belief in God and immortality is worthless, a steadily growing number of persons have reached the conclusion that no form of miraculous or supernatural sanction whatever is essential as the basis for the ethical life. Morality originates in human relations, and its sanctions are those of social demands. Indeed, so well is this now understood, that for the scholar and the thinker no other reason for being moral is demanded. In this sanction morality finds its supreme justification.

\section{V}

This review of some of the phases of the religious life of our time, and of the opinions of a few of the leading thinkers of the present day, will help to make it clear that the repeated assertion is emphatically not true, that there has come about a complete reconciliation between religion and science, and that the whole trend of the time is towards the acceptance of religion in its generally received interpretations. The fact is, that never before was there so much of doubt in regard to the fundamental beliefs of religion as there is at the present moment. Undoubtedly, there is less of outspoken criticism of the old beliefs than there was a half-century ago; but there is abroad far more of the spirit of free inquiry, and less of willingness to receive with unquestioning loyalty the accredited beliefs of the churches. There is taking place a change in the mental attitude of thinking men and women, and there is developing a mental atmosphere which makes belief in spirits and the supernatural less and less congenial to thought. It is true that there has been a great awakening of interest in the occult, in the subtle causes of subconscious phenomena; but this is rather materialistic than spiritual, result of a craving for some tangible evidence in re- 


\section{THE SOCIAL EVOLUTION OF RELIGION}

gard to the nature of the soul and of the life that may come when this one has ended. While these two tendencies go on side by side, and in a degree intertwine with each other, it is not to be doubted that the profoundest movement of our time is towards the elimination of the supernatural, and of all that is occult and spiritualistic. What we are most deeply concerned with is the future of man on this earth of ours, and how to make his life finer and nobler.

What will be the attitude of this new trend of thought with reference to religion? Will it discard it entirely? as seems to be the tendency indicated by Leuba's investigations. On the other hand, there are many hints that the old nature-worship may revive, even though $\mathrm{H}$. G. Wells may hold an agnostic attitude towards what he calls the Veiled Being. Religion has grown up around two centers of influence, that drawing it towards nature and that emphasizing its dependence on the collective life of mankind. As we have seen in reviewing the opinions of Wells, Durkheim, Rignano, Sellars, and Baldwin, the tendency at the present time is towards ignoring nature, and placing all the emphasis on the human side of religion. The physical world is often stern, forbidding, cruel, and destructive; and it requires much idealizing of its forces to find in them what is gentle, sympathetic, and responsive to the needs of human beings.

The evidence collected by Leuba indicates that a large majority of the persons answering his questionnaire do not be lieve in a material god or one that can be seen, heard or feit. The conclusion is that God is not to be found by any searching through the physical universe. If we could ascend up into heaven we would not find God any more fully or positively than we find him here. If we could make our bed in hell he would not be there more tangibly than we find him in the evils that 


\section{THE SOCIAL EVOLUTION OF RELIGION}

beset man on the earth. If we could take the wings of the morning, and dwell in the uttermost parts of the sea, his hand would not lead us or his right hand hold us in a manner different from that which we realize each day right where we are, and under the conditions now known to us in all our experiences. How can we think that the darkness will cover us or the night be light for us in any other degree than has always been known to mankind, simply and solely because we believe in a personal God? In no physical sense can the darkness hide God from us or the night shine as the day or that the two must be to him one and the same. Such poetry has its mighty charm and its great consolation when we think in the manner of the animist or the anthropomorphist. It can have no such meaning for the modern student of science or for him who faces the world as we know it to-day.

It is undoubtedly this truth which has made H. G. Wells refuse to see God in nature as other than a Veiled Being. No physical exploration of the universe would bring God nearer to us in any physical or tangible form. Could we explore eternity, and fly through the infinite or go forth into the absolute, what evidence is there that we should come closer to God than we are to him right here and now? No senses of ours can make him more real for us, and no evidences of reason or of intellectual speculation, can bring him nearer or make him more responsive to our prayers.

God is a principle, an idea or an ideal, a unifying force throughout the universe, an energy that is manifest behind all phenomena. He is this or else he is collective man, man as the spirit which binds together the ages, and gives meaning to all our experiences. God as collective man is always present with us, and we cannot be where he is not. We cannot escape from his presence if we would, and, if we understand ourselves, we 


\section{THE SOCIAL EVOLUTION OF RELIGION}

cannot wish to flee away from what is human in its largest proportions and in its deepest meanings.

However unsatisfactory such a conception of God may be to some persons, we may be certain that it is that towards which many others are moving as making it alone possible for them to believe in God at all. Unless we can join with Goethe in conceiving of the universe as the garment of God, we cannot give him a tangible form or invest him with any kind of physical proportions or features. If he is to be sought for anywhere in the physical universe, it must be as a principle, a law or an underlying energy.

Otherwise, we must seek for God in the life of humanity. If for the moment we are willing to use theological language, we may say that God is incarnate in humanity, typified in its humanness, symbolized in its unfolding life through the ages, and embodied in every man, woman, and child. That is what, in fact, God has meant to those who have most zealously believed in and worshipped him. This has led all the more advanced religions to conceive of God as incarnating himself in man. We may differ from these older interpreters of religion in the belief that God incarnates himself in the unfolding life of collective humanity, and not alone in Jesus, Buddha or any other. Humanity as a whole, as a procession through the centuries, as giving an ideal of what is just, wise, and beautiful in conduct, is what God must mean for us of to-day. Such an idea of God robs it of superstition and of the supernatural, and brings him directly into the world of human interests as a fact and as a genuine reality.

In all ages, however, from the days of primitive animism to these of the doctrine of the immanence of God in nature, the minds of men have been drawn towards various phases of the outward world with subtle sympathy and feelings of fellowship. 


\section{THE SOCIAL EVOLUTION OF RELIGION}

The old world of fawns, dryads, fairies, and other similar imaginative creatures, phased a strong tendency in the classic age. Even during the mediæval period, the most spiritual minded of the mystics found in nature responses to their moods of faith and joy in life. Our own time has newly awakened this tendency, as we see in the great poetry of Goethe, Wordsworth, Emerson, Whitman, and many another. Many a man and woman sees God in the wide world around us, in the glory of sunrise, sea, flower, and star; and in many a phase of that charm and beauty and mystic glow which spreads over nature in choice hours of sympathy with her. The grandeur of the universe, the majesty of its endless spaces, the mightiness of its laws and its forces as revealed by science, will forever, we may believe, bring back to man that awe, that reverence, that mystic response of the heart, which appealed in one way or another to the earliest men. Here is something that religion has developed from in some of its most important phases, and this tendency is not likely to grow less through any time to come for imaginative minds or for poetic natures. We may see no fairies in the woods, find no supernatural powers lurking in the spaces of the sky or any great gods hiding in the vastness. of the universe; but not the less will nature charm, inspire and elevate us through all the times to come. The Veiled Being may forever remain veiled, but that will not keep him from holding intercourse with the poet and with the worshipping heart.

Nor is that other source of religion, the nature of man, and especially man as a collective being, ever likely to lose any of his power to quicken the mind and warm the heart. In all probability, the mythical and mystical interpretations of man's life, which have found numberless expressions in religion, will gradually disappear; and religion will come more and more to concern itself with making the world a fit place in which men 


\section{THE SOCIAL EVOLUTION OF RELIGION}

may live, and the life of man fit to occupy a world brought into subjection to human needs. No other tasks can be greater than these, and none are likely in the future to inspire men with such courage and faith. And about the developing course of man's evolving life may gather all courage, heroism, sacrifice, and loyalty. Men will learn not to make war on each other, to cooperate nation with nation for the promotion of every phase of human welfare, and to advance all those interests which protect the good of the individual and give strength and glory to the lives of nations.

If we think that these great humanitarian tasks may be only materialistic, without charm and poetry, with nothing in them to inspire with great visions or invigorate with masterful ideals, then we have not read aright the history of mankind. The age-long wars of man with man, of nation with nation, may be turned into conquests over nature, the bringing all that is possible of its forces into subjection to man's needs. Here is field for all the bravery men have ever had, as there is in the subduing of disease, the application of the great industrial and economic forces of the world to the benefit of all who live. The glories of chivalry, the glamor and the pride and the charm of it may be directed into these new channels, and men will go forth to fight the real evils men suffer under, as they did to battle in the tournaments of old. The spirit of it may not be other, but the effects of it will be the upbuilding of all that is human, instead of the destruction of individual and nation. When we turn our religion, our chivalry, our love of adventure, our desire to come into intimate communion with God, and all that lies subtly hidden in the deeper and mightier forces of the spiritual world, we shall be ready for these fresh endeavors, these attempts to serve man and to make his career on earth something noble and truly ethical. It may be that such a vision of 


\section{THE SOCLAL EVOLUTION OF RELIGION}

what religion may do for the future of the race may not quicken any heart-throbs in some persons, that it will appear to be merely something humanitarian, and therefore not of a kind to inspire; but undoubtedly, nevertheless, the number of those with each generation is growing greater who are ready to hear such a clarion call to religion and the real salvation of the world.

\section{VI}

Too long have we listened to the metaphysicians and the theologians. They have not led us to the green meadows of life, but into a tangled wilderness of subtleties and abstractions. All their beliefs and dogmas may well be swept away, since all of them have grown out of the primitive animism in one form or another of mythology or personification of the forces of nature and of man. May we not courageously say to them to-day that we are done with them, for they have been false leaders, who have made life dark and forbidding! We are now ready for art, for poetry, for music, for what brightens and glorifies life. Too much have we heard of sin and banishment from God, and a fallen world, and the mediating power of one or another noble and gracious mind. We have come now to believe in all men and women who live, the meanest as well as the greatest. We are coming to see with $\mathrm{H}$. G. Wells, that the world can never be truly happy until all lords and kings and owners are banished, and all men and women are brought into the acceptance of what life has to give of wisdom, opportunity, and happiness. The religion which reserves the world's joy and beauty for a few favored ones on earth or in heaven no longer appeals to us. We see that the world is beautiful, that the music of it, the art of it, the poetry of it should be for all who live. Why has not religion banished the slums, harried out of the world the ghet- 


\section{THE SOCIAL EVOLUTION OF RELIGION}

toes, made impossible the simpleton and the beggar? That it has not we think to be the greatest possible criticism of its methods and its aspirations. No excuse that its tasks have been other, that it was leading men the way to peace of soul and to heaven, can save it from the condemnation it deserves because of its infidelity to man, the greatest and the most dangerous of all infidelities - and the only one that is worthy of a moment's consideration.

The metaphysicians and the theologians have made for us two worlds, a world of material interests, and a world of what is spiritual. The one world is that of food, clothing, houses, and the affairs of industry and economic interests. The other world is that of ghosts, spirits, and gods, of what belongs to the soul and to the world beyond the borders of time and space. These two worlds have been made antagonistic to each other, the one base and the other noble, the one material and the other spiritual. The one is of earth and the other of heaven; one belonging to the present, the other to the future.

We have come more and more to think that there is no such antagonism of these worlds as the theologians and the philosophers have assumed. Our thought is that there is but one world, that world-unity is the true conception. The antagonism of matter and mind is not real, but artificial, a merely metaphysical creation. We know body and mind only as one organism, never separated, never truly in opposition. The belief that they are two, and not one, is product of the primitive animism, the succeeding anthropomorphism, and the still later succeeding metaphysics. Science knows no such distinction, and gives it no true support. The life of man is one, and the world is one.

We must think that there is for the modern mind no world within a world, no spiritual universe within the material uni- 


\section{THE SOCIAL EVOLUTION OF RELIGION}

verse. This, too, is result of the primitive animism, and when we turn back to that we see whence the conception of a world of sense and a world of ghosts or spirits has its origin. It is time we eliminated from our thinking this doubleness of the world we know, and declared for the unity of nature and humanity, matter and mind. We have been deluding ourselves with an antagonism of materialism and spiritualism or idealism. We have forgotten that if man is of the earth earthy, that earthiness enables him to live as a human being, and that without it his life would speedily come to an end. We have made materialism as a philosophy to mean baseness of living, absorption in gross interests, devotion to self and to all that is mean; and therefore we have condemned it. As a fact, philosophical materialism is no more gross or selfish than the highest idealism; and we have made it so only by confounding interests and ideas which have no true relation with each other. Speculative conceptions as to the origin and nature of the universe have no necessary relation to the ethical life of the individual or the nation. Our theories as to the origin and nature of matter, and its relations to mind, do not determine our moral conduct.

We cannot doubt that we live in a world of realities responsive to the senses, that is, in a world of environing conditions, which in large degree determine our individual lives and the nature of our civilization. Within that world of concrete reality man has always been inclined to accept the existence of another world, a world not known to the senses. What is the true nature of that world? The history we have passed in review ought to have given us the clue to its origin and its nature. But we have not forgotten the primitive animism, the anthropomorphism of the barbarian races, and the metaphysics of the more advanced peoples. We have speculated as to the relations 


\section{THE SOCIAL EVOLUTION OF RELIGION}

of body and mind, matter and spirit, and we have entangled ourselves in abstract theories, in speculations having no basis in reality.

What we are coming to see very slowly, but more and more clearly, is that this antagonism of body and mind, matter and spirit, is one created by ourselves, and has no basis in the nature of the universe itself. Within the material world there is another world, we may rightly admit; but that other world is of man's own creation. It is the world of myth and religion, art and science, literature and philosophy, morality and ethics, culture and civilization. These all have been created by man as the result of his nature as man, because of his humanity. From the lowliest beginning with the chipping of stones and erecting wind-breaks as a sort of habitation, and the gathering of food from where it might be had as produced by the spontaneities of nature, he has slowly and painfully, through countless centuries, built up all that world of the advancing civilization and the developing inner life which have made him what he is. It is man's creation from its lowliest to its highest forms, and he $\checkmark$ lives the life now of what we call spirituality or idealism because he has been making for himself within the earthly world of his material habitation another world of a kind fitted to his own needs.

It would be the merest dogmatism to say that it is impossible that there should have come to man from without his own life, from some other world than that in which he knows himself to live, aids he could not otherwise secure in this great process of building up the world of his inner development or the spiritualization of his civilization. All the claims made for such an outside intervention, however, do not historically justify themselves. They lead to every manner and degree of assump- 


\section{THE SOCIAL EVOLUTION OF RELIGION}

tion, and to all the subtleties and abstractions of theology and metaphysies.

We still cling to the acceptance of a double world, a universe within a universe, because we are afraid otherwise, in the rejection of this conception, we will lose our faith in a personal continuity of our individual being hereafter. We have already seen, however, that the old supports of that belief are falling off from all thinking men and women, and that none of the evidences for such continuity are truly valid for our time. As yet there is no positive proof that man will live beyond the grave, and the promise of the future is that science will bring us some light on that problem. Unless it does so there can be no more than belief in regard to immortality. Some investigators go so far as to assert that we are on the very verge of such assurance; but as yet they have brought us no proof that will convince all inquiring minds. That way lies possibility; but we may not cling stubbornly to what is merely traditional in order to assure ourselves by such broken supports that individuality has before it the prospect of eternity as concerns its own littleness within the limits of the universe.

An ever-increasing number of men and women, however, will dare to think that there are problems of far greater importance than the continuity of our individuality, which is assured to us, surely, in the life of the race. These independent minds, also, will be brave enough to believe that the universe is a unity, and that the inner world, the spiritual universe, is a part of man's culture and civilization, that he has created these as a phase of his progressive advance through the ages, and that he is ever enlarging their scope and their certainties. $\mathrm{He}$ eannot be balked of this universe he has made for his own enlargement of life, and his own inner growth in what makes for justice and wisdom. 


\section{THE SOCIAL EVOLUTION OF RELIGION}

\section{VII}

Do we wish to-day to find the most elevated, the most inspiring, the most spiritual, religion? It is on the canvas of the painter, on the pages of the poet or maybe the novelist. Turn with deeply averted face from the prosy preacher of traditions and myths, in the shape of theology and supernatural religion, if you wish to hear the words which burn and the thoughts that quicken life; and go to that great poet, the social creator, who in all ages has made religion, and given joy and beauty to the heart of man. In him and his kind you may find life and uplifting vision; but not in the preacher, unless he too is a poet or creator, and one who is deeply moved by the needs and the strivings of mankind.

We have lived in the old traditions of the past, and they now eling to us and drag us downwards to death of the freemoving spirit. What we have need to recognize is, that new traditions are growing, that new ideals are shaping themselves in the life of our time. These masterful ideas, of beauty in the individual life, of a spirit of loyalty and devotion, of brotherhood and fellowship throughout all the world of humanity, of peace between all nations, of world-unity and a parliament of $\Rightarrow$ man, of a religion which inspires all the strivings of man with hope and courage, are coming more and more to quicken the minds and hearts of the men and women of our day. Freedom and opportunity for the workers of the world, freedom and opportunity for women everywhere - these are motives linking themselves with the newer religion now being born. Care of every child coming into the world, training him to live for and with his kind, is motive that touches the inmost core of any religion that can have meaning for the years to come. That none shall be born under base and mean conditions, that none shall 


\section{THE SOCIAL EVOLUTION OF RELIGION}

grow in ignorance or suffer needless hunger and want in a world that is filled with superabundance, must be part of the coming religion or men will turn from the very name of it and all that it has been held to mean.

The preceding pages have revealed to us the fact that man, collectively and individually, has great creative capacity. When we review the history of the arts and sciences, the growth of culture and civilization, the development of cities and nations, we may realize what great constructive genius man possesses. $<$ Nor can we ignore the evolution of folk-lore, legend and mythology, the remarkable creations of every tribe and people, each and all interesting and impressive, however simple and unimaginative they may seem to be. We have no hesitation in saying that these mythologies, wonderful and startlingly masterful as many of them are, may be regarded as mere fancies of the imaginative mind. So we say of some of the myths underlying the great religions of the past and the present. But the Buddhist and the Zoroastrian retorts on us that our religion, of which we boast its reasonableness and its truthfulness, is no other in its origin than his own. It has in it as much of mythology as either of the others, and its basis in myth is quite as certain. Such retort of one religion against another cannot interest the inquiring mind, for he sees plainly enough that all are growths from the nature of man, and that the man who created these religions under the conditions of the past can produce greater ones in the time to come. Collective man has brought< into existence every religion known to history, and what he has once and again produced he can not only renew, but create greater and more adequate types of religion for the future. This will be one of the great tasks he will undertake in the forthcoming years. In the past he has produced mythologies and religions unconsciously or subconsciously; but in the future he will create with a 


\section{THE SOCIAL EVOLUTION OF RELIGION}

larger consciousness of what he needs and of what will be for the inspiring and the glorifying of humanity.

This also we are to recognize, that man by means of his arts, his sciences, his religions, his ethical systems, has created for himself a spiritual world, a world of hopes and dreams and visions, within the material world; and in this he dwells as in the real and assured world of his desires. $\mathrm{He}$ wishes to escape from the drudgeries and brutalities and miseries of his daily life, and he passes into this other world of his ideals and his spiritual aspirations, this world of his own creation, as into a secure haven of peace and joy. No one man made this spiritual world, no prophet or poet or artist could have brought it into existence; but all the men and women of all the ages have made it to be what it is. What has been brought into existence, and into an existence so real and secure that many persons think it the only world that has any true meaning, is now every day being modified, revised, improved, newly created, and made worthier of human habitation. Therefore, we are not to despair when the old religion slips from the minds of youth and of the thinking men and women, for a new world is being created within the old one, far more beautiful, much truer to the facts of man's nature, and far better calculated to inspire and to uplift.

What man has made, man can make again. He has created many a spiritual world in the past, and he can build more stately mansions for the soul in the years to come. The old creations were visionary, largely unreal, of the substance of dreams, shot through with nightmare visions; but the newer realms of the spirit will be finer, with sounder basic foundations in human nature, and with loftier possibilities for the advancing of all human interests. Religion, therefore, is not passing away, but coming into its own. It may, and doubtless 


\section{THE SOCIAL EVOLUTION OF RELIGION}

will, lose the supernatural and the miraculous, its saints and its prophets; but it will gain in the multitude of its faithful men and women, in those who have the qualities of the hero, and who can give themselves unstintedly for the service of their fellows. We may welcome with joy the day of this new and more beauteous religion, for it means that what belongs to human welfare will grow marvelously in every part of the world, and among all the races of men. 



\section{APPENDIX TO CHAPTER I}

Since this chapter was written there has appeared a very careful interpretation of the processes of evolution, in the form of the lectures of Henry Fairfield Osborn on The Origin and Evolution of Life. In this work he states clearly why the hypothesis of the inheritance of acquired characters is not to be fully accepted at the present day. A summary of his conclusions is here presented for the benefit of those who may be especially interested in this subject.

What Osborn believes is the fundamental biologic law he states in these words: "In each organism the phenomena of life represent the action, reaction, and interaction of four complexes of physico-chemical energy, namely, those of (1) the inorganic environment, (2) the developing organism( protoplasm and body-chromatin), (3) the germ of heredity-chromatin, (4) the life environment. Upon the resultant actions, reactions, and interactions of potential and kinetic energy in each organism selection is constantly operating wherever there is competition with the corresponding actions, reactions, and interactions of other organisms." This law, if it does not wholly discard the theory of Lamarckianism does by no means give it sanction.

Recent investigations are to the effect that chromatin and protoplasm are the earliest elements of life, that they are physico-chemically produced and that the first is possibly the more ancient. Primitive chromatin and protoplasm appear to co-exist, cells arising by symbiosis between the two. Chromatin is the seat of heredity, and the evolution of its energies 


\section{THE SOCIAL EVOLUTION OF RELIGION}

is essentially the evolution of life. "It is in the inconceivable physico-chemical complexity of the microscopic specks of chromation," says Osborn, "that life presents its most marked contrast to any of the phenomena observed within the lifeless world."

The mutations of de Vries, which occur more frequently among plants than animals, are attributable to sudden alterations of molecular and atomic constitution in the hereditychromatin, or to the altered forms of energy supplied to the chromatin during development. At the stage of the simplecelled organisms it would seem that the organism-protoplasm is the more sensitive to environment, while the heredity-chromatin is the more insensitive to environment, and the more stable, in that it has the quality of conserving and reproducing hereditary characters true to type, as in the many-celled animals in which the heredity-chromatin is deeply buried within the tissue of the organism remote from direct environmental reactions.

Osborn has this to say in regard to the operation of environment on the lower forms of life: "Changes of environment play so large and conspicuous a part in the selection and elimination of the invertebrates that the assertion is often made that environment is the cause of evolution, a statement only partly consistent with our fundamental biologic law, which finds that the causes of evolution lie within the four complexes of action, reaction, and interaction."

He proceeds to say that new characters arise definitely, continuously, and adaptively. He regards this gradual evolution of adaptive form as directly contrary to Darwin's theoretic principle of the selection of chance variations. In the following statement he points out why it is that the heredity of acquired characters has been denied, though he refuses to 


\section{THE SOCIAL EVOLUTION OF RELIGION}

accept that denial as found under all circumstances. "A clear distinction exists between the slow, stable heredity-chromatin, or germ evolution, and the unstable body cell evolution as viewed by the experimental zoölogist. The body is unstable because it is immediately sensitive to all variations of environment, growth, and habit, while the chromatin alters very slowly. The peculiar significance of heredity-chromatin, when viewed in the long perspective of geologic time, is its stability in combination with incessant plasticity and adaptability to varying environmental conditions and new forms of bodily action. Chromatin is far more stable than the surface of the earth."

Then the Lamarckian theory of evolution is taken up, and, in accordance with the preceding statement, is defined in modern terms to be the cause of the genesis of new form or new function that are to be sought in the body cells (soma), on the assumption that the cellular actions, reactions and interactions with each other and with the environment are in some way impressed upon and heritable by the chromatin. This theory, that a change in environment, habit and function leads to changes in the evolutionary series Osborn does not find to be fully sustained by the more recent investigations.

On the other hand, the Darwinian theory of evolution, that the genesis of new form and function is to be sought in the germ cells or chromatin is equally defective, in the light of recent knowledge. The hypothesis that the actions, reactions and interactions which cause certain bodily organs to originate, to develop, or to degenerate, to exhibit momentum or inertia in development, do not give rise to corresponding sets of predispositions in the chromatin, and are thus not heritable, is also wanting in full verification. Neither theory accords with the recent results of investigation in palæontology 


\section{THE SOCIAL EVOLUTION OF RELIGION}

and experimental zoölogy as to the actual modes of origin and development of adaptive characters.

"That there may be elements of truth in each explanation is evident from the following consideration of our fundamental biologic law. Adaptive characters present three phases : first, the origin of character form and character function; second, the more or less rapid acceleration or retardation of character form or function; third, the co-ordination and co-operation of character form and function. If we adopt the physico-chemical theory of the origin and development of life it follows that the causes of such origin, velocity (acceleration or retardation) and co-operation must be somewhere within the actions, reactions, and interactions of the four physico-chemical complexes, namely, the physical environment, the developing organism, the heredity-chromatin, the living environment, because these are the only reservoirs of matter and energy we know of in life history."

The causes of evolution, according to Osborn, are to be found, not so much in the interaction of environment and organism as in the physico-chemical energy resulting from the actions, reactions and interactions of different parts of the organism itself. The law according to which changes proceed is unknown as yet. "The only vista which we enjoy at present of a possible future explanation of the causes of character origin, character velocity, and character co-operation is through chemical catalysis, namely, through the hypothesis that all the actions and reactions of form and of motion liberate specific catalytic messengers, such as ferments, enzymes, hormones, chalones, and other as yet undiscovered chemical messengers, which produce specific and co-operating interactions in every character complex of the organism and corresponding predisposition in the physico-chemical energies of the germ; in other 


\section{THE SOCIAL EVOLUTION OF RELIGION}

words, that the accelerators, balances, and retarders of body cell development also affect the germ......'

"The chromatin as the potential energy of form and furction is at once the most conservative and the most progressive center of physico-chemical evolution; it records the body form or past adaptations, it meets the emergencies of the present through the adaptability to new conditions which it imparts to the organism in its distribution throughout every living cell; it is continuously giving rise to new characters and functions. Taking the whole history of vertebrate life, from the beginning, we observe that every prolonged, old adaptive phase in a similar habitat becomes impressed in the hereditary characters of the chromatin. Throughout the development of new adaptive phases the chromatin always retains more or less potentiality of repeating the embryonic, immature, and more rarely some of the mature structures of older adaptive phases in the older environments."

Osborn reaches the conclusion that palaeontology provides positive disproof of the existence of an internal perfecting principle or entelechy of any kind, such as has been assumed to exist by some Lamarckians and vitalists. No such principle exists which would impel animals to evolve in a given direction regardless of the direct, reversed, or alternating directions taken by the organism when seeking its life environment. $\mathrm{He}$ also finds that there is conclusive evidence against Bergson's theory of an élan vital or internal perfecting tendency. The characters assumed to be produced in this manner do not spring up autonomously at any time; but they lie dormant or remain rudimentary for great periods of time. They require something to call them forth, to make them active.

The conclusion is also reached that Lamarckianism has sought in vain for evidence of the inheritance of the effects of 


\section{THE SOCIAL EVOLUTION OF RELIGION}

such action and reaction processes as those on which its claims are based. Nevertheless, there exists some kind of relation between the action, reaction and interaction of the germ, or of the organism and the environment. Probably this opinion is capable of experimental proof or disproof, but that result has not as yet been reached. "We know, for example, that certain cells of the reproductive glands have a profound and commanding influence on the body cells, including even the brain-cell centers of thought and intelligence - all this is, in a sense, an out-flowing from the heredity-germ region, a centrifugal interaction." 


\section{Index}

Abnormality, religion and, 31.33.

Acquired characters, inheritance of, 5, 404, 406, 408.

Agrarian rites, 96.97, 148, 155.156, 223. 225.

Agriculture, 45, 148, 155-156.

Amalgamation and affiliation, 193-194, 201, 294-295.

Amalgamation of religions, 230, 325 . 326.

Ancestor-worship, 168-180, 195-196. See Patriarchalism.

Animals, 9.10, 127.134.

Animal gods, 128-129.

Animatism, 116.

Animism, 116.118, 143, 179, 185, 195 . 196, 273.274, 397. See Ancestor. worship and Patriarchalism.

Anthropomorphism, 185.

Apocalypses, 259.260.

Apocrapha, Old Testament, 260.

Arabia, 202.203, 300-302.

Arabian desert, influence on religion, $299 \cdot 303$.

Aristotle, 164-165, 274-275.

Aryan religion, 173, 208-226, 230.

Aryans, migrations of, 295-296.

Atheism, 378.

Atonement or expiation, 266-271.

Augustine, Saint, quoted, 261 .

Avesta, 213.214. See Zoroaster.

\section{B}

Babylonia, religion of, 161, 205.208, 306.

Bahaism, 289, 316-317. See Moham. medanism.

Baldwin, James Mark, quoted, 13, 381. 384.

Bards or rhapsodists, $84,89,92$. See Recitations and Epic poems.

Bergson, Henri, quoted, 354-355.

Bhagavad-gita, 83, 85, 266. See Ma. habharata.

Bible, Jewish, 86-87. See Sacred books.

Birth-tales of Buddha, 246, 252. See Virgin-birth.

Blood-feud, 146, 187.

Boas, Franz, quoted, 122-123, 125.

Bosanquet, Henry, quoted, 339.

Brahman, 218.220.

Brahmanism, 218-220.

Brahma Samaj, 315.

Breasted, J. H., quoted, 37-38.

Breath, 112.114.

Brinton. Daniel G., quoted, 56.

Buddha, 222, 239-242, 246-247, 253, 271.

Buddhism, 39, 231, 239-251.

and Christianity, 247-250.

in Ceylon, 246.

in China, 247-248, 256-257.

conception of God, 243.

conception of future life, 244-245.

fundamental teachings of, 241.242, 243.

in Japan, 247.

monks of, 242.243.

Nirvana of, 244.

origin of, 239-241, 297.

in Siam, 250-251.

spread of, $245,291$.

Budge, Wallis, quoted, 171.

Burkitt, F. Crawford, quoted, 259.

Burroughs, John, quoted, 352.

\section{c}

Caddoan Tribes, 74, 78.

Caird, Edward, quoted, 338.

Caste in India, 181.182, 218-219.

Celtic religion, $210-212$.

Cheyne, T. K., quoted, 263.

Chief becoming autocratic lord, 152, 154.

Childhood, social influence of, $2,10-12$, $21,34-35,42,60,110,118,129$.

China, 318.

Chinese religion, $159-160,164,178,194$ $197,230.231$.

Christian church, 99-100, 102.

Ohristianity 255, 281, 291, 328, 331 . $332,834 \cdot 335$.

in melting-pot, 331.332, 335, 341 . $342,380,385.387$.

origin of, 235, 251-254, 261, 280. See Jesus Ohrist.

City-State, 150, 153.

Clan, supremacy of, 55-56, 132, 145. 146, 149-150. See Tribe.

Collective mind, 56.58, 106-109, 239, 401-402. See Mind. 
Communal houses, 67. See Communal society.

Communion in eating and drinking, 272. 273.

Communal society, 59, 64, 104, 150, $153,183$.

Comparative religion, $x v, 27,52,311$. 312. See Religion.

Competition, 23.

Confucius, 195.

Congenital transmission, 4. See heredity.

Co-operation, 22.

Cornford, Francis Macdonald, quoted, 162.

Corn-mother, 74, 78, 97-98. See Mothergods.

Cosmic and human processes, 16, 390. $393,396-399$. See Science and religion.

Coulanges, Fustal de, quoted, 173.

Creative power of group, 59.60, 106.108, 113, 367-368. See Collective mind. Creeds, 323.

Critical spirit, $48, \quad 352-354,360-361$, $372 \cdot 373,375,378 \cdot 380,385 \cdot 386,388$, 394, 400-402. See Science.

Croce, Benedetto, quoted, 374-376.

Culture contacts, 48-49. See Migration.

Culture-hero, 267-268.

Culture influence on religion, 232-233, 311.

Cushing, Frank Hamilton, quoted, 75.

Custom, 145, 187-188. See Ethical life. Czaplicka, M. A., quoted, 135-136.

\section{D}

Dance, 61-63. See Song.

Darwin, Charles, 14, 353.

Darwinism and religion, $379,382$.

Davidson, Thomas, quoted, 339.

Delphic oracle, 55 .

Demeter, 96-97, 210. See Eleusinian mysteries and Kora.

Democracy in religion, $50,321.332$.

Demonism in China, 196.

Dempsy, T., quoted, 55.

Dené or Athapascans, 78, 140, 150.

Densmore, Frances, quoted, 111-112.

Deuteronomy, 87.

Deutsch, Emanual, quoted, 283.

Dharma, 222. See Hindu religion.

Dionysus, 126, 234.

Division of labor between sexes, 163. See Sex.

Dramatic form of myth, 142. See Myth.

Dramatic representations, 63. See Rituals.

Dreams, 71, 111-113.
Dream societies, 112-113.

Duality of mind and body, 109-110, 398-399. See Mind.

Dualism, 162, 385, 398-399.

Duchesne, Louis, quoted, 257.

Durkheim, Emile, quoted, 26-27, 57, 365-370.

\section{$\mathbf{E}$}

Economic causes, 45.

Education, 49.

Eggeling, Julius, quoted, 83.

Egyptian religion, 36-38, 81, 197-201, 266, 276-277, 306-307.

Eleusis, mystery of, 24, 67, 97-98, 103. See Demeter and Kora.

Eleusinian mysteries, 223-225, 234, 259-260.

Eliot, Georg, 271, 351.

Emerson, quoted, 281, 309.

Encyclopædia of Religion and Ethics, quoted, 127, 219, 265.

Environment, change in, 43. See Migration.

Epic poems, 88-92. See Bards and Recitations.

Ethical life, 50, 145-147, 329-330. Sef Customs.

Eucharist, 101-102, 272-273. See Communion, Lord's Supper and Mass.

Eugenists, 6, 24-26.

Exogamy, 131-132, 145. See Clan and Tribe.

\section{$\mathbf{F}$}

Family Religion, 195-196, 221. See An. cestor-worship and patriarchalism.

Father-Heaven and Mother-Earth, 69, $76,95,97,157-162,195-196$.

Female descent, 130, 149, 154, 165. See Mother-right.

Female principle, 274-275. See Male principle and Sex.

Female and male principles, $160-165$, $178 \cdot 179$.

Fertility, 225. See Female principle.

Fertility of earth, soil, and women, 95, 97.

Fetish, fetishism, 143. See Animism.

Feudalism, 150-153, 180-181, 195. See Tribe.

Feudalistic religion, 181-182.

Fielding-Hall, Henry, quoted, 250-251.

Finns, 137-138.

Fiske, John, 10-12, 342.

Fletcher, Alice, quoted, 120-123, 125. 126.

Folk-lore of Old Testament, 203, 255, 258. 
Food-group, 49, 70, 109, 149. See Clan. Founders of culture, 46.47.

Founders of religion, 229, 235, 289.290. Frazer, J. G., quoted, 69, 131, 140.141, 176-177, 203, 255, 338 .

Freedom in religion, 320-323, 378-379, 400.

Freud, Sigmund, quoted, 31-33.

\section{G}

Galton, Francis, 6, 23.

Gardner, Percy, quoted, 256.

Gautama, 240-243. See Buddhism.

Generation, creation by, 69. See Fertility.

Genius, 5, 104-105, 175, 235.238. See Founders.

Gilman, Charlotte Perkins, quoted, 352.

God, belief in, 340-347, 355, 356-358, 361-364, 369, 375, 382-383, 391-392. See Animism and Anthropomorphism. Also Monotheism.

communion with, 271-375.

immanence of, 54 .

Gods, origin of, 168.172, 176.177. SeAnimism and Anthropomorphism

Greek Art, 226-268. See Harrison. dramas, 226-228.

Epics, 88-92. See Bards and Recitations.

idea of love, 138 .

religion, 28, 84-86, 105, 162, 171, $222-228,304,377$.

Guardian animals, $130-134$.

spirits, $130-134$.

Gummere, Francis, quoted, 64.

\section{$\mathbf{H}$}

Hall, Stanley, quoted, 3, 276-280.

Harris, Rendel, quoted, 126.

Harrison, Jane Ellen, quoted, 376-381.

Hartland Sidney, quoted, 262-263.

Hatch, Edwin, quoted, 259.

Hearn, William Edward, quoted, 173.

Herd instinct, 21, 109. See Communal society.

Heredity, congenital, 5-9, 14, 17-19, 23, 25

social, 7-9, 14, 20, 23-25. See Tradition.

Herodotus on Greek gods, 77, 82, 89. Hesiod, $76,97$.

Hewitt, J. N. B., quoted, 142.

Hinayana, lesser vehicle of Buddhism, 246.

Hindu religion, 160-161, 165, 222, 315. See Brahmanism and Hinduism.

Holiness, 270.
Holy Ghost, 122, 274.275.

Holy Grail, 99-103.

Homer, 88-92, 104-105.

Homeric Hymns, 90.

Hrdlicka, Ales, quoted, 139.

Hudson, W. H., quoted, 116.

Humanity, collective, as God, 356-358, $361-364,369,379,383-384,392-394$. See Collective mind.

Humanitarianism, 327, 333, 394.

Human, progress, 42-51, 48-49.

Hunting, 149, 154.

Huxley, Thomas H., quoted, 16.17, 353.

\section{I}

Ikhnaton, 36-38.

Iliad and Odyssey, 88.89.

Imagination, 59, 112-113.

Imitation, 12-13, 34, 55-56. See Suggestion.

Immaturity of infancy, 10-12, 34-35. See Childhood.

Immortality, belief in, 340-344, 347-352, $361,399$.

Incarnation, 244-246.

Indian philosophies, 220. See Hindu. ism.

Individual choice in religion, 232-233. See Individuality and Genius.

Individual freedom, 22.

Individuality, 344-345, 381, 399.

Individuality and congenital heredity, 17-19.

Individuality in religion, 29, 56, 113, 146.

Individual originators of religions, 229. 230.

Individuality, origin of in religion, 305 .

Infancy, 10-12, 34-35, See Immaturity of infancy and Childhood.

Inspiration, 106-107. See Revelation.

Invention of tools, 43.

Invention, social, 45.46. See Genius.

Ishtar, 76-77, 96, 156, 161-162, 207.

Isis, 82, 156, 200-201, 210, 234.

Islam, 281-289, 291, 298. See Mohammed and Mohammedanism.

\section{$\mathbf{J}$}

Jacobi, H., quoted, 219.

James, William, quoted, v-vi, 29-30, 236, $238,339$.

Japanese, 47, 196-197, 318.

Jee, Bhagavat Sinh, quoted, 160.

Jesus Christ, 40, 253-254, 271, 281, 320, 323-324, 336, 374, 381, 387.388. See Christianity.

Jevons, F. B., quoted, 232-233. 
Jews, 203-205, 206, 231-232, 235, 251, $293,298 \cdot 300,306$. See Semites and Bible.

Johnston, Reginald Fleming, quoted, 247-248.

Jukes family, 6.

\section{$\mathbf{K}$}

Kalevala, 92. See Finns and Lönnrot. Karma, 128. See Brahmanism.

Koran, 283-284. See Mohammed and Mohammedanism.

Khu-en-Aten, 36-38. See Ikhnaten.

King, 152, 176-177, 181. See Chiefs and Magic.

as magician, 176.

Kings, divine right of, 181 . See Patriarchalism and Ancestor-worship.

Kinship bond, 145, 151.

Kora or Persephone, 97. See Demeter and Eleusinian mysteries.

Krishna, 84, 266.

Kuanyin, 249-250. See Chinese religion.

\section{I}

Lang, Andrew, quoted, 130.

Language, how acquired, 2.3, 9, 33.34, 119.120 .

Laws, 187-188. See Customs and Ethical life.

Leubs, James $H$, quoted, 340.347, 351, $352 \cdot 353$.

Lewes, George Henry, quoted, 109.

Life-index, 129.

Lloyd, on half Japan, quoted, 247.

Lönnrot, 92. See Finns and Kalevala.

Lord Christ and Lord Buddha, 320.

Lord's Supper, 278. See Communion and Mass.

\section{$\mathbf{M}$}

Macdonald, Arthur A., quoted, 84.

MeDougall, William, quoted, 351 .

McTaggart, John, quoted, 338.

Magic, 137-140.' See Shamanism and Witch.

Mahabhareta, 83-85, 266. See Bhaga. vad-gita.

Mahayana, greater vehicle of Buddhism, 246, 248, 256.

Maine, Henry, quoted, 305.

Male descent, 130, 149, 154, 163 . See Patriarchalism and Ancestor-worship.

Man, methods of progress, 293. See Progress.

Mana, 121-122, 125, 126. See Orenda and Tabu.
Manu, code of, 221.

Manus, 163-164.

Marett, R. R., quoted, 116.

Margoliouth, D. S., quoted, 286.

Mass, 273. See Communion and Lord's Supper.

Matriarchate, 154-168. See Motherright.

Matriarchal gods, 96-98. See Mother gods.

Maya, mother of Buddha, 249. See Buddhism.

Medicine-man, 138-139. See Shaman. ism and Magic.

Melanesia, 121.123, 124.

Men and women in contrast, 167. See Sex and Feminine principle.

Migration, 44, 151, 192, 293-297.

Mind as social product, 22 . See Collective mind and Communal society.

Mind, contents of, 3.4, 22, 24. See Stanley Hall.

Miracles, 252, 386. See Science and religion.

Missionary motive, 230, 313. See Universal religion.

Mithraism, 36, 40, 231, 233, 257-258.

Mohammed, 35, 282-287, 298. teachings, $287-289,316$.

Mohammedanism, 281.289, 316. origin of, 281-282.

spread of, 285.286, 316. See Islam and Koran.

Monotheism, origin of, 37, 205, 300-304. See Anthropomorphism.

Moses, 289, 302.

Morality, 145.147, 186-188, 380. See Laws and Ethical principles.

Mother and Maid, 97-98. See Kora and Demeter.

Motherhood, 9. See Feminine principle and Sex.

Mother of God, 207, 252, 275.

Mother-gods, 156.

Mother of the gods, 81, 97, 156.

Mother-right, 154-168. See matriarchate and Female descent.

Murray, Gilbert, quoted, 88-92.

Music, 7, 8, 9. See Dance and Song.

Mutual aid, 22-23. See Co-operation.

Mysteries, 67-68, 98-99, 100-101. See Eleusinian mysteries.

Mysticism, 311.

Myth as origin of religion, 374-375, 380, 384.

Myth defined, 60, 71.82, 104, 128, 141. 142, 186.

\section{$\mathbf{N}$}

Natchez, Culture hero of, 74.

Natural selection, 23. 


\section{INDEX}

Nature-worship, $392-393$.

Navaho, Night Chants of, 78.81, 150.

Nibelungun-lied, 93, 103. See Epic poems.

Nirvana (Nibbana), 39.

Nitze, William A., quoted, 100-102.

Occult, 113, 122-124. recent growth of, 310-311.

O'Donnell, Elliott, quoted, 129.

Olympic gods, 94, 126, 224-225.

Omaha tribe, 120-121.

Orenda, 122-123, 126. See Mana and Tabu.

Osborn, Henry Fairfield, quoted, 404. 409.

Osiris and Isis, 81-82, 171, 200-201. See Isis.

resurrection of, $276-278$.

\section{$\mathbf{P}$}

Paternal origin of the child, 164-165.

Paternal society, 154.

Patria Potestas, 172-173.

Patriarchalism, 94-95, 163.164, 166. See Ancestor-worship.

Patriotism as religion, 327-330.

Paul, Saint, 260, 277.

Pelasgian or Aegean religion, 94-96, 97. 98. See Greek religion.

Persian religion, 212-214, 231.

Personality and social heredity, 19-20, 21.

Philo, 260-261.

Plato, 164-165, 304.

Poetry, social origin of, 64. See Epic poetry.

Plants with souls, 126-127. See Totem. ism.

Pneuma, 114. See Soul.

Prakriti, matter or nature, 160-161.

Priest, 141, 143, 176.

Property, 44.

Psychoanalysis, 31.

Purusha, mind or spirit, 160-161.

Petrie, Flinders. quoted, 201.

\section{R}

Rationalistic tendencies, 326. See Science and religion.

Raven god of Tlingit, 129 .

Recitation of epic works, 85, 89, 92. See Bards and Epic poems.

Religion and science, 352-354, 380. atrophy of, $370-373$. conservatism of, 27, 237, 308-310. definition of, $1,29,41,52,109,123$, $144,148,172,182,238.239,289$, $337 \cdot 340,265 \cdot 366,370 \cdot 371,375$, $379,387$.

founders of, 35-36.

Greek, 28.

growth of, 292, 308.310, 313.314, $326,332.326,337,366-367,371$. $372,402$.

International defined, 229, 234-235, $318-320,323,325$.

relations of to social life, 26.28 , $39.42, \quad 52.55, \quad 61.62, \quad 141.145$, $182-183$.

universality of, viii, 291.294.

Resurrection, 106-108, 237-238, 308. of Christ, 275-280.

Revelation, 106-108, 237-238, 308. See Inspiration.

Ribot, T. A., quoted, 59.

Ridgeway, William, quoted, 170-171.

Richard, Timothy, quoted, 247.

Rignano, Eugenio, quoted, 370-373.

Rig-veda, 82-83, 85, 216-217. See Vedas.

Rituals, religious, $68,78,81,98,141$. $143,144,145$. See Symbolism.

River valleys, 191.

Roman religion, $172,233-234$.

Russia, 319.

\section{$\mathbf{S}$}

Sacra, 173-174.

Sacred things, 124-125, 145, 312-313, 317.

Sacred books, 85, 86-87, 106-107.

Sacrifice, viii-ix, 219-220, 267, 269, 308.

to the dead 134.

to the gods, 144 .

Salvation, xiii, 308.

Schiller, F. O S., quoted, 347-351.

Science, methods of, 47. See Rationalistic tendencies.

and religion, $307,324-326,372$, $376,388.389$.

Self-consciousness, socially developed, 21. See Collective mind and collective Soul.

Sellars, Roy Wood, quoted, 384-388.

Semites, 201-208, 295. See Jews and Babylonians.

Sex, 154, 166-167. See Feminine principle. control of, 69 .

Shah Nameh, 93.

Shaman, 119, 135, 139-140.

Shamanism, 135-140, 143-144. See Magic and Medicine-man.

Showerman, Grant, quoted, 257-258. 
Siberian religion, 119, 139. See Shamanism.

Sin, theory of, 268-270.

Slavery, 45, 163, 168. See War.

Slavs, 208. See Russia.

Smith, George Adam, quoted, 299-300.

Social custom, 46-47, 49. 145, 149, 187. See Laws and Ethical principle.

Social process, 4-5, 7, 15, 20, 49, 109, 149.

Society, nature of, 367-369, 371-372. See social process.

Song. 62-64, 112-123, 138.

Soul, 113-114, 222. See Ánimism and Anthropomorphism. collective, 57, 109, 113-144.

Speck Frank G., quoted, 338.

Spencer Herbert, quoted, 169-170.

Spiritual beliefs, 117-120. See Animism Spiritual world, nature of, 402-403.

State, 153, 184, 190. See Tribe and Feudalism.

influence of on religion, 229, 301, 193-194.

Status or birth in religion, 232-233, 305 .

Suggestion, 13. See imitation.

Superman, 24-26. See Eugenics.

Supreme Self, 221. See Hinduism.

Symbolism, 143-144.

Syncretism in religion, 235, 247.249, $251,255-256,260-261$.

\section{$\mathbf{T}$}

Tabu (tapu or taboo), 124-125, 145, 167. See Mana and Orenda.

Tammuz, 76. See Ishtar.

Tarde, Gabriel, quoted, 12-13.

Territory as social bond, 152. See Blood-bond and Social Contacts.

Teutonic religion, $211-212$.

Theology, 374-375, 377-378, 379-380, $385-386,388,395-396,400$. See Religion.

Theosophy, 314-315. See Hinduism.

Thesmophoria, 223. See Greek religion.

Thomas, Northcote W., quoted, 127.

Toleration and free inquiry, 48. See Science and religion and Rationistic tendencies.

Totemism, 32, 130-131.

Tradition, 46, 49, 184. See Social heredity.

Transmission, congenital, 4.7. See heredity.

social, 4, 7-9. See Social heredity.

Trees, 126. See Totemism.

Tribal contacts, $44,49,151$. See Mi. gration and Amalgamation.
Tribe, formation of, 149-151.

Trinity, 274-275.

Tylor, Edward B., quoted, 115-117, 153.

Unbelief, 341, 347.

Unclean or impure, 124, 145. See Tabu.

Universalist Leader, quoted, 351.

\section{$\boldsymbol{\nabla}$}

Vedas, 341-347. See Rig-Veda and Aryans.

Virgin-birth. 251-252 262-264.

Virgin Mary, 210, 248-250, 275. See Isis.

Vyasa reputed author of Mahabharata, 83,85 .

W

Wakonda, 120-121, 126. See Orenda also Mana.

War social effects of, 44, 151.152, 163, 168192.

Weismann, August quoted. 8-9, 15.

Wells, H. G., quoted, 339, 359-365, 395. Werewolves. 129.

Weston, Jessie L., quoted 99-100.

Wheel of existence 222. See Buddhism.

Wiedermann A., quoted, 265.

Wissler, Clark, quoted 141.

Witch 129, 210. See Shamanism.

Woman, head of family, 155. See Mother-right, Matriarchate, and Fem. inine principle.

Women $43 \quad 45,74.95 .96,154.159$ $162-166,167,173-175,192-193,345$. 346.

Word, 119-120. See Language.

\section{$\mathbf{Y}$}

Yahweh, 203-205.

Yang, male principle in China, 178, 214.

Yin female principle in China 178.

Younghusband, Francis, quoted, 355 . 359.

Youth. 12-13, 40, 42. See Infancy and Childhood.

\section{$\mathbf{z}$}

Zeus, 98, 224. See Greek religion.

Zoroaster (Zarathustra) 212-214. See Persian religion.

Zuni, 75-76. 
, 


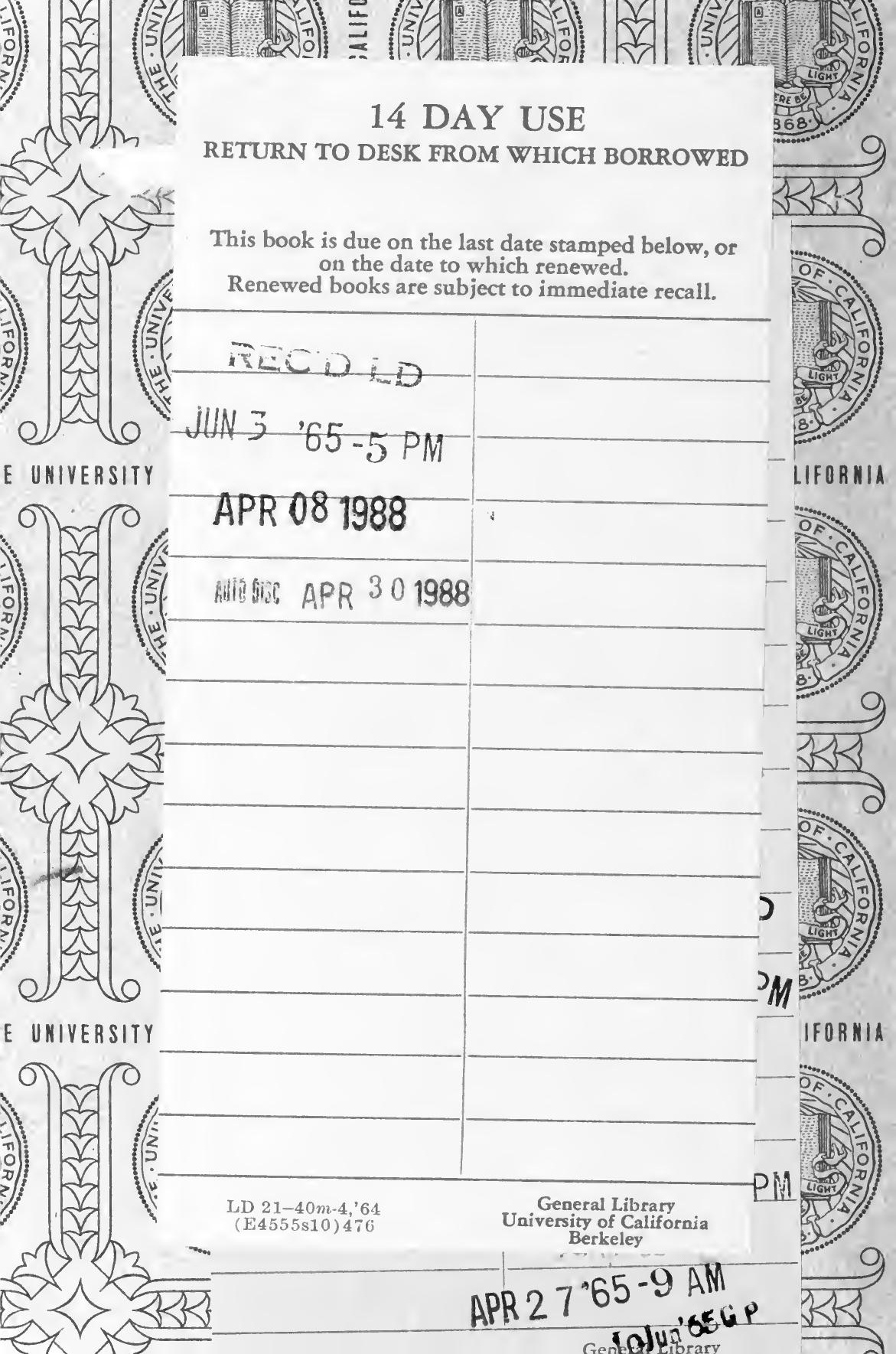




\section{U.C. BERKELEY LIBRARIES}

36,9
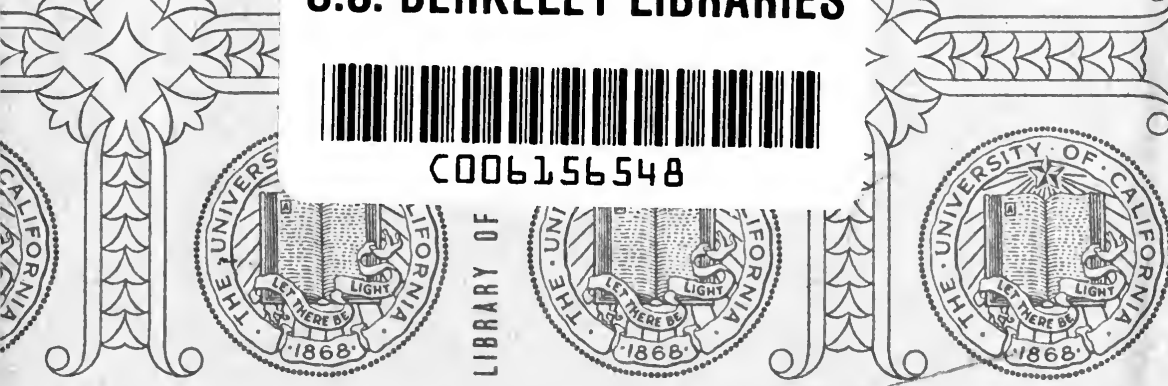

HE UNIVERSITY OF CALIFORNIA

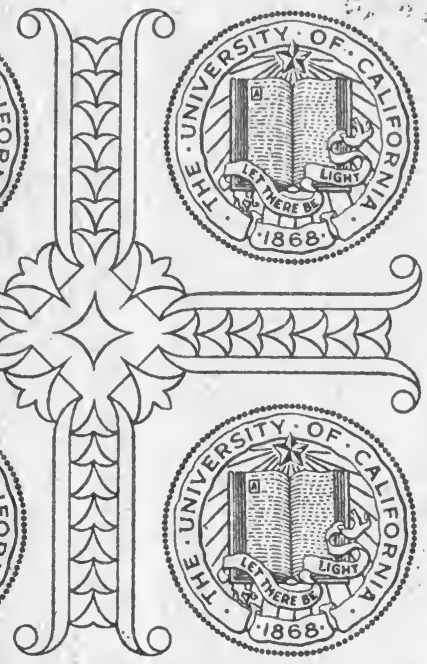

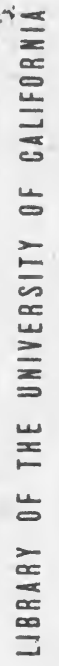

LIBRARY OF THE UNIVERSITY OF CALIFORNIA
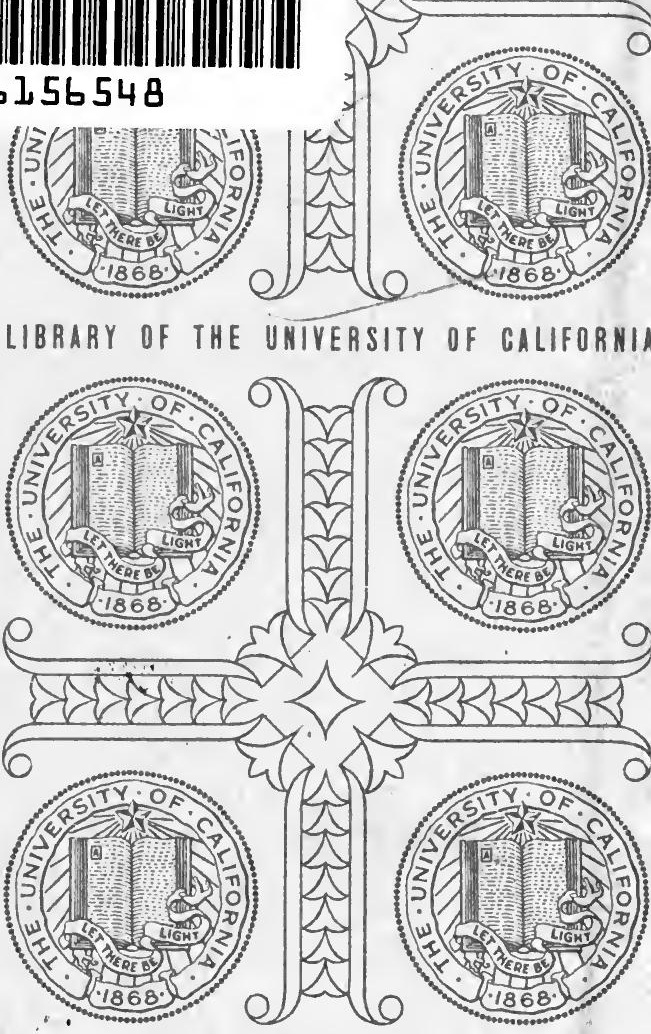

LIBRARY. OF THE UNIVERSITY OF CALIFORMIA
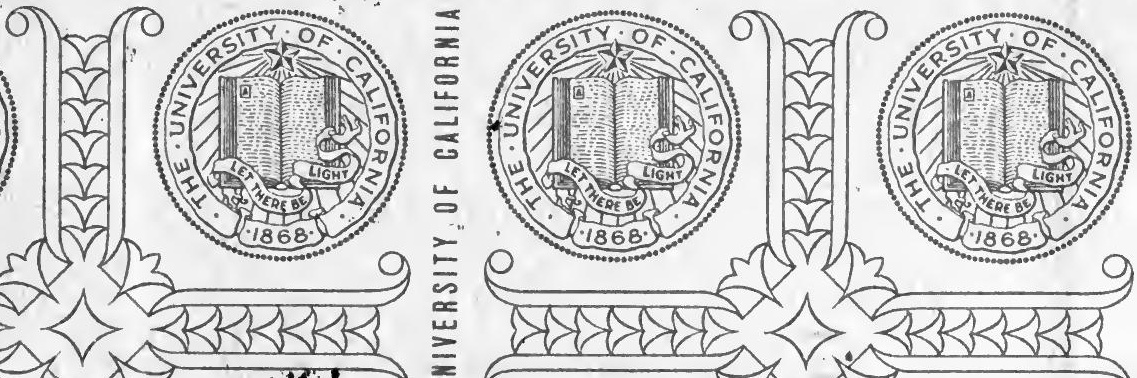
